Faculdade de Economia, Universidade do Porto

\title{
Learning-by-Doing, Technology-Adoption Costs and Wage Inequality
}

\author{
Master's Thesis of \\ Rui Manuel Militão Lousada Leite
}

Supervised by

Óscar J. A. Afonso

December 2007 


\section{Biographical note}

Rui Manuel Militão Lousada Leite was born in Porto, Portugal, on the 25th of August of 1981. He completed his undergraduate degree in Economics at Faculdade de Economia da Universidade do Porto in 2005, where he has since then attended the Master's Programme in Economics, specialising in the scientific areas of Economic Growth and Innovation.

From June 2006 to June 2007 he worked at Centro de Estudos de Economia Industrial, do Trabalho e da Empresa of Faculdade de Economia do Porto, where he provided research assistance for projects in the fields of Health Economics, Bybliometric Analysis and Industrial Economics.

In July 2007 he began working at Gabinete de Planeamento, Estratégia, Avaliação e Relações Internacionais of Ministério das Finanças e Administração Pública, in Lisbon, where he has taken a position as macroeconomist at the Divisão de Modelização e Previsão. 


\section{Acknowledgments}

Many people have contributed to make this thesis possible, and to them I would like to express my gratitude. I thank my supervisor, Óscar Afonso, for his friendship, support, guidance and advice, as well as for suggesting the topic for this thesis.

Attending the Master's Programme in Economics at Faculdade de Economia do Porto has proved to be an invaluable experience. I thank all my colleagues and professors for allowing me to learn so much with them. Although it is not possible to mention everyone, it would be unfair not to thank Professor Manuel Mota Freitas for being always available to spare a word of advice. I am also indebted to Professor Paulo Vasconcelos, a very kind person with whom I learned a great deal about MATLAB. I would like to leave a special word of appreciation to Professor Aurora Teixeira for her friendship and constant encouragement.

Working at Centro de Estudos de Economia Industrial, do Trabalho e da Empresa (CETE) of Faculdade de Economia do Porto (FEP) allowed me to grow both personally and professionally. I would like to thank to all the people with whom I worked, especially Sara Cruz for being such a good friend and next-desk neighbour.

I would also like to thank everyone at Gabinete de Planeamento, Estratégia, Avaliação e Relações Internacionais (GPEARI) of Ministério das Finanças e da Administração Pública (MFAP) with whom I have the pleasure of working. It is only fair to acknowledge their support and understanding during the months that led up to the conclusion of this thesis.

I would like to express my sincere gratitude towards Professor Nuno Sousa Pereira. Working with him at CETE-FEP and GPEARI-MFAP has been a great experience. Above all, I have the privilege of being his friend.

Participants at the EAEPE 2007 Conference (November 2007, Porto, Portugal) have provided helpful comments on preliminary material for this thesis. I gratefully acknowledge their contribution.

My friends, whose names I will not mention as not to forget anyone, have always been there for me, and I thank them for all the good moments we shared.

To all my family I owe their love and support throughout the years. I am most grateful to my parents for their love, wisdom and advice. Without them, living and working in Lisbon while writing this thesis would have been far harder.

Last, but by no means least, I thank Ana for all the good things she brought into my life. Her encouragement and unconditional support were essential while writing this thesis. Above all, the love and friendship we share brighten each and everyday of my life. 


\begin{abstract}
In the skill-biased technological change literature, the market-size channel determines the technological-knowledge bias that drives wage inequality, i.e., technologies that use the more abundant type of labour are favoured. We develop an endogenous growth model with two technologies in which: (i) a specific quality of labour - low or high-skilled - is combined with a specific set of quality-adjusted intermediate goods; (ii) the market-size channel is practically removed; (ii) labour endowments influence technology-adoption costs and learning-by-doing. By solving the transitional dynamics numerically, we show that changes in the relative supply of high-skilled labour affect learningby-doing and technology-adoption costs, which, in turn, influence the direction of technological-knowledge and thus the skill premium. The proposed mechanisms can acommodate some facts that are not explained by the skill-biased technological change literature, thereby supporting the idea that learning-bydoing and technology-adoption costs can provide valuable insights into the path of wage inequality.
\end{abstract}

Keywords: Learning-by-doing; Adoption costs; Technological-knowledge bias; Wage inequality; Numerical simulations.

JEL classification Codes: C61, J31, O31, O33. 


\section{Contents}

1 Introduction $\quad 1$

$\begin{array}{lll}2 & \text { Related literature } & 7\end{array}$

2.1 The skill-biased technological change hypothesis . . . . . . . . . . . 7

2.2 Labour-market features and wage inequality . . . . . . . . . . . . . 12

2.3 The role of economic openness . . . . . . . . . . . . . . . . 15

2.4 Learning-by-doing . . . . . . . . . . . . . . . . . . . . . . . . . . . . . 19

2.5 Technology-adoption costs . . . . . . . . . . . . . . . 23

3 Model $\quad 26$

3.1 Overview . . . . . . . . . . . . . . . . . 26

3.2 Households . . . . . . . . . . . . . . . . . . 26

3.3 Final-goods sector . . . . . . . . . . . . . . . . . 28

3.4 Intermediate-goods sector . . . . . . . . . . . . . . . . . . 32

3.5 Quality-improving R\&D . . . . . . . . . . . . . . . 33

3.6 The technological readiness of labour . . . . . . . . . . . . . . 35

4 Equilibria $\quad 39$

4.1 Equilibrium given a technological-knowledge level . . . . . . . . . . . 39

4.2 Equilibrium with R\&D . . . . . . . . . . . . . . . . 43

4.3 Transition dynamics . . . . . . . . . . . . . . . . . . . 48

4.4 Steady-state . . . . . . . . . . . . . . . . . . . . . . . . . . 49

5 Analysis $\quad \mathbf{5 0}$

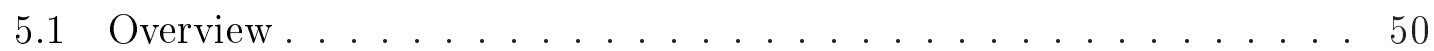

5.2 Fixed-parameter calibration . . . . . . . . . . . . . . 51

5.3 Variable-parameter calibration . . . . . . . . . . . . . . 55

5.4 Sensitivity analysis . . . . . . . . . . . . . . . . 59

6 Conclusions $\quad 65$

$\begin{array}{ll}\text { Appendix A } & 67\end{array}$

$\begin{array}{ll}\text { Appendix B } & 70\end{array}$

$\begin{array}{ll}\text { References } & 91\end{array}$ 


\section{List of Figures}

1 Relative supply of skills in nine OECD countries, 1995-2005. . . . . . 4

2 Fixed-parameter simulations for the United States, 1973-1989. . . . . 52

3 Fixed-parameter simulations for Sweden and the U. K., 1973-1989. . . 54

4 Fixed-parameter simulations for Denmark, 1973-1989. . . . . . . . . 55

5 Variable-parameter simulation for Denmark, 1973-1989. . . . . . . . . 55

6 Variable-parameter simulations for Belgium, 1985-1997. . . . . . . . . 56

7 Variable-parameter simulation for Chile, 1960-1996. . . . . . . . . . 57

8 LBD and TAC effects under predominance of low-skilled labour. . . . 60

$9 \quad$ LBD and TAC effects under predominance of high-skilled labour. . . 62

10 LBD and the relative supply of high-skilled labour. . . . . . . . . . 63

11 TAC and the relative supply of high-skilled labour. . . . . . . . . . . 64 


\section{List of Tables}

1 Baseline non-core parameter values . . . . . . . . . . . . . 51

2 Alternative simulations of transition dynamics . . . . . . . . . . . 58

3 Simulation results for the United States, 1973 (I) . . . . . . . . . . . 71

4 Simulation results for the United States, 1989 (I) . . . . . . . . . . . 72

5 Simulation results for the United States, 1973 (II) . . . . . . . . . . . 73

6 Simulation results for the United States, 1989 (II) . . . . . . . . . . . 74

$7 \quad$ Simulation results for the United States, 1973 (III) . . . . . . . . . . . 75

8 Simulation results for the United States, 1989 (III) _ . . . . . . . . . 76

9 Simulation results for Sweden, $1973 \ldots \ldots$. . . . . . . . . 77

10 Simulation results for Sweden, $1989 \ldots \ldots$. . . . . . . . . 78

11 Simulation results for the United Kingdom, 1973 . . . . . . . . . . . 79

12 Simulation results for the United Kingdom, 1989 . . . . . . . . . . . . 80

13 Simulation results for Denmark, $1973 \ldots \ldots$. . . . . . . . . 81

14 Simulation results for Denmark, 1989 . . . . . . . . . . . . . . . 82

15 Simulation results for Belgium, 1985 . . . . . . . . . . . . 83

16 Simulation results for Belgium, 1997 . . . . . . . . . . . . . 84

17 Simulation results for Chile, 1960 . . . . . . . . . . . . . . 85

18 Simulation results for Chile, $1996 \ldots \ldots$. . . . . . . . . 86

19 Simulation results for The Netherlands, 1983 . . . . . . . . . . . 87

20 Simulation results for The Netherlands, 1994 . . . . . . . . . . . . . 88

21 Simulation results for Canada, $1987 \ldots \ldots$. . . . . . . . . . 89

22 Simulation results for Canada, $1997 \ldots$. . . . . . . . . . . . . . . 90 


\section{Introduction}

During the 1980s and the 1990s the wage structure changed in many developed countries. More-skilled workers have experienced a rise in their relative wage, and the fraction of the total wage bill devoted to paying them also increased. In some cases - for example, in the United States - these trends began forming as early as 1960, although since then there have been times during which the wage structure remained fairly stable or changes to it were partially reversed (see, e. g., Juhn et al., 1993). And even though wage inequality sometimes fell or remained stable along other dimensions - see, e.g., Card and DiNardo (2002) for evidence on male-female and black-white wage differentials in the United States -, skill-related wage differentials increased in most developed countries.

In many countries these changes in the wage structure have been accompanied by an increase in the relative supply of more-skilled labour (see, e.g., Acemoglu, 2003a). In light of this fact, the changes in wage structure seem a little puzzling. All else equal, one would expect skill-related wage differentials to decline in response to an increase in the supply of more-skilled workers.

These changes in the supply of more-skilled labour and in skill-related wage differentials constitute the focus of the present work. After presenting the patterns of wage inequality and labour supply that are relevant for our study, we briefly discuss explanations which aim at reconciling these apparently contradictory trends. Since the dominant explanation links the rise in the relative wage of high-skilled workers to the change in the path of technological-knowledge progress, we then develop a new framework to address some issues not explored by previous works. Indeed, our work builds on the skill-biased technological change literature (e. g., Acemoglu, 1998; Afonso, 2006), complemented with learning-by-doing and technology-adoption costs effects.

\section{A changing wage structure: increases in skill-related wage inequality}

Several studies document the rise in the relative wage of more-skilled workers using different proxies for skill. For example, Katz and Murphy (1992) report that between 1979 and 1987, U.S. college graduates experienced an increase in their relative wage of $11 \%$ when compared to high-school graduates. Juhn et al. (1993) in turn show that in the United States hourly and weekly wage differentials between the 90th wage percentile (more-skilled workers) and 10th wage percentile (less-skilled workers) rose steadily throughout the 1980s in the United States. By 1988 the wage differential between these two groups was $42 \%$ higher than it was in 
1959 (Juhn et al., 1993, p. 419).

In another study, Nickell and Bell (1996) report that during the 1980s the earnings differential between high and low-educated males increased by $4.4 \%$ in Germany, $7.8 \%$ in the United Kingdom and $10.2 \%$ in the United States. Similar patterns are also documented by Acemoglu (2003a), who offers an insight on the behaviour of skill premium in many countries. ${ }^{1}$ Acemoglu shows that between the early $1980 \mathrm{~s}$ and the mid 1990s, the skill premium of male workers nearly doubled in the United States, and increased by roughly $42 \%$ in the United Kingdom; more modest increases occurred in Canada (17.4\%) and in Germany (3.8\%) between the late 1980s and the mid 1990s (Acemoglu, 2003a, p. 123, Table 1b).

The skill premium also increased in some newly industrialised (developing) countries during the 1980s and the 1990s. Zhu and Trefler (2005) show this happened, for example, in Hong Kong, India, Thailand and Uruguay. These results support the findings of Avalos and Savvides (2006), who point to an increase in wage inequality in Latin America and East Asia between the mid 1970s and the mid 1990s. And the study by Brainerd (1998) suggests that the wage differential between the 90th and 10th wage percentiles widened in Russia during the first half of the 1990s.

The evolution of the share of more-skilled workers in the total wage bill is documented by Berman et al. (1998), among others. According to Berman et al. (1998, Table 3) the wage bill share of non-production (more-skilled) workers increased during the 1970s, 1980s and 1990s in ten of a group of eleven open economies. ${ }^{2}$ In five cases - notably Australia, Denmark, Finland, the United Kingdom and the United States - the pace of this increase even accelerated during the 1980s.

Some of these findings are confirmed by Machin and Van Reenen (1998), who report that between 1973 and 1989 the wage bill share of non-production workers increased by approximately $11 \%$ in Sweden, $20 \%$ in Denmark, $22 \%$ in the United States and 30\% in the United Kingdom. Although limited to 1974-1985, Machin and Van Reenen's data on Japan also point to an increase in the wage bill share of non-production workers (approximately 9\%). ${ }^{3}$ And like in the case of skill

\footnotetext{
${ }^{1}$ Acemoglu (2003a) defines the skill premium as the coefficient on workers with at least a college degree relative to high school graduates in a regression of log real annual gross wages on four education categories and a quadratic in age.

${ }^{2}$ The sample of Berman et al. (1998) includes Australia, Austria, Belgium, Denmark, Finland, Japan, Luxembourg, Norway, Sweden, the United Kingdom, the United States and West Germany. Only Belgium experienced a decline in the wage bill share of non-production workers during the 1980s.

${ }^{3}$ The wage bill share of non-production workers increased 2.7 percentage points in Japan, 4 percentage points in Sweden, 6.6 percentage points in Denmark, 7.7 percentage points in the United States and 9.7 percentage points in the United Kingdom (Machin and Van Reenen, 1998, Table 1).
} 
premium patterns, these results still hold if we look at other proxies for skill. An example is the study by Autor et al. (1998, Table 2), which present data that document an increase in the wage bill share of college educated workers in the United States between 1940 and 1996.

\section{Increases in the supply of more-skilled labour}

In addition to these changes in the wage structure, many developed countries have also experienced an increase in the relative supply of more-skilled workers. For example, Kranz (2006, Table 1) shows that the share of workers with more than high school increased in Italy, Germany, the United Kingdom and the United States between the early 1980s and the early 1990s. ${ }^{4}$ However, the increase was more pronounced in the United Kingdom (31.2\% to $42.2 \%)$ and in the United States $(39.52 \%$ to $49.33 \%$ ) than it was in Germany and Italy $(17.49 \%$ to $21.48 \%$ and $6.08 \%$ to $7.35 \%$, respectively). ${ }^{5}$ Changes like these also affected other developed economies. Acemoglu (2003a), for example, shows this happened in The Netherlands and Sweden between the early 1980s and the mid 1990s, and also in Norway, Belgium and Finland during different periods of the 1980s and the 1990s.

Figure 1 shows that this trend continued into the 2000s. In all sample countries the relative supply of college graduates increased between 1993 and 2005, although it reached substantially higher levels in Denmark, Finland and in the United States. The data show that by 2005 the relative supply of college graduates was comparable in France, Ireland, The Netherlands, Spain and the United Kingdom, but also that within this group - its growth was more pronounced in Spain. In fact, between 1993 and 2005 the relative supply of college graduates increased at an annual average rate of $6.9 \%$ in Spain, whereas in the United Kingdom, for example, the annual average growth rate was of $3.8 \%{ }^{6}$

\section{The skill-biased technological change hypothesis}

A possible explanation for the contradiction between the increases in the relative supply of skills and the rise in the skill premium has been provided by the skill-biased technological change literature (e.g., Bound and Johnson, 1992; Katz and Murphy,

\footnotetext{
${ }^{4}$ The definition "workers with more than high school" comprises workers who obtained a college degree or have some college experience (see Table 1 in Kranz, 2006).

${ }^{5}$ In Autor et al. (1998) and Acemoglu (2003b), we can see that the rise in the relative supply of college educated workers in the United States began around the 1940s, and that the growth was particularly strong during the 1970s.

${ }^{6}$ Census data for Canada, for example, show that between 1996 and 2001 the relative supply of college graduates increased at an annual average rate growth rate of $1.8 \%$.
} 

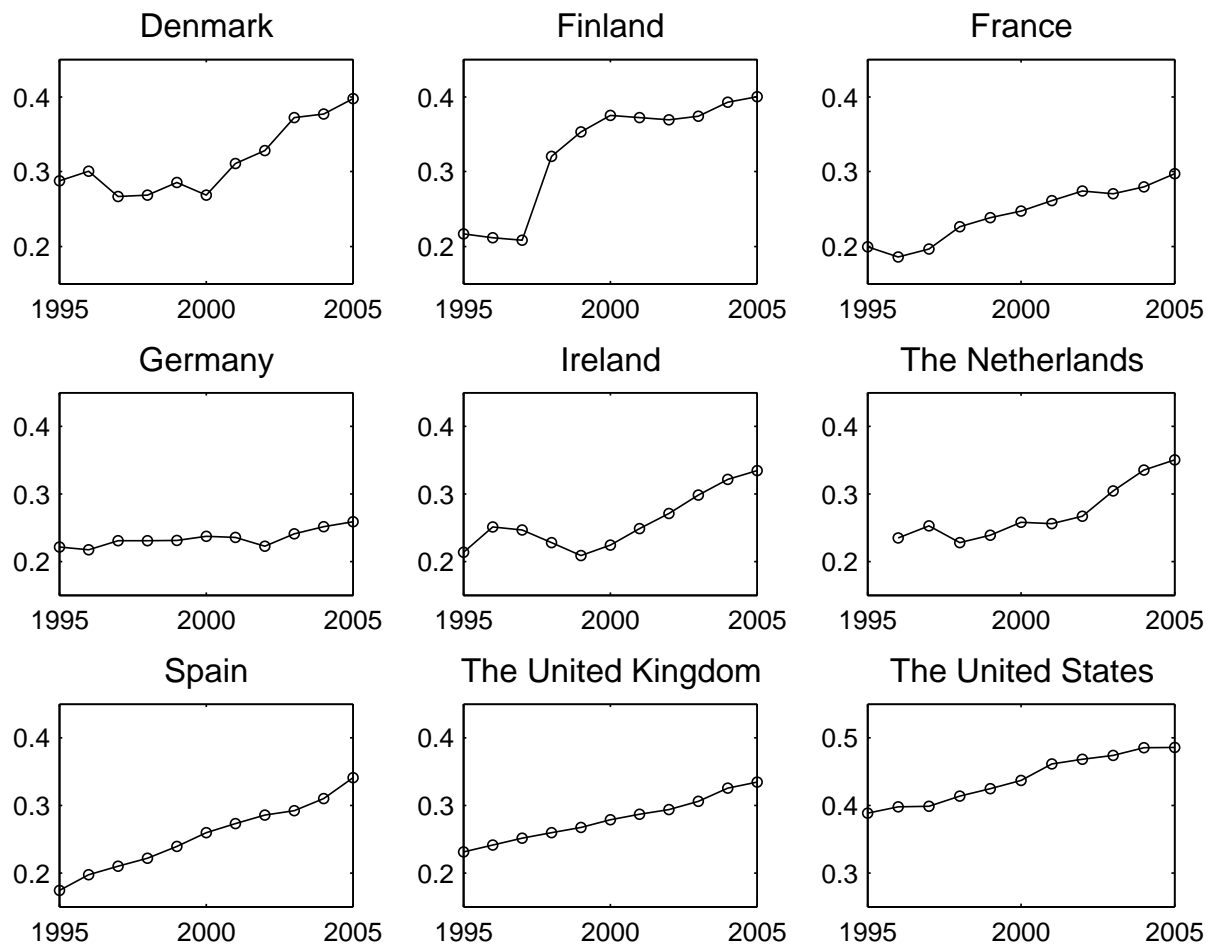

Data for European countries are from European Labour Force Surveys, and data for the United States are from March Current Population Surveys. The relative supply of skills is the ratio of college graduates to non-college graduates among persons aged 15-64. For European countries "college graduates" refers to those who have completed tertiary education (ISCED levels 5 and 6). For the United States it refers to those who have completed at least an Associate's degree.

Figure 1: Relative supply of skills in nine OECD countries, 1995-2005.

1992; Juhn et al., 1993). In simple terms, this strand of the literature argues that technological change is biased towards more-skilled workers, and this induces an increase in the relative demand for them. The additional demand for more-skilled workers exceeds any increase in the relative supply that might exist, thus pushing the skill premium up. An often quoted example of this process is the introduction of the personal computer and other computer related technologies (Card and DiNardo, 2002): some argue that this is linked to the rise in the skill premium that occurred during the 1980s in the United States (e.g., Autor et al., 1998).

Acemoglu (1998, 2002) and Acemoglu and Zilibotti (2001) further enhance the skill-biased technological change hypothesis by considering that technological change responds to shifts in labour endowments. When the supply of a type of labour increases, the market for technologies that complement it broadens and this, in turn, creates additional incentives for conducting $R \& D$ aimed at those technologies. As a result, technological change steers towards those technologies, and this increases the demand for the complementary labour type. Hence, these recent contributions 
interpret the rise in the skill premium as a consequence of the increase in the relative supply of more-skilled workers.

But, at least to some extent, there is empirical evidence that seems to contradict the explanation proposed by this particular version of the skill-biased technological change hypothesis. For example, Acemoglu (2003a) documents a decline in the skill premium in Sweden and The Netherlands between the early 1980s and the mid 1990s. Yet, in both countries the relative supply of skills increased during the same period. And in Canada the skill premium increased between the late 1980s and the late 1990s, in spite of a stable relative supply of skills (Acemoglu, 2003a, p. 123, Table 1b).

Data from developing countries reveal some additional problematic evidence. Crinò (2005), for instance, shows that Hungary and Czech Republic experienced an increase in the skill premium between 1993 and 2004, while at the same time the relative employment of more skilled workers declined in those countries. Another example comes from Mexico, where in 1994-2002 the relative supply of highlyeducated workers increased and the wage differential between the 90th and 10th wage percentiles decreased (Robertson, 2004). And in the study by Zhu and Trefler (2005) we find evidence that identical developments occurred in countries such as Bolivia, South Korea and Philippines.

\section{Building a new framework}

In the present work we propose a model that aims at explaining different patterns of skill premium and relative supply of skilled workers. More specifically, we propose an endogenous R\&D growth model in which learning-by-doing and technology-adoption costs affect the direction of technological change. Like in the skill-biased technological change literature, technological change then influences the relative demand for high-skilled labour, and thus the skill premium. The model is closely related to the contributions of Acemoglu (1998, 2002), Acemoglu and Zilibotti (2001), and Afonso (2006, 2007), but it differs from them in that it takes into account the effects of learning-by-doing and technology-adoption costs.

We consider an economy in which the perfectly competitive production of final goods can be accomplished by using two available technologies, each taking as inputs a specific set of intermediate goods and a specific type of labour. One technology combines low-skilled workers with low-specific intermediate goods, whereas the other couples high-skilled workers with high-specific intermediate goods. The production function for final goods is thus characterised by complementarity between inputs and substitutability between the two technologies. 
The output of the final-goods sector can be used in consumption, in the production of intermediate goods, or in R\&D activities. Intermediate goods are produced under monopolistic competition by combining units of aggregate output and innovative designs. Also, they are quality adjusted in line with the literature on Schumpeterian endogenous growth models (see, e. g., Aghion and Howitt, 1992). Innovation in the intermediate-goods sector is driven by R\&D, which is stripped from scale effects in line with the dominant literature (see, e. g., Jones, 1995a,b).

Distinguishing between low and high-skilled workers allows us to consider productivity differences between them. Acemoglu (1998, 2002), Acemoglu and Zilibotti (2001), and Afonso (2006) consider that high-skilled workers are more productive than low-skilled workers. While in our model we assume that high-skilled workers have indeed an advantage over low-skilled workers, the effects of learning-by-doing and technology-adoption costs provide room to consider cases in which low-skilled workers exhibit higher productivity than high-skilled workers.

Our simulation results show that combining the effects of learning-by-doing and technology-adoption costs with the skill-biased technological change framework yields valuable insights on the dynamics of the skill premium. Accommodation of different paths for the skill premium in response to a given shift in the relative supply of skilled workers becomes possible, thereby creating richer dynamics than those offered by previous works. Results from the sensitivity analysis demonstrate that the effects of learning-by-doing and technology-adoption costs are variable and interdependent, and that they might induce both increases and decreases in the skill premium.

The remainder of this thesis is organised as follows. Chapter 2 provides an overview of the skill-biased technological change literature and of alternative explanations for the patterns of wage inequality and relative supply of skills mentioned above. Since our work contributes to the literature by taking into account the effects of learning-by-doing and technology-adoption costs, we briefly illustrate the importance of those concepts in the economic literature. In Chapter 3 we present a model of the economy, and the equilibria and transitional dynamics underlying the model are worked out in Chapter 4. In Chapter 5 we use this framework to study the behaviour of the skill premium in different scenarios. Finally, Chapter 6 closes the thesis with some concluding comments. 


\section{Related literature}

The purpose of this section is twofold. First we present an overview of alternative explanations for the trend of rising skill premium described in the previous chapter. We start with the skill-biased technological change hypothesis, because our work is closely related to it, and because it is the dominant explanation. Then, we present some works that offer different - possibly complementary - explanations for the observed changes in wage structures: the roles of labour market features, economic openness, and other factors are considered. Second, since our goal is to contribute to the literature by enhancing the skill-biased technological change hypothesis with learning-by-doing and technology-adoption costs elements, we present some works that illustrate the relevance of these two concepts to economics.

\subsection{The skill-biased technological change hypothesis}

It is commonly accepted that the generic rise in the relative wage of high-skilled workers has been caused by increases in the relative demand for those workers (Katz and Murphy, 1992; Freeman, 1995; Acemoglu, 2003b), but there is considerably more debate about what caused that demand shift. The skill-biased technological change literature argues that the surge in the relative demand for highskilled workers was brought about by change in the nature of technological progress. (Johnson, 1997).

The work by Bound and Johnson (1992) is one of the early studies that points to such explanation for the rise in the skill-premium. Using data from the Current Population Survey, Bound and Johnson study how trade-induced declines in manufacturing employment, decreased union power, slower growth in the supply of skilled workers, and technological change contributed to change the United States wage structure during the 1970s and 1980s. The main conclusion of this work is that the most important force behind the increase of the skill premium in the United States during the 1980s was technological change.

According to Bound and Johnson (1992), slower growth of the skilled-labour supply doesn't seem to explain the rising skill premium, as their estimates show that the supply shifts had similar effect on wages both in the 1970s and in the 1980s. Demand factors, in turn, seem to have had sizable, accelerating influence in the 1980s. The importance of technological change, in particular, dwarfs that of other demand-shifting factors, both in terms of the size of the effect and the magnitude of its acceleration between the 1970s to the 1980s.

A similar, relevant work is that of Murphy and Welch (1992), who study the 
wages of white males in the United States between 1963 and 1989. They find the changes observed in the wage structure during that period are inconsistent with a stable structure of labour demand, and assess how international trade, economic cyclicality or a trend factor might have induced labour demand shifts. In this work, skill is proxied by education, trade-induced shifts in labour demand are proxied by the net imports of durable goods as a share of GNP, and cycle-related shifts are proxied by innovations in aggregate unemployment.

Murphy and Welch's regression estimates show that international trade and cyclical unemployment indeed played a role in shifting labour demand away from unskilled workers, and contributed to reduce its relative wage. But the results also show a statistically significant trend factor, suggesting that some other force systematically influenced labour demand and wages. Pervasive skill-biased technological change, as the authors acknowledge, is a likely candidate.

In addition to these two early studies, many other works point to skill-biased technological change as the central explanation for the rising skill premium. For instance, Berman et al. (1998) reach such conclusion analysing data from several developed and developing countries, thereby showing that skill-biased technological change is not a localised phenomenon occuring in a small group of countries, but rather a widespread force affecting countries throughout the world. Results in line with this are provided by Machin and Van Reenen (1998) for a smaller set of OECD countries. And data from the United States, by far the most studied case, is recurrently cited as evidence that skill-biased technological change is to blame as least partially - for the rise in wage inequality (e.g., Katz and Murphy, 1992; Levy and Murnane, 1992; Juhn et al., 1993; Johnson, 1997).

In many of these early works, however, skill-biased technological change is considered to be exogenous and its presence is often measured indirectly (Kiley, 1999; Levy and Murnane, 1996). This is a significant shortcoming because it leaves the question of why (and how) has technological knowledge become skill biased unanswered. Later works address this issue by studying mechanisms that could influence the skill-bias of technology, thereby contributing to the completeness of the skillbiased technological change hypothesis.

The study by Kiley (1999) is one of such contributions. He develops a growth model in which the production of final goods is achieved by combining skilled and unskilled labour with specific sets of intermediate goods. Applied technological change - driven by applied R\&D activities that explore the output of basic research - expands the set of intermediate goods that can be used with each type of labour.

The explanation of how technology becomes increasingly skill-biased is linked 
to the economic incentives surrounding R\&D activities. In the model, profitability of applied R\&D activities directed towards each set of intermediate goods depends positively on the endowment of the respective type of complementary labour. As for the cost of conducting applied R\&D, it increases as the applied R\&D activities exhaust the pool of ideas contained in the output of basic research. Only new output from basic research - which is assumed to grow at a constant rate - can alleviate the cost of applied R\&D.

Following an increase in the supply of skilled labour, the skill premium falls because skilled workers have become more abundant. In addition, the profitability of applied R\&D activities in skilled intermediate-goods increases because the market for those goods has broadened. As a result, applied R\&D resources are shifted from unskilled-specific intermediate goods to skilled-specific intermediate goods. The additional applied $R \& D$ causes the basket of skill-complementary intermediate goods to increase, thereby raising the productivity and wage of skilled labour. Hence, even though the relative wage of skilled labour initially falls in response to the higher number of skilled workers, the skill premium gradually increases as technology becomes skill-biased. Kiley (1999) argues that this is consistent with United States data on wage inequality from 1970s onwards.

The mechanics by which technology becomes increasingly skill-biased in Kiley's model are similar to the ones operating in the model by Acemoglu (1998). There, too, unskilled (skilled) workers are coupled with a specific set of intermediate goods to produce final goods, and the profitability of $\mathrm{R} \& \mathrm{D}$ efforts aimed at intermediate goods is linked to labour endowments. Again, as the supply of one type of labour increases, profitability of $R \& D$ in the respective complementary intermediate-goods also increases. The main difference with respect to Kiley's proposal is that Acemoglu (1998), instead of considering a model with an expanding variety of intermediate goods, builds a quality-ladder model (Segerstrom et al., 1990; Aghion and Howitt, 1992; Grossman and Helpman, 1991a,b). In other words, in Acemoglu's model R\&D increases the quality of existing intermediate goods, not the array of intermediate goods that are produced.

Although with some minor differences, the contributions of Acemoglu (1998), Kiley (1999), and Acemoglu and Zilibotti (2001), among others, point to the marketsize channel as the fundamental factor driving the technological-knowledge bias, and thus the skill premium. Afonso $(2006,2007)$, on the other hand, draws attention to the role of the price channel. In an endogenous quality-ladder model in which the market-size channel is removed from the R\&D aimed at intermediate goods, Afonso shows how shifts in labour endowments affect, through the price channel 
(of final goods), the technological-knowledge bias and the skill premium. Under the assumption that $\mathrm{R} \& \mathrm{D}$ is more efficient in intermediate goods that complement highskilled labour - and that labour endowments influence that efficiency -, an increase in the supply of high-skilled workers triggers a flow of innovations in those goods, heightening the technological-knowledge bias.

The increased productivity of high-specific intermediate goods increases the wage rate of the complementary labour, widening the skill premium. However, the additional productivity also lowers the production cost (and relative price) of final goods produced with skilled labour and skill-specific intermediate goods. This lowers the profitability of $R \& D$ in those intermediate goods, and resources start flowing for R\&D activities aimed at intermediate goods that complement unskilled labour, causing a slowdown in the growth of the technological-knowledge. Eventually, a new steady state is reached in which both the skill-bias of technology and the skill premium are higher.

The works discussed so far link the rise in the skill premium to a change in the nature of technology. A somewhat different, yet related, view is defended by Nahuis and Smulders (2002), who argue that the increase in the wage gap between skilled and unskilled workers is a consequence of structural changes affecting production activities. In their model, unskilled workers perform routine activities to produce final goods, and their productivity depends on their firms' knowledge stock. Skilled workers, on the other hand, perform non-routine tasks that improve the knowledge stock of their firm, and their productivity increases alongside that stockn.

Each representative firm can expand its production either by exploring the existing knowledge stock more intensively or by expanding that stock. The former implies the use of increasing number of unskilled workers, and the latter requires employing more skilled workers. The key feature is that knowledge is non-rival and partially non-excludable, hence each firm can only appropriate a part of the knowledge its skilled workers generate.

The model by Nahuis and Smulders shows that the skill premium can increase if firms are able to appropriate a sufficient part of the knowledge they generate. At first, the expansion of the supply of skilled labour makes the respective wage rate fall, reducing the skill premium. But once more skilled workers are available, the potential to create new knowledge from the existing stock of knowledge can be better explored. Firms have an incentive to follow this path and employ more skilled workers - and also pay them higher wages - if the benefits of additional knowledge outweigh the costs of pursuing it (i. e., if firms can appropriate a sufficient part of the new knowledge). Thus, according to this vision, increases in the skill-premium 
reflect a shift to a more knowledge-intensive system of production.

\section{Empirical evidence and critique}

As already mentioned, empirical support for the skill-biased technological change hypothesis often results from indirect measurement. However, evidence from the adoption of computer-related innovations has been used by many as a more concrete example of skill-biased technological change. Krueger (1993), for example, demonstrates evidence that workers who use computers on their jobs earn higher wages, and that high-skilled workers are more likely to use computers at work. Furthermore, according to Krueger's estimates, the acceleration of computer usage in 1980s can account for as much as half of the increase in the premium paid to high-skilled workers in the United States.

Based on an analysis of the United States manufacturing sector in the 1980s, Berman et al. (1994) present evidence that is consistent with the findings of Krueger (1993). They document a shift in aggregate labour demand towards skilled workers, and show this is mainly caused by a pervasive within-industry trend, and not from changes in the industry composition. Their results also demonstrate that the changes in labour demand are correlated with higher investment in computers and R\&D, implying that this could be the reason behind the additional demand for skilled workers.

These findings are further supported by Autor et al. (1998), who develop one of the most comprehensive studies regarding the link between computer usage and the skill premium. Using 1940-1996 data for the United States, they show that there has been a steady increase both in computer usage rates and relative demand for skilled workers. Again, the trend in skilled-labour demand results from within-industry changes and it has been stronger in industries in which computers are used more intensively. Moreover, Autor et al. (1998) show that the skill upgrading at industry level has been particularly strong since the 1970s and up to the 1980s, which is compatible with the rapid increase in the skill premium.

The analysis of computer usage patterns has also been used as a basis for critique of the skill-biased technological change hypothesis. By conducting a detailed analysis of data on computer usage, Card and DiNardo (2002) detect some inconsistencies in the explanation proposed by this particular version of the skill-biased technological change literature. ${ }^{7}$ For example, they argue that computer usage grew in the United States during the 1990s, but wage inequality remained somewhat stable.

\footnotetext{
${ }^{7}$ The study by Card and DiNardo (2002) analyses computer usage and earnings across age, gender, race and job experience groups. It also takes into account cross-industry differences.
} 
And computer usage patterns can't correctly track the closing of the gender wage gap. Accordingly, Card and DiNardo (2002) argue that other factors contributed to shape wage inequality, namely labour market institutions.

Another issue subject to some debate is whether skill-biased technological change can persistently induce increases in the skill premium. Some authors (e.g., Johnson, 1997) suggest that skill-biased technological change might already have decelerated in the 1990s. In principle, this could fit the proposal of Ciffo-Tille and Lehmann (2004), who argue that technological change might not be permanently biased if $\mathrm{R} \& \mathrm{D}$ resources are alternately allocated towards skilled-intensive and unskilledintensive goods. The main idea underlying Ciffo-Tille and Lehmann's model is that as $R \& D$ resources flow to one type of good - the skilled-intensive good, for example - the profitability of R\&D activities in that good decreases, creating an incentive to shift R\&D resources towards the other good.

Assuming that skill-unskilled labour wage differentials are indeed influenced by the skill-bias of technological knowledge, an obvious implication of this model is that we should observe cycles in both the technological-knowledge bias and skill premia. The decrease in the United States skilled-unskilled wage gap during the 1970s, followed by a rapid increase in that gap during the 1980s, could provide some support to this theory. However, technological-knowledge change is generally considered to have been skill-biased (e.g., Autor et al., 2003).

To sum up, even though the skill-biased technological change hypothesis has met some criticism as the unique explanation for the widespread increase in skill premia, it seems to be the main factor behind it (Autor et al., 2005).

\subsection{Labour-market features and wage inequality}

Although changes in the wage structure have been generally linked to the presence of skill-biased technological change, other explanations have also emerged in the economic literature. A relatively homogeneous body of studies stresses the role of labour market features in shaping the observed changes in the wage structure. Those labour market features can be broadly categorised into two different classes: labourmarket institutions and cohort effects. The first includes things such as minimum wage and unionisation levels; the second refers to differences across groups of workers that have been entering the labour market. 


\section{Institutional Factors}

The importance of institutional factors in the rise of wage inequality has been emphasised by many authors, especially since there is considerable evidence that they influence wages (e.g., Freeman, 1980).

The fall in the minimum wage, for example, is often cited as a source of increased wage inequality, including across skill groups. The reasoning, of course, is that the minimum wage offers some protection for the earnings of the less skilled. Some empirical evidence of the importance of minimum wage has indeed been provided by several studies. DiNardo et al. (1996), for instance, argue that reductions in the United States federal minimum wage led to a more pronounced wage inequality. The thorough study by Lee (1999) seems to validate this conclusion. By analysing regional data from the United States, Lee separates the effects of variations in the minimum wage from the effects of nationwide movements in "underlying" wage inequality. The results show that the minimum wage is indeed the major factor influencing wage dispersion in the lower tail of the wage distribution.

However, the minimum wage is not the only institutional factor affecting wage inequality. Blau and Kahn (1996), for example, argue that a less centralised wagesetting process has led to a higher level of wage inequality in the United States when compared with other OECD countries. Broadly in line with Lee (1999), they show that wage differences between 90th and 10th percentiles are higher in the United States, and that much of this difference is caused by higher wage dispersion at the bottom of the wage distribution.

While the 90-50 percentile wage differential of the United States only ranks as the fourth highest when compared to other countries' differentials, the 50-10 percentile wage gap is the largest of all countries in the sample. Blau and Kahn then point out several differences between the United States and the other countries in terms of institutional factors that affect wage-setting, showing they are weaker in the United States. Moreover, they present evidence that the degree of wage-setting centralisation is negatively correlated with the overall wage dispersion and with the 50-10 percentile wage differential.

Although the work of Blau and Kahn (1996) shows that the effect of weaker institutional arrangements on wage inequality in stronger in the United States, Machin (1997) argues that the decline in unionisation and minimum wages has contributed to increase wage inequality in the United Kingdom in the 1980s and 1990s. In fact, wage dispersion increased more in sectors not covered by a minimum wage system, but Machin's analysis doesn't provide an estimate of how much of this trend can be attributed to the abolishment of the minimum wage system. 
Also during the 1980s and 1990s, the United Kingdom's Conservative government passed legislation that limited union activity and unionisation fell considerably. In the same period, wage dispersion increased faster in sectors without recognised union, and these sectors also increased their relative size with respect to unionised ones. As a result, overall wage inequality itself intensified.

Machin's estimates suggest that unions had indeed some power to reduce overall wage dispersion, and also that this effect declined in the 1980s and 1990s because unionisation levels decreased, not because union activity lost impact. Nevertheless, had unionisation levels remained unchanged and the effect of unions would only have curtailed the increase in wage inequality to about $60 \%$ of its actual value.

Explanations for the patterns of wage inequality based on institutional factors, however, are not problem-free. An important problem is that in labour markets that exhibit higher wage rigidity due to institutional factors, labour demand shocks would, in principle, lead to stronger adjustments in employment levels. Card et al. (1999), for instance, cast some doubt upon this hypothesis by studying the labour markets of the United States, Canada and France.

They argue that a decline in the relative demand for unskilled labour, similar to that which led to lower wages for unskilled workers in the United States (Juhn, 1992), occurred in Canada and France. In these two countries, unskilled employment adjustments should have been more pronounced - when compared to the United States - because institutional factors seem to have induced higher wage rigidity there. But the data presented by Card et al. (1999) offer little support for this "trade-off hypothesis". Indeed, during the 1980s the changes in the wage structure were stronger in the United States than in Canada or France, but changes in unskilled (un)employment were comparable in all three countries.

\section{Cohort Effects}

Another line of research that links labour market features to wage inequality is the one that studies how cohort-effects affect labour earnings. Using data for the United States, some works argue that as the baby-boomers entered the labour market, the wages of young workers fell relative to older workers (e.g., Welch, 1979; Murphy and Welch, 1990). Accordingly, this would increase wage inequality across several dimensions, including the aggregate skill premium. More recently, however, Card and Lemieux (2001) proposed a different explanation: they link the observed rise in the skill premium to the levels of educational attainment of different cohorts.

The main feature of their model is that the college premium of a given age group depends on the relative supply of college workers, both at age-group and aggregate 
level. Furthermore, in contrast with other works (e.g., Katz and Murphy, 1992), they assume imperfect substitution between young and old workers that have the same educational level. Card and Lemieux argue that if educational attainment among new cohorts arriving at the labour market is lower than that of older cohorts, the skill premium will increase over time.

If the proportion of skilled labour within a new, younger group of workers that enters the labour market is lower than the proportion currently existing in the workforce, the skill premium in the new group tends to be higher than skill-premium experienced by older cohorts. Because there is imperfect substitution between skilled workers of different age groups, the pressure for the skill premium to equalise across age groups - decreasing in the younger group and increasing among older workers is limited. As more of these new, less skill-intensive cohorts enter the labour market and become a significant, eventually dominant, part of the force, the average skill premium gradually rises.

Data for the United States, the United Kingdom and Canada provide some support for the hypothesis proposed by Card and Lemieux (2001), but the authors acknowledge that at least some sort of skill-biased technological change and rising demand for skilled workers must also exist. If the demand for these workers remained constant and newer cohorts brought some additional skilled workers to the labour force, this would reduce the skill premium in those age groups.

\subsection{The role of economic openness}

An alternative explanation for the observed changes in the wage structure is linked to economic openness. Based on the observation that, in developed countries, the fall in the relative demand for unskilled workers and the rise in wage inequality were accompanied by an increase in imports (e.g., Sachs and Shatz, 1994), a wide body of literature linking openness to employment and wage changes began to grow.

Early works along this line include Leamer (1994) and Wood (1995), for example. Both works contest that technological change could be the main reason behind the increased wage inequality in the United States, offering an alternative explanation in line with the Stolper-Samuelson theorem. The reasoning is simple: increased international trade with developing countries lowered the domestic price of unskilled-intensive goods, thereby lowering the wage of unskilled workers. Moreover, Wood (1995) argues that eventual effects of technological change on wages stem from the fact that technological change made international trade easier (e.g., lower transportations costs).

In a related study, Borjas and Ramey (1995) use co-integration techniques to 
assess how variations in different variables are linked with variations in the United States skill premium during the 1964-1991. They find that changes in different aspects of labour force composition, immigration and unemployment exhibit little connection with changes in the college wage premium. Unionisation and R\&D exhibit a somewhat stronger connection, but changes in the trade deficit of durable goods are the ones that seem most closely related to the changes in the college premium.

To further support the "trade" explanation, Leamer (1996) presents time-series data of producer prices of textile and apparel in the United States between the late 1940s and the mid-1990s. Relative to a producer price index of a basket of all products, the price of textile and apparel declined in that period. It dropped significantly in the $1970 \mathrm{~s}$, and remained fairly stable in the 1980s, having been accompanied by increases in imports of those goods in that first decade.

According to Leamer (1996), the Stolper-Samuelson predictions would then imply that the relative wages of workers in textile and apparel industries - traditionally, less-skilled workers - should have declined strongly in the 1970s and remained stable in the 1980s. However, this prediction is at odds with the data, because the relative wage of less-skilled workers increased in the 1970s and decreased in the 1980s (e.g., Acemoglu, 2003b). What Leamer, 1996 argues is that the conclusions of StolperSamuelson theorem hold in equilibrium, and that it may take some time to reach it. If true, this would justify why price declines of unskilled-intensive goods in the 1970s only depressed the relative wage of unskilled workers a decade later.

\section{Capital and tasks, not goods}

Although there are many works linking changes in the wage structure to trade, the role of other dimensions of economic openness has also been studied. For example, Feenstra and Hanson (1995)develop a two-country (North-South) model in which wage inequality is shaped by foreign investment and outsourcing. Production of some goods uses capital and skilled labour, whereas others are produced using capital and unskilled workers. Capital is more abundant in the North, which has an advantage over the South in producing some skill-intensive goods, and the skill premium is initially lower there.

Using this simple model, Feenstra and Hanson study the effect on wages of removing barriers to capital. Capital initially flows from the North to the South to take advantage of the higher return. This decreases capital return and, consequently, production costs in the South. The production of some skill-intensive goods becomes competitive in the South, and this increases the relative demand for south- 
ern skilled-labour, increasing their wage relative to unskilled workers. In addition, the subset of skilled goods that the North produces is now more concentrated in skill-intensive good and so the relative demand for unskilled labour falls, increasing the skill premium.

Putting this model against 1980s data for the United States (the North) and Mexico (the South), Feenstra and Hanson's can explain about one-third of the increase in the relative wage of the United States skilled workers. The fact that outsourcing increased in the United States and foreign direct investment increased in Mexico seems to fit their explanation. Furthermore, the authors argue that considering other forms of international competition in the model could enhance its explanatory power.

In a more recent work, Antràs et al. (2005) present an analysis related to that of Feenstra and Hanson (1995), studying how cross-country division of tasks affects work organisation and wages. They develop a two-county model in which countries differ only in the skills of their populations. One country (the North) is skill-abundant and the other (the South) has greater abundance of unskilled labour. As in, e.g., Nahuis and Smulders (2002), skilled workers specialise in knowledgeintensive, managerial tasks and unskilled workers specialise in production (routine) tasks; physical inputs and knowledge are needed to carry out production activities. An additional (and crucial) assumption is that northern managers are more efficient than their southern peers.

The model points out that if cross-country teams of northern mangers and southern production workers are allowed to form, wage inequality might rise in both countries. In the South, some unskilled workers are coupled with more efficient northern managers and experience a boost in their productivity (and wage rate) relative to unskilled workers that interact with local managers. Thus wage inequality among southern unskilled workers increases, widening country-wide wage inequality.

Northern wage dynamics are less linear. Unskilled workers face competition from their southern peers and this reduces their wage. On the other hand, some northern managers now manage southern workers, and thus there are fewer of them available to manage northern unskilled labour. As a result, northern production workers who consume less managerial resources become more valuable and are better paid, and this contributes to decrease overall wage inequality in the North. The path of northern skill premium thus depends on the balance between these two opposite effects.

Other works that link economic openness to patterns of skill premia address the issue of labour migration. For example, Yabuuchi and Chaudhuri (2007) present a 
theoretical analysis of how international migration of labour can affect the wage gap between skilled and unskilled workers in developing economies. They build a model of a small developing economy with three sectors: an informal, agricultural sector uses unskilled labour and land; a sector that combines (unionised) unskilled labour and capital to obtain a low-skill manufacturing good; and a sector that produces a high-skill manufacturing good, taking capital and skilled labour as inputs. Wages of the unskilled sectors are positively related, factors other than land and skilled labour are mobile, and all markets (except the labour market in the unskilled manufacturing sector) are perfectly competitive.

Yabuuchi and Chaudhuri's paper suggests that, for example, emigration of skilled labour might contribute to lower wage inequality in developing economies, but this depends on the capital intensity and institutional settings of markets where unskilled labour is employed. Specifically, emigration of skilled workers decreases wage inequality if capital intensity is higher in the unskilled manufacturing sector than in the skilled manufacturing sector.

When skilled workers emigrate, they become scarcer and better paid, and so in the skilled sector there is an incentive to substitute skilled-labour for capital. Since capital is scarce, it must be drawn from the unskilled manufacturing sector. As a result, in the unskilled manufacturing sector the demand for unskilled workers rises, thereby increasing unskilled wages. Yabuuchi and Chaudhuri show that, under certain conditions, this effect is stronger than the increase in the wages of skilled labour, thereby reducing the skill premium.

Empirical evidence connecting economic openness and wage inequality is mixed (e.g., Haskel and Slaughter, 2001; Lawrence and Slaughter, 1993). For example, Hijzen (2007) provides some evidence that the effects of openness are relevant, but not central in explaining the increase in the skill premium. Following the methodology proposed by Feenstra and Hanson (1997), Hijzen (2007) studies the role of technological change, outsourcing and foreign competition in shaping the increase of wage inequality in the United Kingdom. Hijzen uses sector data for the period 1993-1998, and classifies labour into skilled and unskilled using the Standard Occupational Categories Classification.

His results show that both technological change and outsourcing contributed to reduce the wages of unskilled workers - with the effect of technological change being roughly $70 \%$ stronger than that of outsourcing -, but there is no evidence of the wages of skilled workers being affected. Foreign competition, measured by import prices, seems to have forced a slight reduction in the wages of skilled workers, therefore reducing wage inequality. 
And Wood (1997), for example, finds some contradictory evidence for the role of openness to trade in shaping wage inequality. Data from East Asia for the period between the 1960s and 1970s lends some support to the idea that openness to trade reduces wage inequality in developing countries, but data from Latin America for the late 1980s and early 1990s seems to say otherwise. In a more concrete example by Arbache et al. (2004), we find evidence that openness to trade indeed increased returns to college education in Brazil. Interestingly, in their concluding remarks Arbache et al. (2004) argue that this is due to skill-biased technology being transferred to Brazil through capital imports and foreign direct investment.

Summarising, skill-biased technological change, labour market features and economic openness constitute the main explanations to the recent widespread increase of skill premia. Moreover, a considerable consensus exists in acknowledging the skillbiased technological change hypothesis as the most robust explanation (Johnson, 1997). As in next chapter we study the behaviour of the skill premium through a model in which the skill-biased technological change literature is complemented with elements from the literature on technology-adoption costs and on learning-by-doing, in the following section we briefly present the roots and many economic applications of the latter concept. We leave the discussion of technology-adoption costs for section 2.5 .

\subsection{Learning-by-doing}

Much of the interest on learning-by-doing mechanisms has been spawned by Arrow's (1962) seminal paper. The core of Arrow's work revolves around a simple, yet important, observation concerning the industrial production costs. Arrow notices that the cost of producing an additional unit decreases with the volume of past activity. Somehow, the experience gained during the production process contributes to improve productive efficiency, and to lower the cost of subsequent production.

Arrow (1962) argues that the improvement in each firm's productivity is influenced by both industry-wide investment and industry-wide production due to: (i) knowledge being created as a by-product of production and investment activities; (ii) each firm being able to take advantage of that publicly available knowledge. Since such mechanism could, potentially, generate endogenous growth, this simple connection became the basis for many later works that contribute to what is called endogenous growth theory.

Furthermore, learning-by-doing mechanisms have also been used to study subjects such as international trade and real business cycles, for example. The broad 
application of the concept of learning-by-doing, and the richness of the effects it generates, illustrates its importance in the field of economics.

\section{Learning-by-doing in the endogenous growth theory}

One can say - with a reasonable degree of accuracy - that Arrow's work constituted a pathbreaking contribution to growth theory. Given the dominant perspective that growth was exogenous (Solow, 1956), a mechanism capable of generating sustained growth endogenously, while avoiding some known problems (as in, e.g., the $A K$ model), was nothing short of revolutionary.

The most notable contribution that draws on the concept laid out by Arrow (1962) is, arguably, the work by Romer (1986). In short, Romer spells out the building blocks that allow the creation of a model in which firms generate knowledge while they accumulate capital, thereby contributing to generate endogenous growth. The main feature of such model is that production factors exhibit diminishing returns at firm level, while at the same time they contribute to create knowledge that grows continuously at economy level.

When firms carry out production and install capital, they take as given the aggregate stock of knowledge, which influences their productivity. However, capital accumulation at firm level generates knowledge that increases the aggregate knowledge stock. This, in turn, increases firms' future productivity levels, also implying higher factor returns and capital accumulation in the future. Hence, capital accumulation at $t$ stimulates further capital accumulation at $t+1$, in a process that perpetuates itself. Provided that certain conditions are met, in such model the externalities associated to capital accumulation are sufficient to generate a steady-state in which growth is determined endogenously.

A model closely related is the one proposed by Lucas (1988). The main difference with respect to Romer (1986) is that Lucas analyses the externalities associated with human-capital accumulation, rather than with physical-capital accumulation. Although not directly connected with Arrow's (1962) idea of learning-by-doing - in the sense that knowledge creation is not associated with physical capital accumulation -, the underlying mechanism is familiar. Human capital accumulation by individuals increases their own stock of human capital, and thus their own productivity level. However, individual decisions to accumulate human capital also contribute to raise the aggregate human capital level, which Lucas (1988) argues has a positive impact on each individual's productivity. This aggregate effect then increases the returns to human capital, providing individuals with an incentive to invest more in it.

Other works (e.g., Stokey, 1988; Young, 1993) have drawn on the concept of 
learning-by-doing to generate endogenous-growth models significantly different from the ones proposed by Romer (1986) and Lucas (1988). A central characteristic of those models is that the economy produces not just a single representative good, but a basket of different goods. In these models, the secular process of economic growth doesn't simply translate into a mere increase in the quantity of final goods; economic growth implies a change in the basket of goods that the economy produces.

In the proposal by Stokey (1988), knowledge is combined with labour to produce a basket of final goods. The higher the knowledge stock of the economy, the lower the labour requirements to produce final goods. Stokey assumes that knowledge creation depends on both the existing knowledge stock and on the basket of goods that the economy produces. In line with Arrow (1962), Stokey (1988) argues that knowledge is created as a by-product of the production process, and that the production of a more sophisticated basket of goods commands higher knowledge creation.

At a given time, the economy produces some goods and, in the process, increases the knowledge stock. This lowers production costs (and prices) of final goods, thus allowing the economy to produce more complex goods with the same resources. As Stokey (1988) acknowledges, for this process to generate sustained economic growth - in the sense of a continuously evolving basket of goods -, consumer preferences that favour more sophisticated goods are required.

Young (1993) contributed to this strand of the literature by drawing attention to the fact that, realistically, there might exist some limits to knowledge creation from learning-by-doing. Young (1993) therefore proposes a model in which the economy produces an evolving basket of good, and learning-by-doing resulting from the production of each good is bounded. Furthermore, a significant contribution of Young's work is that his model combines learning-by-doing with innovation. Although learning-by-doing can increase the knowledge stock of the economy and decrease production costs, thereby freeing resources to produce additional goods, only deliberate invention efforts can make new goods available for production.

\section{Other applications of learning-by-doing}

Learning-by-doing mechanisms have also been used within the endogenous growth literature to build models in which growth is not a continuous and stable process, but instead happens in cycles. Although some works show that multi-sector growth models can, in some cases, yield cyclical growth (e.g., Benhabib and Nishimura, 1979), cyclical growth is often thought to be related to what Schumpeter (1942) dubbed as "waves of creative destruction": revolutionary innovations - generated endogenously within the economic system - make the economy move from its cur- 
rent equilibrium to a more advanced one. The economy goes through a process in which existing economic structures are initially destructed, thereby creating a downward cycle, so that new economic structures can emerge, making way for a cycle of economic expansion. The use of learning-by-doing mechanisms to build endogenous growth models that exhibit cyclical growth can be found, for example, in Greiner and Hanusch (1994) and Greiner (1996).

Exploring cyclical effects with learning-by-doing mechanisms, however, is not confined to endogenous growth theory. In recent years similar efforts have been made, for example, in real-business-cycle theory (e.g., Cooper and Johri, 2002; Chang et al., 2002). The standard real-business-cycle model (e.g., King et al., 1988) has some limitations when it comes to adequately replicate the persistent nature of shocks that is observed in the data (Colgey and Nanson, 1995). To address this issue, Cooper and Johri (2002) propose a framework in which larning-by-doing mechanisms play a central role in creating shoch-induced persistent fluctuations. In the model learning-by-doing is linked to organisational capital, which the authors assume to be associated with firms, but also with workers (i. e., workers have knowledge that is valuable to firms' activities).

Based on simulation results, Cooper and Johri show that the learning-by-doing mechanisms can induce much stronger autocorrelation in macroeconomic variables than the standard real-business-cycle models. In the case of i.i.d. shocks, for example, the traditional real-business-cycle model yields a smaller autocorrelation coeficient on aggregate output than the model with learning-by-doing proposed by Cooper and Johri. Depending on the formulation of the process of accumulation of organisational capital, these differences can be quite big.

An alternative approach to the inclusion of learning-by-doing in real-businesscycle models can be found, for example, in Chang et al. (2002). They propose a model in which workers' productive experience, which drives their productivity, increases with the number of hours they worked in the past. This formulation, somewhat closer to the original concept of learning-by-doing proposed by Arrow (1962), can also create more persistent responses of output in response to exogenous shocks.

Models of learning-by-doing have also been used to study international trade (e.g., Young, 1991; Lucas, 1993), providing a more thorough understanding of the benefits of trade. The work of Young (1991), for example, shows how trade interacts with the learning-by-doing that each country experiences while carrying out production. Young's main contribution is to point out that developing countries risk specializing in goods with limited learning-by-doing opportunities. Thus, the 
adverse dynamic effects of trade might outweigh the static gains obtained while trading with more advanced countries.

The applications of learning-by-doing we have presented are a small illustration of the importance that this concept has gained in economics. Because learning-bydoing mechanisms have proved to be intimately connected with factor productivity, we believe they can be a fundamental tool in understanding the recent changes in labour demand and in the structure of wages.

\subsection{Technology-adoption costs}

The paper by Parente and Prescott (1994) is the seminal work concerning cost of technology-adoption. ${ }^{8}$ In their work, Parente and Prescott argue that cross-country differences in barriers to technology adoption can - unlike differences in taxation levels, for example - explain the vast income disparity observed across countries.

The main assumption underpinning their results is that firms wishing to upgrade their technological level, and thus their productivity, have to make an investment, which is, in essence, a sunken adoption-cost. Using data from a wide range of countries $^{9}$, Parente and Prescott show that small, plausible differences in the magnitude of that investment can account for the observed cross-country differences in income levels.

A similar argument, although built upon different assumptions, has been put up by Easterly et al. (1994). Their model considers the case in which the production of final-goods is achieved by combining a continuum of intermediate goods and labour. Barriers to technology adoption exist in this model because the (aggregate) level of human-capital limits the array of intermediate goods that can be used, and Easterly et al. (1994) assume that upgrading the level of human capital is costly (i. e., it consumes units of final goods).

Firm-level evidence (e.g., Baldwin and Lin, 2002) suggests that there are indeed barriers to technology adoption, because innovating implies a learning process. Furthermore, some works point out that technology-adoption costs can account for the productivity slowdown observed in the United States in the 1970s (e.g., Greenwood and Yorukoglu, 1996; Kiley, 2001; Bessen, 2002). In principle, this could stem from the documented fact that adoption of information technologies is associated with significant changes in the organisation of workplaces and production processes (see, e.g., Bresnahan et al., 1999; Brynjolfsson and Hitt, 2000;

\footnotetext{
${ }^{8}$ Parente (1995) is also a relevant, closely related paper.

${ }^{9}$ The countries studied by Parente and Prescott (1994) are the United States, Japan, France, West Germany, South Korea and Taiwan.
} 
Black and Lynch, 2001).

Furthermore, it is worth noticing that previous studies have already drawn on the concept of technology-adoption costs to study the dynamics of wage inequality. Differences in the ability to adopt innovative technologies - which, naturally, imply differences in the adoption costs - are at the core of the work by Lloyd-Ellis (1999). In this work, the increases in the skill premium result from a decline in the growth rate of the capacity of labour to absorb new technologies. In the model proposed by Lloyd-Ellis (1999), for technological innovations to enter the production process they must be adopted by workers that meet a minimum skill requirement. Moreover, that skill requirement increases as more complex innovations arrive. On the other hand, the skill distribution of the economy can also be updated over time, and thus the capacity to absorb more complex innovations may increase.

Lloyd-Ellis's main conclusion is that if the complexity of technological innovations grows faster than the mean absorptive capacity of labour, workers able to implement the new technologies become scarcer, and thus more valuable and better paid. In support of this result, Lloyd-Ellis (1999) points to the decline in the United States educational attainment documented by Bishop (1979) and Jorgensen et al. (1987).

Borghans and ter Weel (2007), on the other hand, stress that technology-adoption costs at individual level might be at the heart of the dynamics of wage inequality. They propose a model in which they link the diffusion of computer technologies to the changes in the pattern of wage inequality and to the timing of those changes. In that model, skilled and unskilled workers, which exhibit inter and intra-group differences in productivity, decide for the adoption of computer technologies based on an individual cost-benefit analysis, comparing adoption-costs with productivity benefits. Borghans and ter Weel (2007) argue that these individual decisions influence the wages of skilled and unskilled workers differently throughout time, ultimately affecting the path of wage inequality. A crucial assumption in the model by Borghans and ter Weel (2007) is that the cost of adoption computers falls exogenously over time.

Initially, the computer-related adoption costs are high and only some skilled workers adopt them. This enhances their productivity, but also the aggregate supply of efficient units of skilled labour. The latter effect outweighs the productivity increase, depressing the wage of skilled workers (because demand for efficient units of labour is stable). Since initially few unskilled workers adopt the computer technology, their wages are less affected by the adverse effect caused by increases in the supply of efficient units of unskilled labour. Therefore, wage inequality falls in the 
early stages of computer adoption.

As the cost of adopting computers falls, more unskilled workers begin adopting that technology. Individually their productivity increases, and this increases the aggregate supply of efficient units of unskilled labour. Like in the case of skilled workers, the adverse effect of additional supply outweighs the productivity gains, negatively affecting the wages of the unskilled. And even though some skilled workers continue to adopt computers, there are now few of them that are still non-adopters. As a result, computer adoption by those non-adopters has little impact on the wage rate of skilled labour. Hence, in the latter stages of technology adoption the skill premium increases.

The work of Borghans and ter Weel (2007) has the merit of bringing out the fact that because technology adoption is costly, the diffusion of new technologies is not an instant process (see, e.g., Mansfield, 1961, 1965; Davies (1979)) and as such has the potential to influence the time path of productivity and wages. Indeed, this view is also defended by Caselli (1999), who argues that the cost of adopting new technologies exists because workers have to upgrade their skills. However, unlike Borghans and ter Weel (2007), Caselli considers the case in which the nature of the technological change can favour either skilled or unskilled labour.

In light of these contributions, it seems clear that technology-adoption costs can have a significant, variable impact on growth, productivity and wages. Therefore, it seems unwise to ignore their effect when studying the path of wage inequality, and we consider it in the model developed in the following chapter. However, in contrast to some of the contributions we presented here, we make no previous assumptions on the relative magnitude of the technology-adoption costs experienced by each type of labour (skilled or unskilled). In our opinion, this feature is important to obtain richer dynamics in terms of the path of wage inequality. 


\section{Model}

\subsection{Overview}

Throughout this chapter we build an endogenous growth model where $R \& D$ is the driving force behind economic growth. We draw on the framework laid out by Afonso $(2006,2007)$, which connects the skill-biased technical change literature (e. g., Acemoglu, 1998, 2002, 2003b) with the Schumpeterian approach to growth (e.g., Aghion and Howitt, 1992; Grossman and Helpman (1991b); Barro and Sala-i-Martin, 2004). We expand this framework by considering the effects of learning-by-doing (Arrow, 1962) and technology-adoption costs (Parente and Prescott, 1994) upon both the skill-bias of technology and wage inequality.

We consider an economy populated by infinitely-lived households, by firms that produce a homogeneous final good, and by firms that produce intermediate goods. Population growth is zero, and time is continuously indexed by $t$ on $\mathbb{R}_{0}^{+}$.

Households supply labour to the economy, consume units of the aggregate output, and own firm equity. Each household's labour endowment is constant, and since population growth is zero the total amount of labour supplied to the economy does not vary over time.

In the final-goods sector firms combine labour and a continuum of qualityadjusted intermediate goods to obtain their output. The production of final goods is perfectly competitive, and the output of all final-goods firms constitutes the economy's aggregate output.

Intermediate-goods producers use units of this aggregate output and blueprints as their inputs. Blueprints consist of information on how to produce and market specific qualities of intermediate goods, and they are obtained through R\&D, which, in turn, drives economic growth, the technological-knowledge bias and the path of wage inequality. The firm that first introduces a new quality of an intermediate good earns the perpetual right to be its sole producer. The legal protection for those production rights is established through a patent system.

\subsection{Households}

Households are endowed with ability $a \in[0,1]$ and supply one of two types of labour. If $a<\bar{a}$ they supply low-skilled labour, $L_{a}$, otherwise they supply highskilled labour, $H_{a}$.

The total amount of low-skilled labour supplied to the economy, $L$, is given by

$\int_{0}^{\bar{a}} L_{a} d a$. The wage rate of this type of labour is $w_{L}(t)$. High-skilled labour, in turn, 
is paid at a wage rate of $w_{H}(t)$, and the amount of it supplied to the economy is given by $H=\int_{\bar{a}}^{1} H_{a} d a$. We assume that $H+L=1$.

All households have identical preferences and wish to maximize their lifetime utility. Preferences are characterized by a constant relative risk aversion (CRRA) utility function. Thus, a household with ability a maximizes

$$
\int_{0}^{\infty} \frac{C_{a}(t)^{1-\theta}-1}{1-\theta} \cdot e^{-\rho t} d t
$$

where $C_{a}(t)$ is its consumption at time $t, \rho$ is the subjective discount rate and $\theta$ is the coefficient of relative risk aversion. Parameter $\theta$ is also the inverse of the inter-temporal elasticity of substitution.

Households accumulate assets $(K)$ in the form of ownership of firms that produce intermediate goods. Those assets earn returns at the interest rate $r(t)$. A household's assets stock is affected by its net savings, given by the difference between its income - wages and interest - and its consumption. The flow budget constraint of a household with ability $a$ is given by:

$$
\dot{K}_{a}(t)=r(t) K_{a}(t)+w_{z}(t) Z_{a}(t)-C_{a}(t)
$$

where $\dot{K}_{a}(t)$ is the change in the assets stock of household $a$, and:

$$
Z=\left\{\begin{array}{l}
L \quad \text { if } \quad a \leq \bar{a} \\
H \quad \text { if } \quad a>\bar{a}
\end{array}\right.
$$

In addition, the borrowing and lending of every household is constrained by a "no Ponzi games" condition: $\lim _{t \rightarrow \infty} K_{a}(t) e^{-\rho t}=0$.

The households' problem is then to maximize (3.1) subject to the constraints imposed by (3.2) and by the "no Ponzi games" condition. The present value Hamiltonian for this problem is:

$$
H(t)=\left(\frac{C_{a}(t)^{1-\theta}-1}{1-\theta}\right) e^{-\rho t}+\mu(t)\left[r(t) K_{a}(t)+w_{Z}(t) Z_{a}(t)-C_{a}(t)\right],
$$

and the first order conditions are:

$$
\begin{gathered}
C_{a}(t)^{-\theta}(t) e^{-\rho t}=\mu(t), \text { and } \\
\mu(t) r(t)=-\dot{\mu}(t) .
\end{gathered}
$$

Differentiating (3.3) with respect to time and substituting the result into equation 
(3.4) yields:

$$
\mu(t) r(t)=\rho C_{a}(t)^{-\theta} e^{-\rho t}+\theta C_{a}(t)^{-\theta-1} \dot{C}_{a}(t) e^{-\rho t},
$$

where $\dot{C}_{a}(t)$ is the change in the consumption of a household with ability $a$. Dividing this result by (3.3) gives the optimal path for consumption of a household with ability $a$ :

$$
\frac{\dot{C}_{a}(t)}{C_{a}(t)}=\frac{r(t)-\rho}{\theta}
$$

which is independent of the ability level. Aggregate consumption, $C(t)$, is given by $\int_{0}^{1} C_{a}(t) d a$. Since population growth is zero, the optimal path for aggregate consumption equals (3.5):

$$
\frac{\dot{C}(t)}{C(t)}=\frac{C_{a}(t)}{C_{a}(t)}=\frac{r(t)-\rho}{\theta},
$$

where $\dot{C}(t)$ is the change in aggregate consumption. Consumption - as well as resources devoted to $\mathrm{R} \& \mathrm{D}, R(t)$, or to the production of intermediate goods, $X(t)$ - comes out of the aggregate output of the final-goods sector, $Y(t)$ :

$$
C(t)+X(t)+R(t)=Y(t) .
$$

\subsection{Final-goods sector}

Firms in this perfectly competitive sector are indexed by $n$ over the range $[0,1]$ and produce final goods. Two substitute production technologies are available. A low-complexity technology - the $L$-technology - uses a combination of low-skilled labour and a continuum of intermediate goods indexed by $j \in[0, J]$. We'll refer to these goods as 'low-specific intermediate goods'. A high-complexity technology - the $H$-technology - combines high-skilled labour and a set of high-specific intermediate goods, continuously indexed by $j \in[J, 1]$.

All firms in the final-goods sector have access to the technologies described above, and the production function of any firm $n$ is given by:

$$
\begin{aligned}
Y_{n}(t)= & A\left\{\left[(1-n) L_{n} \sigma_{L}\right]^{\alpha} \int_{0}^{J}\left(X_{j n}(t) q^{k_{j}(t)}\right)^{1-\alpha} d j\right. \\
& \left.+\left[n H_{n} \sigma_{H}\right]^{\alpha} \int_{J}^{1}\left(X_{j n}(t) q^{k_{j}(t)}\right)^{1-\alpha} d j\right\},
\end{aligned}
$$

where $A$ is an overall efficiency parameter, $\alpha \in] 0,1[$ is the share of labour in the production, and $L_{n}$ and $H_{n}$ are the amounts of low and high-skilled labour used by firm $n$. Both $\int_{0}^{1} L_{n} d n=L$ and $\int_{0}^{1} H_{n} d n=H$ hold at any point in time. The 
terms $n$ and $(1-n)$ imply that low-skilled labour is more productive in producing lower-index final goods, whereas high-skilled labour is more productive in producing higher-index final goods. ${ }^{10}$

In line with the Schumpeterian growth models literature (e. g., Aghion and Howitt, 1992; Barro and Sala-i-Martin, 2004), $X_{j n}(t)$ is the quantity of intermediate good $j$ used by firm $n$, and $q^{k_{j}(t)}$ measures the quality level of that intermediate good. Qualities of intermediate goods are ordered along a quality ladder, and $k_{j}(t)$ is the highest quality rung of intermediate good $j$ available at time $t .^{11}$ Parameter $q$, greater than one, measures the quality improvement that occurs in an intermediate good when a new quality of it is introduced, i. e., when $k_{j}(t)$ increases by one.

Finally, terms $\sigma_{L}$ and $\sigma_{H}$ measure the technological readiness of low and highskilled labour. By technological readiness of labour we mean how efficiently workers use the respective complementary intermediate goods, and how easily they adapt to new, improved versions of those goods.

Although we leave a detailed analysis of $\sigma_{L}$ and $\sigma_{H}$ to section 3.6, a short explanation is now in order. We assume workers must gain some familiarity with the intermediate goods in order to fully explore their potential. This draws on the idea of learning-by-doing popularized by Arrow (1962), and much of the mechanism we propose is also related with the work of Lucas (1988).

We assume that familiarity with intermediate goods, which can be regarded as a form of tacit knowledge, is acquired in the production process. We assume that tacit knowledge acquired by one worker is shared with other workers of the same type. Moreover, at least to some extent, workers acquire different knowledge during the interaction with the intermediate goods, making knowledge exchange beneficial. Thus, labour endowments determine how much tacit knowledge is created and disseminated by each group of workers. We assume that because different sets of intermediate goods are combined with different kinds of workers, tacit knowledge is specific to each type of labour. Finally, we assume that tacit knowledge has a positive effect on workers' efficiency in using intermediate goods. Increased familiarity with intermediate goods improves labour productivity.

Another issue to consider is how workers cope with technological progress, i. e., with the introduction of new versions of intermediate goods. We assume that because workers have to make an effort to adapt to new versions of intermediate goods, the upgrading process is costly and has an effect upon the production of final goods.

\footnotetext{
${ }^{10}$ As we will see later on, a threshold final good $\left.\bar{n} \in\right] 0,1[$ exists such that goods $n<\bar{n}$ are produced with one technology and the remaining final goods are produced using the other technology.

${ }^{11}$ We consider an equilibrium in which final-goods producers only use the highest-quality intermediate goods. Section 3.4 provides further details.
} 
This assumption relates to the work of Parente and Prescott (1994), who stress the negative impact of barriers to technology-adoption in economic growth.

Rather than considering an explicit upgrading cost, we simply assume that part of the production efforts are diverted to the process of adapting to new versions of intermediate goods, resulting in lower productivity and output. Were technologyadoption costless and the introduction of new versions of intermediate goods would result in a greater increase in aggregate output.

To sum up, on the one hand the technological readiness of labour is, in part, determined by how efficiently workers use the respective complementary intermediate goods, in line with the idea of learning-by-doing popularised by Arrow (1962); and on the other hand, it denotes how easily workers adapt to new, improved qualities of intermediate goods, and this is associated with the negative impact of barriers to technology adoption in economic growth stressed by Parente and Prescott (1994).

For simplicity we omit the technical details underlying $\sigma_{L}$ and $\sigma_{H}$ until section 3.6. This avoids some notational cluttering and has no influence on the results we derive along the way.

\section{The behaviour of final-goods firms}

Let $P_{n}(t)$ be the price of the final good produced by firm $n$ and $P_{j}(t)$ denote the price of intermediate good $j$. Profits of any firm $n, \pi_{n}(t)$, are given by:

$$
\begin{aligned}
\pi_{n}(t)= & P_{n}(t) Y_{n}(t)-w_{L}(t) L_{n}(t)-w_{H}(t) H_{n}(t) \\
& -\int_{0}^{J} X_{j n}(t) P_{j}(t) d j-\int_{J}^{1} X_{j n}(t) P_{j}(t) d j .
\end{aligned}
$$

Since the final-goods sector is perfectly competitive, any firm $n$ takes the price of its own product, the price of intermediate goods, and labour wage rates as given. The first-order conditions of the profit maximization problem require that the marginal contribution of each input to profits equals zero. Thus, differentiating (3.8) with respect to $X_{j n}$, equating the result to zero, and solving for $X_{j n}$ yields: ${ }^{12}$

$$
X_{j n}=P_{j}^{-1 / \alpha}\left(P_{n} A\right)^{1 / \alpha}\left[(1-n) L_{n} \sigma_{L}\right](1-\alpha)^{1 / \alpha}\left(q^{k_{j}}\right)^{(1-\alpha) / \alpha}, \text { if } 0 \leq j \leq J,
$$

and:

$$
X_{j n}=P_{j}^{-1 / \alpha}\left(P_{n} A\right)^{1 / \alpha}\left[n H_{n} \sigma_{H}\right](1-\alpha)^{1 / \alpha}\left(q^{k_{j}}\right)^{(1-\alpha) / \alpha}, \text { if } J \leq j \leq 1 .
$$

\footnotetext{
${ }^{12}$ We drop the time arguments to simplify the notation, and we will do so whenever that is convenient and causes no confusion.
} 
These two expressions represent, respectively, the demand of firm $n$ for lowspecific and high-specific intermediate goods. Firms demand more intermediate goods when the prices of their own goods increase, or when intermediate-goods prices decrease. Also, firms use more intermediate goods when they employ more workers, i. e., when $L_{n}$ or $H_{n}$ are higher. This effect is due to the complementarity between labour and intermediate goods in (3.7).

Using (3.9) and (3.10) to subsitute for $X_{j n}$ in (3.7) we obtain:

$$
\begin{aligned}
Y_{n}= & A\left\{\left[(1-n) L_{n} \sigma_{L}\right]\left[\frac{(1-\alpha)}{P_{j}}\right]^{(1-\alpha) / \alpha}\left(P_{n} A\right)^{(1-\alpha) / \alpha} \int_{0}^{J}\left(q^{k_{j}}\right)^{(1-\alpha) / \alpha} d j\right. \\
& \left.+\left[n H_{n} \sigma_{H}\right]\left[\frac{(1-\alpha)}{P_{j}}\right]^{(1-\alpha) / \alpha}\left(P_{n} A\right)^{(1-\alpha) / \alpha} \int_{J}^{1}\left(q^{k_{j}}\right)^{(1-\alpha) / \alpha} d j\right\} .
\end{aligned}
$$

The price $P_{j}$ doesn't enter the integral because it is independent of $j$, as we will see later on. After some manipulation, this expression simplifies to:

$$
Y_{n}=A^{1 / \alpha}\left[\frac{P_{n}(1-\alpha)}{P_{j}}\right]^{(1-\alpha) / \alpha}\left\{\left[(1-n) L_{n} \sigma_{L}\right] Q_{L}+\left[n H_{n} \sigma_{H}\right] Q_{H}\right\} \text {, }
$$

where:

$$
Q_{L}=\int_{0}^{J}\left(q^{k_{j}}\right)^{(1-\alpha) / \alpha} d j \text { and } Q_{H}=\int_{J}^{1}\left(q^{k_{j}}\right)^{(1-\alpha) / \alpha} d j .
$$

The terms $Q_{L}$ and $Q_{H}$ measure the aggregate quality of the intermediate goods that complement, respectively, low and high-skilled labour.

We can use the ratio $Q_{H} / Q_{L}$ as a measure of the technological knowledge bias. For instance, a higher value for the ratio $Q_{H} / Q_{L}$ implies that the aggregate quality of high-specific intermediate goods is higher than the aggregate quality of lowspecific intermediate goods. In this case we say that technological knowledge is biased towards the $H$-technology. Whenever we refer to increases (decreases) in the technological-knowledge bias, we mean increases (decreases) of the $Q_{H} / Q_{L}$ ratio.

The composite final good is taken as the economy's aggregate ouput, $Y(t)$, which is thus given by:

$$
Y=\int_{0}^{1} P_{n} Y_{n} d n
$$

Finally, assuming the normalization $\exp \int_{0}^{1} \ln P_{n} d n=1$, i. e., taking $Y$ as numeraire at each time, we can write expression (3.12) as:

$$
Y=\exp \int_{0}^{1} \ln Y_{n} d n
$$




\subsection{Intermediate-goods sector}

To obtain one unit of any quality-adjusted intermediate good, $X_{j}$, firms in this sector use one unit of aggregate output. Hence, the marginal cost of producing intermediate goods is independent of their quality, constant across intermediate goods and equal to one.

Each quality of an intermediate good is exclusively produced by the owner of its patent. Suppose that at each time $t$, the monopolist that holds the patent for the highest quality of intermediate good $j$ can (potentially) obtain a profit flow of:

$$
\pi_{j}(t)=\left(P_{j}(t)-1\right) X_{j}(t)
$$

where $X_{j}(t)$ is the aggregate demand for the highest-quality intermediate good $j$.

The goal of the monopolist is to choose the sequence of prices $\left[P_{j}(t), P_{j}(t+1)\right.$, ...] that maximizes the present discounted value of all profit flows. Following Acemoglu and Zilibotti (2001), we assume that intermediate goods bought by the producers of final goods fully depreciate at the end of each period. Under such assumption, the monopolist faces no dynamic constraints and every period chooses $P_{j}(t)$ so as to maximize (3.13).

To determine the price for the highest-quality intermediate good $j$, we start by computing the aggregate demand, $X_{j}$. Since all firms in the final-goods sector face the same intermediate-goods prices, we can immediately use (3.9) and (3.10) to compute $X_{j}=\int_{0}^{1} X_{j n} d n$ for all intermediate-goods $j \in[0,1]$. This yields:

$$
X_{j}=\left(P_{j}-1\right)\left[\frac{A(1-\alpha)}{P_{j}}\right]^{1 / \alpha}\left(q^{k_{j}}\right)^{(1-\alpha) / \alpha} \sigma_{L} \int_{0}^{1}(1-n) L_{n}\left(P_{n}\right)^{1 / \alpha} d n
$$

for intermediate goods $j \in[0, J]$, and:

$$
X_{j}=\left(P_{j}-1\right)\left[\frac{A(1-\alpha)}{P_{j}}\right]^{1 / \alpha}\left(q^{k_{j}}\right)^{(1-\alpha) / \alpha} \sigma_{H} \int_{0}^{1} n H_{n}\left(P_{n}\right)^{1 / \alpha} d n,
$$

for intermediate goods $j \in[J, 1]{ }^{13}$ Taking into account (3.14) and (3.15), the maximization of $(3.13)$ with respect to $P_{j}$ yields:

$$
P_{j}=\frac{1}{1-\alpha}
$$

for all $j \in[0,1]$. The monopoly price for any highest-quality intermediate-good is:

\footnotetext{
${ }^{13} \mathrm{As}$ it will become clear later on, the integral terms in (3.14) and (3.15) will be $\int_{0}^{\bar{n}}(1-n) L_{n}\left(P_{n}\right)^{1 / \alpha} d n$ and $\int_{\bar{n}}^{1} n L_{n}\left(P_{n}\right)^{1 / \alpha} d n$, respectively.
} 
(i) a mark-up over the marginal cost of production, since $\alpha \in] 0,1[$; (ii) constant across intermediate goods and time invariant; and (iii) independent of the quality level of the intermediate good.

Whether or not a monopolist can price its output according to (3.16) depends on the substitutability between different qualities of a same intermediate good and on the value of $q$. Following Barro and Sala-i-Martin (2004, chapter 7), we assume that $q>1 /(1-\alpha)$ and that monopolists set $P_{j}$ according to (3.16), effectively driving the monopolists of lower qualities of intermediate-good $j$ out of the market. ${ }^{14}$

\subsection{Quality-improving R\&D}

Firms in the intermediate-goods sector carry out R\&D activities that are aimed at improving the quality level of intermediate goods. Let $\delta_{j}(k, t)$ denote the probability of the $k$-th quality of intermediate good $j$ being introduced at time $t$, thereby improving the quality level of that good from $q^{k}$ to $q^{k+1}$. We assume that this probability is given by

$$
\delta_{j}(k, t)=R_{j}(k, t) \Psi_{j}(k, t) \zeta_{j}(t) \xi_{j}(k, t)
$$

for all $j \in[0,1]$. This function for the probability of success of R\&D is adapted from Afonso (2006). We assume that this function is the same for low-specific and high-specific intermediate goods, whereas Afonso's proposal considers the case in which R\&D aimed at high-specific intermediate goods is more effective. ${ }^{15}$

The term $R_{j}(k, t)$ is the total amount of $\mathrm{R} \& \mathrm{D}$ spending aimed at improving intermediate good $j$. As described by (3.6), R\&D spending comes out of the aggregate output of the final-goods sector. Because aggregate output is an input of R\&D activities, this specification fits in the "lab-equipment" class that Rivera-Batiz and Romer (1991) refer to.

In addition, our formulation implies that in equilibrium there will be constant returns to scale in R\&D expenditures, in line with Romer (1993), for example. Empirical evidence with respect to this is somewhat mixed (Kortum, 1993; Thompson, 1996; Morrison and Siegel, 1997).

As for the other terms, $\Psi_{j}(k, t)$ represents the learning effect, $\zeta_{j}(t)$ is the adverse

\footnotetext{
${ }^{14}$ For a detailed discussion of pricing strategies and its relation with the value of $q$ see Barro and Sala-i-Martin (2004, chapter 7). The alternative use of limit pricing strategies would not alter the nature of the results. Furthermore, it is shown that the monopolist gains a one-rung quality advantage over its closest competitor.

${ }^{15}$ Afonso (2006, p. 15) reflects an "absolute advantage of the high-skilled labour over low-skilled labour to learn, assimilate and implement advanced technological knowledge" in the probability function of R\&D success. We take a different approach, explained in detail in section 3.6.
} 
effect induced by the size of the market for intermediate goods, and $\xi_{j}(k, t)$ is the complexity effect. We now explain each one of them with more detail.

\section{Learning effect}

This effect relates past successful R\&D in an intermediate good with the probability of success of current R\&D aimed that good. Two related assumptions shape this effect. The first is that technological knowledge is non-rival, i. e., once discovered it can be used by any firm. The second assumption is that the legal system only gives protection to production rights.

In other words, it stops firms from producing qualities of intermediate goods introduced by others, but it gives no protection to the technological knowledge underlying those goods. Firms are free to resort to means such as reverse engineering to obtain the technological knowledge embodied in an intermediate good and use it in $R \& D$ activities aimed at creating new qualities of that good.

The second assumption, connected with the first, is that firms indeed learn from past intermediate-goods innovations, and use that knowledge in their R\&D efforts to introduce new qualities of intermediate goods. Together with the first assumption, this implies that R\&D efforts aimed at an intermediate good become more effective as new qualities of that good are introduced.

Since $q^{k_{j}(t)}$ is a measure of the past successful R\&D in intermediate good $j$, we model the learning effect as:

$$
\Psi_{j}(k, t)=\Gamma q^{k_{j}(t)}
$$

where $\Gamma>0$ is a learning coefficient.

\section{Market-size effect}

Successfully introducing a new quality of an intermediate good is a two-step process. A firm must invent the new quality of an intermediate good, but it must also market it adequately. Many tasks involved in this last step are more difficult to execute in larger markets: for example, as Becker and Murphy (1992) point out, co-ordination among agents might be harder to achieve with increased market size. Furthermore, information dissemination and processing can become more complex as the market grows, and innovators may experience additional difficulties in marketing their products.

Since in our model final-goods firms buy intermediate goods to use in combination with labour, the economy's endowment of each type of labour ( $L$ and $H$ ) 
provides a good measure of the size of the market for the respective complementary intermediate goods. Therefore, we model the adverse market-size effect on innovation probability as:

$$
\zeta_{j}(t)=Z^{-1}
$$

where $Z=L$ if $j \leq J$ and $Z=H$ if $j>J$. This follows Dinopoulos and Thompson (1999) in removing the scale effects from the R\&D activities, and is in line with the literature on scale effects (e.g., Jones, 1995a,b).

\section{Complexity effect}

The complexity effect can be expressed by:

$$
\xi_{j}(k, t)=\chi^{-1} q^{-(1 / \alpha) k_{j}(t)},
$$

where $\chi$ is a positive constant. In line with Barro and Sala-i-Martin (2004, chapter 7 ), this effect reflects an increasing difficulty to improve the quality of intermediate goods as their quality level rises. All else equal, every time an improvement occurs in one intermediate good the probability of further R\&D success diminishes. A common theoretical justification provided for this assumption is that the first qualities to be introduced are the easiest to invent, therefore making innovation more difficult by emptying the pool of trivial ideas.

A convenient feature of this effect is that, together with the learning effect, steers the economy to a constant growth rate over time, i. e., it helps the economy to achieve a steady state.

\subsection{The technological readiness of labour}

In section 3.3 we briefly discussed the meaning of the terms $\sigma_{L}$ and $\sigma_{H}$. There we said they measure the technological readiness of labour, i. e., they measure how efficiently workers use and adapt to new versions of intermediate-goods. We assumed this was influenced both by factors related to learning-by-doing and adoption of new versions of intermediate goods. In this section we motivate and specify in greater depth these two terms.

We model $\sigma_{L}$ and $\sigma_{H}$ as:

$$
\begin{gathered}
\sigma_{L}=L^{l} \exp \left(\phi_{1} L\right) \\
\sigma_{H}=c \times H^{h} \exp \left(\phi_{2} H\right),
\end{gathered}
$$


where $\phi_{1}, \phi_{2}<0 ; l, h \geq 1$; and $c \geq 1$. In both cases $\exp (\cdot)$ captures the effect of technology adoption. The terms $L^{l}$ and $H^{h}$ are related to learning-by-doing effects. Finally, $c$ reflects an absolute advantage of high-skilled labour over low-skilled labour in terms of technological readiness.

\section{Technology learning}

We assume that workers acquire technical expertise in intermediate good $j$ (i.e., learn how to use it efficiently) by interacting with it during the production process. Furthermore, we assume that goods from the same technology share a common technological ground, making expertise gained while working with one good useful for working with other goods of the same type. Due to these two assumptions, low (high-)skilled workers acquire technical expertise in low (high-)specific intermediate goods as a whole simply by working with one intermediate good of that type.

In addition, we assume that different workers learn different aspects of the technology, and that they exchange their technical expertise with other workers that use goods of the same type. Moreover, we assume that this exchange is beneficial for the workers involved in it. Hence, the amount of technical expertise that exists in the economy for each type of intermediate goods is linked to the total amount of labour that is being combined with those goods. That is to say, the labour endowments $L$ and $H$ influence the amount of technical expertise that exists for low and high-specific intermediate goods, respectively.

The parameters $l$ and $h$ help to shape this effect. For example, since $L$ takes values over the range $[0,1]$, a parameter $l$ lower than one would imply that as the available economy-wide technical expertise in low-specific intermediate goods grows (as $L$ increases), the benefit that low-skilled workers obtain from it increases at an increasing rate. On the other hand, assuming a value for $l$ greater than one implies that the benefit increases at a decreasing rate; we consider this latter case.

It is interesting to note that what we have described implies the existence of two kinds of spillovers: one that involves intermediate goods of the same type and other that involves workers of the same type. The spillovers across intermediate goods of the same type are similar to the cross-industry knowledge spillovers of earlier models of endogenous growth with learning-by-doing (e.g., Stokey (1988); Young (1993)). The spillovers involving workers of the same type are related, for example, to what Lucas (1988) proposes. In his work, Lucas (1988) develops a model in which the average level of human capital, which is influenced by each individual's human-capital stock, contributes to the productivity of all production factors (the external effect of human capital). Here, we create a mechanism through which the 
productivity of the production factors of one technology is affected by the technical expertise gathered by workers associated with that technology.

Summing up, learning-by-doing effects positively affect the technological readiness of labour, and thus increase its productivity. Finally, it should be noted that because workers and intermediate goods are complementary in the production function, these effects act not only upon the productivity of labour, but also upon the productivity of the respective complementary intermediate goods. Thus, the productivity of the $L$-technology ( $H$-technology) as a whole is influenced by the learning made by low-skilled (high-skilled) workers.

\section{Technology adoption}

In their analysis of the technology adoption phenomenon, Parente and Prescott (1994) argue that firms wishing to increase their technological-knowledge level face barriers to the adoption of the available technology. According to them, these barriers can be caused, for example, by legal constraints or strikes, and they play a role in determining the output of an economy and its growth rate. Others have argued that the adoption of new technologies causes firms to bear unmeasured adjustment costs. Bessen (2002), for example, points out that these costs cover things like adapting to new organizational patterns or putting complementary investments in place. ${ }^{16}$

As already stated, in our model we include the effects of barriers to technology adoption. We assume that when new qualities of intermediate goods are introduced, workers have to adapt to them and this reduces their technological readiness, thus reducing their productivity. As a result, the positive effect of the improvement in the average quality of intermediate goods diminishes. Some productive resources are eaten up by the process of adapting to the new qualities of the intermediate goods, and $Y(t)$ increases less than if the barriers to technology adoption were smaller.

Furthermore, we assume that these barriers are specific to each type of technology, and that they are linked to the endowments of low-skilled and high-skilled labour. For example, barriers to technology adoption in the $L$-technology are higher when there are more low-skilled workers that need to adapt to new versions of lowspecific intermediate goods. Hence, a higher value of $L$ implies a lower value (i. e. more negative) of $\exp \left(\phi_{1} L\right)$.

For some values of $L, H, \phi_{1}$ and $\phi_{2}$, the barriers to technology adoption might be greater in $H$-technology than in $L$-technology. This differs from approaches such as those of Caselli (1999) and Lloyd-Ellis (1999) in which it is assumed that more-skilled

\footnotetext{
${ }^{16}$ Bessen (2002) provides compelling evidence that adjustment costs increased during the shift to the information technologies paradigm.
} 
workers have an advantage over less-skilled workers in adopting new technologies. This perspective overlooks the fact, which, in our opinion, is not negligible, that different types of workers use different types of technologies. For this reason, it might happen that low-skilled workers are better prepared than high-skilled ones to adapt to new qualities of the intermediate goods they use. 


\section{Equilibria}

We will now proceed with the analysis of the model presented in chapter 3. First we derive the equilibrium for a given technological-knowledge state, i. e., for given values of the aggregate quality indexes $Q_{L}$ and $Q_{H}$. Then we bring into consideration the R\&D activities, and derive the law of motion for both $Q_{L}$ and $Q_{H}$. Later on, we use these results to characterise the steady-state and transitional dynamics of the economy.

\subsection{Equilibrium given a technological-knowledge level}

One feature of the production function described in (3.11) is that low-skilled workers of the $L$-technology are more productive in producing low-index final goods, and inputs of the $H$-technology are more productive in producing high-index final goods.

This suggests the existence of a threshold $\bar{n}$ such that the production of final goods $n \in[0, \bar{n}]$ only uses the $L$-technology, while all the other final goods are produced exclusively with the $H$-technology. It turns out that this is true and we can write the production function as: ${ }^{17}$

$$
Y_{n}=\left\{\begin{array}{ll}
A^{1 / \alpha}(1-n) L_{n} \sigma_{L}\left[\frac{(1-\alpha) P_{n}}{1 /(1-\alpha)}\right]^{(1-\alpha) / \alpha} Q_{L} & \text { if } \quad 0 \leq n \leq \bar{n} \\
A^{1 / \alpha} n H_{n} \sigma_{H}\left[\frac{(1-\alpha) P_{n}}{1 /(1-\alpha)}\right]^{(1-\alpha) / \alpha} Q_{H} & \text { if } \quad \bar{n}<n \leq 1
\end{array} .\right.
$$

As a result, we need to obtain the value of $\bar{n}$ before we can characterise the equilibrium for a given level of technological knowledge.

\section{Final-goods threshold}

In equilibrium, the marginal value product of a given type of labour must be equal across all final goods that are produced using it. Otherwise, there would be an incentive to shift labour allocations across final goods whose production depends on the same type of labour. We start by computing the marginal value products of low and high-skilled labour. They are, respectively:

$$
\frac{\partial\left(P_{n} Y_{n}\right)}{\partial L_{n}}=(1-n)\left(P_{n} A\right)^{1 / \alpha}\left[\frac{1-\alpha}{1 /(1-\alpha)}\right]^{(1-\alpha) / \alpha} \sigma_{L} Q_{L}
$$

\footnotetext{
${ }^{17}$ See Appendix A for a formal proof.
} 
and:

$$
\frac{\partial\left(P_{n} Y_{n}\right)}{\partial H_{n}}=n\left(P_{n} A\right)^{1 / \alpha}\left[\frac{1-\alpha}{1 /(1-\alpha)}\right]^{(1-\alpha) / \alpha} \sigma_{H} Q_{H} .
$$

Notice that $A, Q_{L}, Q_{H}, L, H, \sigma_{L}$ and $\sigma_{H}$ are all independent of $n$. Hence, it must be that in equilibrium $(1-n)\left(P_{n}\right)^{1 / \alpha}$ is constant across $n \in[0, \bar{n}]$, and $n\left(P_{n}\right)^{1 / \alpha}$ is constant across $n \in[\bar{n}, 1]$.

Let us define two constant price-indexes, $P_{L}$ and $P_{H}$, as:

$$
\begin{gathered}
\left(P_{L}\right)^{1 / \alpha}=(1-n)\left(P_{n}\right)^{1 / \alpha}, \text { if } 0 \leq n \leq \bar{n}, \text { and } \\
\left(P_{H}\right)^{1 / \alpha}=n\left(P_{n}\right)^{1 / \alpha}, \text { if } \bar{n}<n \leq 1 .
\end{gathered}
$$

Plugging these definitions into (4.1) we obtain:

$$
Y_{n}=\left\{\begin{array}{ll}
A^{1 / \alpha}(1-n)^{1 / \alpha} L_{n} \sigma_{L}\left[\frac{(1-\alpha) P_{L}}{1 /(1-\alpha)}\right]^{(1-\alpha) / \alpha} Q_{L} & \text { if } \quad 0 \leq n \leq \bar{n} \\
A^{1 / \alpha} n^{1 / \alpha} H_{n} \sigma_{H}\left[\frac{(1-\alpha) P_{H}}{1 /(1-\alpha)}\right]^{(1-\alpha) / \alpha} Q_{H} & \text { if } \bar{n}<n \leq 1
\end{array} .\right.
$$

From the consumer's maximization problem we know that $P_{n}(t) Y_{n}(t)$ is equal for all $n$. In turn, this implies that for final goods $n=0$ and $n=1$ we can write:

$$
P_{0}(t) Y_{0}(t)=P_{1}(t) Y_{1}(t)
$$

Substituting $Y_{1}(t)$ and $Y_{0}(t)$ using (4.6) and then applying some algebra to simplify the expressions, we obtain:

$$
\left(P_{L}\right)^{1 / \alpha} L_{0} \sigma_{L} Q_{L}=\left(P_{H}\right)^{1 / \alpha} H_{1} \sigma_{H} Q_{H}
$$

In equilibrium $L_{n}$ is constant across $n \in[0, \bar{n}]$, and $H_{n}$ is constant across $n \in[\bar{n}, 1]$. More specifically: ${ }^{18}$

$$
L_{n}=\frac{L}{\bar{n}},
$$

for all $n \in[0, \bar{n}]$, and:

$$
H_{n}=\frac{H}{1-\bar{n}},
$$

for all $n \in[\bar{n}, 1]$. Using (4.8) and (4.9) to substitute for $L_{0}$ and for $H_{1}$ in (4.7), and

\footnotetext{
${ }^{18}$ See Appendix A for a full derivation of these results.
} 
then rearranging terms, yields:

$$
\frac{P_{H}}{P_{L}}=\left[\frac{H}{L} \times \frac{\sigma_{H}}{\sigma_{L}} \times \frac{\bar{n}}{1-\bar{n}} \times \frac{Q_{H}}{Q_{L}}\right]^{-\alpha} .
$$

Finally, using (4.10) together with (4.4) and (4.5) gives us the value of $\bar{n}$ :

$$
\bar{n}=\left\{1+\left[\frac{H}{L} \times \frac{\sigma_{H}}{\sigma_{L}} \times \frac{Q_{H}}{Q_{L}}\right]^{1 / 2}\right\}^{-1} .
$$

The share of final goods that are produced using the $H$-technology depends on the relative supply of low and high-skilled labour, on the technological readiness of low and high-skilled labour, and on the skill-bias of the technological knowledge, given by $Q_{H} / Q_{L}$.

\section{Macroeconomic Aggregates}

Having derived the value of $\bar{n}$, we can now compute equilibrium values for the relevant macroeconomic aggregates. Since we are determining the equilibrium for a given technological-knowledge level, no R\&D activities take place and, for that reason, $R=0$. As a result, we only need to compute $X$ and $Y$, because (3.6) then implicitly defines the value of $C$.

The aggregate expenditure in the production of intermediate goods, $X$, is given by:

$$
X=\int_{0}^{1} X_{j}=\int_{0}^{J} X_{j} d j+\int_{J}^{1} X_{j} d j
$$

where $X_{j}=\int_{0}^{1} X_{j n} d n$ is the aggregate demand for (and expenditure in) intermediate $\operatorname{good} j$.

As we have seen before, the $L$-technology is only used to produce final-goods $n \in[0, \bar{n}]$, and so only final-goods firms $n \in[0, \bar{n}]$ demand low-specific intermediate goods. The same reasoning applies to high-specific intermediate goods, bought only by final-goods firms $n \in[\bar{n}, 1]$. Therefore, the expression above is the same as:

$$
X=\int_{0}^{J} \int_{0}^{\bar{n}} X_{j n} d n d j+\int_{J}^{1} \int_{\bar{n}}^{1} X_{j n} d n d j
$$

Using (3.14) and (3.10) to substitute for $X_{j n}$ as necessary, this expression evaluates to:

$$
X=\left[\frac{A(1-\alpha)}{1 /(1-\alpha)}\right]^{1 / \alpha}\left[L\left(P_{L}\right)^{1 / \alpha} \sigma_{L} Q_{L}+H\left(P_{H}\right)^{1 / \alpha} \sigma_{H} Q_{H}\right]
$$


Aggregate output is defined as:

$$
Y=\int_{0}^{1} P_{n} Y_{n} d n=\int_{0}^{\bar{n}} P_{n} Y_{n} d n+\int_{\bar{n}}^{1} P_{n} Y_{n} d n
$$

Substituting the value of $Y_{n}(t)$ according to (4.6) and computing the integrals yields:

$$
Y=A^{1 / \alpha}\left[\frac{1-\alpha}{1 /(1-\alpha)}\right]^{(1-\alpha) / \alpha}\left[L\left(P_{L}\right)^{1 / \alpha} \sigma_{L} Q_{L}+H\left(P_{H}\right)^{1 / \alpha} \sigma_{H} Q_{H}\right] .
$$

Expressions (4.12) and (4.13) can be written in a more compact way. The price indexes $P_{L}$ and $P_{H}$ can be expressed as:

$$
\begin{gathered}
P_{L}=e^{-\alpha}\left\{1+\left[\frac{\sigma_{H}}{\sigma_{L}} \times \frac{H}{L} \times \frac{Q_{H}}{Q_{L}}\right]^{1 / 2}\right\}^{\alpha}, \\
P_{H}=e^{-\alpha}\left\{1+\left[\frac{\sigma_{H}}{\sigma_{L}} \times \frac{H}{L} \times \frac{Q_{H}}{Q_{L}}\right]^{-1 / 2}\right\}^{\alpha} .
\end{gathered}
$$

Using these expressions together with (4.12) and (4.13) yields, at each $t$ :

$$
\begin{gathered}
X=e^{-1}\left[\frac{A(1-\alpha)}{1 /(1-\alpha)}\right]^{1 / \alpha}\left[\left(L \sigma_{L} Q_{L}\right)^{1 / 2}+\left(H \sigma_{H} Q_{H}\right)^{1 / 2}\right]^{2}, \\
Y=e^{-1} A^{1 / \alpha}\left[\frac{1-\alpha}{1 /(1-\alpha)}\right]^{(1-\alpha) / \alpha}\left[\left(L \sigma_{L} Q_{L}\right)^{1 / 2}+\left(H \sigma_{H} Q_{H}\right)^{1 / 2}\right]^{2} .
\end{gathered}
$$

\section{Wages}

In equilibrium, production factors are paid at their marginal productivities. Differentiation of (4.17) with respect to $L$ and $H$ yields, respectively, the wage rates for low and high-skilled labour:

$$
\begin{gathered}
w_{L}=\frac{\lambda}{2}\left[e^{\phi_{1} L} L^{1+l} Q_{L}\right]^{-1 / 2}\left[\phi_{1} e^{\phi_{1} L} L^{1+l} Q_{L}+e^{\phi_{1} L}(1+l) L^{l} Q_{L}\right], \\
w_{H}=\frac{\lambda}{2}\left[c e^{\phi_{2} H} H^{1+h} Q_{H}\right]^{-1 / 2}\left[c \phi_{2} e^{\phi_{2} H} H^{1+h} Q_{H}+c e^{\phi_{2} H}(1+h) H^{h} Q_{H}\right],
\end{gathered}
$$

where:

$$
\lambda=2 e^{-1}\left[\frac{A(1-\alpha)}{1 /(1-\alpha)}\right]^{1 / \alpha}\left\{\left[e^{\phi_{1} L} L^{1+l} Q_{L}\right]^{1 / 2}+\left[c e^{\phi_{2} H} H^{1+\phi} Q_{H}\right]^{1 / 2}\right\} .
$$


Finally, we can define the wage ratio (skill premium), measuring intra-country wage inequality at each $t$ :

$$
\frac{w_{H}}{w_{L}}=\left[\frac{e^{\phi_{1} L} L^{1+l}}{c e^{\phi_{2} H} H^{1+h}} \times \frac{Q_{L}}{Q_{H}}\right]^{1 / 2}\left[\frac{c e^{\phi_{2} H} H^{h}}{e^{\phi_{1} L} L^{l}} \times \frac{Q_{H}}{Q_{L}}\right]\left[\frac{\phi_{2} H+(1+h)}{\phi_{1} L+(1+l)}\right] .
$$

As can be seen in this result, the skill premium depends both on labour endowments and on the technological-knowledge bias, $\frac{Q_{H}}{Q_{L}}$.

On the one hand, due to full employment and decreasing marginal productivity of labour, an increase in $H$, for example, would create pressure for $w_{H}$ (and $w_{H} / w_{L}$ ) to fall. On the other hand, the increase in $H$ augments the technological readiness of high-skilled labour (see equation 3.22), increasing its productivity, and pushing $w_{H}$ and the skill premium up. The initial reaction of the skill premium thus depends on the relative strength of these two effects.

Furthermore, in this case $\bar{n}$ falls (see equation 4.11 ); i. e., more final goods are produced with the $H$-technology and sold at a relatively low price. ${ }^{19}$ Conversely, the relative price of final goods produced with the $L$-technology increases, and thus profit opportunities in the production of intermediate goods to be used by the $L$-technology also increase. This induces a flow of resources to R\&D in low-specific intermediate goods, thereby causing a gradual slowdown in the technological-knowledge bias, which is reflected in the skill premium, as can be seen in the expression above.

\subsection{Equilibrium with R\&D}

To determine the aggregate spending in $R \& D$, we must understand how $R \& D$ is carried out in the intermediate-goods sector. Specifically, we need to find out which firms conduct R\&D activities, and determine the value of an innovation. Derivation of the laws of motion of $Q_{L}(t)$ and $Q_{H}(t)$ is then a straightforward process.

\section{Innovator firms}

Let $\tau$ denote the time when an innovation occurs in intermediate good $j$, thereby raising its quality level from $q^{k-1}$ to $q^{k}$. Suppose the innovation is introduced by an outside firm seeking to displace the incumbent that currently holds the monopoly of that good. After displacing the old monopolist, this $k$-th innovator becomes the new monopolist for intermediate good $j$.

Prior to the innovation, the profits of this $k$-th innovator were zero because the

\footnotetext{
${ }^{19}$ Together, equations 4.4 and 4.5 define that $\frac{P_{H}}{P_{L}}=\left(\frac{n}{1-n}\right)^{\alpha}$.
} 
$(k-1)$-th innovator controlled the market. ${ }^{20}$ After introducing the $k$-th quality, the firm begins earning the profit flow described by equation (3.13). Accordingly, the change in this firm's profits is given by:

$$
\begin{aligned}
\Delta \pi_{j} & =\pi_{j}(\tau)-0 \\
& =\left(P_{j}(\tau)-1\right)\left\{\left[\frac{P_{z} A(1-\alpha)}{P_{j}(\tau)}\right]^{1 / \alpha} Z \sigma_{Z}\left(q^{k_{j}(\tau)}\right)^{(1-\alpha) / \alpha}\right\},
\end{aligned}
$$

where $Z=L$ if $j \leq J$, otherwise $Z=H$.

Notice that because the firm gains a one-rung quality advantage over its closest competitor, then $P_{j}(t)=1 /(1-\alpha)$ and the equation above becomes:

$$
\Delta \pi_{j}=\left[\frac{1}{1-\alpha}-1\right]\left[\frac{P_{z} A(1-\alpha)}{1 /(1-\alpha)}\right]^{1 / \alpha} Z \sigma_{Z}\left(q^{k_{j}(\tau)}\right)^{(1-\alpha) / \alpha} .
$$

Consider now the scenario in which the latest innovator in intermediate good $j$ is the current monopolist in that good. Suppose this firm has a one-rung quality advantage over its closest competitor. Prior to the innovation, the firm earns a profit flow of:

$$
\pi_{j}(\tau-1)=\left(P_{j}(\tau-1)-1\right)\left\{\left[\frac{P_{z} A(1-\alpha)}{P_{j}(\tau-1)}\right]^{1 / \alpha} Z \sigma_{Z}\left(q^{k_{j}(\tau-1)}\right)^{(1-\alpha) / \alpha}\right\} .
$$

After the innovation is introduced, the firm's profit flow becomes (as implicit in eq. 4.21):

$$
\pi_{j}(\tau)=\left(P_{j}(\tau)-1\right)\left\{\left[\frac{P_{z} A(1-\alpha)}{P_{j}(\tau)}\right]^{1 / \alpha} Z \sigma_{Z}\left(q^{k_{j}(\tau)}\right)^{(1-\alpha) / \alpha}\right\} .
$$

Since innovation occurs at time $\tau, k_{j}(\tau-1)=k_{j}(\tau)-1$. We also know that $P_{j}(\tau-1)=1 /(1-\alpha)$ and $P_{j}(\tau)=[1 /(1-\alpha)]^{2}$, because the firm starts with a one-rung quality advantage and the increases it to two rungs. These informations, together with equations (4.22) and (4.23), allow us to write the change in this firm's

\footnotetext{
${ }^{20}$ Remember that, in line with Barro and Sala-i-Martin (2004, chapter 7), we consider that the most recent innovators use monopoly pricing strategies and drive previous innovators out of the market. In equilibrium, only the highest quality of each intermediate good is produced.
} 
profits:

$$
\begin{aligned}
\Delta \pi_{j} & =\pi_{j}(\tau)-\pi_{j}(\tau-1) \\
& =\lambda\left\{\left[\frac{1}{(1-\alpha)}+1\right]\left[\frac{1}{1-\alpha}\right]^{-1 / \alpha}-(q)^{-(1-\alpha) / \alpha}\right\},
\end{aligned}
$$

where:

$$
\lambda=\left[\frac{1}{(1-\alpha)}-1\right]\left[\frac{P_{z} A(1-\alpha)}{1 /(1-\alpha)}\right]^{1 / \alpha} Z \sigma_{Z}\left(q^{k_{j}(t)}\right)^{(1-\alpha) / \alpha} .
$$

Because $\lambda$ equals the right-hand side of (4.21), comparing the two scenarios we have described is straightforward. As long as:

$$
\left[\frac{1}{(1-\alpha)}+1\right]\left[\frac{1}{1-\alpha}\right]^{-1 / \alpha}-(q)^{-(1-\alpha) / \alpha}<1,
$$

introducing a new quality of intermediate good $j$ is more profitable to an outside firm than it is to the current monopolist in that good.

Recall that we have assumed that $q>1 /(1-\alpha)$. Let $q-\varepsilon=[1 /(1-\alpha)]$, where $\varepsilon>0$. Using this information and a little algebra we can write the above expression as:

$$
(1-\alpha)^{1 / \alpha}+(q-\varepsilon)^{(\alpha-1) / \alpha}<1+(q)^{(\alpha-1) / \alpha} .
$$

This condition is always true because $\alpha \in] 0,1[$ and $\varepsilon>0$. Thus, R\&D activities are carried out by outside firms rather than by the current monopolists. This "replacement effect" is a common feature of Schumpeterian models of quality ladders (see, e. g., Aghion and Howitt, 1992; Barro and Sala-i-Martin, 2004).

At this point we established two important aspects of the innovation dynamics in the intermediate-goods sector. First, R\&D activities in the intermediate-goods sector are always carried out by outside firms. Second, these firms build a one-rung quality advantage over the monopolist they replace and set $P_{j}(t)=1 /(1-\alpha)$. This advantage is independent of the current quality level of the intermediate good, and equal across intermediate goods.

\section{The value of an innovation}

Let $\tau$ be the time when a firm introduces the quality $k$ for intermediate good $j$, and let $\tau+d$ denote the time when another firm introduces the quality $k+1$ for that same good. The firm that introduces the quality $k$ becomes the monopolist between 
$\tau$ and $\tau+d$, and earns a sum of profits given by:

$$
V_{j}(k, t)=\int_{\tau}^{\tau+d} \pi_{j}(k, t) e^{-r(t)} d t
$$

where $\pi_{j}(k, t)$ is the profit flow described by equation $(4.21) . V_{j}(k, t)$ is the reward for introducing the $k$-th quality of intermediate good $j$.

The term $d$ is both the duration of the monopoly of the $k$-th innovator, and the time between two consecutive innovations. Because innovations in intermediate arrive randomly, $d$ is undetermined and the true value of $V_{j}(k, t)$ is unknown. However, when the interest rate $r(t)$ is constant between $\tau$ and $\tau+d$, which will be the case in equilibrium, we obtain:

$$
E\left[V_{j}(k, t)\right]=\frac{\pi_{j}(k, t)}{r(t)+\delta_{j}(k, t)}
$$

The expected value of introducing the $k$-th quality of intermediate good $j$ depends positively on the dimension of the profits the innovator can earn, and is negatively affected by the interest rate and by the probability of quality $(k+1)$ being introduced. This last term, $\delta_{j}(k, t)$, captures the effect of Schumpeterian "creative destruction". The positive $\delta_{j}(k, t)$ reflects the fact that new qualities of intermediate goods are eventually introduced in the market, implying that new firms destroy the monopolies of old firms. A higher $\delta_{j}(k, t)$ causes this to happen faster, thereby reducing the monopoly length and the monopolist's total profits.

\section{Aggregate R\&D spending}

We assume free entry in the R\&D activities of the intermediate-goods sector . Firms face no legal or economic barriers if they decide to take-up or abandon R\&D efforts, hence there is no constraint on the number of firms that might conduct R\&D. In addition, we assume that all firms have access to the same R\&D technology.

Furthermore, we assume that when an innovation is introduced as a consequence of the R\&D efforts of many firms, the probability of a firm becoming the successful innovator is proportional to its share on aggregate R\&D. For example, if $R \& D$ spending is shared equally among one hundred firms, each firm has a $1 \%$ probability of being the innovator. With this assumption we can abstract from the number of firms that participate in the R\&D efforts, and concentrate exclusively on the aggregate level analysis. 
The aggregate level free-entry condition can be written as:

$$
R_{j}(k-1, t)=E\left[V_{j}(k, t)\right] \delta_{j}(k-1, t),
$$

which means that the R\&D spending aimed at improving intermediate good $j$ should equal the expected payoff generated by the innovation. Using (4.24) to substitute for $E\left[V_{j}(k, t)\right]$ and $(3.17)$ to substitute for $\delta_{j}(k-1, t)$ and $\delta_{j}(k, t)$ in this expression, we obtain:

$$
R_{j}(k, t)=\pi(k, t) \frac{\Psi_{j}(k-1, t) \zeta_{j}(t) \xi_{j}(k-1, t)}{\Psi_{j}(k, t) \zeta_{j}(t) \xi_{j}(k, t)}-\frac{r(t)}{\Psi_{j}(k, t) \zeta_{j}(t) \xi_{j}(k, t)} .
$$

Finally, using equations (3.18), (3.19), (3.20) and (4.21) as well as the fact that monopolists in the intermediate-goods sector set $P_{j}(t)=1 /(1-\alpha)$, this expression becomes:

$$
\begin{aligned}
R_{j}(k, t)= & \left\{\left(\frac{1}{1-\alpha}-1\right)\left[P_{Z}(t) A(1-\alpha)^{2}\right]^{1 / \alpha} \sigma_{Z} q^{(1-\alpha) / \alpha}\right. \\
& \left.-r(t) \frac{\chi}{\Gamma}\right\} Z\left(q^{k_{j}(t)}\right)^{(1-\alpha) / \alpha}
\end{aligned}
$$

where $Z$ follows the definition given before.

Equilibrium aggregate $\mathrm{R} \& \mathrm{D}$ spending, $R(t)$, can now be computed through:

$$
R(t)=\int_{0}^{1} R_{j}(k, t) d j=\int_{0}^{J} R_{j}(k, t) d j+\int_{J}^{1} R_{j}(k, t) d j .
$$

Using equation (4.26) to substitute for $R_{j}(k, t)$ and applying the definitions of $Z$ as necessary, this expression becomes:

$$
\begin{aligned}
R= & Q_{L} L\left\{\left(\frac{1}{1-\alpha}-1\right)\left[P_{L} A(1-\alpha)^{2}\right]^{1 / \alpha} \sigma_{L}-r \frac{\chi}{\Gamma}\right\} \\
& +Q_{H} H\left\{\left(\frac{1}{1-\alpha}-1\right)\left[P_{H} A(1-\alpha)^{2}\right]^{1 / \alpha} \sigma_{H}-r \frac{\chi}{\Gamma}\right\} .
\end{aligned}
$$

\section{Laws of motion of $Q_{L}$ and $Q_{H}$}

To derive the laws of motion of $Q_{L}(t)$ and $Q_{H}(t)$, we can use the approach laid out by Barro and Sala-i-Martin (2004). Remember we have defined the aggregate quality indexes as:

$$
\begin{gathered}
Q_{L}(t)=\int_{0}^{J}\left(q^{k_{j}(t)}\right)^{(1-\alpha) / \alpha} d j, \text { and } \\
Q_{H}(t)=\int_{J}^{1}\left(q^{k_{j}(t)}\right)^{(1-\alpha) / \alpha} .
\end{gathered}
$$


Suppose a new quality of intermediate good $j$ is introduced, all else remaining equal. The change in the corresponding aggregate quality index is given by:

$$
\Delta Q_{Z}=\left(q^{k_{j}+1}\right)^{(1-\alpha) / \alpha}-\left(q^{k_{j}}\right)^{(1-\alpha) / \alpha}=\left(q^{k_{j}}\right)^{(1-\alpha) / \alpha}\left(q^{(1-\alpha) / \alpha}-1\right),
$$

where $Z=L$ if $j[0, J]$, otherwise $Z=H$. In addition, it is possible to show that when the free-entry condition holds, we have:

$$
\delta_{j}(k, t)=\left\{\left(\frac{1}{1-\alpha}-\alpha\right)\left[P_{L}(t) A(1-\alpha)^{2}\right]^{1 / \alpha} \sigma_{L} q^{(1-\alpha) / \alpha} \frac{\Gamma}{\chi}\right\}-r(t)=\delta_{L}(t),
$$

for all $j \in[0, J]$, and

$$
\delta_{j}(k, t)=\left\{\left(\frac{1}{1-\alpha}-\alpha\right)\left[P_{H}(t) A(1-\alpha)^{2}\right]^{1 / \alpha} \sigma_{H} q^{(1-\alpha) / \alpha} \frac{\Gamma}{\chi}\right\}-r(t)=\delta_{H}(t),
$$

for all $j \in[J, 1]$. Finally, using the fact that $\delta_{L}(t)$ and $\delta_{H}(t)$ are independent of $j$, we can compute:

$$
\frac{\dot{Q_{L}}(t)}{Q_{L}(t)}=\frac{\int_{0}^{J} \delta_{L}\left(q^{k_{j}}\right)^{(1-\alpha) / \alpha}\left(q^{(1-\alpha) / \alpha}-1\right) d j}{Q_{L}(t)} \equiv \delta_{L}\left(q^{(1-\alpha) / \alpha}-1\right),
$$

and

$$
\frac{\dot{Q_{H}}(t)}{Q_{H}(t)}=\frac{\int_{J}^{1} \delta_{H}\left(q^{k_{j}}\right)^{(1-\alpha) / \alpha}\left(q^{(1-\alpha) / \alpha}-1\right) d j}{Q_{H}(t)} \equiv \delta_{H}\left(q^{(1-\alpha) / \alpha}-1\right) .
$$

\subsection{Transition dynamics}

Since in our model all macroeconomic aggregates can be expressed as multiples of the aggregate quality indexes ${ }^{21}, Q_{L}(t)$ and $Q_{H}(t)$, the paths of all relevant variables outside the steady-state, including that of the wage ratio, depend on a single differential equation that governs the path of the technological-knowledge bias, i. e., the path of $\frac{Q_{H}(t)}{Q_{L}(t)}$.

Thus, if we define $S$ as the technological-knowledge bias (i. e., $S=Q_{H} / Q_{L}$ ), $S$ is governed by $\hat{S}(t) \equiv \frac{\dot{S}(t)}{S(t)}=\frac{\dot{Q_{H}(t)}}{Q_{H}(t)}-\frac{\dot{Q_{L}(t)}}{Q_{L}(t)}$. Now, using (4.31), (4.30), (4.29), (4.28),

\footnotetext{
${ }^{21}$ As can be seen in (3.12), (4.12) and (4.27), the macroeconomic aggregates $Y, X$ and $R$ can be expressed as multiples of the aggregate quality indexes $Q_{L}$ and $Q_{H}$. Then, since $Y=C+X+R$ it is also possible to express $C$ as a multiple of $Q_{L}$ and $Q_{H}$.
} 
(4.15), (4.14), (3.22), (3.21) we obtain:

$$
\begin{aligned}
\hat{S} & =\left[q^{(1-\alpha) / \alpha}-1\right] \times\left\{\left(\frac{1}{1-\alpha}-1\right)\left[A(1-\alpha)^{2}\right]^{1 / \alpha} q^{(1-\alpha) / \alpha} \frac{\Gamma}{\chi}\right\} \times e^{-1} \\
& \times\left[c H^{h} e^{\phi_{2} H}\left(1+\frac{c H^{h+1} e^{\phi_{2} H}}{L^{l+1} e^{\phi_{1} L}} S\right)^{-1 / 2}-L^{l} e^{\phi_{1} L}\left(1+\frac{c H^{h+1} e^{\phi_{2} H}}{L^{l+1} e^{\phi_{1} L}} S\right)^{1 / 2}\right] .
\end{aligned}
$$

\subsection{Steady-state}

Along the balanced growth path all variables grow at the same constant rate. From (3.5) we know that consumption grows at the rate $\frac{r-\rho}{\theta}$. Since all other macroeconomic aggregates must grow at this same constant rate, which we call $g^{*}$, we can characterise it by imposing that (where ${ }^{*}$ indicates steady-state):

$$
g^{*} \equiv \frac{\dot{Q}_{L}^{*}}{Q_{L}^{*}}=\frac{\dot{Q}_{H}^{*}}{Q_{H}^{*}}=\frac{r^{*}-\rho}{\theta},
$$

from which we can obtain the constant steady-state interest rate, $r^{*}$. In addition, from $\frac{\dot{Q}_{L}^{*}}{Q_{L}^{*}}=\frac{Q_{H}^{*}}{Q_{H}^{*}}$ we find that final-goods price indexes, $P_{L}^{*}$ and $P_{H}^{*}$, the threshold final good, $\bar{n}^{*}$, and the skill premium, $\frac{w_{H}^{*}}{w_{L}^{*}}$, remain stable; i. e., $\frac{P_{H}^{*}}{P_{H}}=\frac{P_{L}^{*}}{P_{L}}=\frac{\dot{n}^{*}}{\bar{n}^{*}}=$ $\frac{w_{H}^{*}}{w_{H}^{*}}-\frac{w_{L}^{*}}{w_{L}^{*}}=0$. Also, wages rise steadily in line with the technological-knowledge progress; i. e., $\frac{w_{H}^{*}}{w_{H}^{*}}=\frac{w_{L}^{*}}{w_{L}^{*}}=\frac{Q_{L}^{*}}{Q_{L}^{*}}=\frac{Q_{H}^{*}}{Q_{H}^{*}}$.

We note in particular that in the steady state, a higher technical readiness of high-skilled labour relative to that of low-skilled labour decreases the relative price of high-specific intermediate goods. The reason for this is that a higher $\frac{\sigma_{H}}{\sigma_{L}}$ implies that broader range of final goods is produced using the $H$-technology - see (4.11) -, thus increasing the demand for high-specific intermediate goods. Hence, the relative price of those goods must be lower in order to equalise profits in both technologies. 


\section{Analysis}

\subsection{Overview}

In this section we fit our model to real data from a wide range of countries and periods. The goal is to understand to which extent the behaviour of the skill premium can be explained by changes in the relative supply of high-skilled workers, in learning-by-doing, in technology-adoption costs, or by simultaneous changes in more than one of these dimensions. We follow the calibration approach pioneered by Kydland and Prescott (1982). For an overview of this technique see, for example, Kydland and Prescott (1996) and Dejong and Dave (2007, chapter 7).

Our calibration strategy is as follows. First, we distinguish between core and noncore parameters. Core parameters are those which are related to the main focus of our study: how learning-by-doing and technology-adoption costs can influence the technological-knowledge bias and wage inequality. Therefore, $\phi_{1}, \phi_{2}, l, h$ and $c$ are considered core parameters in our model.

The remaining parameters of our model are non-core parameters, and we take into consideration previous literature to determine their values. Since our model is closely related to the one presented by Afonso (2006), we follow it whenever that is possible. Table 1 presents the baseline values for non-core parameters. After we have set the values of the non-core parameters, we search the core parameter space for values that allow us to reproduce the data observed for different countries. In order to assess the validity of the mechanism we propose, we then see if there is a reasonably homogeneous set of core parameter values that allows the replication of observed data for all countries.

The process of determining core-parameter values is straightforward. From the data available for a given country we gather information about the skill premium and relative supply of high-skilled workers at the beginning and ending of a certain period. Then, we set $\frac{H}{L}$ to the value observed in the beginning of that period, and compute steady-state skill premia obtained with different combinations of $c, \phi_{1}, \phi_{2}$, $l$ and $h$. We repeat the same procedure while setting $\frac{H}{L}$ to the value observed in the ending of the reference period. Our computations are restricted to parameter combinations in which: (i) $\phi_{1}=\phi_{2}$; (ii) $\phi_{1}, \phi_{2} \in[-2,0]$; (iii) $l=h$; (iv) $l, h \in[1,2]$; and $(\mathrm{v}) c \in[1,1.5]$. The results are then gathered in tables like the ones presented in appendix B. Finally, we search these tables for parameter values that can replicate the initial and final steady-state values of the skill premium, as well as the transition dynamics between the two.

We focus our attention in two types of calibration. The first one is that in 
which a set of parameter values can replicate both the initial and final conditions observed in the data. We call this a fixed-parameter calibration. We also consider cases in which we start with a set of parameter values that replicates the initial conditions, and then allow for slight changes in either the learning-by-doing or the technology-adoption parameters. When considering these changes, we assume that they occur at the same time as the shift in $\frac{H}{L}$. This type of procedure, which we refer to as a variable-parameter calibration, attempts to reflect the fact that the learning-by-doing and technology-adoption costs might change over time.

\begin{tabular}{|c|c|}
\hline Parameter & Value \\
\hline$A$ & 1.5 \\
$q$ & 3.33 \\
$\alpha$ & 0.7 \\
$\rho$ & 0.02 \\
$\theta$ & 1.5 \\
$\Gamma$ & 1.6 \\
$\chi$ & 4 \\
\hline
\end{tabular}

Table 1: Baseline non-core parameter values.

\subsection{Fixed-parameter calibration}

Using data from Machin and Van Reenen (1998), we start by calibrating the model to replicate the behaviour of the skill premium in the United States between 1973 and 1989. During this period, the employment share of non-production workers increased from 0.246 to 0.303 , leading to a shift in the ratio $\frac{H}{L}$ from 0.326 to $0.435 .{ }^{22}$ In addition, the ratio between wages of non-production and production workers rose from 1.553 to 1.623. Figure 2 presents the simulated paths of technologicalknowledge bias and skill premium using two different model calibrations.

In the two top panels we can see the results obtained by setting $c=1.35$, $l=h=1.8$ and $\phi_{1}=\phi_{2}=-1.2$. Given the initial value of $\frac{H}{L}$, the steady-state is characterised by a skill-premium of 1.556. When the relative supply of high-skilled workers shifts from 0.326 to 0.435 (at $t=20$ ), the economy leaves the steady state and the skill premium immediately drops to 1.531. This drop in the skill-premium results from the interaction of two effects.

On the one hand, changes in $H$ and $L$ induce changes in the technological readiness of both types of labour. The increase of $H$ causes the technological readiness of high-skilled labour to increase $\left(\sigma_{H}\right.$ shifts from 0.081 to 0.109$)$, whereas that of

\footnotetext{
${ }^{22}$ Workers allocated to non-production activities are used as a proxy for high-skilled workers. The increase in $H$ from 0.246 to 0.303 implies a decrease in $L$ from 0.754 to 0.697 .
} 

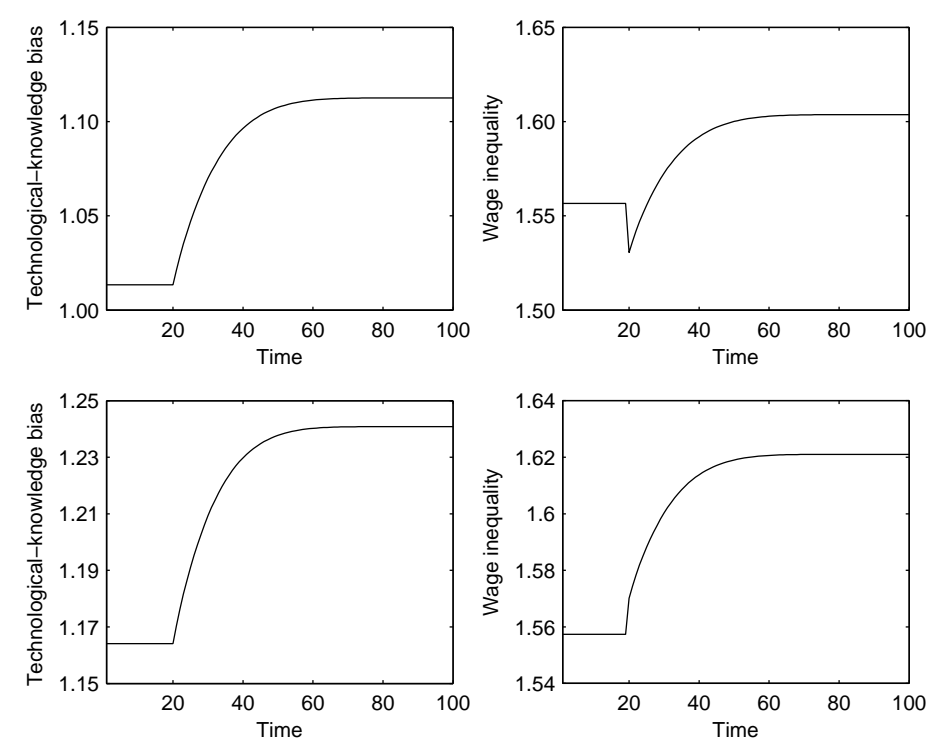

Figure 2: Fixed-parameter simulations for the United States, 1973-1989.

low-skilled labour decreases with the decrease of $L$ ( $\sigma_{L}$ shifts from 0.243 to 0.226 ). By themselves, these changes to $\sigma_{L}$ and $\sigma_{H}$ would increase the productivity of high-skilled labour, and lower the productivity of low-skilled labour - see equation (3.11). Since production factors are paid at their marginal productivity, these changes would, in turn, create a stimulus for the skill premium to increase.

On the other hand, a higher value for $\frac{H}{L}$ also means that high-skilled labour has become more abundant and low-skilled labour has become scarcer. With decreasing marginal productivity and full employment of $L$ and $H$, this induces an increase in the marginal productivity of $L$ and a decrease in the marginal productivity of $H$, putting downward pressure upon the skill premium. In the present case we can see that this effect dominates the effect induced by the shifts in $\sigma_{L}$ and $\sigma_{H}$, hence the initial drop in $\frac{w_{H}}{w_{L}}$.

After the exogenous shift and corresponding short-run adjustments take place, a transition to a new steady state follows. As the top left panel shows, the shift in the relative supply of high-skilled labour causes the technological-knowledge bias to start growing (at decreasing rates), and this induces an increase in the skill premium. This is because labour is complementary with intermediate goods - see, for example, equation (3.7). As the aggregate quality of high-specific intermediate goods increases relative to that of low-specific intermediate goods, so does the productivity of highskilled labour relative to that of low-skilled labour. Again, with production factors being paid at their marginal productivity, the skill premium rises. Once the new steady-state is reached, the skill premium stabilises at 1.604, a value higher than 
that observed initially. ${ }^{23}$

The simulation results seem to provide a reasonable approximation to the real behaviour of the skill premium. On the one hand, the initial and ending values are very close to the ones reported by Machin and Van Reenen (1998). On the other hand, Machin and Van Reenen's data also shows that an initial drop in the skill premium indeed exists: from 1.556 in 1973, the ratio between the wages of production and non-production workers drops to 1.531 in 1977.

The bottom panels of Figure 2 summarise the results from an alternative model calibration $\left(c=1.45, \phi_{1}=\phi_{2}=-0.45\right.$, and $\left.l=h=1.4\right)$. Simulated initial and ending values of the skill premium are once again very close to the real values. But with this calibration the model is unable to replicate the drop in the skill premium that follows the change in the relative supply of high-skilled workers.

However, similar parameter values are useful in replicating the behaviour of the skill premium in the United Kingdom and Sweden. Machin and Van Reenen (1998) show that between 1973 and 1989 the relative supply of non-production workers increased from 0.372 to 0.435 , while their wage premium increased from 1.487 to 1.509. In the United Kingdom $\frac{H}{L}$ shifted from 0.351 to 0.481 and $\frac{w_{H}}{w_{L}}$ increased from 1.316 to 1.470 .

Figure 3 shows simulation results using $c=1.45, \phi_{1}=\phi_{2}=-0.2$ and $l=h=$ 1.4, for the United Kingdom; and $c=1.4, \phi_{1}=\phi_{2}=-0.2$ and $l=h=1.25$, for Sweden.

The results for Sweden obtained with our model point to an increase in the skill premium from 1.479 to 1.510 in response to the reported shift in the $\frac{H}{L}$ ratio. For the United Kingdom our simulations show an increase in the skill premium from to 1.318 to 1.441. The simulated values for Sweden are consistent with the real ones, but in the case of the United Kingdom the fit is poorer. Nevertheless, using a fixedparameter calibration our model can explain roughly $80 \%$ of the increase in the skill premium that has occurred in the United Kingdom during the period 1973-1989.

It is interesting to note that in both cases there is an initial increase in the skill premium. This suggests that the effects of the changes in the technological readiness of both types of labour were more important than the effects induced by the changes in the relative abundance of high-skilled workers. The data put forth by Machin and Van Reenen (1998) seems to support this kind of short-run adjustment in the case of Sweden, but evidence for the United Kingdom is somewhat mixed.

All the three previous cases we discussed link an increase in the relative supply of

\footnotetext{
${ }^{23}$ The relation between the technological-knowledge bias and the skill premium can be clearly seen in equation (4.20): increases in $\frac{Q_{H}}{Q_{L}}$ cause $\frac{w_{H}}{w_{L}}$ on the left-hand side to increase.
} 

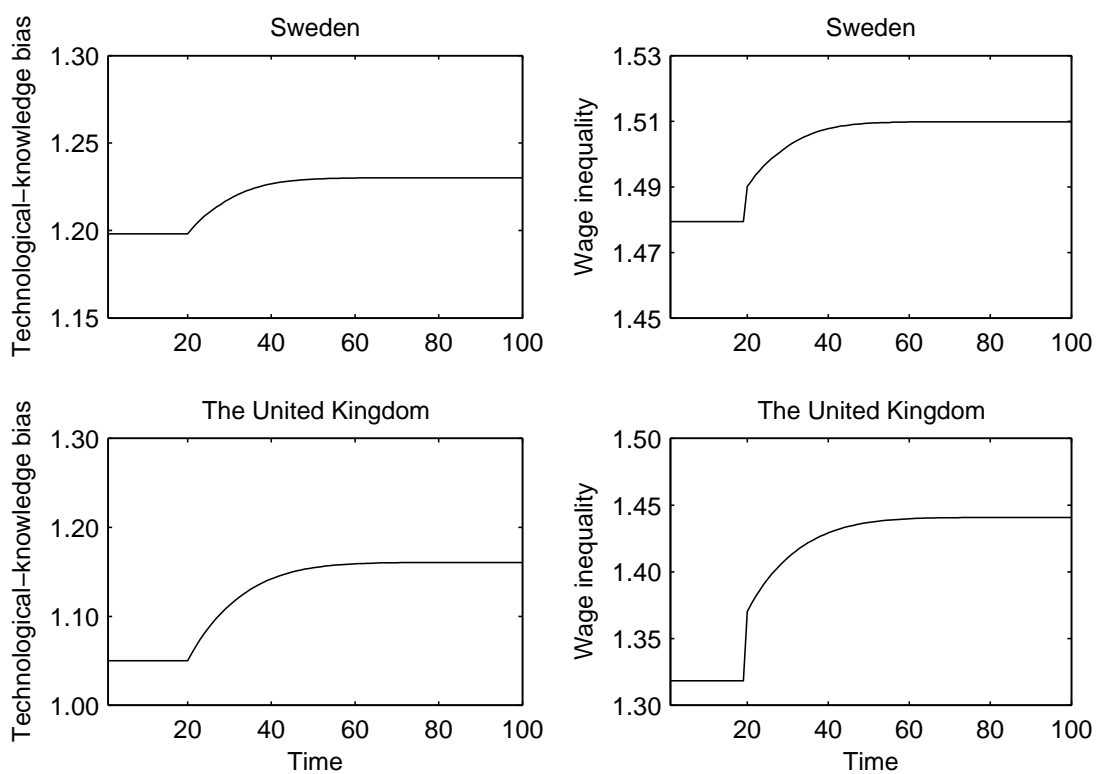

Figure 3: Fixed-parameter simulations for Sweden and the U. K., 1973-1989.

high-skilled labour to an increase in the skill premium. But our model can also accommodate cases like that of Denmark, in which an increase in $\frac{H}{L}$ ratio appears associated with a decrease in the skill premium. ${ }^{24}$ According to Machin and Van Reenen (1998), between 1973 and 1989 the $\frac{H}{L}$ ratio shifted from 0.335 to 0.466 and yet the skill premium decreased from 1.511 to 1.437 . Figure 4 shows the results of a simulation aimed at replicating these facts in which we have set $c=1.2, \phi_{1}=\phi_{2}=-0.55$ and $l=h=1.25$.

Simulation results replicate once again very accurately the path of the skill premium. The initial simulated skill-premium is equal to the observed value and our simulation can account for roughly $56 \%$ of the observed drop in it. Furthermore, the drop in the skill premium and the small recovery that we see in the simulation results fits well into the data from Machin and Van Reenen (1998). In this case, contrary to the scenario simulated above for the United States, the increase in $\frac{w_{L}}{w_{H}}$ induced by the increase in the technological-knowledge bias isn't enough to offset its initial drop.

The results we presented in this subsection are a good approximation to the observed facts. But there is some variability in the parameter values underlying the different simulations, although it should be noticed that the main divergence in core-parameter values is between the United States and the group of European countries.

\footnotetext{
${ }^{24}$ Note that cases like that of Denmark are not captured by the skill-biased technological-change literature.
} 

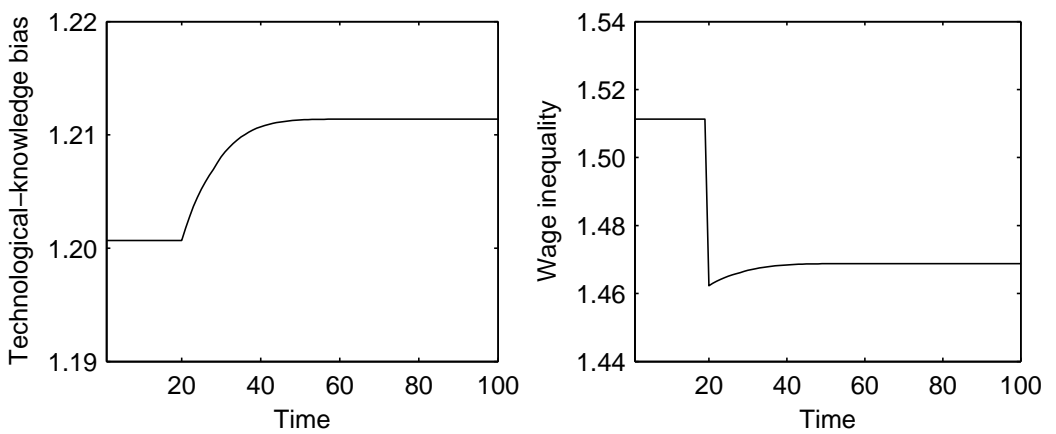

Figure 4: Fixed-parameter simulations for Denmark, 1973-1989.

\subsection{Variable-parameter calibration}

In order to keep the analysis manageable, we perform two kinds of simulations. First we perform simulations in which we hold $c, \phi_{1}$ and $\phi_{2}$ constant and allow the learning-by-doing parameters to vary over time. We then simulate scenarios in which we hold $c, l$ and $h$ constant and allow for variations in $\phi_{1}$ and $\phi_{2}$. Throughout these simulations we use a baseline value of 1.2 for the constant $c$.

Figure 5 shows a simulation of the case of Denmark (see Machin and Van Reenen, 1998) in which we calibrate $\phi_{1}=\phi_{2}$ to -0.4 , and consider a decrease in the learningby-doing effects by making $l=h$ change from 1.15 to 1.2 .
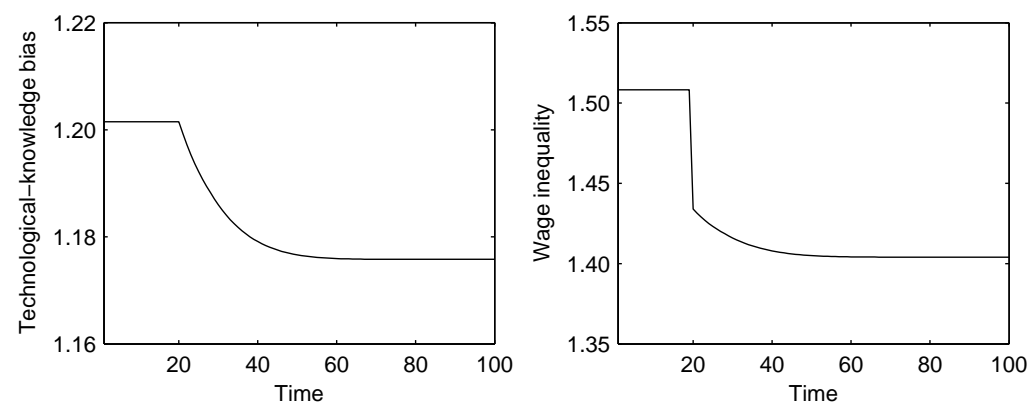

Figure 5: Variable-parameter simulation for Denmark, 1973-1989.

The results show that this calibration is fit to explain the decrease in the skill premium that occurred in Denmark, although its simulated path between steadystates somewhat deviates from the actually observed one (see previous subsection). Nevertheless, this is an example of how alterations in the learning-by-doing parameters can help to account for - and are compatible with - different kinds of changes in the skill premium when there are shifts in the $\frac{H}{L}$ ratio.

Figure 6 shows the results from another simulation, this one aimed at replicating Acemoglu's (2003a) data for Belgium: a decrease in the skill premium from 1.419 to 1.365 and an slight increase (from 0.105 to 0.119 ) in the $\frac{H}{L}$ ratio, during the 
period 1985-1997. We calibrate $l=h$ to 1.15 and let $\phi_{1}, \phi_{2}$ change from -0.35 at the initial steady-state to -0.3 , i. e., we consider a decrease in the barriers to technology adoption. Although our calibration slightly overestimates the initial steady-state skill premium (by roughly 1\%), it accurately replicates its subsequent decrease. Like in the learning-by-doing example presented above, simultaneous shifts in labour endowments and in technology-adoption parameters can help to account for a decrease in the skill premium.
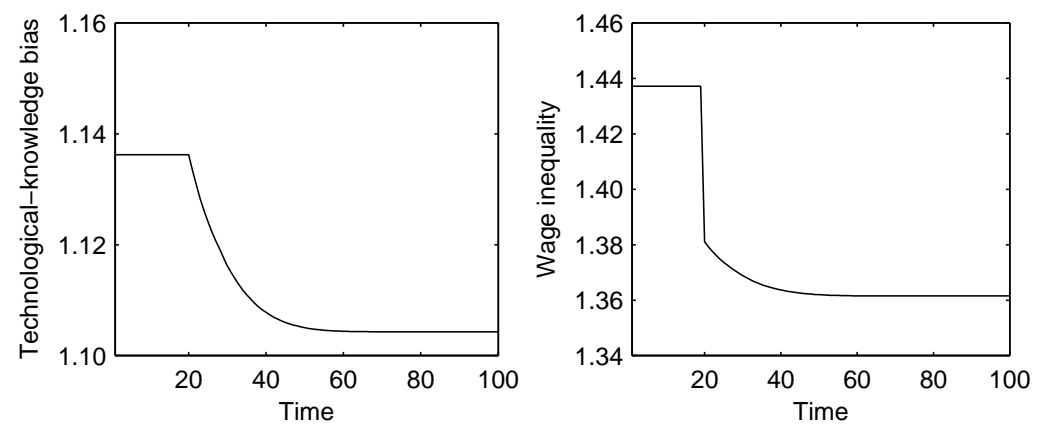

Figure 6: Variable-parameter simulations for Belgium, 1985-1997.

So far we have only presented variable-parameter simulations for cases in which the skill premium decreases in developed countries. Table 2 provides some additional calibration configurations and results that replicate the observed data for Canada, The Netherlands and the United States. Together with the two cases mentioned before, these variable-parameter calibrations suggest that if we allow for small variations in the learning-by-doing and technology adoption effects, our model can replicate a wide range of different situations with a relatively homogeneous set of parameters.

Since structural variations might indeed affect economies over time these scenarios are not only plausible, but they reinforce the idea that learning-by-doing and technology adoption costs are important in understanding the evolution of skillrelated wage inequality.

We are also able to replicate the trajectory of developing countries: a good example would be the Chilean case during 1960-1996. According to Beyer et al. (1999), in 1960 around $7.5 \%$ of all heads of household in Chile had university education. By 1996 that number had risen to 21.1\%. Taking these figures as a proxy for the relative abundance of high-skilled labour in Chile's economy, the ratio $H / L$ shifted from 0.081 in 1960 to 0.267 in 1996.

During the same period the average per-capita labour income of heads of household with a university degree increased from 176, 675 pesos in 1960 to 666, 813 pesos in 1996, whereas for heads of households without a university degree the average 

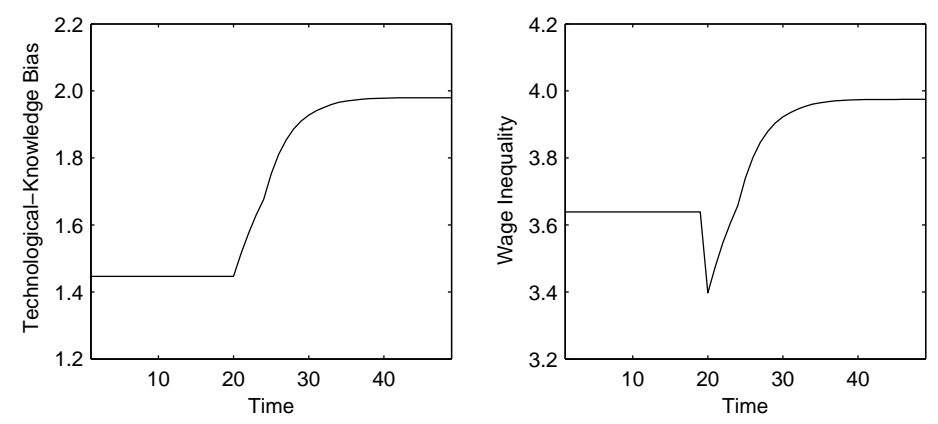

Figure 7: Variable-parameter simulation for Chile, 1960-1996.

pay increased from 47, 234 pesos to 169,220 pesos. $^{25}$ Hence, the ratio between the wages of workers with university education (high-skilled labour) and wages of workers without university education (low-skilled labour) increased from 3.740 to 3.941.

In Figure 7 we can see the transition dynamics obtained in a simulation in which learning-by-doing parameters decline (i.e., all else equal learning-by-doing effects become stronger). We consider $\phi_{1}=\phi_{2}=-1.55$ and $c=1.2$, and that $l, h$ are initially 1.45 and then shift to 1.3. The initial and ending simulated skill premia are, respectively, 3.639 and 3.975. Although the initial skill premia deviates moderately from its real value (about 3\% lower), the simulation provides a satisfactory replication of the transition that occured in Chile. The skill premium initially drops in response to the increase in $H / L$ and the decrease in $l, h$, but as the technological-knowledge bias increases the $w_{H} / w_{L}$ ratio also picks up.

The increase in the technological-knowledge bias is due to a stronger increase in $\sigma_{H}$ than in $\sigma_{L}$. The shift in $H / L$ alone would induce an increase (decrease) in the technological readiness of high-skilled (low-skilled) labour, but the effects of a decrease in learning-by-doing parameters prevent $\sigma_{L}$ from falling. However, whereas for high-skilled labour both effects act to push $\sigma_{H}$ up, for low-skilled labour the drop in its relative abundance works against the positive effect of a lower $l$, causing $\sigma_{L}$ to increase only slightly.

\footnotetext{
${ }^{25}$ The average per capita labour income figures are quoted in 1996 pesos.
} 


\begin{tabular}{|c|c|c|c|c|c|c|c|c|}
\hline Country & Initial $\frac{H}{L}$ & Final $\frac{H}{L}$ & Initial $\frac{w_{H}}{w_{L}}$ & Final $\frac{w_{H}}{w_{L}}$ & $\phi_{1}=\phi_{2}$ & $l=h$ & new $\phi_{1}=\phi_{2}$ & new $l=h$ \\
\hline The Netherlands $^{a}$ & 0.087 & 0.337 & 1.359 & 1.305 & -0.7 & 1.35 & -0.5 & 1.35 \\
$1983-1994$ & & & $(1.354)$ & $(1.296)$ & & & & \\
\hline Canada $^{a}$ & 0.241 & 0.256 & 1.303 & 1.379 & -0.3 & 1.2 & -0.35 & 1.2 \\
$1987-1997$ & & & $(1.299)$ & $(1.364)$ & & & & \\
\hline The United States $^{b}$ & 0.326 & 0.435 & 1.533 & 1.623 & -0.75 & 1.35 & -0.75 & 1.3 \\
$1973-1989$ & & & $(1.578)$ & $(1.604)$ & & & & \\
\hline
\end{tabular}

${ }^{a}$ Original country data is from Acemoglu (2003a). ${ }^{b}$ Original country data is from Machin and van Reenen (1998).

Simulated skill premia are given in parenthesis.

Table 2: Alternative simulations of transition dynamics. 


\subsection{Sensitivity analysis}

In this section we analyse in greater depth how the technological-knowledge bias and $H$-premium respond to different values of: $(i)$ core parameters and; $(i i)$ relative supply of high-skilled labour. More specifically, we try to understand how changes in these parameters and variables influence the technological-knowledge bias and the $H$-premium, by affecting the technological readiness of labour.

We start by computing steady-states for various combinations of $(l, h)$ and $\left(\phi_{2}, \phi_{2}\right)$ while keeping $H / L$ constant. We consider a case in which low-skilled labour is relatively more abundant (setting $H / L=0.25$ ), and other in which high-skilled labour is relatively more abundant (setting $H / L=4) .{ }^{26}$ Thus we can analyse how learningby-doing and technology-adoption costs shape the technological-knowledge bias and the $H$-premium in a scenario of relatively more abundant low (high)-skilled labour.

Then we perform the similar computations, but this time we keep one type of parameters fixed and consider different combinations of $H / L$ and values for parameters of the other type. Using these simulations we can see how learning-by-doing and technology-adoption costs influence the steady-state under different levels of relative abundance of high-skilled labour, and vice-versa.

There is a caveat, though: when comparing how different values of $H / L$ influence the steady-state we must remember that the $H$-premium is affected by means of two channels. First, the labour endowments affect the technological readiness of each type of labour, and this in turn influences the direction of the technologicalknowledge bias and the $H$-premium. Second, wages - and thus the $H$-premium also respond to supply-demand interactions in labour markets.

Throughout these computations we assume that $c=1$, i. e., we assume that there is no absolute advantage of high-skilled labour over low-skilled labour. This assumption simplifies the analysis without qualitatively changing the results. Furthermore, we assume again that $l=h$ and $\phi_{1}=\phi_{2}$, so that the results don't reflect differences in the sensitivity of each type of labour to the effects of learning-by-doing (LBD) and technology adoption costs (TAC).

\section{LBD and TAC effects under predominance of low-skilled labour}

As can be seen in Figure 8, in a case in which low-skilled labour is relatively more abundant, the steady-state levels of the technological-knowledge bias and $H$-premium are higher: $(i)$ when learning-by-doing parameters are lower; $(i i)$ when technology-adoption costs parameters are lower, i. e., more negative.

\footnotetext{
${ }^{26}$ Since we assumed that $H+L=1$ and $H, L \in[0,1]$, in the first case we have $L=0.8$ and $H=0.2$, and in the second $L=0.2$ and $H=0.8$.
} 

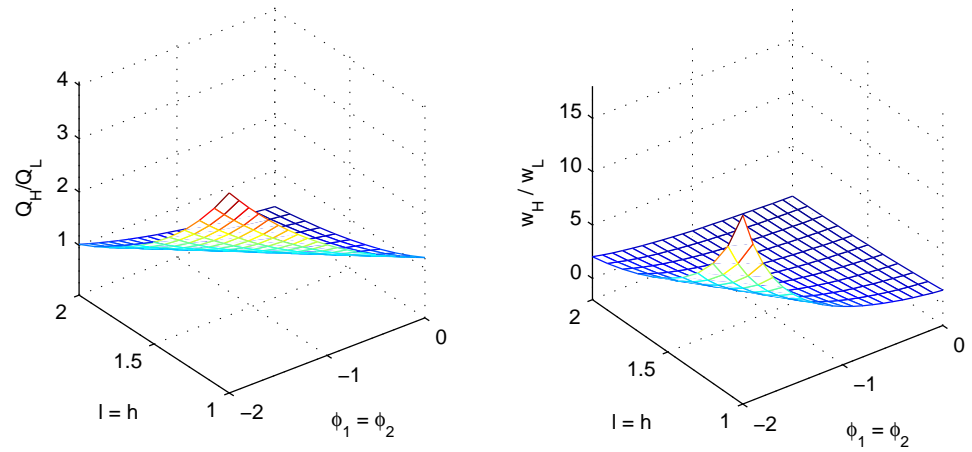

Simulated steady-state values of the technological-knowledge bias and $H$-premium for different values of the learningby-doing and technology-adoption costs parameters, assuming predominance of low-skilled labour. Results are from simulations based on $L=0.8, H=0.2, c=1$.

Figure 8: LBD and TAC effects under predominance of low-skilled labour.

All else equal, lower technology-adoption costs parameters cause $\exp \left(\phi_{1} L\right)$ and $\exp \left(\phi_{2} H\right)$ to be lower for given values of $L$ and $H$. This implies a stronger adverse effect of technology-adoption costs, which in turn reduces the technological readiness and the productivity of labour (see 3.21). Because the adverse effect of technology adoption costs is also dependent on the size of labour endowments, the influence of lower values of $\phi_{1}$ and $\phi_{2}$ is enhanced by the size of $L$ and $H$, respectively. Hence, low-skilled labour is more affected because it is relatively more abundant, and the drag on its productivity is stronger than it is for high-skilled labour.

These effects have two consequences. First, since production factors are paid at their marginal productivity, the downward pressure on wages is stronger for low-skilled labour, causing the $H$-premium to increase. Second, because the profitability of R\&D activities also depends on the technological readiness of labour - see equations 4.21 and 4.24-, its stronger decrease in low-skilled labour makes R\&D in high-specific intermediate goods relatively more attractive. This leads to a higher technological-knowledge bias, which also contributes to the increase of the $H$-premium - see equation (4.20).

Lower learning-by-doing parameters also induce an increase in the $H$-premium, but the underlying mechanism is different. Lower values for $l, h$ imply a stronger learning-by-doing effect for given values of $L$ and $H$, i. e., $L^{l}$ and $H^{h}$ are higher. ${ }^{27}$ But since the size of learning-by-doing effects is also related to labour endowments, the greater the number of workers of a given type in the economy, the stronger the learning-by-doing effect they experience.

\footnotetext{
${ }^{27}$ Recall that $L$ and $H$ take values over the range $[0,1]$. Therefore, for values of $l(h)$ closer to one, $L^{l}\left(H^{h}\right)$ is higher for each given value of $L(H)$.
} 
In a situation in which $L$ is high, much of the learning-by-doing experienced by low-skilled labour is determined by the size of $L$, with the parameter $l$ playing only a minor role. For the relatively scarcer high-skilled the opposite happens: since $H$ is low the parameter $h$ plays a bigger role in determining the size of the learningby-doing effect. Therefore, the increase in learning-by-doing that results from lower values of $l$ and $h$ is more significant for high-skilled labour. ${ }^{28}$

The technological readiness and productivity of labour react accordingly: increases are more pronounced for high-skilled labour. Again, this raises the $H$ premium because the productivity ratio changes in favour of high-skilled labour, but also because of effects upon R\&D. It becomes relatively more attractive to do $\mathrm{R} \& \mathrm{D}$ in high-specific intermediate goods because $\sigma_{H}$ increases relatively more than $\sigma_{L}$, and this means that $Q_{H} / Q_{L}$ and the $H$-premium increase.

\section{LBD and TAC effects under predominance of high-skilled labour}

As expected, the simulations for the case in which high-skilled labour is relatively more abundant produce opposite results (see Figure 9). Lower values of $l$ and $h$ lead to a lower technological-knowledge bias and a lower $H$-premium. This is because the decrease in the learning-by-doing parameters now favours low-skilled labour more intensely: given that $L$ is smaller than $H$, decreases in $l$ improve $L^{l}$ more than decreases in $h$ improve $H^{h}$. The connection between learning-by-doing effects and wages (through labour productivity and through the influence of the technologicalknowledge bias) then implies that the wage of low-skilled labour rises more than the wage of high-skilled labour, thus reducing the $H$-premium.

Lower technology-adoption costs parameters also produce a lower technologicalknowledge bias and a lower $H$-premium. Since $H$ is greater than $L$, an equal decrease in $h$ and $l$ produces a more pronounced decline in the technological readiness of highskilled labour than in that of low-skilled labour. Again, this is because the adverse effect of technology-adoption costs - which influence $\sigma_{L}$ and $\sigma_{H}$ - also depend on the size of $L$ and $H$. Given lower values of $\sigma_{H} / \sigma_{L}$, R\&D becomes relatively more attractive in low-specific intermediate goods, thus inducing lower values for the technological-knowledge bias and $H$-premium. The lowering of high-skilled workers' wage is also due to the decrease in its relative productivity.

\footnotetext{
${ }^{28}$ Assume that $L=0.8$ and $H=0.2$. When $l$ and $h$ both shift from 1.3 to 1.1 , for example, $L^{l}$ shifts from 0.748 to 0.782 and $H^{h}$ shifts from 0.123 to 0.170 . The decrease in the learning-by-doing parameter is much more relevant for high-skilled. Furthermore, $H^{h} / L^{l}$ increases and so does the ratio between the technological readiness of high and low-skilled labour (assuming that $\phi_{1}=\phi_{2}$, i. e., there are no differences in the parameters of the technology-adoption costs).
} 

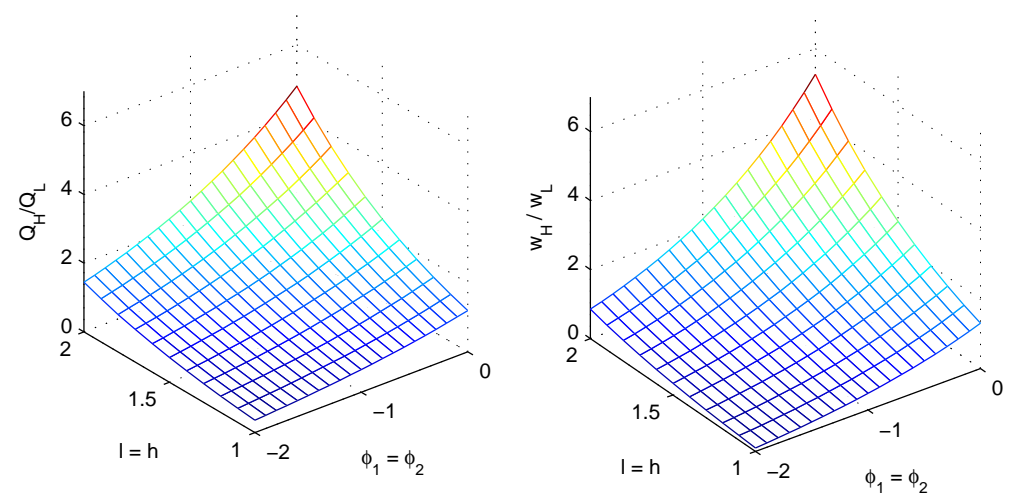

Simulated steady-state values of the technological-knowledge bias and $H$-premium for different values of the learningby-doing and technology-adoption costs parameters, assuming predominance of high-skilled labour. Results are from simulations based on $L=0.2, H=0.8, c=1$.

Figure 9: LBD and TAC effects under predominance of high-skilled labour.

\section{Interaction between LBD and the relative supply of high-skilled labour}

In Figure 10 we can see how different $H / L$ ratios and learning-by-doing parameters interact to shape the technological-knowledge bias and $H$-premium. In line with the results discussed previously - and shown in Figures 8 and 9 -, decreases in learningby-doing parameters are associated with lower technological-knowledge biases and $H$-premia when high-skilled labour is relatively more abundant (high $H / L$ ), and lead to higher technological-knowledge biases and $H$-premia when $H / L$ is low.

Simulation results also show under which conditions does a higher relative abundance of high-skilled labour implies higher values of $Q_{H} / Q_{L}$ and $w_{H} / w_{L}$. We can see that the $H$-premia and technological-knowledge biases tend to be lower in the presence of higher $H / L$ ratios if learning-by-doing parameters are low. Conversely, they tend to be higher in the presence of higher $H / L$ ratios if $l$ and $h$ are also high. Hence, for given values of $\phi_{1}$ and $\phi_{2}$, the technological-knowledge bias and wage ratio favour of the more abundant type of labour when learning-by-doing parameters are higher.

The reason behind this last result has already been discussed. When learningby-doing parameters are high, the size of labour endowments is responsible for determining much of the (positive) learning-by-doing effects. Hence, the more abundant labour type experiences greater learning-by-doing and this in turn benefits its technological readiness, productivity and relative wage rate. 

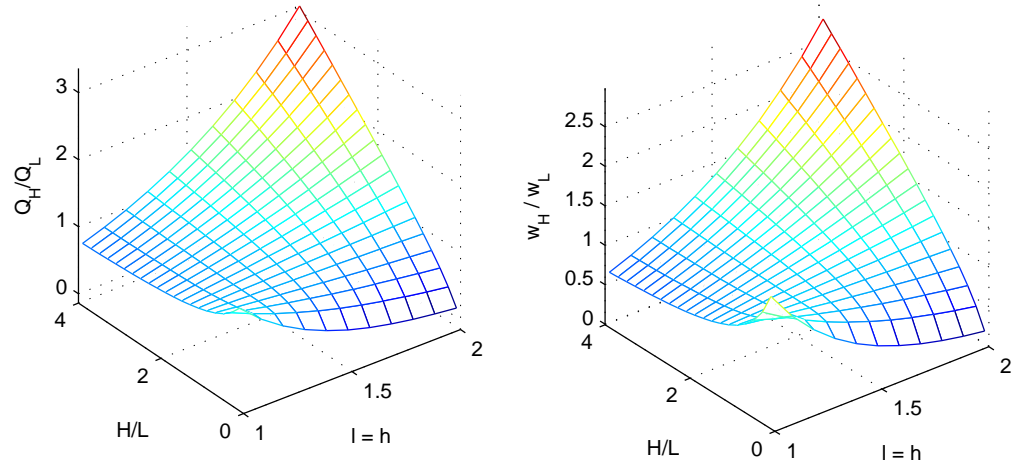

Simulated steady-state values of the technological-knowledge bias and $H$-premium for different values of $H / L$ and learning-by-doing parameters. Results are from simulations based on $\phi_{1}=\phi_{2}=-0.4$ and $c=1$.

Figure 10: LBD and the relative supply of high-skilled labour.

\section{Interaction between TAC and the relative supply of high-skilled labour}

Now we concentrate our attention on how different combinations of technologyadoption costs parameters and $H / L$ ratios shape the bias of the technologicalknowledge and $w_{H} / w_{L}$ (see Figure 11). Simulation results show that, all else equal, there is a lower technological-knowledge biases and $H$-premia when high-skilled labour is relatively more abundant only if technology-adoption costs parameters are sufficiently negative.

The reason for this - as discussed above - is that the adverse effect of technologyadoption costs depends on both the abundance of the underlying type of labour and on technology-adoption costs parameters. If the latter are small (i. e., close to zero) the increase in the adverse effect of technology-adoption costs induced by an increase of $H$ is also small. This leaves room for the positive effect of learning-by-doing which is positively influenced by the size of the $H$ - to dominate the adverse effect of technology-adoption costs. The changes in the technological readiness of $H$ (and $L$ ) then imply that the technological-knowledge bias and wage ratio favour high-skilled labour.

Accordingly, lower (i. e., more negative) values of $\phi_{1}$ and $\phi_{2}$ are associated with stronger technological-knowledge biases and higher $H$-premia only if $L$ is relatively more abundant. The lower values of $\phi_{1}$ and $\phi_{2}$ induce a stronger adverse effect of technology adoption costs for the most abundant type of labour, thus decreasing its technological readiness, productivity and relative wage more significantly. This is consistent with the findings discussed previously and depicted in Figures 8 and 9 . In the case in which $L=0.8$ (Figure 8), low values of $\phi_{1}$ and $\phi_{2}$ appear associated with higher technological-knowledge biases and $H$-premia, whereas in the case in 

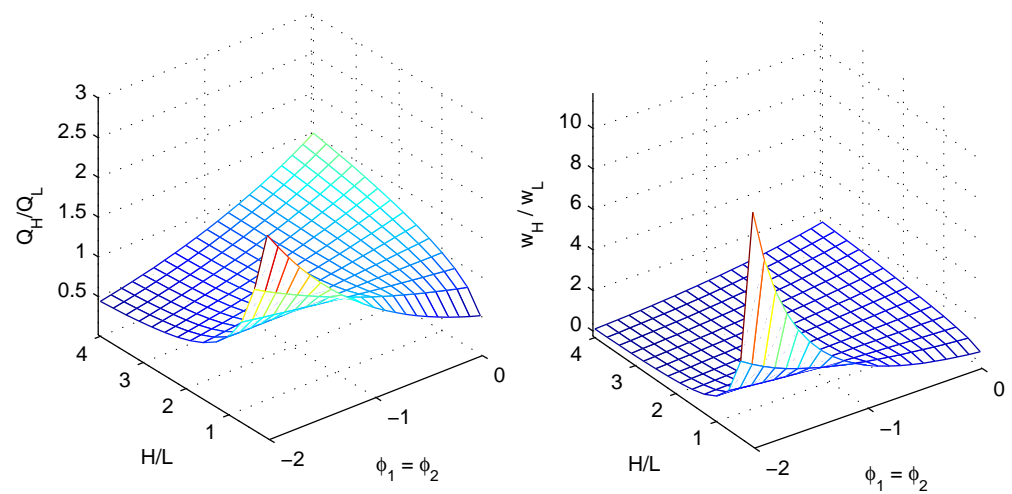

Simulated steady-state values of the technological-knowledge bias and $H$-premium for different values of $H / L$ and technology-adoption costs parameters. Results are from simulations based on $l=h=1.3$ and $c=1$.

Figure 11: TAC and the relative supply of high-skilled labour.

which $L=0.2$ they appear associated with lower technological-knowledge biases and $H$-premia (Figure 9). 


\section{Conclusions}

In this thesis we have presented some recent facts concerning trends in skill-related wage inequality and in the relative supply of more-skilled workers. The increase of the skill premium in spite of a higher abundance of more-skilled workers has been the dominant trend. However, other paths of skill premium and skill-labour supply also exist.

We have reviewed some factors that might have shaped the apparently contradictory rise in skill-labour supplies and skill premia. Namely, we have presented explanations based on economic openness, labour market features and skill-biased technological change, and we observe that the latter is the main explanation. Furthermore, we have illustrated the economic importance of learning-by-doing and technology-adoption costs. These two concepts are then connected with the skillbiased technological change framework in order to build a model to study the path of wage inequality.

We have proposed an endogenous growth model in which individuals decide on income allocation between consumption and savings, and two production technologies are used in the perfectly competitive final-goods sector. One combines low-skilled labour with a specific set of (complementary) quality-adjusted intermediate goods, and the other uses high-skilled complemented with a continuum of high-specific quality adjusted intermediate goods. Intermediate goods, which are improved by $\mathrm{R} \& \mathrm{D}$, are produced in monopolistic competition. Labour endowments are linked with learning-by-doing and technology-adoption costs to measure the technological readiness of each type of labour. Technological readiness of labour is connected with the direction of technological-knowledge progress and, thus, with wage inequality.

Our simulation results can be interpreted in comparison with previous literature about skill-biased technological change. In that literature, the bias that drive wage inequality is mainly induced through the market-size channel. In our model, the path of wage inequality is similarly influenced by the direction of technologicalknowledge progress, but this direction, however, is strongly influenced by the price channel and the effects of the technological readiness of labour.

In contrast with the skill-biased technological change literature, the operation of the price channel under technological readiness of labour can accommodate the recent changes in wage inequality that have been observed both in developed and developing countries. Specifically, whereas in the skill-biased technological change literature an exogenous increase in the relative abundance of high-skilled labour always increases the skill premium, in our model it can either induce increases or decreases of that premium. 
The proposed theoretical framework can also be extended to explore, in particular, the effects of several other dimensions of technological readiness of labour. Thus, for example, the consideration of (i) human-capital accumulation, (ii) governmental intervention, and (iii) R\&D also supported by leader firms (by considering that they have smaller costs in R\&D activities) are avenues for further research. That is, these facts can be readily incorporated into the model, and their effects on technological-knowledge bias, wage inequality and growth can be examined. 


\section{Appendix A}

\section{Proof of the existence of a final-goods threshold}

Let $\pi_{n}^{L}$ denote the profits of a representative final-goods firm $n$ that produces its output using only $L$-technology. Then,

$$
\pi_{n}^{L}=P_{n} Y_{n}-w_{L} L_{n}-\int_{0}^{J} P_{j} X_{j n} d j
$$

Now substitute $X_{j n}$ using (3.9) and $Y_{n}$ using the adequate components of (3.11). This yields:

$$
\pi_{n}^{L}=P_{n}\left\{\lambda\left[\frac{P_{n}(1-\alpha)}{P_{J}}\right]^{(1-\alpha) / \alpha} Q_{L}\right\}-w_{L} L_{n}-P_{j}\left\{\lambda\left[\frac{P_{n}(1-\alpha)}{P_{J}}\right]^{1 / \alpha} Q_{L}\right\}
$$

where $\lambda=A^{1 / \alpha}(1-n) \sigma_{L}$. Dividing the expression for $L_{n}$ and then rearranging terms gives us:

$$
\frac{\pi_{n}^{L}}{L_{n}}=\alpha\left(P_{n} A\right)^{1 / \alpha}(1-n) \sigma_{L}\left[\frac{1-\alpha}{P_{j}}\right]^{(1-\alpha) / \alpha} Q_{L}-w_{L}
$$

This result represents the profits per unit of low-skilled labour obtained by a final-goods firm $n$ that uses only $L$-technology. A similar derivation can be applied to a representative final-goods firm that uses exclusively the $H$-technology. This yields:

$$
\frac{\pi_{n}^{H}}{H_{n}}=\alpha\left(P_{n} A\right)^{1 / \alpha} n \sigma_{H}\left[\frac{1-\alpha}{P_{j}}\right]^{(1-\alpha) / \alpha} Q_{H}-w_{H} .
$$

In equilibrium, comptetion implies that $\pi_{n}^{L} \leq 0$ and $\pi_{n}^{H} \leq 0$, hence each producer makes zero profits per unit of labour (low or high-skilled). Furthermore, since all final goods have to be produced, it must be that $\pi_{n}^{L}=0, \pi_{n}^{H}=0$ or both. In other words, each final good has to be produceed, and firms have to use either the $L$-technology, the $H$-technology, or both.

Moreover, equations (6.2) and (6.1) imply that, in equilibrium, low (high-)skilled workers cannot be unemployed, as this would imply that their wage would fall to zero, thus creating a profitable deviation in using the $L(H$-)technology. Then it must be that each technology is used to produce at least some of the final goods.

In addition, notice that the difference between (6.2) and (6.1) is given by:

$$
\frac{\pi_{n}^{H}}{H_{n}}-\frac{\pi_{n}^{L}}{L_{n}}=\alpha\left(P_{n} A\right)^{1 / \alpha}\left[\frac{1-\alpha}{P_{j}}\right]^{(1-\alpha) / \alpha}\left[n\left(\sigma_{L} Q_{L}+\sigma_{H} Q_{H}\right)-\sigma_{L} Q_{L}\right]+w_{L}-w_{H},
$$


which is an increasing function of $n \in[0,1]$. It follows from here that a threshold final-good $\bar{n}$ must exist such that final goods $n<\bar{n}$ are produced using exclusively the $L$-technology, and final goods $n>\bar{n}$ are produced using exclusively the $H$ technology. QED

\section{Proof of equations (4.8) and (4.9)}

From the consumer's utility maximization we know that $P_{n}(t) Y_{n}(t)$ is constant across $n$. We also know from (4.4) that $P_{n}=P_{L}(1-n)^{-\alpha}$ for all $n \in[0, \bar{n}]$. Therefore, for final good $n=0$ and another final good $n \in[0, \bar{n}]$ we can write:

$$
P_{L} Y_{0}=P_{L}(1-n)^{-\alpha} Y_{n}
$$

We can substitute $Y_{0}$ and $Y_{n}$ in this expression using equation (4.6), and rearrange terms to obtain:

$$
P_{L} L_{0} \sigma_{L} A^{1 / \alpha}\left[\frac{P_{L}(1-\alpha)}{P_{j}}\right]^{(1-\alpha) / \alpha} Q_{L}=P_{L} L_{n} \sigma_{L} A^{1 / \alpha}\left[\frac{P_{L}(1-\alpha)}{P_{j}}\right]^{(1-\alpha) / \alpha} Q_{L} .
$$

This holds only if $L_{0}=L_{n}$ for all other $n \in[0, \bar{n}]$. Thus, it must be that all firms $n \in[0, \bar{n}]$ use the same amount of low-skilled labour. Since the total amount of low-skilled labour available in the economy is $L$, then:

$$
L_{n}=\frac{L}{\bar{n}}
$$

Equation (4.5), in turn, tells us that $P_{n}=P_{H}(n)^{-\alpha}$ for all $n \in[\bar{n}, 1]$. Then, for final good $n=1$ and another final good $n \in[\bar{n}, 1]$ we can write:

$$
P_{H} Y_{1}=P_{H}(n)^{-\alpha} Y_{n}
$$

Using (4.6) to substitute for $Y_{1}$ and $Y_{n}$ yields:

$$
P_{H} H_{1} \sigma_{H} A^{1 / \alpha}\left[\frac{P_{H}(1-\alpha)}{P_{j}}\right]^{[(1-\alpha) / \alpha]} Q_{H}=P_{L} H_{n} \sigma_{H} A^{1 / \alpha}\left[\frac{P_{H}(1-\alpha)}{P_{j}}\right]^{[(1-\alpha) / \alpha]} Q_{H} .
$$

So, for this equality to hold it must be $H_{1}=H_{n}$ for all other $n \in[\bar{n}, 1]$. Hence:

$$
H_{n}=\frac{H}{1-\bar{n}},
$$


where $H$ is the total amount of high-skilled labour available in the economy and $(1-\bar{n})$ is the number of firms using it. QED 


\section{Appendix B}

In this appendix we present the tables that gather simulatied skill premia for the countries analysed in chapter 5 . Tables 3 to 8 present simulation results based on Machin and Van Reenen's (1998) data for the United States during the period 19731989. Concerning this same period, Tables 9 and 10 present (simulation) results for Sweden, Tables 11 and 12 present results for the United Kingdom, and Tables 13 and 14 present results for Denmark.

Simulated skill premia for Belgium concerning the period between 1985 and 1997 can be found in Tables 15 and 16, and in Tables 17 and 18 the results for Chile 1960-1990 are presented. Tables 19 and 20 hold the results for The Netherlands with respect to the period 1983-1994. Finally, in Tables 21 and 22 we present simulated skill premia for Canada during the period 1987-1997. 


\begin{tabular}{|c|c|c|c|c|c|c|c|c|c|c|c|c|c|c|c|c|c|c|c|c|c|}
\hline & & & & & & & & & & & $l=h$ & & & & & & & & & & \\
\hline$\phi_{1}=\phi_{2}$ & 1.000 & 1.050 & 1.100 & 1.150 & 1.200 & 1.250 & 1.300 & 1.350 & 1.400 & 1.450 & 1.500 & 1.550 & 1.600 & 1.650 & 1.700 & 1.750 & 1.800 & 1.850 & 1.900 & 1.950 & 2.000 \\
\hline 0.000 & 1.568 & 1.483 & 1.402 & 1.325 & 1.254 & 1.185 & 1.121 & 1.060 & 1.002 & 0.947 & 0.896 & 0.847 & 0.801 & 0.757 & 0.716 & 0.677 & 0.640 & 0.605 & 0.572 & 0.541 & 0.511 \\
\hline-0.050 & 1.630 & 1.540 & 1.456 & 1.376 & 1.301 & 1.230 & 1.162 & 1.099 & 1.039 & 0.982 & 0.928 & 0.877 & 0.829 & 0.784 & 0.741 & 0.701 & 0.662 & 0.626 & 0.592 & 0.560 & 0.529 \\
\hline-0.100 & 1.694 & 1.600 & 1.512 & 1.429 & 1.351 & 1.276 & 1.206 & 1.140 & 1.077 & 1.018 & 0.962 & 0.909 & 0.859 & 0.812 & 0.768 & 0.726 & 0.686 & 0.648 & 0.613 & 0.579 & 0.548 \\
\hline-0.150 & 1.761 & 1.664 & 1.571 & 1.484 & 1.402 & 1.325 & 1.252 & 1.183 & 1.117 & 1.056 & 0.997 & 0.942 & 0.891 & 0.842 & 0.795 & 0.752 & 0.710 & 0.671 & 0.634 & 0.599 & 0.566 \\
\hline-0.200 & 1.832 & 1.729 & 1.633 & 1.542 & 1.457 & 1.376 & 1.299 & 1.227 & 1.159 & 1.095 & 1.034 & 0.977 & 0.923 & 0.872 & 0.824 & 0.779 & 0.736 & 0.695 & 0.657 & 0.620 & 0.586 \\
\hline-0.250 & 1.905 & 1.799 & 1.698 & 1.603 & 1.513 & 1.429 & 1.349 & 1.274 & 1.203 & 1.137 & 1.073 & 1.013 & 0.957 & 0.904 & 0.854 & 0.807 & 0.762 & 0.720 & 0.680 & 0.642 & 0.607 \\
\hline-0.300 & 1.984 & 1.872 & 1.766 & 1.667 & 1.573 & 1.484 & 1.401 & 1.323 & 1.248 & 1.179 & 1.113 & 1.051 & 0.992 & 0.937 & 0.885 & 0.836 & 0.789 & 0.746 & 0.704 & 0.665 & 0.628 \\
\hline-0.350 & 2.065 & 1.948 & 1.837 & 1.733 & 1.635 & 1.543 & 1.456 & 1.374 & 1.297 & 1.224 & 1.155 & 1.091 & 1.029 & 0.972 & 0.918 & 0.866 & 0.818 & 0.773 & 0.730 & 0.689 & 0.651 \\
\hline-0.400 & 2.152 & 2.029 & 1.913 & 1.803 & 1.701 & 1.604 & 1.513 & 1.427 & 1.347 & 1.271 & 1.199 & 1.132 & 1.068 & 1.008 & 0.952 & 0.898 & 0.848 & 0.801 & 0.756 & 0.714 & 0.674 \\
\hline-0.450 & 2.243 & 2.114 & 1.992 & 1.877 & 1.769 & 1.668 & 1.573 & 1.483 & 1.398 & 1.320 & 1.245 & 1.175 & 1.109 & 1.046 & 0.987 & 0.931 & 0.879 & 0.830 & 0.783 & 0.739 & 0.698 \\
\hline-0.500 & 2.339 & 2.203 & 2.075 & 1.954 & 1.842 & 1.735 & 1.635 & 1.542 & 1.454 & 1.371 & 1.293 & 1.220 & 1.150 & 1.085 & 1.024 & 0.966 & 0.912 & 0.860 & 0.812 & 0.766 & 0.723 \\
\hline-0.550 & 2.440 & 2.297 & 2.162 & 2.036 & 1.917 & 1.806 & 1.702 & 1.604 & 1.512 & 1.424 & 1.343 & 1.267 & 1.195 & 1.127 & 1.063 & 1.002 & 0.945 & 0.892 & 0.842 & 0.794 & 0.749 \\
\hline-0.600 & 2.547 & 2.396 & 2.254 & 2.121 & 1.997 & 1.881 & 1.771 & 1.668 & 1.572 & 1.481 & 1.396 & 1.316 & 1.240 & 1.170 & 1.103 & 1.040 & 0.981 & 0.925 & 0.873 & 0.823 & 0.777 \\
\hline-0.650 & 2.660 & 2.501 & 2.351 & 2.212 & 2.081 & 1.959 & 1.844 & 1.736 & 1.635 & 1.540 & 1.451 & 1.367 & 1.289 & 1.215 & 1.145 & 1.079 & 1.018 & 0.960 & 0.905 & 0.854 & 0.805 \\
\hline-0.700 & 2.779 & 2.611 & 2.454 & 2.307 & 2.170 & 2.041 & 1.920 & 1.808 & 1.702 & 1.602 & 1.509 & 1.421 & 1.339 & 1.262 & 1.189 & 1.121 & 1.056 & 0.996 & 0.939 & 0.885 & 0.835 \\
\hline-0.750 & 2.907 & 2.729 & 2.563 & 2.408 & 2.263 & 2.128 & 2.001 & 1.883 & 1.772 & 1.667 & 1.570 & 1.478 & 1.392 & 1.311 & 1.235 & 1.164 & 1.097 & 1.034 & 0.974 & 0.918 & 0.866 \\
\hline-0.800 & 3.041 & 2.853 & 2.678 & 2.514 & 2.362 & 2.219 & 2.086 & 1.962 & 1.845 & 1.736 & 1.633 & 1.537 & 1.447 & 1.363 & 1.283 & 1.209 & 1.139 & 1.073 & 1.011 & 0.953 & 0.898 \\
\hline-0.850 & 3.184 & 2.985 & 2.800 & 2.627 & 2.466 & 2.316 & 2.176 & 2.045 & 1.922 & 1.808 & 1.700 & 1.600 & 1.505 & 1.417 & 1.334 & 1.256 & 1.183 & 1.114 & 1.050 & 0.989 & 0.932 \\
\hline-0.900 & 3.336 & 3.125 & 2.928 & 2.746 & 2.576 & 2.418 & 2.270 & 2.132 & 2.004 & 1.883 & 1.771 & 1.665 & 1.566 & 1.474 & 1.387 & 1.305 & 1.229 & 1.157 & 1.090 & 1.027 & 0.967 \\
\hline-0.950 & 3.499 & 3.273 & 3.066 & 2.873 & 2.693 & 2.526 & 2.370 & 2.225 & 2.089 & 1.963 & 1.845 & 1.734 & 1.630 & 1.533 & 1.442 & 1.357 & 1.277 & 1.202 & 1.132 & 1.066 & 1.004 \\
\hline-1.000 & 3.672 & 3.433 & 3.211 & 3.006 & 2.817 & 2.640 & 2.476 & 2.323 & 2.180 & 2.047 & 1.922 & 1.806 & 1.698 & 1.596 & 1.501 & 1.412 & 1.328 & 1.250 & 1.176 & 1.107 & 1.043 \\
\hline-1.050 & 3.854 & 3.602 & 3.366 & 3.149 & 2.948 & 2.761 & 2.587 & 2.426 & 2.275 & 2.135 & 2.004 & 1.882 & 1.768 & 1.662 & 1.562 & 1.469 & 1.381 & 1.299 & 1.222 & 1.150 & 1.083 \\
\hline-1.100 & 4.054 & 3.782 & 3.532 & 3.301 & 3.087 & 2.889 & 2.706 & 2.535 & 2.376 & 2.229 & 2.091 & 1.963 & 1.843 & 1.731 & 1.626 & 1.528 & 1.437 & 1.351 & 1.271 & 1.195 & 1.125 \\
\hline-1.150 & 4.266 & 3.976 & 3.709 & 3.463 & 3.236 & 3.026 & 2.831 & 2.651 & 2.483 & 2.327 & 2.182 & 2.047 & 1.921 & 1.804 & 1.694 & 1.591 & 1.495 & 1.405 & 1.321 & 1.243 & 1.169 \\
\hline-1.200 & 4.495 & 4.183 & 3.898 & 3.635 & 3.394 & 3.170 & 2.964 & 2.773 & 2.596 & 2.431 & 2.279 & 2.136 & 2.004 & 1.880 & 1.765 & 1.657 & 1.557 & 1.463 & 1.375 & 1.292 & 1.215 \\
\hline-1.250 & 4.740 & 4.406 & 4.100 & 3.820 & 3.562 & 3.325 & 3.106 & 2.903 & 2.716 & 2.542 & 2.380 & 2.230 & 2.091 & 1.961 & 1.840 & 1.727 & 1.621 & 1.523 & 1.430 & 1.344 & 1.263 \\
\hline-1.300 & 5.005 & 4.646 & 4.318 & 4.018 & 3.742 & 3.489 & 3.257 & 3.042 & 2.843 & 2.659 & 2.488 & 2.330 & 2.183 & 2.046 & 1.918 & 1.800 & 1.689 & 1.585 & 1.489 & 1.399 & 1.314 \\
\hline-1.350 & 5.292 & 4.904 & 4.552 & 4.230 & 3.935 & 3.665 & 3.417 & 3.189 & 2.978 & 2.783 & 2.602 & 2.435 & 2.280 & 2.136 & 2.002 & 1.877 & 1.760 & 1.652 & 1.550 & 1.456 & 1.367 \\
\hline-1.400 & 5.604 & 5.184 & 4.804 & 4.458 & 4.142 & 3.854 & 3.589 & 3.346 & 3.122 & 2.915 & 2.724 & 2.547 & 2.383 & 2.231 & 2.089 & 1.958 & 1.835 & 1.721 & 1.615 & 1.516 & 1.423 \\
\hline-1.450 & 5.943 & 5.487 & 5.076 & 4.703 & 4.365 & 4.055 & 3.772 & 3.513 & 3.275 & 3.055 & 2.852 & 2.665 & 2.492 & 2.331 & 2.182 & 2.043 & 1.915 & 1.795 & 1.683 & 1.579 & 1.482 \\
\hline-1.500 & 6.313 & 5.817 & 5.371 & 4.969 & 4.604 & 4.272 & 3.969 & 3.692 & 3.438 & 3.204 & 2.989 & 2.791 & 2.607 & 2.437 & 2.280 & 2.134 & 1.998 & 1.872 & 1.755 & 1.645 & 1.543 \\
\hline-1.550 & 6.718 & 6.177 & 5.692 & 5.256 & 4.862 & 4.505 & 4.180 & 3.884 & 3.612 & 3.363 & 3.135 & 2.924 & 2.730 & 2.550 & 2.384 & 2.229 & 2.086 & 1.954 & 1.830 & 1.715 & 1.608 \\
\hline-1.600 & 7.164 & 6.570 & 6.041 & 5.568 & 5.142 & 4.757 & 4.407 & 4.089 & 3.799 & 3.534 & 3.290 & 3.066 & 2.860 & 2.669 & 2.493 & 2.330 & 2.180 & 2.040 & 1.910 & 1.789 & 1.676 \\
\hline-1.650 & 7.656 & 7.002 & 6.423 & 5.907 & 5.445 & 5.029 & 4.652 & 4.310 & 3.999 & 3.716 & 3.456 & 3.217 & 2.998 & 2.796 & 2.610 & 2.438 & 2.278 & 2.131 & 1.994 & 1.866 & 1.748 \\
\hline-1.700 & 8.202 & 7.479 & 6.842 & 6.278 & 5.775 & 5.323 & 4.916 & 4.549 & 4.215 & 3.911 & 3.633 & 3.379 & 3.145 & 2.931 & 2.733 & 2.551 & 2.383 & 2.227 & 2.082 & 1.948 & 1.824 \\
\hline-1.750 & 8.810 & 8.007 & 7.304 & 6.684 & 6.134 & 5.643 & 5.203 & 4.806 & 4.446 & 4.120 & 3.823 & 3.551 & 3.303 & 3.075 & 2.865 & 2.672 & 2.493 & 2.328 & 2.176 & 2.035 & 1.904 \\
\hline-1.800 & 9.492 & 8.594 & 7.815 & 7.131 & 6.528 & 5.992 & 5.514 & 5.084 & 4.696 & 4.345 & 4.027 & 3.736 & 3.471 & 3.228 & 3.005 & 2.800 & 2.611 & 2.436 & 2.275 & 2.126 & 1.988 \\
\hline-1.850 & 10.262 & 9.252 & 8.382 & 7.625 & 6.961 & 6.374 & 5.852 & 5.386 & 4.966 & 4.588 & 4.246 & 3.934 & 3.651 & 3.391 & 3.154 & 2.936 & 2.735 & 2.551 & 2.380 & 2.223 & 2.077 \\
\hline-1.900 & 11.137 & 9.992 & 9.016 & 8.173 & 7.438 & 6.793 & 6.222 & 5.714 & 5.259 & 4.851 & 4.482 & 4.147 & 3.843 & 3.566 & 3.313 & 3.081 & 2.868 & 2.672 & 2.492 & 2.325 & 2.171 \\
\hline-1.950 & 12.139 & 10.832 & 9.728 & 8.784 & 7.967 & 7.255 & 6.628 & 6.073 & 5.578 & 5.135 & 4.737 & 4.377 & 4.050 & 3.754 & 3.483 & 3.236 & 3.009 & 2.801 & 2.610 & 2.434 & 2.271 \\
\hline-2.000 & 13.298 & 11.791 & 10.534 & 9.469 & 8.556 & 7.765 & 7.074 & 6.465 & 5.925 & 5.444 & 5.013 & 4.624 & 4.273 & 3.955 & 3.666 & 3.402 & 3.160 & 2.939 & 2.736 & 2.549 & 2.376 \\
\hline
\end{tabular}




\begin{tabular}{|c|c|c|c|c|c|c|c|c|c|c|c|c|c|c|c|c|c|c|c|c|c|}
\hline & & & & & & & & & & & $l=h$ & & & & & & & & & & \\
\hline$\phi_{1}=\phi_{2}$ & 1.000 & 1.050 & 1.100 & 1.150 & 1.200 & 1.250 & 1.300 & 1.350 & 1.400 & 1.450 & 1.500 & 1.550 & 1.600 & 1.650 & 1.700 & 1.750 & 1.800 & 1.850 & 1.900 & 1.950 & 2.000 \\
\hline 0.000 & 1.569 & 1.505 & 1.443 & 1.384 & 1.328 & 1.274 & 1.222 & 1.172 & 1.124 & 1.079 & 1.035 & 0.992 & 0.952 & 0.913 & 0.876 & 0.840 & 0.806 & 0.773 & 0.742 & 0.711 & 0.682 \\
\hline-0.050 & 1.616 & 1.549 & 1.486 & 1.425 & 1.367 & 1.311 & 1.257 & 1.206 & 1.156 & 1.109 & 1.064 & 1.020 & 0.978 & 0.938 & 0.900 & 0.863 & 0.828 & 0.794 & 0.762 & 0.731 & 0.701 \\
\hline-0.100 & 1.665 & 1.596 & 1.530 & 1.467 & 1.407 & 1.349 & 1.293 & 1.240 & 1.189 & 1.141 & 1.094 & 1.049 & 1.006 & 0.964 & 0.925 & 0.887 & 0.850 & 0.816 & 0.782 & 0.750 & 0.719 \\
\hline-0.150 & 1.716 & 1.644 & 1.576 & 1.511 & 1.448 & 1.389 & 1.331 & 1.276 & 1.223 & 1.173 & 1.125 & 1.078 & 1.034 & 0.992 & 0.950 & 0.911 & 0.874 & 0.838 & 0.803 & 0.770 & 0.739 \\
\hline-0.200 & 1.769 & 1.695 & 1.624 & 1.556 & 1.491 & 1.430 & 1.370 & 1.313 & 1.259 & 1.207 & 1.157 & 1.109 & 1.063 & 1.019 & 0.977 & 0.936 & 0.898 & 0.861 & 0.825 & 0.791 & 0.759 \\
\hline-0.250 & 1.824 & 1.747 & 1.674 & 1.604 & 1.537 & 1.472 & 1.410 & 1.352 & 1.296 & 1.241 & 1.190 & 1.140 & 1.093 & 1.048 & 1.004 & 0.963 & 0.923 & 0.885 & 0.848 & 0.813 & 0.779 \\
\hline-0.300 & 1.881 & 1.802 & 1.726 & 1.653 & 1.583 & 1.517 & 1.453 & 1.392 & 1.334 & 1.277 & 1.224 & 1.173 & 1.124 & 1.077 & 1.033 & 0.990 & 0.948 & 0.909 & 0.871 & 0.835 & 0.800 \\
\hline-0.350 & 1.942 & 1.858 & 1.780 & 1.704 & 1.631 & 1.563 & 1.496 & 1.433 & 1.373 & 1.315 & 1.260 & 1.207 & 1.157 & 1.108 & 1.062 & 1.018 & 0.975 & 0.934 & 0.895 & 0.858 & 0.822 \\
\hline-0.400 & 2.004 & 1.918 & 1.835 & 1.757 & 1.682 & 1.610 & 1.542 & 1.476 & 1.414 & 1.354 & 1.297 & 1.242 & 1.190 & 1.140 & 1.092 & 1.046 & 1.002 & 0.960 & 0.920 & 0.882 & 0.845 \\
\hline-0.450 & 2.069 & 1.980 & 1.894 & 1.812 & 1.734 & 1.660 & 1.589 & 1.521 & 1.456 & 1.394 & 1.335 & 1.279 & 1.225 & 1.173 & 1.123 & 1.076 & 1.031 & 0.987 & 0.946 & 0.906 & 0.868 \\
\hline-0.500 & 2.138 & 2.044 & 1.955 & 1.870 & 1.789 & 1.712 & 1.638 & 1.567 & 1.500 & 1.436 & 1.375 & 1.316 & 1.260 & 1.207 & 1.156 & 1.107 & 1.060 & 1.015 & 0.973 & 0.932 & 0.892 \\
\hline-0.550 & 2.208 & 2.111 & 2.018 & 1.929 & 1.846 & 1.765 & 1.689 & 1.616 & 1.546 & 1.480 & 1.416 & 1.355 & 1.298 & 1.242 & 1.189 & 1.139 & 1.091 & 1.044 & 1.000 & 0.958 & 0.917 \\
\hline-0.600 & 2.283 & 2.181 & 2.085 & 1.992 & 1.905 & 1.821 & 1.742 & 1.666 & 1.594 & 1.524 & 1.459 & 1.396 & 1.336 & 1.279 & 1.224 & 1.172 & 1.122 & 1.074 & 1.029 & 0.985 & 0.943 \\
\hline-0.650 & 2.361 & 2.255 & 2.154 & 2.058 & 1.966 & 1.880 & 1.797 & 1.718 & 1.643 & 1.571 & 1.503 & 1.438 & 1.376 & 1.317 & 1.260 & 1.206 & 1.155 & 1.105 & 1.058 & 1.013 & 0.970 \\
\hline-0.700 & 2.442 & 2.332 & 2.226 & 2.126 & 2.031 & 1.941 & 1.855 & 1.772 & 1.695 & 1.620 & 1.549 & 1.482 & 1.418 & 1.356 & 1.298 & 1.242 & 1.188 & 1.137 & 1.089 & 1.042 & 0.997 \\
\hline-0.750 & 2.529 & 2.412 & 2.302 & 2.197 & 2.098 & 2.004 & 1.914 & 1.829 & 1.748 & 1.671 & 1.597 & 1.527 & 1.461 & 1.397 & 1.336 & 1.278 & 1.223 & 1.170 & 1.120 & 1.072 & 1.026 \\
\hline-0.800 & 2.618 & 2.497 & 2.381 & 2.272 & 2.168 & 2.070 & 1.977 & 1.888 & 1.804 & 1.724 & 1.647 & 1.575 & 1.506 & 1.440 & 1.377 & 1.317 & 1.259 & 1.205 & 1.153 & 1.103 & 1.056 \\
\hline-0.850 & 2.713 & 2.585 & 2.464 & 2.350 & 2.242 & 2.140 & 2.042 & 1.950 & 1.862 & 1.779 & 1.699 & 1.624 & 1.552 & 1.484 & 1.418 & 1.356 & 1.297 & 1.241 & 1.187 & 1.135 & 1.086 \\
\hline-0.900 & 2.812 & 2.678 & 2.552 & 2.432 & 2.319 & 2.212 & 2.111 & 2.014 & 1.923 & 1.836 & 1.753 & 1.675 & 1.600 & 1.529 & 1.462 & 1.397 & 1.336 & 1.278 & 1.222 & 1.169 & 1.118 \\
\hline-0.950 & 2.917 & 2.776 & 2.644 & 2.518 & 2.399 & 2.288 & 2.182 & 2.081 & 1.986 & 1.896 & 1.810 & 1.728 & 1.651 & 1.577 & 1.507 & 1.440 & 1.376 & 1.316 & 1.258 & 1.203 & 1.151 \\
\hline-1.000 & 3.028 & 2.880 & 2.740 & 2.608 & 2.484 & 2.367 & 2.256 & 2.152 & 2.052 & 1.958 & 1.869 & 1.784 & 1.703 & 1.627 & 1.554 & 1.484 & 1.418 & 1.356 & 1.296 & 1.239 & 1.185 \\
\hline-1.050 & 3.145 & 2.988 & 2.841 & 2.703 & 2.573 & 2.450 & 2.335 & 2.225 & 2.121 & 2.023 & 1.930 & 1.842 & 1.758 & 1.678 & 1.603 & 1.531 & 1.462 & 1.397 & 1.335 & 1.276 & 1.220 \\
\hline-1.100 & 3.268 & 3.103 & 2.948 & 2.803 & 2.667 & 2.538 & 2.416 & 2.302 & 2.194 & 2.091 & 1.994 & 1.902 & 1.815 & 1.732 & 1.653 & 1.579 & 1.507 & 1.440 & 1.376 & 1.315 & 1.256 \\
\hline-1.150 & 3.399 & 3.224 & 3.061 & 2.908 & 2.765 & 2.629 & 2.502 & 2.382 & 2.269 & 2.162 & 2.061 & 1.965 & 1.874 & 1.788 & 1.706 & 1.628 & 1.555 & 1.485 & 1.418 & 1.354 & 1.294 \\
\hline-1.200 & 3.537 & 3.353 & 3.180 & 3.019 & 2.868 & 2.726 & 2.593 & 2.467 & 2.348 & 2.236 & 2.131 & 2.031 & 1.936 & 1.846 & 1.761 & 1.680 & 1.604 & 1.531 & 1.462 & 1.396 & 1.333 \\
\hline-1.250 & 3.685 & 3.489 & 3.306 & 3.136 & 2.977 & 2.828 & 2.687 & 2.556 & 2.431 & 2.314 & 2.204 & 2.099 & 2.000 & 1.907 & 1.818 & 1.734 & 1.655 & 1.579 & 1.507 & 1.439 & 1.374 \\
\hline-1.300 & 3.841 & 3.633 & 3.440 & 3.260 & 3.092 & 2.935 & 2.787 & 2.649 & 2.518 & 2.396 & 2.280 & 2.171 & 2.068 & 1.971 & 1.878 & 1.791 & 1.708 & 1.629 & 1.555 & 1.484 & 1.417 \\
\hline-1.350 & 4.008 & 3.787 & 3.581 & 3.391 & 3.214 & 3.048 & 2.892 & 2.747 & 2.610 & 2.481 & 2.360 & 2.246 & 2.139 & 2.037 & 1.941 & 1.850 & 1.763 & 1.682 & 1.604 & 1.531 & 1.461 \\
\hline-1.400 & 4.186 & 3.951 & 3.732 & 3.530 & 3.342 & 3.167 & 3.003 & 2.850 & 2.706 & 2.571 & 2.445 & 2.325 & 2.213 & 2.106 & 2.006 & 1.911 & 1.821 & 1.736 & 1.656 & 1.579 & 1.507 \\
\hline-1.450 & 4.378 & 4.125 & 3.893 & 3.678 & 3.478 & 3.293 & 3.120 & 2.959 & 2.808 & 2.666 & 2.533 & 2.408 & 2.290 & 2.179 & 2.074 & 1.975 & 1.881 & 1.793 & 1.709 & 1.630 & 1.554 \\
\hline-1.500 & 4.583 & 4.312 & 4.064 & 3.835 & 3.623 & 3.427 & 3.244 & 3.074 & 2.914 & 2.765 & 2.626 & 2.494 & 2.371 & 2.255 & 2.145 & 2.042 & 1.944 & 1.852 & 1.765 & 1.682 & 1.604 \\
\hline-1.550 & 4.803 & 4.513 & 4.247 & 4.003 & 3.777 & 3.569 & 3.375 & 3.195 & 3.027 & 2.870 & 2.723 & 2.585 & 2.456 & 2.334 & 2.220 & 2.112 & 2.010 & 1.914 & 1.823 & 1.737 & 1.655 \\
\hline-1.600 & 5.041 & 4.728 & 4.443 & 4.181 & 3.941 & 3.719 & 3.514 & 3.323 & 3.146 & 2.981 & 2.826 & 2.681 & 2.545 & 2.418 & 2.298 & 2.185 & 2.079 & 1.979 & 1.884 & 1.794 & 1.709 \\
\hline-1.650 & 5.299 & 4.961 & 4.653 & 4.373 & 4.116 & 3.880 & 3.662 & 3.459 & 3.272 & 3.097 & 2.934 & 2.782 & 2.639 & 2.506 & 2.380 & 2.262 & 2.151 & 2.046 & 1.947 & 1.854 & 1.765 \\
\hline-1.700 & 5.578 & 5.211 & 4.880 & 4.578 & 4.303 & 4.051 & 3.819 & 3.604 & 3.405 & 3.220 & 3.049 & 2.888 & 2.738 & 2.598 & 2.466 & 2.342 & 2.226 & 2.117 & 2.013 & 1.916 & 1.824 \\
\hline-1.750 & 5.882 & 5.483 & 5.124 & 4.799 & 4.504 & 4.234 & 3.986 & 3.758 & 3.547 & 3.351 & 3.169 & 3.000 & 2.842 & 2.695 & 2.557 & 2.427 & 2.305 & 2.191 & 2.083 & 1.981 & 1.885 \\
\hline-1.800 & 6.215 & 5.779 & 5.389 & 5.038 & 4.719 & 4.430 & 4.165 & 3.921 & 3.697 & 3.489 & 3.297 & 3.119 & 2.952 & 2.797 & 2.652 & 2.515 & 2.388 & 2.268 & 2.155 & 2.049 & 1.949 \\
\hline-1.850 & 6.580 & 6.102 & 5.676 & 5.295 & 4.952 & 4.640 & 4.356 & 4.096 & 3.857 & 3.637 & 3.433 & 3.244 & 3.068 & 2.904 & 2.752 & 2.609 & 2.475 & 2.349 & 2.231 & 2.120 & 2.016 \\
\hline-1.900 & 6.982 & 6.455 & 5.990 & 5.575 & 5.202 & 4.866 & 4.561 & 4.283 & 4.027 & 3.793 & 3.577 & 3.376 & 3.191 & 3.018 & 2.857 & 2.707 & 2.566 & 2.434 & 2.311 & 2.195 & 2.085 \\
\hline-1.950 & 7.428 & 6.844 & 6.332 & 5.879 & 5.474 & 5.110 & 4.781 & 4.483 & 4.210 & 3.960 & 3.729 & 3.517 & 3.320 & 3.138 & 2.968 & 2.810 & 2.662 & 2.524 & 2.394 & 2.273 & 2.158 \\
\hline-2.000 & 7.925 & 7.275 & 6.709 & 6.211 & 5.769 & 5.374 & 5.019 & 4.697 & 4.405 & 4.137 & 3.892 & 3.666 & 3.458 & 3.265 & 3.085 & 2.919 & 2.763 & 2.618 & 2.482 & 2.354 & 2.235 \\
\hline
\end{tabular}




\begin{tabular}{|c|c|c|c|c|c|c|c|c|c|c|c|c|c|c|c|c|c|c|c|c|c|}
\hline & & & & & & & & & & & $l=h$ & & & & & & & & & & \\
\hline$\phi_{1}=\phi_{2}$ & 1.000 & 1.050 & 1.100 & 1.150 & 1.200 & 1.250 & 1.300 & 1.350 & 1.400 & 1.450 & 1.500 & 1.550 & 1.600 & 1.650 & 1.700 & 1.750 & 1.800 & 1.850 & 1.900 & 1.950 & 2.000 \\
\hline 0.000 & 1.746 & 1.651 & 1.561 & 1.476 & 1.395 & 1.319 & 1.247 & 1.180 & 1.115 & 1.054 & 0.997 & 0.943 & 0.891 & 0.843 & 0.797 & 0.753 & 0.712 & 0.673 & 0.637 & 0.602 & 0.569 \\
\hline-0.050 & 1.814 & 1.715 & 1.621 & 1.532 & 1.448 & 1.369 & 1.293 & 1.223 & 1.156 & 1.093 & 1.033 & 0.977 & 0.923 & 0.873 & 0.825 & 0.780 & 0.737 & 0.697 & 0.659 & 0.623 & 0.589 \\
\hline-0.100 & 1.886 & 1.782 & 1.683 & 1.591 & 1.503 & 1.421 & 1.342 & 1.269 & 1.199 & 1.133 & 1.071 & 1.012 & 0.957 & 0.904 & 0.855 & 0.808 & 0.763 & 0.722 & 0.682 & 0.645 & 0.609 \\
\hline-0.150 & 1.960 & 1.852 & 1.749 & 1.652 & 1.561 & 1.475 & 1.393 & 1.316 & 1.244 & 1.175 & 1.111 & 1.049 & 0.991 & 0.937 & 0.885 & 0.837 & 0.791 & 0.747 & 0.706 & 0.667 & 0.631 \\
\hline-0.200 & 2.039 & 1.925 & 1.818 & 1.717 & 1.621 & 1.531 & 1.446 & 1.366 & 1.290 & 1.219 & 1.151 & 1.088 & 1.028 & 0.971 & 0.917 & 0.867 & 0.819 & 0.774 & 0.731 & 0.691 & 0.653 \\
\hline-0.250 & 2.122 & 2.002 & 1.890 & 1.784 & 1.684 & 1.590 & 1.502 & 1.418 & 1.339 & 1.265 & 1.195 & 1.128 & 1.066 & 1.006 & 0.950 & 0.898 & 0.848 & 0.801 & 0.757 & 0.715 & 0.676 \\
\hline-0.300 & 2.208 & 2.083 & 1.966 & 1.855 & 1.751 & 1.652 & 1.560 & 1.472 & 1.390 & 1.312 & 1.239 & 1.170 & 1.105 & 1.043 & 0.985 & 0.930 & 0.879 & 0.830 & 0.784 & 0.740 & 0.699 \\
\hline-0.400 & 2.396 & 2.258 & 2.129 & 2.008 & 1.893 & 1.785 & 1.684 & 1.589 & 1.499 & 1.414 & 1.335 & 1.260 & 1.189 & 1.122 & 1.059 & 1.000 & 0.944 & 0.891 & 0.841 & 0.794 & 0.750 \\
\hline-0.450 & 2.497 & 2.353 & 2.217 & 2.089 & 1.970 & 1.857 & 1.750 & 1.651 & 1.557 & 1.469 & 1.386 & 1.308 & 1.234 & 1.164 & 1.099 & 1.037 & 0.979 & 0.924 & 0.872 & 0.823 & 0.777 \\
\hline-0.500 & 2.604 & 2.452 & 2.309 & 2.176 & 2.050 & 1.932 & 1.821 & 1.716 & 1.618 & 1.526 & 1.439 & 1.357 & 1.281 & 1.208 & 1.140 & 1.075 & 1.015 & 0.958 & 0.904 & 0.853 & 0.805 \\
\hline-0.550 & 2.715 & 2.556 & 2.407 & 2.265 & 2.134 & 2.010 & 1.894 & 1.785 & 1.683 & 1.586 & 1.495 & 1.410 & 1.330 & 1.254 & 1.183 & 1.116 & 1.052 & 0.993 & 0.937 & 0.884 & 0.834 \\
\hline-0.600 & 2.835 & 2.666 & 2.509 & 2.362 & 2.222 & 2.093 & 1.971 & 1.857 & 1.750 & 1.649 & 1.554 & 1.465 & 1.381 & 1.302 & 1.228 & 1.158 & 1.092 & 1.030 & 0.971 & 0.916 & 0.865 \\
\hline-0.650 & 2.960 & 2.784 & 2.617 & 2.462 & 2.317 & 2.181 & 2.053 & 1.933 & 1.820 & 1.714 & 1.615 & 1.522 & 1.434 & 1.352 & 1.274 & 1.202 & 1.133 & 1.068 & 1.008 & 0.950 & 0.896 \\
\hline-0.700 & 3.094 & 2.906 & 2.732 & 2.569 & 2.416 & 2.272 & 2.138 & 2.012 & 1.894 & 1.783 & 1.680 & 1.582 & 1.491 & 1.404 & 1.324 & 1.247 & 1.176 & 1.109 & 1.045 & 0.986 & 0.929 \\
\hline-0.750 & 3.236 & 3.038 & 2.853 & 2.680 & 2.519 & 2.369 & 2.227 & 2.096 & 1.972 & 1.856 & 1.747 & 1.645 & 1.549 & 1.459 & 1.375 & 1.295 & 1.221 & 1.151 & 1.084 & 1.022 & 0.964 \\
\hline-0.850 & 3.545 & 3.323 & 3.116 & 2.924 & 2.745 & 2.577 & 2.422 & 2.276 & 2.140 & 2.012 & 1.893 & 1.781 & 1.676 & 1.577 & 1.485 & 1.398 & 1.317 & 1.240 & 1.168 & 1.101 & 1.037 \\
\hline-0.900 & 3.714 & 3.479 & 3.260 & 3.057 & 2.868 & 2.691 & 2.527 & 2.373 & 2.230 & 2.096 & 1.971 & 1.853 & 1.744 & 1.640 & 1.544 & 1.453 & 1.368 & 1.288 & 1.213 & 1.143 & 1.077 \\
\hline-0.950 & 3.894 & 3.644 & 3.412 & 3.197 & 2.998 & 2.812 & 2.637 & 2.477 & 2.326 & 2.185 & 2.053 & 1.930 & 1.815 & 1.707 & 1.606 & 1.511 & 1.422 & 1.339 & 1.260 & 1.187 & 1.118 \\
\hline-1.000 & 4.087 & 3.821 & 3.575 & 3.347 & 3.135 & 2.939 & 2.756 & 2.585 & 2.427 & 2.278 & 2.140 & 2.011 & 1.890 & 1.776 & 1.671 & 1.571 & 1.478 & 1.391 & 1.309 & 1.233 & 1.160 \\
\hline-1.050 & 4.292 & 4.008 & 3.748 & 3.505 & 3.281 & 3.073 & 2.880 & 2.700 & 2.533 & 2.377 & 2.231 & 2.095 & 1.968 & 1.850 & 1.739 & 1.635 & 1.537 & 1.446 & 1.361 & 1.281 & 1.205 \\
\hline-1.100 & 4.513 & 4.210 & 3.932 & 3.674 & 3.436 & 3.216 & 3.012 & 2.822 & 2.645 & 2.481 & 2.327 & 2.185 & 2.051 & 1.927 & 1.810 & 1.701 & 1.599 & 1.504 & 1.415 & 1.331 & 1.252 \\
\hline-1.150 & 4.749 & 4.426 & 4.128 & 3.854 & 3.602 & 3.368 & 3.151 & 2.950 & 2.764 & 2.590 & 2.429 & 2.279 & 2.138 & 2.008 & 1.885 & 1.771 & 1.664 & 1.564 & 1.471 & 1.383 & 1.301 \\
\hline-1.200 & 5.002 & 4.656 & 4.338 & 4.047 & 3.777 & 3.529 & 3.300 & 3.087 & 2.890 & 2.707 & 2.536 & 2.378 & 2.230 & 2.093 & 1.965 & 1.845 & 1.733 & 1.628 & 1.530 & 1.438 & 1.353 \\
\hline-1.250 & 5.277 & 4.904 & 4.564 & 4.252 & 3.965 & 3.701 & 3.457 & 3.232 & 3.023 & 2.829 & 2.650 & 2.483 & 2.327 & 2.183 & 2.048 & 1.922 & 1.805 & 1.695 & 1.592 & 1.496 & 1.406 \\
\hline-1.300 & 5.572 & 5.170 & 4.806 & 4.472 & 4.166 & 3.884 & 3.625 & 3.386 & 3.164 & 2.960 & 2.770 & 2.594 & 2.430 & 2.277 & 2.136 & 2.003 & 1.880 & 1.765 & 1.657 & 1.557 & 1.463 \\
\hline-1.350 & 5.891 & 5.459 & 5.066 & 4.708 & 4.381 & 4.080 & 3.804 & 3.550 & 3.315 & 3.098 & 2.897 & 2.711 & 2.538 & 2.377 & 2.228 & 2.089 & 1.959 & 1.839 & 1.726 & 1.620 & 1.522 \\
\hline-1.400 & 6.237 & 5.771 & 5.347 & 4.962 & 4.611 & 4.290 & 3.995 & 3.724 & 3.475 & 3.245 & 3.032 & 2.835 & 2.652 & 2.483 & 2.326 & 2.179 & 2.043 & 1.916 & 1.798 & 1.687 & 1.584 \\
\hline-1.450 & 6.615 & 6.108 & 5.650 & 5.236 & 4.858 & 4.514 & 4.199 & 3.911 & 3.645 & 3.401 & 3.175 & 2.967 & 2.774 & 2.595 & 2.429 & 2.275 & 2.131 & 1.998 & 1.873 & 1.758 & 1.649 \\
\hline-1.500 & 7.027 & 6.475 & 5.979 & 5.531 & 5.125 & 4.755 & 4.418 & 4.110 & 3.827 & 3.567 & 3.327 & 3.106 & 2.902 & 2.713 & 2.538 & 2.375 & 2.224 & 2.084 & 1.953 & 1.831 & 1.718 \\
\hline-1.550 & 7.478 & 6.876 & 6.336 & 5.851 & 5.412 & 5.015 & 4.653 & 4.323 & 4.021 & 3.744 & 3.489 & 3.255 & 3.038 & 2.838 & 2.653 & 2.482 & 2.322 & 2.175 & 2.037 & 1.909 & 1.790 \\
\hline-1.600 & 7.974 & 7.314 & 6.725 & 6.198 & 5.724 & 5.295 & 4.906 & 4.552 & 4.229 & 3.933 & 3.662 & 3.413 & 3.183 & 2.971 & 2.775 & 2.594 & 2.426 & 2.270 & 2.126 & 1.991 & 1.866 \\
\hline-1.650 & 8.522 & 7.795 & 7.150 & 6.576 & 6.061 & 5.597 & 5.178 & 4.798 & 4.452 & 4.136 & 3.847 & 3.581 & 3.337 & 3.112 & 2.905 & 2.713 & 2.536 & 2.372 & 2.219 & 2.077 & 1.946 \\
\hline-1.800 & 10.566 & 9.567 & 8.699 & 7.938 & 7.267 & 6.670 & 6.138 & 5.659 & 5.228 & 4.837 & 4.482 & 4.159 & 3.863 & 3.593 & 3.345 & 3.116 & 2.906 & 2.712 & 2.533 & 2.367 & 2.213 \\
\hline-1.850 & 11.423 & 10.299 & 9.330 & 8.488 & 7.749 & 7.095 & 6.514 & 5.995 & 5.528 & 5.107 & 4.726 & 4.379 & 4.064 & 3.775 & 3.511 & 3.268 & 3.045 & 2.839 & 2.650 & 2.474 & 2.312 \\
\hline-1.900 & 12.397 & 11.123 & 10.036 & 9.098 & 8.280 & 7.562 & 6.926 & 6.361 & 5.855 & 5.400 & 4.989 & 4.617 & 4.278 & 3.970 & 3.688 & 3.430 & 3.193 & 2.975 & 2.774 & 2.588 & 2.417 \\
\hline-1.950 & 13.512 & 12.057 & 10.829 & 9.778 & 8.869 & 8.076 & 7.378 & 6.760 & 6.209 & 5.716 & 5.272 & 4.872 & 4.509 & 4.179 & 3.877 & 3.602 & 3.350 & 3.118 & 2.905 & 2.709 & 2.528 \\
\hline-2.000 & 14.802 & 13.125 & 11.726 & 10.541 & 9.524 & 8.644 & 7.875 & 7.197 & 6.596 & 6.060 & 5.580 & 5.147 & 4.757 & 4.403 & 4.080 & 3.786 & 3.518 & 3.271 & 3.045 & 2.837 & 2.645 \\
\hline
\end{tabular}




\begin{tabular}{|c|c|c|c|c|c|c|c|c|c|c|c|c|c|c|c|c|c|c|c|c|c|}
\hline & & & & & & & & & & & $l=h$ & & & & & & & & & & \\
\hline$\phi_{1}=\phi_{2}$ & 1.000 & 1.050 & 1.100 & 1.150 & 1.200 & 1.250 & 1.300 & 1.350 & 1.400 & 1.450 & 1.500 & 1.550 & 1.600 & 1.650 & 1.700 & 1.750 & 1.800 & 1.850 & 1.900 & 1.950 & 2.000 \\
\hline 0.000 & 1.746 & 1.675 & 1.606 & 1.541 & 1.478 & 1.418 & 1.360 & 1.305 & 1.252 & 1.201 & 1.152 & 1.105 & 1.060 & 1.016 & 0.975 & 0.935 & 0.897 & 0.861 & 0.826 & 0.792 & 0.760 \\
\hline-0.050 & 1.798 & 1.725 & 1.654 & 1.586 & 1.521 & 1.459 & 1.399 & 1.342 & 1.286 & 1.234 & 1.184 & 1.135 & 1.089 & 1.045 & 1.002 & 0.961 & 0.922 & 0.884 & 0.848 & 0.813 & 0.780 \\
\hline-0.100 & 1.853 & 1.777 & 1.703 & 1.633 & 1.566 & 1.502 & 1.440 & 1.381 & 1.324 & 1.269 & 1.217 & 1.167 & 1.120 & 1.073 & 1.030 & 0.987 & 0.947 & 0.908 & 0.871 & 0.835 & 0.801 \\
\hline-0.150 & 1.910 & 1.831 & 1.755 & 1.682 & 1.612 & 1.546 & 1.482 & 1.421 & 1.362 & 1.306 & 1.252 & 1.200 & 1.151 & 1.104 & 1.058 & 1.014 & 0.973 & 0.933 & 0.894 & 0.857 & 0.822 \\
\hline-0.200 & 1.969 & 1.887 & 1.808 & 1.733 & 1.660 & 1.591 & 1.525 & 1.462 & 1.401 & 1.343 & 1.287 & 1.234 & 1.183 & 1.134 & 1.087 & 1.042 & 0.999 & 0.959 & 0.919 & 0.881 & 0.844 \\
\hline-0.250 & 2.031 & 1.945 & 1.863 & 1.785 & 1.710 & 1.639 & 1.570 & 1.505 & 1.442 & 1.382 & 1.324 & 1.269 & 1.217 & 1.166 & 1.118 & 1.071 & 1.027 & 0.985 & 0.944 & 0.905 & 0.867 \\
\hline-0.300 & 2.094 & 2.005 & 1.921 & 1.840 & 1.762 & 1.688 & 1.617 & 1.549 & 1.484 & 1.422 & 1.363 & 1.306 & 1.251 & 1.199 & 1.149 & 1.102 & 1.056 & 1.012 & 0.970 & 0.930 & 0.891 \\
\hline-0.350 & 2.161 & 2.069 & 1.981 & 1.897 & 1.816 & 1.739 & 1.665 & 1.596 & 1.528 & 1.464 & 1.402 & 1.343 & 1.287 & 1.234 & 1.182 & 1.133 & 1.085 & 1.040 & 0.997 & 0.955 & 0.915 \\
\hline-0.400 & 2.231 & 2.134 & 2.043 & 1.956 & 1.872 & 1.792 & 1.716 & 1.643 & 1.574 & 1.507 & 1.444 & 1.383 & 1.324 & 1.269 & 1.216 & 1.165 & 1.116 & 1.069 & 1.024 & 0.982 & 0.941 \\
\hline-0.450 & 2.303 & 2.204 & 2.108 & 2.017 & 1.930 & 1.848 & 1.769 & 1.693 & 1.621 & 1.552 & 1.486 & 1.423 & 1.362 & 1.305 & 1.250 & 1.198 & 1.148 & 1.099 & 1.053 & 1.009 & 0.967 \\
\hline-0.500 & 2.379 & 2.275 & 2.176 & 2.081 & 1.991 & 1.905 & 1.823 & 1.745 & 1.670 & 1.599 & 1.530 & 1.465 & 1.403 & 1.343 & 1.287 & 1.232 & 1.180 & 1.130 & 1.083 & 1.037 & 0.993 \\
\hline-0.550 & 2.458 & 2.349 & 2.247 & 2.148 & 2.054 & 1.965 & 1.880 & 1.799 & 1.721 & 1.647 & 1.576 & 1.509 & 1.444 & 1.382 & 1.324 & 1.268 & 1.214 & 1.162 & 1.113 & 1.066 & 1.021 \\
\hline-0.600 & 2.541 & 2.428 & 2.320 & 2.218 & 2.120 & 2.026 & 1.939 & 1.854 & 1.774 & 1.697 & 1.624 & 1.554 & 1.487 & 1.423 & 1.363 & 1.305 & 1.249 & 1.196 & 1.145 & 1.096 & 1.050 \\
\hline-0.650 & 2.628 & 2.510 & 2.398 & 2.291 & 2.189 & 2.092 & 2.000 & 1.913 & 1.829 & 1.749 & 1.673 & 1.601 & 1.532 & 1.466 & 1.403 & 1.343 & 1.285 & 1.230 & 1.178 & 1.128 & 1.080 \\
\hline-0.700 & 2.719 & 2.595 & 2.478 & 2.367 & 2.260 & 2.160 & 2.064 & 1.973 & 1.886 & 1.804 & 1.725 & 1.650 & 1.578 & 1.510 & 1.444 & 1.382 & 1.323 & 1.266 & 1.212 & 1.160 & 1.110 \\
\hline-0.750 & 2.815 & 2.685 & 2.562 & 2.446 & 2.336 & 2.231 & 2.131 & 2.036 & 1.946 & 1.860 & 1.778 & 1.700 & 1.626 & 1.555 & 1.488 & 1.423 & 1.362 & 1.303 & 1.247 & 1.193 & 1.142 \\
\hline-0.800 & 2.915 & 2.779 & 2.651 & 2.529 & 2.414 & 2.304 & 2.200 & 2.102 & 2.008 & 1.919 & 1.834 & 1.753 & 1.676 & 1.602 & 1.532 & 1.466 & 1.402 & 1.341 & 1.283 & 1.228 & 1.175 \\
\hline-0.850 & 3.020 & 2.878 & 2.744 & 2.616 & 2.496 & 2.382 & 2.272 & 2.170 & 2.073 & 1.980 & 1.892 & 1.808 & 1.728 & 1.651 & 1.579 & 1.510 & 1.444 & 1.381 & 1.321 & 1.264 & 1.209 \\
\hline-0.900 & 3.131 & 2.981 & 2.841 & 2.708 & 2.581 & 2.462 & 2.349 & 2.242 & 2.140 & 2.044 & 1.952 & 1.865 & 1.782 & 1.702 & 1.627 & 1.556 & 1.487 & 1.422 & 1.360 & 1.301 & 1.244 \\
\hline-0.950 & 3.248 & 3.091 & 2.943 & 2.803 & 2.671 & 2.547 & 2.429 & 2.317 & 2.211 & 2.110 & 2.015 & 1.924 & 1.838 & 1.755 & 1.677 & 1.603 & 1.532 & 1.465 & 1.400 & 1.339 & 1.281 \\
\hline-1.000 & 3.371 & 3.205 & 3.050 & 2.903 & 2.766 & 2.635 & 2.512 & 2.395 & 2.284 & 2.180 & 2.080 & 1.986 & 1.896 & 1.811 & 1.730 & 1.652 & 1.579 & 1.509 & 1.442 & 1.379 & 1.319 \\
\hline-1.050 & 3.500 & 3.326 & 3.163 & 3.009 & 2.864 & 2.728 & 2.599 & 2.477 & 2.361 & 2.252 & 2.148 & 2.050 & 1.957 & 1.868 & 1.784 & 1.704 & 1.628 & 1.555 & 1.486 & 1.420 & 1.358 \\
\hline-1.100 & 3.638 & 3.454 & 3.282 & 3.120 & 2.968 & 2.825 & 2.690 & 2.562 & 2.442 & 2.328 & 2.220 & 2.117 & 2.020 & 1.928 & 1.840 & 1.757 & 1.678 & 1.603 & 1.531 & 1.463 & 1.398 \\
\hline-1.150 & 3.783 & 3.589 & 3.407 & 3.237 & 3.077 & 2.927 & 2.785 & 2.652 & 2.526 & 2.407 & 2.294 & 2.187 & 2.086 & 1.990 & 1.899 & 1.813 & 1.731 & 1.653 & 1.578 & 1.508 & 1.441 \\
\hline-1.200 & 3.937 & 3.732 & 3.540 & 3.361 & 3.192 & 3.034 & 2.886 & 2.746 & 2.614 & 2.489 & 2.372 & 2.260 & 2.155 & 2.055 & 1.960 & 1.870 & 1.785 & 1.704 & 1.627 & 1.554 & 1.484 \\
\hline-1.250 & 4.101 & 3.884 & 3.680 & 3.491 & 3.313 & 3.148 & 2.991 & 2.845 & 2.706 & 2.576 & 2.453 & 2.337 & 2.227 & 2.123 & 2.024 & 1.931 & 1.842 & 1.758 & 1.678 & 1.602 & 1.530 \\
\hline-1.300 & 4.275 & 4.044 & 3.829 & 3.629 & 3.442 & 3.267 & 3.103 & 2.948 & 2.803 & 2.667 & 2.538 & 2.417 & 2.302 & 2.193 & 2.091 & 1.993 & 1.901 & 1.814 & 1.731 & 1.652 & 1.577 \\
\hline-1.350 & 4.462 & 4.215 & 3.987 & 3.775 & 3.577 & 3.392 & 3.220 & 3.057 & 2.905 & 2.762 & 2.627 & 2.500 & 2.381 & 2.267 & 2.160 & 2.059 & 1.963 & 1.872 & 1.786 & 1.704 & 1.626 \\
\hline-1.400 & 4.660 & 4.397 & 4.155 & 3.930 & 3.720 & 3.525 & 3.343 & 3.172 & 3.012 & 2.862 & 2.721 & 2.588 & 2.463 & 2.345 & 2.233 & 2.127 & 2.027 & 1.933 & 1.843 & 1.758 & 1.677 \\
\hline-1.450 & 4.873 & 4.592 & 4.333 & 4.094 & 3.872 & 3.666 & 3.473 & 3.293 & 3.125 & 2.967 & 2.819 & 2.680 & 2.549 & 2.425 & 2.309 & 2.199 & 2.094 & 1.996 & 1.902 & 1.814 & 1.730 \\
\hline-1.500 & 5.100 & 4.800 & 4.524 & 4.269 & 4.033 & 3.814 & 3.611 & 3.421 & 3.244 & 3.078 & 2.923 & 2.777 & 2.639 & 2.510 & 2.388 & 2.273 & 2.164 & 2.062 & 1.964 & 1.872 & 1.785 \\
\hline-1.550 & 5.347 & 5.023 & 4.727 & 4.455 & 4.204 & 3.972 & 3.757 & 3.556 & 3.369 & 3.195 & 3.031 & 2.878 & 2.734 & 2.599 & 2.471 & 2.351 & 2.238 & 2.131 & 2.029 & 1.933 & 1.843 \\
\hline-1.600 & 5.612 & 5.263 & 4.946 & 4.655 & 4.387 & 4.140 & 3.911 & 3.699 & 3.502 & 3.318 & 3.146 & 2.985 & 2.833 & 2.692 & 2.558 & 2.433 & 2.314 & 2.202 & 2.097 & 1.997 & 1.903 \\
\hline-1.650 & 5.898 & 5.522 & 5.180 & 4.868 & 4.582 & 4.319 & 4.076 & 3.851 & 3.642 & 3.448 & 3.266 & 3.097 & 2.938 & 2.789 & 2.649 & 2.518 & 2.394 & 2.278 & 2.167 & 2.063 & 1.965 \\
\hline-1.700 & 6.209 & 5.801 & 5.432 & 5.097 & 4.790 & 4.509 & 4.251 & 4.012 & 3.790 & 3.585 & 3.393 & 3.215 & 3.048 & 2.892 & 2.745 & 2.607 & 2.478 & 2.356 & 2.241 & 2.133 & 2.030 \\
\hline-1.750 & 6.548 & 6.104 & 5.704 & 5.342 & 5.014 & 4.713 & 4.437 & 4.183 & 3.948 & 3.730 & 3.528 & 3.340 & 3.164 & 3.000 & 2.846 & 2.701 & 2.566 & 2.438 & 2.318 & 2.205 & 2.098 \\
\hline-1.800 & 6.918 & 6.433 & 5.999 & 5.608 & 5.253 & 4.931 & 4.636 & 4.365 & 4.115 & 3.884 & 3.670 & 3.471 & 3.286 & 3.113 & 2.952 & 2.800 & 2.658 & 2.525 & 2.399 & 2.281 & 2.169 \\
\hline-1.850 & 7.324 & 6.792 & 6.319 & 5.894 & 5.512 & 5.165 & 4.849 & 4.559 & 4.293 & 4.048 & 3.821 & 3.611 & 3.415 & 3.233 & 3.063 & 2.904 & 2.755 & 2.615 & 2.484 & 2.360 & 2.244 \\
\hline-1.900 & 7.772 & 7.186 & 6.667 & 6.205 & 5.791 & 5.417 & 5.077 & 4.767 & 4.483 & 4.222 & 3.981 & 3.758 & 3.552 & 3.359 & 3.180 & 3.013 & 2.856 & 2.710 & 2.572 & 2.443 & 2.321 \\
\hline-1.950 & 8.269 & 7.619 & 7.049 & 6.544 & 6.093 & 5.689 & 5.322 & 4.990 & 4.686 & 4.408 & 4.151 & 3.915 & 3.696 & 3.493 & 3.304 & 3.128 & 2.963 & 2.809 & 2.665 & 2.530 & 2.403 \\
\hline-2.000 & 8.822 & 8.098 & 7.468 & 6.914 & 6.422 & 5.983 & 5.587 & 5.229 & 4.903 & 4.606 & 4.333 & 4.081 & 3.849 & 3.634 & 3.435 & 3.249 & 3.076 & 2.914 & 2.763 & 2.621 & 2.488 \\
\hline
\end{tabular}




\begin{tabular}{|c|c|c|c|c|c|c|c|c|c|c|c|c|c|c|c|c|c|c|c|c|c|}
\hline & & & & & & & & & & & $l=h$ & & & & & & & & & & \\
\hline$\phi_{1}=\phi_{2}$ & 1.000 & 1.050 & 1.100 & 1.150 & 1.200 & 1.250 & 1.300 & 1.350 & 1.400 & 1.450 & 1.500 & 1.550 & 1.600 & 1.650 & 1.700 & 1.750 & 1.800 & 1.850 & 1.900 & 1.950 & 2.000 \\
\hline 0.000 & 1.315 & 1.243 & 1.175 & 1.111 & 1.051 & 0.993 & 0.939 & 0.888 & 0.840 & 0.794 & 0.751 & 0.710 & 0.671 & 0.635 & 0.600 & 0.567 & 0.536 & 0.507 & 0.479 & 0.453 & 0.429 \\
\hline-0.050 & 1.366 & 1.291 & 1.220 & 1.153 & 1.091 & 1.031 & 0.974 & 0.921 & 0.871 & 0.823 & 0.778 & 0.736 & 0.695 & 0.657 & 0.621 & 0.587 & 0.555 & 0.525 & 0.496 & 0.469 & 0.443 \\
\hline-0.100 & 1.420 & 1.341 & 1.267 & 1.198 & 1.132 & 1.070 & 1.011 & 0.955 & 0.903 & 0.853 & 0.806 & 0.762 & 0.720 & 0.681 & 0.644 & 0.608 & 0.575 & 0.543 & 0.513 & 0.485 & 0.459 \\
\hline-0.150 & 1.476 & 1.394 & 1.317 & 1.244 & 1.175 & 1.110 & 1.049 & 0.991 & 0.936 & 0.885 & 0.836 & 0.790 & 0.746 & 0.705 & 0.666 & 0.630 & 0.595 & 0.562 & 0.532 & 0.502 & 0.475 \\
\hline-0.200 & 1.535 & 1.449 & 1.369 & 1.293 & 1.221 & 1.153 & 1.089 & 1.029 & 0.971 & 0.918 & 0.867 & 0.819 & 0.774 & 0.731 & 0.691 & 0.652 & 0.616 & 0.582 & 0.550 & 0.520 & 0.491 \\
\hline-0.250 & 1.597 & 1.508 & 1.423 & 1.343 & 1.268 & 1.197 & 1.131 & 1.068 & 1.008 & 0.952 & 0.899 & 0.849 & 0.802 & 0.758 & 0.716 & 0.676 & 0.639 & 0.603 & 0.570 & 0.538 & 0.509 \\
\hline-0.300 & 1.663 & 1.569 & 1.480 & 1.397 & 1.318 & 1.244 & 1.174 & 1.109 & 1.047 & 0.988 & 0.933 & 0.881 & 0.832 & 0.786 & 0.742 & 0.701 & 0.662 & 0.625 & 0.590 & 0.557 & 0.527 \\
\hline-0.350 & 1.731 & 1.633 & 1.540 & 1.453 & 1.370 & 1.293 & 1.220 & 1.151 & 1.087 & 1.026 & 0.968 & 0.914 & 0.863 & 0.814 & 0.769 & 0.726 & 0.686 & 0.647 & 0.611 & 0.577 & 0.545 \\
\hline-0.400 & 1.804 & 1.700 & 1.603 & 1.511 & 1.425 & 1.344 & 1.268 & 1.196 & 1.129 & 1.065 & 1.005 & 0.949 & 0.895 & 0.845 & 0.797 & 0.753 & 0.711 & 0.671 & 0.633 & 0.598 & 0.565 \\
\hline-0.450 & 1.880 & 1.771 & 1.669 & 1.573 & 1.483 & 1.398 & 1.318 & 1.243 & 1.173 & 1.106 & 1.044 & 0.984 & 0.929 & 0.876 & 0.827 & 0.781 & 0.737 & 0.695 & 0.656 & 0.620 & 0.585 \\
\hline-0.500 & 1.960 & 1.846 & 1.739 & 1.638 & 1.543 & 1.455 & 1.371 & 1.292 & 1.219 & 1.149 & 1.084 & 1.022 & 0.964 & 0.909 & 0.858 & 0.810 & 0.764 & 0.721 & 0.680 & 0.642 & 0.606 \\
\hline-0.550 & 2.045 & 1.924 & 1.812 & 1.706 & 1.606 & 1.514 & 1.426 & 1.344 & 1.266 & 1.194 & 1.126 & 1.062 & 1.001 & 0.944 & 0.890 & 0.840 & 0.792 & 0.748 & 0.705 & 0.666 & 0.628 \\
\hline-0.600 & 2.135 & 2.008 & 1.889 & 1.778 & 1.674 & 1.576 & 1.484 & 1.398 & 1.317 & 1.242 & 1.170 & 1.103 & 1.040 & 0.980 & 0.924 & 0.872 & 0.822 & 0.775 & 0.731 & 0.690 & 0.651 \\
\hline-0.650 & 2.229 & 2.095 & 1.971 & 1.854 & 1.744 & 1.642 & 1.545 & 1.455 & 1.370 & 1.291 & 1.216 & 1.146 & 1.080 & 1.018 & 0.959 & 0.905 & 0.853 & 0.804 & 0.759 & 0.715 & 0.675 \\
\hline-0.700 & 2.330 & 2.188 & 2.057 & 1.934 & 1.819 & 1.711 & 1.609 & 1.515 & 1.426 & 1.343 & 1.265 & 1.191 & 1.122 & 1.057 & 0.996 & 0.939 & 0.885 & 0.835 & 0.787 & 0.742 & 0.700 \\
\hline-0.750 & 2.436 & 2.287 & 2.148 & 2.018 & 1.896 & 1.783 & 1.677 & 1.578 & 1.485 & 1.397 & 1.315 & 1.239 & 1.166 & 1.099 & 1.035 & 0.975 & 0.919 & 0.866 & 0.816 & 0.770 & 0.726 \\
\hline-0.800 & 2.549 & 2.391 & 2.244 & 2.107 & 1.979 & 1.860 & 1.748 & 1.644 & 1.546 & 1.455 & 1.369 & 1.288 & 1.213 & 1.142 & 1.076 & 1.013 & 0.954 & 0.899 & 0.847 & 0.799 & 0.753 \\
\hline-0.850 & 2.669 & 2.502 & 2.346 & 2.201 & 2.067 & 1.941 & 1.823 & 1.714 & 1.611 & 1.515 & 1.425 & 1.341 & 1.262 & 1.187 & 1.118 & 1.053 & 0.991 & 0.934 & 0.880 & 0.829 & 0.781 \\
\hline-0.900 & 2.796 & 2.619 & 2.454 & 2.301 & 2.159 & 2.026 & 1.903 & 1.787 & 1.679 & 1.578 & 1.484 & 1.395 & 1.313 & 1.235 & 1.162 & 1.094 & 1.030 & 0.970 & 0.913 & 0.860 & 0.811 \\
\hline-0.950 & 2.932 & 2.744 & 2.569 & 2.407 & 2.256 & 2.117 & 1.986 & 1.865 & 1.751 & 1.645 & 1.546 & 1.453 & 1.366 & 1.285 & 1.209 & 1.137 & 1.071 & 1.008 & 0.949 & 0.893 & 0.841 \\
\hline-1.000 & 3.077 & 2.877 & 2.691 & 2.520 & 2.360 & 2.212 & 2.075 & 1.946 & 1.827 & 1.715 & 1.611 & 1.514 & 1.423 & 1.337 & 1.258 & 1.183 & 1.113 & 1.047 & 0.986 & 0.928 & 0.874 \\
\hline-1.050 & 3.232 & 3.018 & 2.821 & 2.639 & 2.470 & 2.314 & 2.168 & 2.033 & 1.907 & 1.789 & 1.680 & 1.578 & 1.482 & 1.393 & 1.309 & 1.231 & 1.157 & 1.089 & 1.024 & 0.964 & 0.907 \\
\hline-1.100 & 3.397 & 3.170 & 2.960 & 2.766 & 2.587 & 2.421 & 2.267 & 2.124 & 1.991 & 1.868 & 1.752 & 1.645 & 1.544 & 1.451 & 1.363 & 1.281 & 1.204 & 1.132 & 1.065 & 1.002 & 0.943 \\
\hline-1.150 & 3.576 & 3.332 & 3.108 & 2.902 & 2.712 & 2.536 & 2.373 & 2.221 & 2.081 & 1.950 & 1.829 & 1.716 & 1.610 & 1.511 & 1.419 & 1.333 & 1.253 & 1.178 & 1.107 & 1.041 & 0.980 \\
\hline-1.200 & 3.767 & 3.506 & 3.267 & 3.047 & 2.844 & 2.657 & 2.484 & 2.324 & 2.176 & 2.038 & 1.910 & 1.790 & 1.679 & 1.576 & 1.479 & 1.389 & 1.305 & 1.226 & 1.152 & 1.083 & 1.018 \\
\hline-1.250 & 3.973 & 3.692 & 3.436 & 3.201 & 2.985 & 2.786 & 2.603 & 2.433 & 2.276 & 2.130 & 1.995 & 1.869 & 1.752 & 1.643 & 1.542 & 1.447 & 1.359 & 1.276 & 1.199 & 1.126 & 1.059 \\
\hline-1.300 & 4.195 & 3.893 & 3.618 & 3.367 & 3.136 & 2.924 & 2.729 & 2.549 & 2.382 & 2.228 & 2.085 & 1.953 & 1.829 & 1.715 & 1.608 & 1.508 & 1.415 & 1.329 & 1.248 & 1.172 & 1.101 \\
\hline-1.350 & 4.436 & 4.110 & 3.814 & 3.545 & 3.298 & 3.072 & 2.864 & 2.672 & 2.496 & 2.332 & 2.181 & 2.041 & 1.911 & 1.790 & 1.677 & 1.573 & 1.475 & 1.384 & 1.299 & 1.220 & 1.146 \\
\hline-1.400 & 4.697 & 4.345 & 4.026 & 3.736 & 3.471 & 3.230 & 3.008 & 2.804 & 2.616 & 2.443 & 2.283 & 2.134 & 1.997 & 1.869 & 1.751 & 1.641 & 1.538 & 1.443 & 1.353 & 1.270 & 1.193 \\
\hline-1.450 & 4.981 & 4.599 & 4.254 & 3.942 & 3.658 & 3.399 & 3.162 & 2.944 & 2.744 & 2.560 & 2.390 & 2.233 & 2.088 & 1.954 & 1.829 & 1.713 & 1.605 & 1.504 & 1.410 & 1.323 & 1.242 \\
\hline-1.500 & 5.291 & 4.875 & 4.501 & 4.164 & 3.858 & 3.580 & 3.326 & 3.094 & 2.881 & 2.685 & 2.505 & 2.339 & 2.185 & 2.043 & 1.911 & 1.788 & 1.675 & 1.569 & 1.470 & 1.379 & 1.293 \\
\hline-1.550 & 5.630 & 5.176 & 4.770 & 4.405 & 4.075 & 3.776 & 3.503 & 3.255 & 3.027 & 2.819 & 2.627 & 2.450 & 2.287 & 2.137 & 1.998 & 1.868 & 1.749 & 1.637 & 1.534 & 1.437 & 1.348 \\
\hline-1.600 & 6.004 & 5.506 & 5.063 & 4.666 & 4.309 & 3.986 & 3.694 & 3.427 & 3.184 & 2.961 & 2.757 & 2.569 & 2.397 & 2.237 & 2.090 & 1.953 & 1.827 & 1.709 & 1.600 & 1.499 & 1.405 \\
\hline-1.650 & 6.416 & 5.868 & 5.383 & 4.951 & 4.563 & 4.214 & 3.899 & 3.612 & 3.352 & 3.114 & 2.896 & 2.696 & 2.512 & 2.343 & 2.187 & 2.043 & 1.909 & 1.786 & 1.671 & 1.564 & 1.465 \\
\hline-1.700 & 6.873 & 6.268 & 5.734 & 5.261 & 4.839 & 4.461 & 4.120 & 3.812 & 3.532 & 3.277 & 3.045 & 2.832 & 2.636 & 2.456 & 2.291 & 2.138 & 1.997 & 1.866 & 1.745 & 1.633 & 1.528 \\
\hline-1.750 & 7.383 & 6.710 & 6.121 & 5.602 & 5.141 & 4.729 & 4.360 & 4.027 & 3.726 & 3.453 & 3.204 & 2.976 & 2.768 & 2.577 & 2.401 & 2.239 & 2.089 & 1.951 & 1.824 & 1.705 & 1.595 \\
\hline-1.800 & 7.955 & 7.203 & 6.549 & 5.976 & 5.471 & 5.022 & 4.621 & 4.261 & 3.936 & 3.642 & 3.374 & 3.131 & 2.909 & 2.705 & 2.518 & 2.346 & 2.188 & 2.042 & 1.907 & 1.782 & 1.666 \\
\hline-1.850 & 8.600 & 7.754 & 7.024 & 6.390 & 5.834 & 5.342 & 4.905 & 4.514 & 4.162 & 3.845 & 3.558 & 3.297 & 3.059 & 2.842 & 2.643 & 2.460 & 2.292 & 2.138 & 1.995 & 1.863 & 1.741 \\
\hline-1.900 & 9.333 & 8.374 & 7.556 & 6.849 & 6.234 & 5.693 & 5.215 & 4.789 & 4.408 & 4.065 & 3.756 & 3.476 & 3.221 & 2.989 & 2.777 & 2.582 & 2.404 & 2.239 & 2.088 & 1.949 & 1.819 \\
\hline-1.950 & 10.173 & 9.078 & 8.153 & 7.361 & 6.677 & 6.080 & 5.555 & 5.089 & 4.675 & 4.303 & 3.970 & 3.668 & 3.394 & 3.146 & 2.919 & 2.712 & 2.522 & 2.348 & 2.187 & 2.039 & 1.903 \\
\hline-2.000 & 11.144 & 9.881 & 8.828 & 7.936 & 7.171 & 6.508 & 5.929 & 5.418 & 4.966 & 4.562 & 4.201 & 3.875 & 3.581 & 3.315 & $\begin{array}{l}3.072 \\
2\end{array}$ & 2.851 & 2.648 & 2.463 & 2.293 & 2.136 & 1.992 \\
\hline
\end{tabular}




\begin{tabular}{|c|c|c|c|c|c|c|c|c|c|c|c|c|c|c|c|c|c|c|c|c|c|}
\hline & & & & & & & & & & & $l=h$ & & & & & & & & & & \\
\hline$\phi_{1}=\phi_{2}$ & 1.000 & 1.050 & 1.100 & 1.150 & 1.200 & 1.250 & 1.300 & 1.350 & 1.400 & 1.450 & 1.500 & 1.550 & 1.600 & 1.650 & 1.700 & 1.750 & 1.800 & 1.850 & 1.900 & 1.950 & 2.000 \\
\hline 0.000 & 1.315 & 1.261 & 1.210 & 1.160 & 1.113 & 1.068 & 1.024 & 0.982 & 0.942 & 0.904 & 0.867 & 0.832 & 0.798 & 0.765 & 0.734 & 0.704 & 0.675 & 0.648 & 0.621 & 0.596 & 0.572 \\
\hline-0.050 & 1.354 & 1.298 & 1.245 & 1.194 & 1.145 & 1.099 & 1.054 & 1.010 & 0.969 & 0.929 & 0.892 & 0.855 & 0.820 & 0.786 & 0.754 & 0.723 & 0.694 & 0.665 & 0.638 & 0.612 & 0.587 \\
\hline-0.100 & 1.395 & 1.337 & 1.283 & 1.230 & 1.179 & 1.130 & 1.084 & 1.040 & 0.997 & 0.956 & 0.917 & 0.879 & 0.843 & 0.808 & 0.775 & 0.743 & 0.713 & 0.684 & 0.655 & 0.629 & 0.603 \\
\hline-0.150 & 1.438 & 1.378 & 1.321 & 1.266 & 1.214 & 1.164 & 1.116 & 1.070 & 1.026 & 0.983 & 0.943 & 0.904 & 0.866 & 0.831 & 0.796 & 0.764 & 0.732 & 0.702 & 0.673 & 0.646 & 0.619 \\
\hline-0.200 & 1.482 & 1.420 & 1.361 & 1.304 & 1.250 & 1.198 & 1.148 & 1.101 & 1.055 & 1.011 & 0.969 & 0.929 & 0.891 & 0.854 & 0.819 & 0.785 & 0.752 & 0.721 & 0.692 & 0.663 & 0.636 \\
\hline-0.250 & 1.529 & 1.464 & 1.403 & 1.344 & 1.288 & 1.234 & 1.182 & 1.133 & 1.086 & 1.041 & 0.997 & 0.956 & 0.916 & 0.878 & 0.842 & 0.807 & 0.773 & 0.741 & 0.711 & 0.681 & 0.653 \\
\hline-0.300 & 1.577 & 1.510 & 1.446 & 1.385 & 1.326 & 1.271 & 1.218 & 1.166 & 1.118 & 1.071 & 1.026 & 0.983 & 0.942 & 0.903 & 0.866 & 0.829 & 0.795 & 0.762 & 0.730 & 0.700 & 0.671 \\
\hline-0.350 & 1.627 & 1.557 & 1.491 & 1.428 & 1.367 & 1.309 & 1.254 & 1.201 & 1.151 & 1.103 & 1.056 & 1.012 & 0.969 & 0.929 & 0.890 & 0.853 & 0.817 & 0.783 & 0.750 & 0.719 & 0.689 \\
\hline-0.400 & 1.680 & 1.607 & 1.538 & 1.472 & 1.410 & 1.349 & 1.291 & 1.237 & 1.185 & 1.135 & 1.087 & 1.041 & 0.998 & 0.955 & 0.915 & 0.877 & 0.840 & 0.805 & 0.771 & 0.739 & 0.708 \\
\hline-0.450 & 1.734 & 1.659 & 1.587 & 1.519 & 1.453 & 1.391 & 1.332 & 1.275 & 1.220 & 1.169 & 1.119 & 1.072 & 1.026 & 0.983 & 0.941 & 0.902 & 0.864 & 0.828 & 0.793 & 0.760 & 0.728 \\
\hline-0.500 & 1.791 & 1.713 & 1.638 & 1.567 & 1.499 & 1.434 & 1.373 & 1.314 & 1.257 & 1.204 & 1.152 & 1.103 & 1.056 & 1.012 & 0.969 & 0.928 & 0.888 & 0.851 & 0.815 & 0.781 & 0.748 \\
\hline-0.550 & 1.851 & 1.769 & 1.691 & 1.617 & 1.547 & 1.479 & 1.415 & 1.354 & 1.296 & 1.240 & 1.187 & 1.136 & 1.088 & 1.041 & 0.997 & 0.954 & 0.914 & 0.875 & 0.838 & 0.803 & 0.769 \\
\hline-0.600 & 1.913 & 1.828 & 1.747 & 1.670 & 1.596 & 1.526 & 1.460 & 1.396 & 1.335 & 1.278 & 1.223 & 1.170 & 1.120 & 1.072 & 1.026 & 0.982 & 0.940 & 0.900 & 0.862 & 0.825 & 0.790 \\
\hline-0.650 & 1.979 & 1.890 & 1.805 & 1.725 & 1.648 & 1.575 & 1.506 & 1.440 & 1.377 & 1.317 & 1.260 & 1.205 & 1.153 & 1.104 & 1.056 & 1.011 & 0.968 & 0.926 & 0.887 & 0.849 & 0.813 \\
\hline-0.700 & 2.047 & 1.954 & 1.866 & 1.782 & 1.702 & 1.626 & 1.554 & 1.485 & 1.420 & 1.358 & 1.299 & 1.242 & 1.188 & 1.137 & 1.087 & 1.041 & 0.996 & 0.953 & 0.912 & 0.873 & 0.836 \\
\hline-0.750 & 2.119 & 2.021 & 1.929 & 1.841 & 1.758 & 1.679 & 1.604 & 1.533 & 1.465 & 1.400 & 1.339 & 1.280 & 1.224 & 1.171 & 1.120 & 1.071 & 1.025 & 0.981 & 0.939 & 0.898 & 0.860 \\
\hline-0.800 & 2.193 & 2.092 & 1.996 & 1.904 & 1.817 & 1.735 & 1.657 & 1.583 & 1.512 & 1.445 & 1.381 & 1.320 & 1.262 & 1.206 & 1.154 & 1.103 & 1.056 & 1.010 & 0.966 & 0.924 & 0.885 \\
\hline-0.850 & 2.274 & 2.167 & 2.065 & 1.969 & 1.879 & 1.793 & 1.711 & 1.634 & 1.561 & 1.491 & 1.424 & 1.361 & 1.301 & 1.243 & 1.189 & 1.137 & 1.087 & 1.040 & 0.994 & 0.951 & 0.910 \\
\hline-0.900 & 2.357 & 2.245 & 2.139 & 2.038 & 1.944 & 1.854 & 1.769 & 1.688 & 1.611 & 1.539 & 1.470 & 1.404 & 1.341 & 1.282 & 1.225 & 1.171 & 1.120 & 1.071 & 1.024 & 0.979 & 0.937 \\
\hline-0.950 & 2.445 & 2.327 & 2.215 & 2.110 & 2.011 & 1.917 & 1.828 & 1.744 & 1.664 & 1.589 & 1.517 & 1.448 & 1.383 & 1.322 & 1.263 & 1.207 & 1.154 & 1.103 & 1.054 & 1.008 & 0.964 \\
\hline-1.000 & 2.538 & 2.413 & 2.296 & 2.186 & 2.082 & 1.984 & 1.891 & 1.803 & 1.720 & 1.641 & 1.566 & 1.495 & 1.427 & 1.363 & 1.302 & 1.244 & 1.189 & 1.136 & 1.086 & 1.038 & 0.993 \\
\hline-1.050 & 2.635 & 2.504 & 2.381 & 2.266 & 2.156 & 2.054 & 1.957 & 1.865 & 1.778 & 1.695 & 1.617 & 1.543 & 1.473 & 1.406 & 1.343 & 1.283 & 1.225 & 1.171 & 1.119 & 1.069 & 1.022 \\
\hline-1.100 & 2.739 & 2.600 & 2.471 & 2.349 & 2.235 & 2.127 & 2.025 & 1.929 & 1.838 & 1.752 & 1.671 & 1.594 & 1.521 & 1.451 & 1.385 & 1.323 & 1.263 & 1.207 & 1.153 & 1.102 & 1.053 \\
\hline-1.150 & 2.848 & 2.702 & 2.565 & 2.437 & 2.317 & 2.204 & 2.097 & 1.997 & 1.902 & 1.812 & 1.727 & 1.647 & 1.570 & 1.498 & 1.430 & 1.365 & 1.303 & 1.244 & 1.188 & 1.135 & 1.085 \\
\hline-1.200 & 2.964 & 2.810 & 2.665 & 2.530 & 2.404 & 2.285 & 2.173 & 2.067 & 1.968 & 1.874 & 1.786 & 1.702 & 1.622 & 1.547 & 1.476 & 1.408 & 1.344 & 1.283 & 1.225 & 1.170 & 1.118 \\
\hline-1.250 & 3.088 & 2.924 & 2.771 & 2.628 & 2.495 & 2.370 & 2.252 & 2.142 & 2.038 & 1.939 & 1.847 & 1.759 & 1.677 & 1.598 & 1.524 & 1.454 & 1.387 & 1.323 & 1.263 & 1.206 & 1.152 \\
\hline-1.300 & 3.219 & 3.045 & 2.883 & 2.732 & 2.591 & 2.459 & 2.336 & 2.220 & 2.111 & 2.008 & 1.911 & 1.820 & 1.733 & 1.651 & 1.574 & 1.501 & 1.431 & 1.366 & 1.303 & 1.244 & 1.187 \\
\hline-1.350 & 3.359 & 3.174 & 3.002 & 2.842 & 2.693 & 2.554 & 2.424 & 2.302 & 2.187 & 2.080 & 1.978 & 1.883 & 1.792 & 1.707 & 1.626 & 1.550 & 1.478 & 1.409 & 1.344 & 1.283 & 1.224 \\
\hline-1.400 & 3.509 & 3.311 & 3.128 & 2.959 & 2.801 & 2.654 & 2.517 & 2.388 & 2.268 & 2.155 & 2.049 & 1.949 & 1.854 & 1.765 & 1.681 & 1.602 & 1.526 & 1.455 & 1.387 & 1.323 & 1.263 \\
\hline-1.450 & 3.669 & 3.457 & 3.262 & 3.082 & 2.915 & 2.760 & 2.615 & 2.480 & 2.353 & 2.234 & 2.123 & 2.018 & 1.919 & 1.826 & 1.738 & 1.655 & 1.577 & 1.503 & 1.432 & 1.366 & 1.303 \\
\hline-1.500 & 3.841 & 3.614 & 3.406 & 3.214 & 3.036 & 2.872 & 2.719 & 2.576 & 2.442 & 2.317 & 2.200 & 2.090 & 1.987 & 1.890 & 1.798 & 1.711 & 1.630 & 1.552 & 1.479 & 1.410 & 1.344 \\
\hline-1.550 & 4.026 & 3.782 & 3.559 & 3.354 & 3.165 & 2.991 & 2.828 & 2.677 & 2.537 & 2.405 & 2.282 & 2.167 & 2.058 & 1.956 & 1.860 & 1.770 & 1.685 & 1.604 & 1.528 & 1.456 & 1.387 \\
\hline-1.600 & 4.225 & 3.963 & 3.723 & 3.504 & 3.303 & 3.117 & 2.945 & 2.785 & 2.636 & 2.498 & 2.368 & 2.247 & 2.133 & 2.026 & 1.926 & 1.831 & 1.742 & 1.658 & 1.579 & 1.504 & 1.432 \\
\hline-1.650 & 4.441 & 4.157 & 3.900 & 3.665 & 3.450 & 3.251 & 3.069 & 2.899 & 2.742 & 2.596 & 2.459 & 2.331 & 2.212 & 2.100 & 1.995 & 1.896 & 1.803 & 1.715 & 1.632 & 1.554 & 1.479 \\
\hline-1.700 & 4.675 & 4.367 & 4.090 & 3.837 & 3.606 & 3.395 & 3.200 & 3.020 & 2.854 & 2.699 & 2.555 & 2.420 & 2.295 & 2.177 & 2.067 & 1.963 & 1.866 & 1.774 & 1.687 & 1.606 & 1.529 \\
\hline-1.750 & 4.930 & 4.595 & 4.294 & 4.022 & 3.775 & 3.548 & 3.340 & 3.149 & 2.972 & 2.808 & 2.656 & 2.514 & 2.382 & 2.258 & 2.143 & 2.034 & 1.932 & 1.836 & 1.745 & 1.660 & 1.580 \\
\hline-1.800 & 5.208 & 4.843 & 4.516 & 4.222 & 3.955 & 3.712 & 3.490 & 3.286 & 3.098 & 2.924 & 2.763 & 2.614 & 2.474 & 2.344 & 2.222 & 2.108 & 2.001 & 1.901 & 1.806 & 1.717 & 1.633 \\
\hline-1.850 & 5.514 & 5.114 & 4.757 & 4.438 & 4.150 & 3.889 & 3.650 & 3.433 & 3.232 & 3.048 & 2.877 & 2.718 & 2.571 & 2.434 & 2.306 & 2.186 & 2.074 & 1.969 & 1.870 & 1.777 & 1.689 \\
\hline-1.900 & 5.851 & 5.410 & 5.020 & 4.672 & 4.360 & 4.078 & 3.822 & 3.589 & 3.375 & 3.179 & 2.997 & 2.830 & 2.674 & 2.529 & 2.394 & 2.268 & 2.150 & 2.040 & 1.936 & 1.839 & 1.748 \\
\hline-1.950 & 6.225 & 5.736 & 5.307 & 4.927 & 4.588 & 4.283 & 4.007 & 3.757 & 3.528 & 3.318 & 3.125 & 2.947 & 2.783 & 2.630 & 2.487 & 2.355 & 2.231 & 2.115 & 2.006 & 1.905 & 1.809 \\
\hline-2.000 & 6.642 & 6.097 & 5.622 & 5.205 & 4.835 & 4.504 & 4.206 & 3.937 & 3.691 & 3.467 & 3.262 & 3.073 & 2.898 & 2.736 & 2.586 & 2.446 & 2.316 & 2.194 & 2.080 & 1.973 & 1.873 \\
\hline
\end{tabular}




\begin{tabular}{|c|c|c|c|c|c|c|c|c|c|c|c|c|c|c|c|c|c|c|c|c|c|}
\hline & & & & & & & & & & & $l=h$ & & & & & & & & & & \\
\hline$\phi_{1}=\phi_{2}$ & 1.000 & 1.050 & 1.100 & 1.150 & 1.200 & 1.250 & 1.300 & 1.350 & 1.400 & 1.450 & 1.500 & 1.550 & 1.600 & 1.650 & 1.700 & 1.750 & 1.800 & 1.850 & 1.900 & 1.950 & 2.000 \\
\hline 0.000 & 1.657 & 1.576 & 1.501 & 1.428 & 1.359 & 1.294 & 1.231 & 1.172 & 1.115 & 1.062 & 1.010 & 0.962 & 0.915 & 0.871 & 0.829 & 0.789 & 0.751 & 0.715 & 0.680 & 0.647 & 0.616 \\
\hline-0.050 & 1.714 & 1.631 & 1.552 & 1.477 & 1.405 & 1.337 & 1.272 & 1.211 & 1.152 & 1.096 & 1.043 & 0.993 & 0.945 & 0.899 & 0.856 & 0.814 & 0.775 & 0.737 & 0.702 & 0.668 & 0.636 \\
\hline-0.100 & 1.775 & 1.689 & 1.606 & 1.528 & 1.453 & 1.383 & 1.315 & 1.251 & 1.191 & 1.133 & 1.078 & 1.025 & 0.976 & 0.928 & 0.883 & 0.840 & 0.799 & 0.761 & 0.724 & 0.689 & 0.655 \\
\hline-0.150 & 1.839 & 1.748 & 1.663 & 1.581 & 1.504 & 1.430 & 1.360 & 1.294 & 1.230 & 1.171 & 1.113 & 1.059 & 1.007 & 0.958 & 0.912 & 0.867 & 0.825 & 0.785 & 0.747 & 0.710 & 0.676 \\
\hline-0.200 & 1.905 & 1.811 & 1.721 & 1.637 & 1.555 & 1.479 & 1.407 & 1.338 & 1.272 & 1.210 & 1.150 & 1.094 & 1.041 & 0.989 & 0.941 & 0.895 & 0.851 & 0.810 & 0.770 & 0.733 & 0.697 \\
\hline-0.250 & 1.974 & 1.876 & 1.783 & 1.694 & 1.610 & 1.531 & 1.455 & 1.383 & 1.315 & 1.250 & 1.189 & 1.130 & 1.075 & 1.022 & 0.972 & 0.924 & 0.879 & 0.836 & 0.795 & 0.756 & 0.719 \\
\hline-0.300 & 2.047 & 1.944 & 1.847 & 1.755 & 1.667 & 1.584 & 1.506 & 1.431 & 1.360 & 1.293 & 1.229 & 1.169 & 1.111 & 1.056 & 1.004 & 0.954 & 0.908 & 0.863 & 0.820 & 0.780 & 0.742 \\
\hline-0.350 & 2.123 & 2.015 & 1.914 & 1.818 & 1.726 & 1.640 & 1.558 & 1.481 & 1.407 & 1.337 & 1.271 & 1.208 & 1.148 & 1.091 & 1.037 & 0.986 & 0.937 & 0.891 & 0.847 & 0.805 & 0.766 \\
\hline-0.400 & 2.202 & 2.091 & 1.984 & 1.884 & 1.789 & 1.698 & 1.613 & 1.532 & 1.456 & 1.383 & 1.314 & 1.248 & 1.187 & 1.128 & 1.072 & 1.018 & 0.968 & 0.920 & 0.874 & 0.831 & 0.790 \\
\hline-0.450 & 2.286 & 2.169 & 2.058 & 1.953 & 1.854 & 1.760 & 1.671 & 1.586 & 1.507 & 1.431 & 1.359 & 1.291 & 1.227 & 1.165 & 1.107 & 1.052 & 1.000 & 0.950 & 0.903 & 0.858 & 0.816 \\
\hline-0.500 & 2.374 & 2.251 & 2.135 & 2.026 & 1.922 & 1.824 & 1.731 & 1.643 & 1.560 & 1.481 & 1.406 & 1.335 & 1.268 & 1.205 & 1.144 & 1.087 & 1.033 & 0.981 & 0.932 & 0.886 & 0.842 \\
\hline-0.550 & 2.466 & 2.338 & 2.216 & 2.100 & 1.993 & 1.890 & 1.794 & 1.702 & 1.615 & 1.533 & 1.455 & 1.382 & 1.312 & 1.246 & 1.183 & 1.124 & 1.067 & 1.014 & 0.963 & 0.915 & 0.869 \\
\hline-0.600 & 2.563 & 2.427 & 2.301 & 2.181 & 2.067 & 1.960 & 1.859 & 1.764 & 1.673 & 1.588 & 1.507 & 1.430 & 1.357 & 1.289 & 1.224 & 1.162 & 1.103 & 1.048 & 0.995 & 0.945 & 0.898 \\
\hline-0.650 & 2.665 & 2.524 & 2.390 & 2.264 & 2.146 & 2.034 & 1.928 & 1.828 & 1.734 & 1.644 & 1.560 & 1.480 & 1.405 & 1.333 & 1.266 & 1.201 & 1.141 & 1.083 & 1.028 & 0.977 & 0.927 \\
\hline-0.700 & 2.773 & 2.624 & 2.484 & 2.351 & 2.228 & 2.110 & 2.000 & 1.895 & 1.797 & 1.704 & 1.616 & 1.533 & 1.454 & 1.380 & 1.309 & 1.243 & 1.179 & 1.120 & 1.063 & 1.009 & 0.958 \\
\hline-0.750 & 2.886 & 2.729 & 2.583 & 2.444 & 2.314 & 2.191 & 2.075 & 1.966 & 1.863 & 1.766 & 1.674 & 1.588 & 1.506 & 1.428 & 1.355 & 1.286 & 1.220 & 1.158 & 1.099 & 1.043 & 0.990 \\
\hline-0.800 & 3.006 & 2.841 & 2.686 & 2.541 & 2.404 & 2.275 & 2.154 & 2.040 & 1.933 & 1.831 & 1.735 & 1.645 & 1.560 & 1.479 & 1.403 & 1.330 & 1.262 & 1.197 & 1.136 & 1.078 & 1.023 \\
\hline-0.850 & 3.133 & 2.958 & 2.796 & 2.643 & 2.499 & 2.363 & 2.237 & 2.118 & 2.005 & 1.899 & 1.799 & 1.705 & 1.616 & 1.532 & 1.452 & 1.377 & 1.306 & 1.239 & 1.175 & 1.115 & 1.058 \\
\hline-0.900 & 3.267 & 3.084 & 2.912 & 2.750 & 2.600 & 2.458 & 2.325 & 2.199 & 2.082 & 1.971 & 1.866 & 1.768 & 1.675 & 1.587 & 1.504 & 1.426 & 1.352 & 1.282 & 1.216 & 1.153 & 1.094 \\
\hline-0.950 & 3.410 & 3.215 & 3.034 & 2.864 & 2.705 & 2.556 & 2.416 & 2.285 & 2.162 & 2.046 & 1.936 & 1.833 & 1.736 & 1.644 & 1.558 & 1.476 & 1.399 & 1.327 & 1.258 & 1.193 & 1.131 \\
\hline-1.000 & 3.561 & 3.355 & 3.163 & 2.984 & 2.816 & 2.660 & 2.513 & 2.375 & 2.246 & 2.124 & 2.010 & 1.902 & 1.800 & 1.705 & 1.615 & 1.530 & 1.449 & 1.373 & 1.302 & 1.234 & 1.170 \\
\hline-1.050 & 3.721 & 3.503 & 3.300 & 3.111 & 2.934 & 2.769 & 2.615 & 2.470 & 2.334 & 2.206 & 2.086 & 1.974 & 1.868 & 1.768 & 1.674 & 1.585 & 1.501 & 1.422 & 1.348 & 1.277 & 1.211 \\
\hline-1.100 & 3.892 & 3.661 & 3.445 & 3.245 & 3.059 & 2.884 & 2.722 & 2.569 & 2.427 & 2.293 & 2.167 & 2.049 & 1.938 & 1.834 & 1.736 & 1.643 & 1.556 & 1.473 & 1.396 & 1.322 & 1.253 \\
\hline-1.150 & 4.072 & 3.828 & 3.600 & 3.388 & 3.190 & 3.006 & 2.835 & 2.675 & 2.524 & 2.384 & 2.252 & 2.128 & 2.012 & 1.903 & 1.800 & 1.703 & 1.612 & 1.527 & 1.446 & 1.369 & 1.297 \\
\hline-1.200 & 4.269 & 4.007 & 3.764 & 3.539 & 3.330 & 3.135 & 2.954 & 2.785 & 2.627 & 2.480 & 2.341 & 2.212 & 2.090 & 1.975 & 1.868 & 1.767 & 1.672 & 1.582 & 1.498 & 1.418 & 1.343 \\
\hline-1.250 & 4.477 & 4.197 & 3.939 & 3.700 & 3.478 & 3.272 & 3.081 & 2.902 & 2.736 & 2.581 & 2.435 & 2.299 & 2.171 & 2.052 & 1.939 & 1.833 & 1.734 & 1.640 & 1.552 & 1.469 & 1.391 \\
\hline-1.300 & 4.701 & 4.401 & 4.125 & 3.871 & 3.635 & 3.417 & 3.215 & 3.026 & 2.851 & 2.687 & 2.534 & 2.391 & 2.257 & 2.131 & 2.014 & 1.903 & 1.799 & 1.701 & 1.609 & 1.523 & 1.441 \\
\hline-1.350 & 4.942 & 4.619 & 4.325 & 4.053 & 3.803 & 3.571 & 3.357 & 3.157 & 2.972 & 2.799 & 2.638 & 2.488 & 2.347 & 2.215 & 2.092 & 1.976 & 1.867 & 1.765 & 1.669 & 1.579 & 1.494 \\
\hline-1.400 & 5.200 & 4.855 & 4.539 & 4.248 & 3.981 & 3.735 & 3.507 & 3.296 & 3.100 & 2.918 & 2.748 & 2.590 & 2.442 & 2.303 & 2.174 & 2.053 & 1.939 & 1.832 & 1.731 & 1.637 & 1.548 \\
\hline-1.450 & 5.480 & 5.108 & 4.768 & 4.457 & 4.172 & 3.910 & 3.668 & 3.444 & 3.236 & 3.044 & 2.864 & 2.697 & 2.542 & 2.396 & 2.260 & 2.133 & 2.014 & 1.902 & 1.797 & 1.698 & 1.605 \\
\hline-1.500 & 5.784 & 5.381 & 5.015 & 4.681 & 4.376 & 4.096 & 3.838 & 3.601 & 3.381 & 3.177 & 2.987 & 2.811 & 2.647 & 2.494 & 2.351 & 2.218 & 2.092 & 1.975 & 1.865 & 1.762 & 1.665 \\
\hline-1.550 & 6.113 & 5.676 & 5.281 & 4.922 & 4.595 & 4.296 & 4.021 & 3.768 & 3.534 & 3.318 & 3.117 & 2.931 & 2.758 & 2.597 & 2.447 & 2.306 & 2.175 & 2.052 & 1.937 & 1.829 & 1.728 \\
\hline-1.600 & 6.472 & 5.997 & 5.569 & 5.182 & 4.830 & 4.509 & 4.215 & 3.945 & 3.697 & 3.468 & 3.255 & 3.059 & 2.876 & 2.706 & 2.548 & 2.400 & 2.262 & 2.133 & 2.013 & 1.900 & 1.794 \\
\hline-1.650 & 6.864 & 6.346 & 5.881 & 5.462 & 5.083 & 4.738 & 4.424 & 4.136 & 3.871 & 3.627 & 3.402 & 3.194 & 3.000 & 2.821 & 2.654 & 2.499 & 2.354 & 2.218 & 2.092 & 1.973 & 1.862 \\
\hline-1.700 & 7.295 & 6.727 & 6.220 & 5.766 & 5.356 & 4.985 & 4.647 & 4.339 & 4.056 & 3.797 & 3.558 & 3.337 & 3.132 & 2.943 & 2.767 & 2.603 & 2.450 & 2.308 & 2.175 & 2.051 & 1.935 \\
\hline-1.750 & 7.771 & 7.145 & 6.591 & 6.096 & 5.652 & 5.251 & 4.888 & 4.557 & 4.255 & 3.978 & 3.723 & 3.489 & 3.272 & 3.071 & 2.886 & 2.713 & 2.552 & 2.402 & 2.263 & 2.132 & 2.011 \\
\hline-1.800 & 8.297 & 7.605 & 6.996 & 6.456 & 5.973 & 5.539 & 5.147 & 4.791 & 4.467 & 4.171 & 3.900 & 3.651 & 3.421 & 3.208 & 3.011 & 2.829 & 2.660 & 2.502 & 2.355 & 2.218 & 2.090 \\
\hline-1.850 & 8.884 & 8.115 & 7.442 & 6.849 & 6.322 & 5.851 & 5.427 & 5.044 & 4.696 & 4.379 & 4.089 & 3.823 & 3.579 & 3.353 & 3.145 & 2.952 & 2.773 & 2.607 & 2.452 & 2.308 & 2.174 \\
\hline-1.900 & 9.541 & 8.681 & 7.935 & 7.281 & 6.704 & 6.190 & 5.730 & 5.316 & 4.941 & 4.601 & 4.291 & 4.007 & 3.747 & 3.507 & 3.286 & 3.082 & 2.893 & 2.718 & 2.555 & 2.403 & 2.262 \\
\hline-1.950 & 10.282 & 9.313 & 8.481 & 7.757 & 7.122 & 6.560 & 6.059 & 5.611 & 5.206 & 4.840 & 4.508 & 4.204 & 3.926 & 3.671 & 3.437 & 3.220 & 3.020 & 2.835 & 2.663 & 2.504 & 2.355 \\
\hline-2.000 & .123 & .025 & 9.091 & .285 & .583 & 6.965 & 6.418 & 5.931 & 5.493 & 5.098 & 4.740 & 4.415 & 4.118 & 3.846 & 3.597 & 3.367 & 3.155 & 2.959 & 2.778 & 2.609 & 2.453 \\
\hline
\end{tabular}




\begin{tabular}{|c|c|c|c|c|c|c|c|c|c|c|c|c|c|c|c|c|c|c|c|c|c|}
\hline & & & & & & & & & & & $l=h$ & & & & & & & & & & \\
\hline$\phi_{1}=\phi_{2}$ & 1.000 & 1.050 & 1.100 & 1.150 & 1.200 & 1.250 & 1.300 & 1.350 & 1.400 & 1.450 & 1.500 & 1.550 & 1.600 & 1.650 & 1.700 & 1.750 & 1.800 & 1.850 & 1.900 & 1.950 & 2.000 \\
\hline 0.000 & 1.656 & 1.589 & 1.524 & 1.462 & 1.402 & 1.345 & 1.290 & 1.238 & 1.187 & 1.139 & 1.093 & 1.048 & 1.005 & 0.964 & 0.925 & 0.887 & 0.851 & 0.816 & 0.783 & 0.751 & 0.721 \\
\hline-0.050 & 1.706 & 1.636 & 1.569 & 1.505 & 1.443 & 1.384 & 1.328 & 1.273 & 1.221 & 1.171 & 1.123 & 1.077 & 1.033 & 0.991 & 0.950 & 0.912 & 0.874 & 0.838 & 0.804 & 0.771 & 0.740 \\
\hline-0.100 & 1.758 & 1.686 & 1.616 & 1.550 & 1.486 & 1.425 & 1.366 & 1.309 & 1.256 & 1.204 & 1.155 & 1.108 & 1.062 & 1.018 & 0.977 & 0.936 & 0.898 & 0.861 & 0.826 & 0.792 & 0.760 \\
\hline-0.150 & 1.812 & 1.737 & 1.665 & 1.596 & 1.530 & 1.466 & 1.406 & 1.348 & 1.292 & 1.238 & 1.188 & 1.139 & 1.092 & 1.047 & 1.004 & 0.962 & 0.923 & 0.885 & 0.848 & 0.813 & 0.780 \\
\hline-0.200 & 1.868 & 1.790 & 1.715 & 1.644 & 1.575 & 1.510 & 1.447 & 1.387 & 1.329 & 1.274 & 1.222 & 1.171 & 1.123 & 1.076 & 1.032 & 0.989 & 0.948 & 0.909 & 0.872 & 0.836 & 0.801 \\
\hline-0.250 & 1.926 & 1.845 & 1.768 & 1.694 & 1.623 & 1.555 & 1.490 & 1.428 & 1.368 & 1.311 & 1.257 & 1.205 & 1.155 & 1.106 & 1.061 & 1.017 & 0.974 & 0.934 & 0.895 & 0.858 & 0.823 \\
\hline-0.300 & 1.987 & 1.903 & 1.822 & 1.746 & 1.672 & 1.602 & 1.534 & 1.470 & 1.408 & 1.349 & 1.293 & 1.239 & 1.187 & 1.138 & 1.090 & 1.045 & 1.002 & 0.960 & 0.920 & 0.882 & 0.845 \\
\hline-0.350 & 2.050 & 1.963 & 1.879 & 1.799 & 1.723 & 1.650 & 1.580 & 1.514 & 1.450 & 1.389 & 1.330 & 1.275 & 1.221 & 1.171 & 1.122 & 1.075 & 1.030 & 0.987 & 0.946 & 0.906 & 0.868 \\
\hline-0.400 & 2.116 & 2.025 & 1.938 & 1.855 & 1.776 & 1.700 & 1.628 & 1.559 & 1.493 & 1.430 & 1.369 & 1.312 & 1.257 & 1.204 & 1.153 & 1.105 & 1.059 & 1.014 & 0.972 & 0.931 & 0.892 \\
\hline-0.450 & 2.185 & 2.091 & 2.000 & 1.914 & 1.832 & 1.753 & 1.678 & 1.606 & 1.538 & 1.472 & 1.410 & 1.350 & 1.293 & 1.239 & 1.187 & 1.136 & 1.089 & 1.043 & 0.999 & 0.957 & 0.917 \\
\hline-0.500 & 2.257 & 2.158 & 2.064 & 1.975 & 1.889 & 1.808 & 1.729 & 1.655 & 1.584 & 1.516 & 1.452 & 1.390 & 1.331 & 1.275 & 1.221 & 1.169 & 1.120 & 1.072 & 1.027 & 0.984 & 0.943 \\
\hline-0.550 & 2.332 & 2.230 & 2.131 & 2.038 & 1.949 & 1.864 & 1.783 & 1.706 & 1.633 & 1.563 & 1.495 & 1.431 & 1.370 & 1.312 & 1.256 & 1.203 & 1.152 & 1.103 & 1.056 & 1.012 & 0.969 \\
\hline-0.600 & 2.410 & 2.303 & 2.201 & 2.104 & 2.011 & 1.923 & 1.839 & 1.759 & 1.683 & 1.610 & 1.541 & 1.474 & 1.411 & 1.350 & 1.293 & 1.238 & 1.185 & 1.134 & 1.086 & 1.040 & 0.996 \\
\hline-0.650 & 2.493 & 2.381 & 2.275 & 2.173 & 2.076 & 1.985 & 1.898 & 1.815 & 1.735 & 1.660 & 1.588 & 1.519 & 1.453 & 1.391 & 1.331 & 1.274 & 1.219 & 1.167 & 1.117 & 1.070 & 1.024 \\
\hline-0.700 & 2.579 & 2.462 & 2.351 & 2.245 & 2.145 & 2.049 & 1.958 & 1.872 & 1.790 & 1.711 & 1.636 & 1.565 & 1.497 & 1.432 & 1.370 & 1.311 & 1.255 & 1.201 & 1.150 & 1.100 & 1.053 \\
\hline-0.750 & 2.670 & 2.547 & 2.431 & 2.320 & 2.216 & 2.116 & 2.022 & 1.931 & 1.846 & 1.764 & 1.687 & 1.613 & 1.543 & 1.475 & 1.411 & 1.350 & 1.292 & 1.236 & 1.183 & 1.132 & 1.084 \\
\hline-0.800 & 2.765 & 2.636 & 2.515 & 2.399 & 2.290 & 2.186 & 2.088 & 1.994 & 1.905 & 1.820 & 1.740 & 1.663 & 1.590 & 1.520 & 1.454 & 1.390 & 1.330 & 1.272 & 1.217 & 1.165 & 1.115 \\
\hline-0.850 & 2.865 & 2.730 & 2.603 & 2.482 & 2.368 & 2.259 & 2.156 & 2.059 & 1.966 & 1.878 & 1.795 & 1.715 & 1.639 & 1.567 & 1.498 & 1.432 & 1.370 & 1.310 & 1.253 & 1.199 & 1.147 \\
\hline-0.900 & 2.970 & 2.829 & 2.695 & 2.569 & 2.449 & 2.335 & 2.229 & 2.127 & 2.031 & 1.939 & 1.852 & 1.769 & 1.690 & 1.615 & 1.544 & 1.476 & 1.411 & 1.349 & 1.290 & 1.234 & 1.180 \\
\hline-0.950 & 3.081 & 2.932 & 2.792 & 2.659 & 2.534 & 2.416 & 2.304 & 2.198 & 2.097 & 2.002 & 1.911 & 1.825 & 1.743 & 1.665 & 1.591 & 1.521 & 1.454 & 1.390 & 1.329 & 1.271 & 1.215 \\
\hline-1.000 & 3.198 & 3.041 & 2.894 & 2.755 & 2.624 & 2.500 & 2.383 & 2.272 & 2.167 & 2.068 & 1.973 & 1.884 & 1.799 & 1.718 & 1.641 & 1.568 & 1.498 & 1.432 & 1.369 & 1.308 & 1.251 \\
\hline-1.050 & 3.321 & 3.156 & 3.001 & 2.855 & 2.717 & 2.588 & 2.465 & 2.350 & 2.240 & 2.136 & 2.038 & 1.945 & 1.856 & 1.772 & 1.692 & 1.616 & 1.544 & 1.475 & 1.410 & 1.348 & 1.288 \\
\hline-1.100 & 3.451 & 3.277 & 3.114 & 2.960 & 2.816 & 2.680 & 2.552 & 2.431 & 2.316 & 2.208 & 2.106 & 2.009 & 1.916 & 1.829 & 1.746 & 1.667 & 1.592 & 1.521 & 1.453 & 1.388 & 1.327 \\
\hline-1.150 & 3.589 & 3.405 & 3.233 & 3.071 & 2.920 & 2.777 & 2.643 & 2.516 & 2.396 & 2.283 & 2.176 & 2.075 & 1.979 & 1.888 & 1.802 & 1.720 & 1.642 & 1.568 & 1.497 & 1.430 & 1.367 \\
\hline-1.200 & 3.735 & 3.541 & 3.359 & 3.188 & 3.029 & 2.879 & 2.738 & 2.605 & 2.480 & 2.362 & 2.250 & 2.144 & 2.044 & 1.950 & 1.860 & 1.775 & 1.694 & 1.617 & 1.544 & 1.474 & 1.408 \\
\hline-1.250 & 3.891 & 3.684 & 3.492 & 3.312 & 3.144 & 2.986 & 2.838 & 2.699 & 2.568 & 2.444 & 2.327 & 2.217 & 2.113 & 2.014 & 1.920 & 1.832 & 1.748 & 1.668 & 1.592 & 1.520 & 1.451 \\
\hline-1.300 & 4.057 & 3.837 & 3.633 & 3.442 & 3.265 & 3.099 & 2.943 & 2.797 & 2.660 & 2.530 & 2.408 & 2.293 & 2.184 & 2.081 & 1.984 & 1.891 & 1.804 & 1.721 & 1.642 & 1.567 & 1.496 \\
\hline-1.350 & 4.233 & 3.999 & 3.782 & 3.581 & 3.394 & 3.218 & 3.054 & 2.901 & 2.756 & 2.621 & 2.493 & 2.372 & 2.259 & 2.151 & 2.049 & 1.953 & 1.862 & 1.776 & 1.694 & 1.616 & 1.543 \\
\hline-1.400 & 4.421 & 4.172 & 3.942 & 3.728 & 3.530 & 3.344 & 3.171 & 3.010 & 2.858 & 2.716 & 2.582 & 2.455 & 2.337 & 2.224 & 2.118 & 2.018 & 1.923 & 1.833 & 1.748 & 1.668 & 1.591 \\
\hline-1.450 & 4.623 & 4.357 & 4.111 & 3.884 & 3.673 & 3.478 & 3.295 & 3.125 & 2.965 & 2.815 & 2.675 & 2.543 & 2.418 & 2.301 & 2.190 & 2.086 & 1.987 & 1.893 & 1.805 & 1.721 & 1.641 \\
\hline-1.500 & 4.839 & 4.554 & 4.292 & 4.050 & 3.826 & 3.619 & 3.426 & 3.246 & 3.078 & 2.920 & 2.773 & 2.634 & 2.504 & 2.381 & 2.266 & 2.157 & 2.053 & 1.956 & 1.864 & 1.776 & 1.694 \\
\hline-1.550 & 5.073 & 4.766 & 4.485 & 4.227 & 3.989 & 3.769 & 3.564 & 3.374 & 3.197 & 3.031 & 2.876 & 2.730 & 2.594 & 2.465 & 2.344 & 2.230 & 2.123 & 2.021 & 1.925 & 1.834 & 1.748 \\
\hline-1.600 & 5.324 & 4.993 & 4.692 & 4.416 & 4.162 & 3.928 & 3.711 & 3.510 & 3.322 & 3.148 & 2.984 & 2.832 & 2.688 & 2.554 & 2.427 & 2.308 & 2.195 & 2.089 & 1.989 & 1.895 & 1.805 \\
\hline-1.650 & 5.596 & 5.239 & 4.914 & 4.618 & 4.347 & 4.097 & 3.867 & 3.653 & 3.455 & 3.271 & 3.099 & 2.938 & 2.787 & 2.646 & 2.514 & 2.389 & 2.271 & 2.161 & 2.056 & 1.958 & 1.864 \\
\hline-1.700 & 5.891 & 5.504 & 5.153 & 4.835 & 4.545 & 4.278 & 4.033 & 3.806 & 3.596 & 3.401 & 3.219 & 3.050 & 2.892 & 2.743 & 2.604 & 2.474 & 2.351 & 2.235 & 2.126 & 2.023 & 1.926 \\
\hline-1.750 & 6.212 & 5.791 & 5.412 & 5.069 & 4.756 & 4.471 & 4.209 & 3.968 & 3.745 & 3.539 & 3.347 & 3.168 & 3.002 & 2.846 & 2.700 & 2.563 & 2.434 & 2.313 & 2.199 & 2.092 & 1.991 \\
\hline-1.800 & 6.563 & 6.103 & 5.691 & 5.320 & 4.984 & 4.678 & 4.398 & 4.141 & 3.904 & 3.685 & 3.482 & 3.293 & 3.118 & 2.954 & 2.800 & 2.656 & 2.522 & 2.395 & 2.276 & 2.164 & 2.058 \\
\hline-1.850 & 6.949 & 6.444 & 5.995 & 5.592 & 5.229 & 4.900 & 4.600 & 4.325 & 4.073 & 3.840 & 3.625 & 3.426 & 3.240 & 3.067 & 2.906 & 2.755 & 2.613 & 2.481 & 2.356 & 2.239 & 2.129 \\
\hline-1.900 & 7.374 & 6.817 & 6.325 & 5.887 & 5.494 & 5.139 & 4.817 & 4.523 & 4.253 & 4.006 & 3.777 & 3.566 & 3.369 & 3.187 & 3.017 & 2.858 & 2.710 & 2.571 & 2.440 & 2.318 & 2.202 \\
\hline-1.950 & 7.845 & 7.228 & 6.687 & 6.208 & 5.781 & 5.397 & 5.050 & 4.734 & 4.446 & 4.182 & 3.938 & 3.714 & 3.506 & 3.314 & 3.134 & 2.967 & 2.811 & 2.665 & 2.528 & 2.400 & 2.279 \\
\hline-2.000 & 8.369 & 7.683 & 7.085 & 6.559 & 6.093 & 5.676 & 5.300 & 4.961 & 4.652 & 4.369 & 4.110 & 3.872 & 3.652 & 3.448 & 3.258 & 3.082 & 2.918 & 2.765 & 2.621 & 2.486 & 2.360 \\
\hline
\end{tabular}




\begin{tabular}{|c|c|c|c|c|c|c|c|c|c|c|c|c|c|c|c|c|c|c|c|c|c|}
\hline & & & & & & & & & & & $l=h$ & & & & & & & & & & \\
\hline$\phi_{1}=\phi_{2}$ & 1.000 & 1.050 & 1.100 & 1.150 & 1.200 & 1.250 & 1.300 & 1.350 & 1.400 & 1.450 & 1.500 & 1.550 & 1.600 & 1.650 & 1.700 & 1.750 & 1.800 & 1.850 & 1.900 & 1.950 & 2.000 \\
\hline 0.000 & 1.746 & 1.657 & 1.572 & 1.492 & 1.416 & 1.344 & 1.275 & 1.210 & 1.149 & 1.090 & 1.035 & 0.982 & 0.932 & 0.884 & 0.839 & 0.796 & 0.756 & 0.717 & 0.681 & 0.646 & 0.613 \\
\hline-0.050 & 1.810 & 1.717 & 1.629 & 1.546 & 1.467 & 1.391 & 1.320 & 1.252 & 1.189 & 1.128 & 1.070 & 1.015 & 0.963 & 0.914 & 0.868 & 0.823 & 0.781 & 0.741 & 0.703 & 0.667 & 0.633 \\
\hline-0.100 & 1.878 & 1.781 & 1.689 & 1.602 & 1.519 & 1.441 & 1.367 & 1.296 & 1.230 & 1.167 & 1.107 & 1.050 & 0.996 & 0.945 & 0.896 & 0.850 & 0.807 & 0.765 & 0.726 & 0.689 & 0.654 \\
\hline-0.150 & 1.948 & 1.847 & 1.751 & 1.660 & 1.574 & 1.493 & 1.416 & 1.343 & 1.273 & 1.208 & 1.145 & 1.087 & 1.030 & 0.977 & 0.927 & 0.879 & 0.834 & 0.791 & 0.750 & 0.712 & 0.675 \\
\hline-0.200 & 2.022 & 1.916 & 1.816 & 1.722 & 1.632 & 1.547 & 1.467 & 1.391 & 1.318 & 1.250 & 1.185 & 1.124 & 1.066 & 1.011 & 0.958 & 0.909 & 0.862 & 0.818 & 0.776 & 0.736 & 0.698 \\
\hline-0.250 & 2.099 & 1.988 & 1.884 & 1.785 & 1.692 & 1.604 & 1.520 & 1.440 & 1.365 & 1.294 & 1.227 & 1.163 & 1.103 & 1.046 & 0.991 & 0.940 & 0.891 & 0.845 & 0.801 & 0.760 & 0.721 \\
\hline-0.300 & 2.180 & 2.065 & 1.955 & 1.852 & 1.755 & 1.662 & 1.575 & 1.492 & 1.414 & 1.340 & 1.270 & 1.204 & 1.141 & 1.082 & 1.026 & 0.972 & 0.922 & 0.874 & 0.828 & 0.785 & 0.745 \\
\hline-0.350 & 2.265 & 2.143 & 2.030 & 1.922 & 1.821 & 1.724 & 1.633 & 1.547 & 1.466 & 1.388 & 1.316 & 1.247 & 1.181 & 1.120 & 1.061 & 1.006 & 0.953 & 0.903 & 0.856 & 0.812 & 0.770 \\
\hline-0.400 & 2.355 & 2.228 & 2.109 & 1.996 & 1.889 & 1.788 & 1.694 & 1.604 & 1.519 & 1.439 & 1.363 & 1.291 & 1.223 & 1.159 & 1.099 & 1.041 & 0.986 & 0.934 & 0.886 & 0.839 & 0.795 \\
\hline-0.450 & 2.448 & 2.316 & 2.191 & 2.073 & 1.961 & 1.856 & 1.757 & 1.663 & 1.575 & 1.491 & 1.412 & 1.337 & 1.267 & 1.200 & 1.137 & 1.077 & 1.020 & 0.967 & 0.916 & 0.868 & 0.822 \\
\hline-0.500 & 2.547 & 2.407 & 2.277 & 2.153 & 2.036 & 1.927 & 1.823 & 1.725 & 1.633 & 1.546 & 1.464 & 1.386 & 1.312 & 1.243 & 1.177 & 1.115 & 1.056 & 1.000 & 0.947 & 0.898 & 0.850 \\
\hline-0.550 & 2.651 & 2.505 & 2.368 & 2.238 & 2.116 & 2.001 & 1.893 & 1.791 & 1.694 & 1.603 & 1.517 & 1.436 & 1.359 & 1.287 & 1.219 & 1.154 & 1.093 & 1.035 & 0.980 & 0.928 & 0.880 \\
\hline-0.600 & 2.761 & 2.607 & 2.463 & 2.327 & 2.199 & 2.079 & 1.966 & 1.859 & 1.758 & 1.663 & 1.573 & 1.489 & 1.409 & 1.334 & 1.262 & 1.195 & 1.131 & 1.071 & 1.014 & 0.961 & 0.910 \\
\hline-0.650 & 2.876 & 2.715 & 2.563 & 2.421 & 2.286 & 2.161 & 2.042 & 1.930 & 1.825 & 1.726 & 1.632 & 1.544 & 1.461 & 1.382 & 1.308 & 1.238 & 1.172 & 1.109 & 1.050 & 0.994 & 0.941 \\
\hline-0.700 & 2.998 & 2.828 & 2.669 & 2.519 & 2.379 & 2.246 & 2.122 & 2.004 & 1.895 & 1.791 & 1.694 & 1.601 & 1.515 & 1.433 & 1.355 & 1.282 & 1.214 & 1.148 & 1.087 & 1.029 & 0.974 \\
\hline-0.750 & 3.128 & 2.948 & 2.780 & 2.623 & 2.475 & 2.336 & 2.206 & 2.083 & 1.968 & 1.860 & 1.758 & 1.662 & 1.571 & 1.486 & 1.405 & 1.329 & 1.257 & 1.190 & 1.126 & 1.065 & 1.008 \\
\hline-0.800 & 3.264 & 3.075 & 2.898 & 2.732 & 2.577 & 2.431 & 2.294 & 2.166 & 2.045 & 1.932 & 1.825 & 1.725 & 1.630 & 1.541 & 1.457 & 1.378 & 1.303 & 1.232 & 1.166 & 1.103 & 1.044 \\
\hline-0.850 & 3.409 & 3.209 & 3.022 & 2.848 & 2.684 & 2.531 & 2.387 & 2.253 & 2.126 & 2.007 & 1.896 & 1.791 & 1.692 & 1.599 & 1.511 & 1.428 & 1.351 & 1.277 & 1.208 & 1.142 & 1.081 \\
\hline-0.900 & 3.562 & 3.351 & 3.154 & 2.969 & 2.797 & 2.636 & 2.485 & 2.344 & 2.211 & 2.087 & 1.970 & 1.860 & 1.756 & 1.659 & 1.568 & 1.481 & 1.400 & 1.324 & 1.252 & 1.184 & 1.119 \\
\hline-0.950 & 3.726 & 3.501 & 3.293 & 3.098 & 2.917 & 2.747 & 2.588 & 2.440 & 2.301 & 2.170 & 2.047 & 1.932 & 1.824 & 1.723 & 1.627 & 1.537 & 1.452 & 1.372 & 1.297 & 1.226 & 1.160 \\
\hline-1.000 & 3.899 & 3.661 & 3.440 & 3.234 & 3.043 & 2.864 & 2.697 & 2.541 & 2.394 & 2.257 & 2.129 & 2.008 & 1.895 & 1.789 & 1.689 & 1.595 & 1.507 & 1.423 & 1.345 & 1.271 & 1.201 \\
\hline-1.050 & 4.084 & 3.831 & 3.597 & 3.379 & 3.177 & 2.988 & 2.812 & 2.647 & 2.493 & 2.349 & 2.215 & 2.088 & 1.970 & 1.858 & 1.754 & 1.656 & 1.563 & 1.476 & 1.395 & 1.318 & 1.245 \\
\hline-1.100 & 4.281 & 4.012 & 3.763 & 3.533 & 3.318 & 3.119 & 2.933 & 2.760 & 2.598 & 2.446 & 2.305 & 2.172 & 2.048 & 1.931 & 1.822 & 1.719 & 1.623 & 1.532 & 1.447 & 1.367 & 1.291 \\
\hline-1.150 & 4.492 & 4.206 & 3.941 & 3.696 & 3.468 & 3.257 & 3.061 & 2.878 & 2.708 & 2.548 & 2.400 & 2.260 & 2.130 & 2.008 & 1.893 & 1.786 & 1.685 & 1.590 & 1.501 & 1.417 & 1.339 \\
\hline-1.200 & 4.718 & 4.412 & 4.129 & 3.869 & 3.628 & 3.404 & 3.197 & 3.004 & 2.824 & 2.656 & 2.500 & 2.353 & 2.216 & 2.088 & 1.968 & 1.856 & 1.750 & 1.651 & 1.558 & 1.471 & 1.389 \\
\hline-1.250 & 4.961 & 4.633 & 4.332 & 4.054 & 3.798 & 3.561 & 3.341 & 3.136 & 2.947 & 2.770 & 2.605 & 2.451 & 2.307 & 2.173 & 2.047 & 1.929 & 1.819 & 1.715 & 1.618 & 1.526 & 1.441 \\
\hline-1.300 & 5.222 & 4.870 & 4.548 & 4.252 & 3.979 & 3.727 & 3.493 & 3.277 & 3.077 & 2.890 & 2.716 & 2.554 & 2.403 & 2.262 & 2.130 & 2.006 & 1.890 & 1.782 & 1.680 & 1.585 & 1.495 \\
\hline-1.350 & 5.504 & 5.125 & 4.780 & 4.463 & 4.172 & 3.903 & 3.656 & 3.427 & 3.214 & 3.017 & 2.834 & 2.663 & 2.504 & 2.355 & 2.217 & 2.087 & 1.966 & 1.852 & 1.746 & 1.646 & 1.552 \\
\hline-1.400 & 5.806 & 5.400 & 5.029 & 4.689 & 4.378 & 4.092 & 3.829 & 3.585 & 3.360 & 3.152 & 2.958 & 2.778 & 2.610 & 2.454 & 2.308 & 2.172 & 2.045 & 1.926 & 1.814 & 1.710 & 1.612 \\
\hline-1.450 & 6.137 & 5.697 & 5.297 & 4.932 & 4.599 & 4.294 & 4.013 & 3.754 & 3.515 & 3.294 & 3.090 & 2.899 & 2.723 & 2.558 & 2.405 & 2.262 & 2.128 & 2.003 & 1.886 & 1.777 & 1.675 \\
\hline-1.500 & 6.496 & 6.018 & 5.586 & 5.194 & 4.836 & 4.509 & 4.210 & 3.934 & 3.680 & 3.446 & 3.229 & 3.028 & 2.841 & 2.668 & 2.506 & 2.356 & 2.216 & 2.085 & 1.962 & 1.848 & 1.740 \\
\hline-1.550 & 6.887 & 6.367 & 5.899 & 5.475 & 5.091 & 4.741 & 4.420 & 4.126 & 3.856 & 3.607 & 3.377 & 3.164 & 2.967 & 2.784 & 2.614 & 2.455 & 2.308 & 2.170 & 2.042 & 1.921 & 1.809 \\
\hline-1.600 & 7.314 & 6.747 & 6.238 & 5.780 & 5.366 & 4.989 & 4.646 & 4.332 & 4.044 & 3.779 & 3.534 & 3.309 & 3.100 & 2.907 & 2.727 & 2.560 & 2.405 & 2.260 & 2.125 & 1.999 & 1.881 \\
\hline-1.650 & 7.784 & 7.162 & 6.608 & 6.111 & 5.663 & 5.257 & 4.888 & 4.552 & 4.244 & 3.962 & 3.702 & 3.463 & 3.241 & 3.037 & 2.847 & 2.671 & 2.507 & 2.355 & 2.213 & 2.081 & 1.957 \\
\hline-1.700 & 8.302 & 7.618 & 7.011 & 6.470 & 5.984 & 5.546 & 5.149 & 4.788 & 4.459 & 4.157 & 3.880 & 3.626 & 3.391 & 3.175 & 2.974 & 2.788 & 2.616 & 2.455 & 2.306 & 2.167 & 2.037 \\
\hline-1.750 & 8.876 & 8.119 & 7.453 & 6.861 & 6.333 & 5.858 & 5.430 & 5.042 & 4.689 & 4.366 & 4.071 & 3.800 & 3.551 & 3.321 & 3.109 & 2.912 & 2.730 & 2.561 & 2.404 & 2.257 & 2.121 \\
\hline-1.800 & 9.515 & 8.674 & 7.939 & 7.290 & 6.713 & 6.198 & 5.734 & 5.316 & 4.936 & 4.590 & 4.275 & 3.986 & 3.721 & 3.477 & 3.252 & 3.044 & 2.851 & 2.673 & 2.507 & 2.353 & 2.210 \\
\hline-1.850 & 10.230 & 9.291 & 8.476 & 7.761 & 7.129 & 6.567 & 6.064 & 5.611 & 5.202 & 4.831 & 4.493 & 4.185 & 3.902 & 3.642 & 3.403 & 3.183 & 2.979 & 2.791 & 2.616 & 2.454 & 2.303 \\
\hline-1.900 & 11.037 & 9.981 & 9.072 & 8.280 & 7.585 & 6.970 & 6.422 & 5.932 & 5.490 & 5.090 & 4.728 & 4.397 & 4.095 & 3.819 & 3.565 & 3.331 & 3.115 & 2.916 & 2.731 & 2.560 & 2.401 \\
\hline-1.950 & 11.953 & 10.757 & 9.737 & 8.856 & 8.088 & 7.412 & 6.813 & 6.279 & 5.801 & 5.370 & 4.980 & 4.625 & 4.303 & 4.007 & 3.737 & 3.488 & 3.259 & 3.048 & 2.853 & 2.672 & 2.505 \\
\hline-2.000 & 13.002 & 11.636 & 10.483 & 9.497 & 8.643 & 7.898 & 7.241 & 6.659 & 6.139 & 5.672 & 5.251 & 4.871 & 4.525 & 4.209 & 3.920 & 3.656 & 3.413 & 3.189 & 2.982 & 2.791 & 2.615 \\
\hline
\end{tabular}




\begin{tabular}{|c|c|c|c|c|c|c|c|c|c|c|c|c|c|c|c|c|c|c|c|c|c|}
\hline & & & & & & & & & & & $l=h$ & & & & & & & & & & \\
\hline$\phi_{1}=\phi_{2}$ & 1.000 & 1.050 & 1.100 & 1.150 & 1.200 & 1.250 & 1.300 & 1.350 & 1.400 & 1.450 & 1.500 & 1.550 & 1.600 & 1.650 & 1.700 & 1.750 & 1.800 & 1.850 & 1.900 & 1.950 & 2.000 \\
\hline 0.000 & 1.746 & 1.683 & 1.623 & 1.564 & 1.508 & 1.454 & 1.402 & 1.351 & 1.303 & 1.256 & 1.211 & 1.168 & 1.126 & 1.086 & 1.046 & 1.009 & 0.972 & 0.937 & 0.904 & 0.871 & 0.840 \\
\hline-0.050 & 1.793 & 1.728 & 1.665 & 1.605 & 1.547 & 1.491 & 1.438 & 1.386 & 1.336 & 1.288 & 1.241 & 1.196 & 1.153 & 1.112 & 1.072 & 1.033 & 0.996 & 0.960 & 0.925 & 0.892 & 0.860 \\
\hline-0.100 & 1.841 & 1.774 & 1.710 & 1.648 & 1.588 & 1.530 & 1.475 & 1.421 & 1.370 & 1.320 & 1.272 & 1.226 & 1.182 & 1.139 & 1.098 & 1.058 & 1.020 & 0.983 & 0.947 & 0.913 & 0.880 \\
\hline-0.150 & 1.891 & 1.822 & 1.755 & 1.691 & 1.630 & 1.570 & 1.513 & 1.458 & 1.405 & 1.353 & 1.304 & 1.257 & 1.212 & 1.167 & 1.125 & 1.084 & 1.045 & 1.007 & 0.970 & 0.935 & 0.901 \\
\hline-0.200 & 1.943 & 1.872 & 1.803 & 1.736 & 1.673 & 1.611 & 1.552 & 1.495 & 1.441 & 1.388 & 1.337 & 1.289 & 1.242 & 1.196 & 1.153 & 1.111 & 1.070 & 1.031 & 0.994 & 0.958 & 0.923 \\
\hline-0.250 & 1.997 & 1.923 & 1.851 & 1.783 & 1.717 & 1.654 & 1.593 & 1.534 & 1.478 & 1.423 & 1.372 & 1.321 & 1.273 & 1.226 & 1.181 & 1.138 & 1.097 & 1.057 & 1.018 & 0.981 & 0.945 \\
\hline-0.300 & 2.053 & 1.976 & 1.902 & 1.831 & 1.764 & 1.698 & 1.635 & 1.575 & 1.517 & 1.461 & 1.407 & 1.355 & 1.305 & 1.257 & 1.211 & 1.167 & 1.124 & 1.083 & 1.043 & 1.005 & 0.968 \\
\hline-0.350 & 2.111 & 2.032 & 1.955 & 1.882 & 1.811 & 1.744 & 1.679 & 1.616 & 1.556 & 1.499 & 1.443 & 1.390 & 1.338 & 1.289 & 1.242 & 1.196 & 1.152 & 1.109 & 1.069 & 1.029 & 0.992 \\
\hline-0.400 & 2.171 & 2.089 & 2.010 & 1.934 & 1.861 & 1.791 & 1.724 & 1.660 & 1.598 & 1.538 & 1.481 & 1.426 & 1.373 & 1.322 & 1.273 & 1.226 & 1.181 & 1.137 & 1.095 & 1.055 & 1.016 \\
\hline-0.450 & 2.234 & 2.149 & 2.067 & 1.988 & 1.913 & 1.840 & 1.771 & 1.704 & 1.640 & 1.579 & 1.520 & 1.463 & 1.408 & 1.356 & 1.305 & 1.257 & 1.210 & 1.165 & 1.122 & 1.081 & 1.041 \\
\hline-0.500 & 2.300 & 2.211 & 2.126 & 2.044 & 1.966 & 1.891 & 1.819 & 1.750 & 1.684 & 1.621 & 1.560 & 1.501 & 1.445 & 1.391 & 1.339 & 1.289 & 1.241 & 1.195 & 1.150 & 1.108 & 1.067 \\
\hline-0.550 & 2.368 & 2.275 & 2.187 & 2.103 & 2.022 & 1.944 & 1.870 & 1.798 & 1.730 & 1.664 & 1.601 & 1.540 & 1.483 & 1.427 & 1.373 & 1.322 & 1.273 & 1.225 & 1.179 & 1.135 & 1.093 \\
\hline-0.600 & 2.439 & 2.342 & 2.251 & 2.163 & 2.079 & 1.999 & 1.922 & 1.848 & 1.777 & 1.709 & 1.644 & 1.582 & 1.522 & 1.464 & 1.409 & 1.356 & 1.305 & 1.256 & 1.209 & 1.164 & 1.120 \\
\hline-0.650 & 2.512 & 2.413 & 2.317 & 2.225 & 2.139 & 2.055 & 1.976 & 1.899 & 1.826 & 1.756 & 1.689 & 1.624 & 1.562 & 1.503 & 1.446 & 1.391 & 1.339 & 1.288 & 1.240 & 1.193 & 1.149 \\
\hline-0.700 & 2.590 & 2.486 & 2.387 & 2.292 & 2.201 & 2.115 & 2.032 & 1.953 & 1.877 & 1.804 & 1.735 & 1.668 & 1.604 & 1.543 & 1.484 & 1.428 & 1.374 & 1.322 & 1.272 & 1.224 & 1.178 \\
\hline-0.750 & 2.670 & 2.562 & 2.459 & 2.360 & 2.266 & 2.176 & 2.090 & 2.008 & 1.930 & 1.855 & 1.782 & 1.714 & 1.647 & 1.584 & 1.524 & 1.465 & 1.409 & 1.356 & 1.304 & 1.255 & 1.207 \\
\hline-0.800 & 2.754 & 2.642 & 2.534 & 2.431 & 2.334 & 2.240 & 2.151 & 2.065 & 1.984 & 1.907 & 1.832 & 1.761 & 1.692 & 1.627 & 1.564 & 1.504 & 1.447 & 1.391 & 1.338 & 1.287 & 1.238 \\
\hline-0.850 & 2.843 & 2.724 & 2.613 & 2.506 & 2.404 & 2.307 & 2.214 & 2.126 & 2.041 & 1.960 & 1.883 & 1.810 & 1.739 & 1.671 & 1.606 & 1.544 & 1.485 & 1.428 & 1.373 & 1.321 & 1.270 \\
\hline-0.900 & 2.935 & 2.812 & 2.695 & 2.583 & 2.477 & 2.376 & 2.279 & 2.188 & 2.100 & 2.017 & 1.937 & 1.860 & 1.787 & 1.717 & 1.650 & 1.586 & 1.525 & 1.466 & 1.409 & 1.355 & 1.303 \\
\hline-0.950 & 3.033 & 2.902 & 2.780 & 2.664 & 2.553 & 2.448 & 2.348 & 2.253 & 2.161 & 2.075 & 1.992 & 1.913 & 1.837 & 1.765 & 1.695 & 1.629 & 1.566 & 1.505 & 1.446 & 1.391 & 1.337 \\
\hline-1.000 & 3.135 & 2.999 & 2.871 & 2.748 & 2.633 & 2.524 & 2.419 & 2.320 & 2.226 & 2.135 & 2.049 & 1.967 & 1.889 & 1.814 & 1.742 & 1.674 & 1.608 & 1.545 & 1.485 & 1.427 & 1.372 \\
\hline-1.050 & 3.242 & 3.099 & 2.965 & 2.837 & 2.717 & 2.602 & 2.494 & 2.390 & 2.292 & 2.198 & 2.109 & 2.024 & 1.943 & 1.865 & 1.791 & 1.720 & 1.652 & 1.587 & 1.525 & 1.465 & 1.408 \\
\hline-1.100 & 3.354 & 3.205 & 3.064 & 2.930 & 2.804 & 2.685 & 2.571 & 2.464 & 2.361 & 2.264 & 2.171 & 2.083 & 1.998 & 1.918 & 1.841 & 1.768 & 1.697 & 1.630 & 1.566 & 1.505 & 1.446 \\
\hline-1.150 & 3.473 & 3.316 & 3.167 & 3.027 & 2.896 & 2.771 & 2.652 & 2.540 & 2.434 & 2.332 & 2.236 & 2.144 & 2.056 & 1.973 & 1.893 & 1.817 & 1.745 & 1.675 & 1.609 & 1.545 & 1.484 \\
\hline-1.200 & 3.599 & 3.433 & 3.277 & 3.130 & 2.992 & 2.861 & 2.737 & 2.620 & 2.509 & 2.403 & 2.303 & 2.207 & 2.117 & 2.030 & 1.947 & 1.869 & 1.793 & 1.722 & 1.653 & 1.587 & 1.525 \\
\hline-1.250 & 3.731 & 3.556 & 3.391 & 3.238 & 3.092 & 2.955 & 2.826 & 2.704 & 2.588 & 2.478 & 2.373 & 2.274 & 2.179 & 2.089 & 2.004 & 1.922 & 1.844 & 1.770 & 1.699 & 1.631 & 1.566 \\
\hline-1.300 & 3.871 & 3.686 & 3.513 & 3.351 & 3.198 & 3.054 & 2.919 & 2.791 & 2.670 & 2.555 & 2.446 & 2.343 & 2.245 & 2.151 & 2.062 & 1.977 & 1.897 & 1.820 & 1.746 & 1.676 & 1.609 \\
\hline-1.350 & 4.020 & 3.824 & 3.641 & 3.470 & 3.310 & 3.159 & 3.017 & 2.882 & 2.756 & 2.636 & 2.522 & 2.415 & 2.313 & 2.215 & 2.123 & 2.035 & 1.951 & 1.871 & 1.795 & 1.723 & 1.653 \\
\hline-1.400 & 4.178 & 3.970 & 3.777 & 3.596 & 3.427 & 3.268 & 3.119 & 2.978 & 2.846 & 2.721 & 2.602 & 2.490 & 2.383 & 2.282 & 2.186 & 2.095 & 2.008 & 1.925 & 1.846 & 1.771 & 1.699 \\
\hline-1.450 & 4.347 & 4.125 & 3.920 & 3.729 & 3.550 & 3.383 & 3.227 & 3.079 & 2.940 & 2.809 & 2.685 & 2.568 & 2.457 & 2.352 & 2.252 & 2.157 & 2.067 & 1.981 & 1.899 & 1.821 & 1.747 \\
\hline-1.500 & 4.526 & 4.290 & 4.072 & 3.870 & 3.681 & 3.505 & 3.340 & 3.185 & 3.039 & 2.902 & 2.772 & 2.650 & 2.534 & 2.425 & 2.321 & 2.222 & 2.128 & 2.039 & 1.954 & 1.874 & 1.797 \\
\hline-1.550 & 4.717 & 4.466 & 4.234 & 4.019 & 3.819 & 3.633 & 3.459 & 3.296 & 3.143 & 2.999 & 2.864 & 2.736 & 2.615 & 2.501 & 2.392 & 2.290 & 2.192 & 2.100 & 2.011 & 1.928 & 1.848 \\
\hline-1.600 & 4.924 & 4.654 & 4.406 & 4.178 & 3.966 & 3.769 & 3.585 & 3.413 & 3.252 & 3.101 & 2.959 & 2.826 & 2.699 & 2.580 & 2.467 & 2.360 & 2.259 & 2.162 & 2.071 & 1.984 & 1.901 \\
\hline-1.650 & 5.145 & 4.855 & 4.590 & 4.346 & 4.121 & 3.912 & 3.718 & 3.537 & 3.367 & 3.209 & 3.060 & 2.920 & 2.787 & 2.663 & 2.545 & 2.434 & 2.328 & 2.228 & 2.133 & 2.042 & 1.956 \\
\hline-1.700 & 5.383 & 5.071 & 4.787 & 4.526 & 4.286 & 4.064 & 3.859 & 3.667 & 3.489 & 3.322 & 3.165 & 3.018 & 2.880 & 2.750 & 2.626 & 2.510 & 2.400 & 2.296 & 2.197 & 2.103 & 2.014 \\
\hline-1.750 & 5.640 & 5.303 & 4.997 & 4.718 & 4.462 & 4.226 & 4.008 & 3.805 & 3.617 & 3.441 & 3.276 & 3.122 & 2.977 & 2.840 & 2.712 & 2.590 & 2.475 & 2.367 & 2.264 & 2.166 & 2.074 \\
\hline-1.800 & 5.919 & 5.554 & 5.224 & 4.924 & 4.650 & 4.398 & 4.166 & 3.951 & 3.752 & 3.566 & 3.393 & 3.231 & 3.078 & 2.935 & 2.801 & 2.674 & 2.554 & 2.441 & 2.334 & 2.232 & 2.136 \\
\hline-1.850 & 6.222 & 5.825 & 5.468 & 5.145 & 4.851 & 4.582 & 4.335 & 4.106 & 3.895 & 3.699 & 3.516 & 3.345 & 3.185 & 3.035 & 2.894 & 2.762 & 2.636 & 2.518 & 2.407 & 2.301 & 2.201 \\
\hline-1.900 & 6.553 & 6.119 & 5.732 & 5.383 & 5.066 & 4.778 & 4.514 & 4.271 & 4.047 & 3.839 & 3.646 & 3.466 & 3.298 & 3.140 & 2.992 & 2.853 & 2.723 & 2.599 & 2.483 & 2.373 & 2.268 \\
\hline-1.950 & 6.916 & 6.440 & 6.018 & 5.639 & 5.298 & 4.988 & 4.706 & 4.447 & 4.208 & 3.988 & 3.783 & 3.593 & 3.416 & 3.250 & 3.095 & 2.950 & 2.813 & 2.684 & 2.562 & 2.447 & 2.339 \\
\hline-2.000 & 7.316 & 6.792 & 6.329 & 5.917 & 5.548 & 5.214 & 4.911 & 4.634 & 4.380 & 4.145 & 3.929 & 3.728 & 3.541 & 3.366 & 3.203 & 3.051 & 2.907 & 2.772 & 2.645 & 2.525 & 2.412 \\
\hline
\end{tabular}




\begin{tabular}{|c|c|c|c|c|c|c|c|c|c|c|c|c|c|c|c|c|c|c|c|c|c|}
\hline & & & & & & & & & & & $l=h$ & & & & & & & & & & \\
\hline$\phi_{1}=\phi_{2}$ & 1.000 & 1.050 & 1.100 & 1.150 & 1.200 & 1.250 & 1.300 & 1.350 & 1.400 & 1.450 & 1.500 & 1.550 & 1.600 & 1.650 & 1.700 & 1.750 & 1.800 & 1.850 & 1.900 & 1.950 & 2.000 \\
\hline 0.000 & 1.315 & 1.245 & 1.178 & 1.116 & 1.056 & 1.000 & 0.947 & 0.897 & 0.849 & 0.804 & 0.761 & 0.720 & 0.682 & 0.646 & 0.611 & 0.579 & 0.548 & 0.519 & 0.491 & 0.465 & 0.440 \\
\hline-0.050 & 1.365 & 1.291 & 1.223 & 1.157 & 1.096 & 1.037 & 0.981 & 0.929 & 0.879 & 0.832 & 0.788 & 0.746 & 0.706 & 0.668 & 0.633 & 0.599 & 0.567 & 0.537 & 0.508 & 0.481 & 0.455 \\
\hline-0.100 & 1.417 & 1.341 & 1.269 & 1.201 & 1.136 & 1.075 & 1.018 & 0.963 & 0.911 & 0.862 & 0.816 & 0.772 & 0.731 & 0.692 & 0.655 & 0.620 & 0.587 & 0.555 & 0.525 & 0.497 & 0.471 \\
\hline-0.150 & 1.473 & 1.393 & 1.318 & 1.246 & 1.179 & 1.115 & 1.055 & 0.999 & 0.945 & 0.894 & 0.846 & 0.800 & 0.757 & 0.716 & 0.678 & 0.641 & 0.607 & 0.574 & 0.544 & 0.514 & 0.487 \\
\hline-0.200 & 1.530 & 1.447 & 1.368 & 1.294 & 1.224 & 1.157 & 1.095 & 1.036 & 0.979 & 0.927 & 0.876 & 0.829 & 0.784 & 0.742 & 0.702 & 0.664 & 0.628 & 0.594 & 0.562 & 0.532 & 0.504 \\
\hline-0.250 & 1.591 & 1.504 & 1.422 & 1.344 & 1.270 & 1.201 & 1.136 & 1.074 & 1.016 & 0.960 & 0.908 & 0.859 & 0.812 & 0.768 & 0.727 & 0.688 & 0.650 & 0.615 & 0.582 & 0.551 & 0.521 \\
\hline-0.300 & 1.655 & 1.563 & 1.477 & 1.396 & 1.319 & 1.247 & 1.179 & 1.114 & 1.054 & 0.996 & 0.942 & 0.890 & 0.842 & 0.796 & 0.753 & 0.712 & 0.673 & 0.637 & 0.602 & 0.570 & 0.539 \\
\hline-0.350 & 1.722 & 1.626 & 1.536 & 1.451 & 1.371 & 1.295 & 1.223 & 1.156 & 1.093 & 1.033 & 0.976 & 0.923 & 0.873 & 0.825 & 0.780 & 0.737 & 0.697 & 0.659 & 0.624 & 0.590 & 0.558 \\
\hline-0.400 & 1.792 & 1.692 & 1.597 & 1.508 & 1.424 & 1.345 & 1.271 & 1.201 & 1.135 & 1.072 & 1.013 & 0.957 & 0.905 & 0.855 & 0.808 & 0.764 & 0.722 & 0.683 & 0.646 & 0.610 & 0.577 \\
\hline-0.450 & 1.867 & 1.761 & 1.662 & 1.569 & 1.481 & 1.398 & 1.320 & 1.247 & 1.178 & 1.112 & 1.051 & 0.993 & 0.938 & 0.886 & 0.838 & 0.792 & 0.748 & 0.707 & 0.668 & 0.632 & 0.597 \\
\hline-0.500 & 1.945 & 1.834 & 1.730 & 1.632 & 1.540 & 1.453 & 1.372 & 1.295 & 1.223 & 1.155 & 1.091 & 1.030 & 0.973 & 0.919 & 0.868 & 0.820 & 0.775 & 0.733 & 0.692 & 0.654 & 0.619 \\
\hline-0.550 & 2.027 & 1.910 & 1.801 & 1.698 & 1.602 & 1.511 & 1.426 & 1.346 & 1.270 & 1.200 & 1.132 & 1.069 & 1.009 & 0.953 & 0.900 & 0.851 & 0.803 & 0.759 & 0.717 & 0.678 & 0.640 \\
\hline-0.600 & 2.114 & 1.991 & 1.876 & 1.769 & 1.667 & 1.572 & 1.483 & 1.398 & 1.320 & 1.246 & 1.176 & 1.110 & 1.048 & 0.989 & 0.934 & 0.882 & 0.833 & 0.787 & 0.743 & 0.702 & 0.663 \\
\hline-0.650 & 2.206 & 2.076 & 1.956 & 1.842 & 1.736 & 1.636 & 1.542 & 1.455 & 1.372 & 1.294 & 1.221 & 1.152 & 1.087 & 1.026 & 0.969 & 0.915 & 0.864 & 0.816 & 0.770 & 0.727 & 0.687 \\
\hline-0.700 & 2.303 & 2.167 & 2.040 & 1.920 & 1.808 & 1.704 & 1.605 & 1.513 & 1.426 & 1.345 & 1.269 & 1.197 & 1.129 & 1.065 & 1.005 & 0.949 & 0.896 & 0.846 & 0.798 & 0.754 & 0.712 \\
\hline-0.750 & 2.406 & 2.262 & 2.128 & 2.002 & 1.884 & 1.775 & 1.671 & 1.575 & 1.484 & 1.399 & 1.319 & 1.243 & 1.173 & 1.106 & 1.044 & 0.985 & 0.929 & 0.877 & 0.828 & 0.782 & 0.738 \\
\hline-0.800 & 2.515 & 2.363 & 2.221 & 2.089 & 1.965 & 1.849 & 1.741 & 1.639 & 1.544 & 1.455 & 1.371 & 1.292 & 1.218 & 1.149 & 1.083 & 1.022 & 0.964 & 0.910 & 0.859 & 0.810 & 0.765 \\
\hline-0.850 & 2.631 & 2.470 & 2.320 & 2.180 & 2.050 & 1.928 & 1.814 & 1.707 & 1.607 & 1.514 & 1.426 & 1.344 & 1.266 & 1.194 & 1.125 & 1.061 & 1.001 & 0.944 & 0.891 & 0.840 & 0.793 \\
\hline-0.900 & 2.754 & 2.583 & 2.425 & 2.277 & 2.140 & 2.011 & 1.891 & 1.779 & 1.674 & 1.576 & 1.484 & 1.397 & 1.316 & 1.240 & 1.169 & 1.102 & 1.039 & 0.980 & 0.924 & 0.872 & 0.822 \\
\hline-0.950 & 2.885 & 2.704 & 2.536 & 2.380 & 2.234 & 2.099 & 1.973 & 1.855 & 1.744 & 1.641 & 1.544 & 1.454 & 1.369 & 1.290 & 1.215 & 1.145 & 1.079 & 1.017 & 0.959 & 0.904 & 0.853 \\
\hline-1.000 & 3.025 & 2.832 & 2.654 & 2.489 & 2.335 & 2.192 & 2.059 & 1.934 & 1.818 & 1.710 & 1.608 & 1.513 & 1.424 & 1.341 & 1.263 & 1.190 & 1.121 & 1.056 & 0.996 & 0.939 & 0.885 \\
\hline-1.050 & 3.174 & 2.969 & 2.780 & 2.604 & 2.442 & 2.290 & 2.150 & 2.018 & 1.896 & 1.782 & 1.676 & 1.576 & 1.483 & 1.395 & 1.313 & 1.237 & 1.165 & 1.097 & 1.034 & 0.974 & 0.919 \\
\hline-1.100 & 3.333 & 3.115 & 2.913 & 2.727 & 2.555 & 2.395 & 2.246 & 2.107 & 1.979 & 1.858 & 1.746 & 1.642 & 1.544 & 1.452 & 1.366 & 1.286 & 1.211 & 1.140 & 1.074 & 1.012 & 0.954 \\
\hline-1.150 & 3.504 & 3.270 & 3.056 & 2.858 & 2.675 & 2.505 & 2.348 & 2.202 & 2.066 & 1.939 & 1.821 & 1.711 & 1.608 & 1.512 & 1.422 & 1.338 & 1.259 & 1.185 & 1.116 & 1.051 & 0.990 \\
\hline-1.200 & 3.687 & 3.438 & 3.208 & 2.997 & 2.803 & 2.623 & 2.456 & 2.301 & 2.158 & 2.024 & 1.900 & 1.784 & 1.676 & 1.575 & 1.480 & 1.392 & 1.310 & 1.232 & 1.160 & 1.092 & 1.028 \\
\hline-1.250 & 3.884 & 3.617 & 3.372 & 3.146 & 2.939 & 2.748 & 2.571 & 2.407 & 2.255 & 2.114 & 1.983 & 1.861 & 1.747 & 1.641 & 1.542 & 1.449 & 1.363 & 1.282 & 1.206 & 1.135 & 1.068 \\
\hline-1.300 & 4.097 & 3.809 & 3.546 & 3.306 & 3.084 & 2.881 & 2.693 & 2.519 & 2.358 & 2.209 & 2.071 & 1.942 & 1.822 & 1.711 & 1.607 & 1.509 & 1.419 & 1.334 & 1.254 & 1.180 & 1.110 \\
\hline-1.350 & 4.327 & 4.017 & 3.734 & 3.476 & 3.240 & 3.023 & 2.823 & 2.638 & 2.468 & 2.310 & 2.164 & 2.028 & 1.902 & 1.784 & 1.675 & 1.573 & 1.477 & 1.388 & 1.305 & 1.227 & 1.154 \\
\hline-1.400 & 4.576 & 4.241 & 3.937 & 3.660 & 3.407 & 3.175 & 2.962 & 2.766 & 2.585 & 2.417 & 2.262 & 2.119 & 1.986 & 1.862 & 1.747 & 1.639 & 1.539 & 1.446 & 1.358 & 1.277 & 1.201 \\
\hline-1.450 & 4.846 & 4.483 & 4.155 & 3.857 & 3.585 & 3.337 & 3.110 & 2.901 & 2.709 & 2.531 & 2.367 & 2.215 & 2.074 & 1.944 & 1.822 & 1.709 & 1.604 & 1.506 & 1.414 & 1.329 & 1.249 \\
\hline-1.500 & 5.141 & 4.747 & 4.391 & 4.070 & 3.778 & 3.512 & 3.269 & 3.046 & 2.841 & 2.652 & 2.478 & 2.317 & 2.169 & 2.031 & 1.902 & 1.783 & 1.673 & 1.569 & 1.473 & 1.384 & 1.300 \\
\hline-1.550 & 5.463 & 5.033 & 4.647 & 4.300 & 3.985 & 3.699 & 3.439 & 3.200 & 2.982 & 2.781 & 2.596 & 2.426 & 2.268 & 2.122 & 1.987 & 1.862 & 1.745 & 1.636 & 1.535 & 1.441 & 1.353 \\
\hline-1.600 & 5.817 & 5.346 & 4.926 & 4.549 & 4.209 & 3.901 & 3.621 & 3.366 & 3.133 & 2.919 & 2.722 & 2.541 & 2.374 & 2.220 & 2.077 & 1.944 & 1.821 & 1.707 & 1.601 & 1.502 & 1.409 \\
\hline-1.650 & 6.207 & 5.690 & 5.230 & 4.820 & 4.452 & 4.119 & 3.818 & 3.544 & 3.294 & 3.066 & 2.856 & 2.664 & 2.486 & 2.323 & 2.172 & 2.032 & 1.902 & 1.781 & 1.670 & 1.565 & 1.469 \\
\hline-1.700 & 6.639 & 6.068 & 5.564 & 5.116 & 4.715 & 4.355 & 4.030 & 3.735 & 3.467 & 3.223 & 3.000 & 2.794 & 2.606 & 2.432 & 2.272 & 2.124 & 1.987 & 1.860 & 1.742 & 1.633 & 1.531 \\
\hline-1.750 & 7.119 & 6.486 & 5.930 & 5.439 & 5.002 & 4.611 & 4.259 & 3.942 & 3.654 & 3.392 & 3.153 & 2.934 & 2.733 & 2.549 & 2.379 & 2.222 & 2.077 & 1.943 & 1.819 & 1.704 & 1.596 \\
\hline-1.800 & 7.656 & 6.949 & 6.334 & 5.794 & 5.315 & 4.889 & 4.508 & 4.165 & 3.855 & 3.573 & 3.317 & 3.083 & 2.870 & 2.673 & 2.493 & 2.327 & 2.173 & 2.031 & 1.900 & 1.778 & 1.666 \\
\hline-1.850 & 8.260 & 7.467 & 6.782 & 6.185 & 5.659 & 5.193 & 4.778 & 4.406 & 4.071 & 3.768 & 3.494 & 3.243 & 3.015 & 2.806 & 2.614 & 2.437 & 2.275 & 2.125 & 1.986 & 1.858 & 1.739 \\
\hline-1.900 & 8.945 & 8.049 & 7.282 & 6.618 & 6.038 & 5.526 & 5.073 & 4.669 & 4.306 & 3.979 & 3.683 & 3.415 & 3.171 & 2.947 & 2.743 & 2.555 & 2.383 & 2.224 & 2.077 & 1.941 & 1.816 \\
\hline-1.950 & 9.726 & 8.706 & 7.842 & 7.100 & 6.456 & 5.893 & 5.396 & 4.955 & 4.561 & 4.207 & 3.888 & 3.600 & 3.338 & 3.099 & 2.881 & 2.681 & 2.498 & 2.329 & 2.173 & 2.030 & 1.897 \\
\hline-2.000 & 10.627 & 9.455 & 8.473 & 7.639 & 6.921 & 6.297 & 5.750 & 5.267 & 4.838 & 4.454 & 4.109 & 3.799 & 3.517 & 3.261 & 3.028 & 2.815 & 2.620 & 2.441 & 2.276 & 2.124 & 1.984 \\
\hline
\end{tabular}

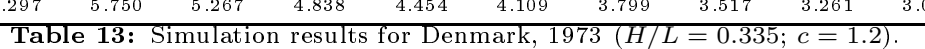




\begin{tabular}{|c|c|c|c|c|c|c|c|c|c|c|c|c|c|c|c|c|c|c|c|c|c|}
\hline & & & & & & & & & & & $l=h$ & & & & & & & & & & \\
\hline$\phi_{1}=\phi_{2}$ & 1.000 & 1.050 & 1.100 & 1.150 & 1.200 & 1.250 & 1.300 & 1.350 & 1.400 & 1.450 & 1.500 & 1.550 & 1.600 & 1.650 & 1.700 & 1.750 & 1.800 & 1.850 & 1.900 & 1.950 & 2.000 \\
\hline 0.000 & 1.314 & 1.265 & 1.217 & 1.172 & 1.128 & 1.086 & 1.046 & 1.006 & 0.969 & 0.932 & 0.897 & 0.864 & 0.832 & 0.800 & 0.770 & 0.741 & 0.714 & 0.687 & 0.661 & 0.636 & 0.613 \\
\hline-0.050 & 1.351 & 1.300 & 1.251 & 1.204 & 1.159 & 1.115 & 1.073 & 1.033 & 0.994 & 0.957 & 0.921 & 0.886 & 0.853 & 0.821 & 0.790 & 0.760 & 0.732 & 0.704 & 0.678 & 0.652 & 0.628 \\
\hline-0.100 & 1.389 & 1.336 & 1.286 & 1.237 & 1.190 & 1.145 & 1.102 & 1.060 & 1.020 & 0.982 & 0.945 & 0.909 & 0.875 & 0.842 & 0.810 & 0.779 & 0.750 & 0.722 & 0.695 & 0.668 & 0.643 \\
\hline-0.150 & 1.428 & 1.374 & 1.321 & 1.271 & 1.223 & 1.176 & 1.132 & 1.089 & 1.047 & 1.008 & 0.969 & 0.933 & 0.897 & 0.863 & 0.831 & 0.799 & 0.769 & 0.740 & 0.712 & 0.685 & 0.659 \\
\hline-0.200 & 1.469 & 1.412 & 1.359 & 1.307 & 1.256 & 1.208 & 1.162 & 1.118 & 1.075 & 1.034 & 0.995 & 0.957 & 0.921 & 0.886 & 0.852 & 0.820 & 0.789 & 0.759 & 0.730 & 0.702 & 0.676 \\
\hline-0.250 & 1.512 & 1.453 & 1.397 & 1.343 & 1.291 & 1.242 & 1.194 & 1.148 & 1.105 & 1.062 & 1.021 & 0.982 & 0.945 & 0.909 & 0.874 & 0.841 & 0.809 & 0.778 & 0.748 & 0.720 & 0.693 \\
\hline-0.300 & 1.556 & 1.495 & 1.437 & 1.381 & 1.327 & 1.276 & 1.227 & 1.179 & 1.134 & 1.091 & 1.049 & 1.008 & 0.970 & 0.933 & 0.897 & 0.863 & 0.830 & 0.798 & 0.767 & 0.738 & 0.710 \\
\hline-0.350 & 1.601 & 1.538 & 1.478 & 1.421 & 1.365 & 1.311 & 1.261 & 1.212 & 1.165 & 1.120 & 1.077 & 1.035 & 0.996 & 0.957 & 0.920 & 0.885 & 0.851 & 0.819 & 0.787 & 0.757 & 0.728 \\
\hline-0.400 & 1.649 & 1.584 & 1.521 & 1.461 & 1.404 & 1.349 & 1.296 & 1.246 & 1.197 & 1.151 & 1.106 & 1.063 & 1.022 & 0.983 & 0.945 & 0.908 & 0.873 & 0.840 & 0.807 & 0.776 & 0.747 \\
\hline-0.450 & 1.698 & 1.631 & 1.566 & 1.504 & 1.444 & 1.387 & 1.333 & 1.280 & 1.230 & 1.182 & 1.136 & 1.092 & 1.050 & 1.009 & 0.970 & 0.932 & 0.896 & 0.861 & 0.828 & 0.796 & 0.766 \\
\hline-0.500 & 1.750 & 1.680 & 1.612 & 1.548 & 1.486 & 1.427 & 1.371 & 1.317 & 1.265 & 1.215 & 1.168 & 1.122 & 1.078 & 1.036 & 0.996 & 0.957 & 0.920 & 0.884 & 0.850 & 0.817 & 0.785 \\
\hline-0.550 & 1.804 & 1.731 & 1.661 & 1.594 & 1.530 & 1.469 & 1.410 & 1.354 & 1.301 & 1.249 & 1.200 & 1.153 & 1.107 & 1.064 & 1.022 & 0.982 & 0.944 & 0.907 & 0.872 & 0.838 & 0.806 \\
\hline-0.600 & 1.860 & 1.784 & 1.711 & 1.642 & 1.575 & 1.512 & 1.451 & 1.393 & 1.337 & 1.284 & 1.233 & 1.185 & 1.138 & 1.093 & 1.050 & 1.009 & 0.969 & 0.931 & 0.895 & 0.860 & 0.827 \\
\hline-0.650 & 1.919 & 1.839 & 1.764 & 1.692 & 1.623 & 1.557 & 1.494 & 1.433 & 1.376 & 1.321 & 1.268 & 1.218 & 1.169 & 1.123 & 1.079 & 1.036 & 0.995 & 0.956 & 0.919 & 0.883 & 0.848 \\
\hline-0.700 & 1.980 & 1.897 & 1.818 & 1.743 & 1.672 & 1.603 & 1.538 & 1.475 & 1.416 & 1.359 & 1.304 & 1.252 & 1.202 & 1.154 & 1.108 & 1.064 & 1.022 & 0.982 & 0.943 & 0.906 & 0.870 \\
\hline-0.750 & 2.044 & 1.957 & 1.876 & 1.797 & 1.723 & 1.651 & 1.584 & 1.519 & 1.457 & 1.398 & 1.341 & 1.287 & 1.236 & 1.186 & 1.139 & 1.093 & 1.050 & 1.008 & 0.968 & 0.930 & 0.893 \\
\hline-0.800 & 2.111 & 2.021 & 1.936 & 1.854 & 1.776 & 1.702 & 1.631 & 1.564 & 1.500 & 1.439 & 1.380 & 1.324 & 1.271 & 1.219 & 1.170 & 1.123 & 1.079 & 1.036 & 0.994 & 0.955 & 0.917 \\
\hline-0.850 & 2.182 & 2.088 & 1.998 & 1.913 & 1.831 & 1.755 & 1.681 & 1.611 & 1.545 & 1.481 & 1.420 & 1.362 & 1.307 & 1.254 & 1.203 & 1.155 & 1.108 & 1.064 & 1.021 & 0.981 & 0.942 \\
\hline-0.900 & 2.256 & 2.157 & 2.063 & 1.974 & 1.890 & 1.809 & 1.733 & 1.660 & 1.591 & 1.525 & 1.462 & 1.402 & 1.344 & 1.290 & 1.237 & 1.187 & 1.139 & 1.093 & 1.049 & 1.007 & 0.967 \\
\hline-0.950 & 2.334 & 2.230 & 2.131 & 2.038 & 1.951 & 1.867 & 1.787 & 1.711 & 1.639 & 1.571 & 1.505 & 1.443 & 1.384 & 1.327 & 1.272 & 1.221 & 1.171 & 1.124 & 1.078 & 1.035 & 0.993 \\
\hline-1.000 & 2.415 & 2.306 & 2.203 & 2.106 & 2.014 & 1.927 & 1.844 & 1.765 & 1.690 & 1.619 & 1.551 & 1.486 & 1.424 & 1.365 & 1.309 & 1.255 & 1.204 & 1.155 & 1.108 & 1.063 & 1.020 \\
\hline-1.050 & 2.501 & 2.387 & 2.279 & 2.177 & 2.080 & 1.989 & 1.903 & 1.820 & 1.742 & 1.668 & 1.598 & 1.530 & 1.466 & 1.405 & 1.347 & 1.291 & 1.238 & 1.187 & 1.139 & 1.093 & 1.048 \\
\hline-1.100 & 2.592 & 2.471 & 2.358 & 2.251 & 2.150 & 2.055 & 1.964 & 1.878 & 1.797 & 1.720 & 1.646 & 1.577 & 1.510 & 1.447 & 1.386 & 1.329 & 1.274 & 1.221 & 1.171 & 1.123 & 1.077 \\
\hline-1.150 & 2.687 & 2.560 & 2.441 & 2.329 & 2.223 & 2.123 & 2.029 & 1.939 & 1.854 & 1.774 & 1.697 & 1.625 & 1.556 & 1.490 & 1.427 & 1.367 & 1.310 & 1.256 & 1.204 & 1.155 & 1.107 \\
\hline-1.200 & 2.788 & 2.654 & 2.529 & 2.411 & 2.300 & 2.195 & 2.096 & 2.003 & 1.914 & 1.830 & 1.751 & 1.675 & 1.603 & 1.535 & 1.470 & 1.408 & 1.349 & 1.292 & 1.239 & 1.187 & 1.138 \\
\hline-1.250 & 2.895 & 2.753 & 2.621 & 2.497 & 2.380 & 2.270 & 2.167 & 2.069 & 1.977 & 1.889 & 1.806 & 1.727 & 1.652 & 1.581 & 1.514 & 1.450 & 1.388 & 1.330 & 1.274 & 1.221 & 1.171 \\
\hline-1.300 & 3.008 & 2.859 & 2.719 & 2.588 & 2.465 & 2.350 & 2.241 & 2.139 & 2.042 & 1.950 & 1.864 & 1.782 & 1.704 & 1.630 & 1.560 & 1.493 & 1.430 & 1.369 & 1.311 & 1.256 & 1.204 \\
\hline-1.350 & 3.128 & 2.970 & 2.822 & 2.684 & 2.554 & 2.433 & 2.319 & 2.212 & 2.110 & 2.015 & 1.924 & 1.839 & 1.758 & 1.681 & 1.608 & 1.538 & 1.472 & 1.410 & 1.350 & 1.293 & 1.239 \\
\hline-1.400 & 3.257 & 3.088 & 2.931 & 2.785 & 2.649 & 2.521 & 2.401 & 2.288 & 2.182 & 2.082 & 1.988 & 1.898 & 1.814 & 1.734 & 1.658 & 1.585 & 1.517 & 1.452 & 1.390 & 1.331 & 1.274 \\
\hline-1.450 & 3.394 & 3.214 & 3.047 & 2.892 & 2.748 & 2.613 & 2.487 & 2.369 & 2.257 & 2.153 & 2.054 & 1.960 & 1.872 & 1.789 & 1.710 & 1.634 & 1.563 & 1.496 & 1.431 & 1.370 & 1.312 \\
\hline-1.500 & 3.540 & 3.348 & 3.171 & 3.006 & 2.853 & 2.711 & 2.578 & 2.453 & 2.337 & 2.227 & 2.123 & 2.026 & 1.933 & 1.846 & 1.764 & 1.686 & 1.612 & 1.541 & 1.474 & 1.411 & 1.350 \\
\hline-1.550 & 3.697 & 3.491 & 3.302 & 3.127 & 2.965 & 2.814 & 2.674 & 2.543 & 2.420 & 2.304 & 2.196 & 2.094 & 1.997 & 1.906 & 1.820 & 1.739 & 1.662 & 1.589 & 1.519 & 1.453 & 1.391 \\
\hline-1.600 & 3.865 & 3.644 & 3.442 & 3.256 & 3.083 & 2.924 & 2.775 & 2.637 & 2.507 & 2.386 & 2.272 & 2.165 & 2.064 & 1.969 & 1.879 & 1.795 & 1.714 & 1.638 & 1.566 & 1.497 & 1.432 \\
\hline-1.650 & 4.046 & 3.808 & 3.592 & 3.393 & 3.209 & 3.040 & 2.883 & 2.736 & 2.600 & 2.472 & 2.353 & 2.240 & 2.135 & 2.035 & 1.941 & 1.853 & 1.769 & 1.690 & 1.614 & 1.543 & 1.476 \\
\hline-1.700 & 4.241 & 3.985 & 3.752 & 3.539 & 3.344 & 3.163 & 2.996 & 2.841 & 2.697 & 2.563 & 2.437 & 2.319 & 2.208 & 2.104 & 2.006 & 1.913 & 1.826 & 1.743 & 1.665 & 1.591 & 1.521 \\
\hline-1.750 & 4.453 & 4.175 & 3.924 & 3.696 & 3.487 & 3.294 & 3.117 & 2.953 & 2.800 & 2.658 & 2.526 & 2.402 & 2.286 & 2.176 & 2.074 & 1.977 & 1.886 & 1.800 & 1.718 & 1.641 & 1.568 \\
\hline-1.800 & 4.683 & 4.381 & 4.110 & 3.864 & 3.640 & 3.434 & 3.246 & 3.071 & 2.910 & 2.759 & 2.620 & 2.489 & 2.367 & 2.252 & 2.145 & 2.044 & 1.948 & 1.858 & 1.773 & 1.693 & 1.617 \\
\hline-1.850 & 4.934 & 4.605 & 4.311 & 4.045 & 3.804 & 3.584 & 3.382 & 3.197 & 3.025 & 2.866 & 2.719 & 2.581 & 2.453 & 2.332 & 2.219 & 2.113 & 2.013 & 1.919 & 1.831 & 1.747 & 1.668 \\
\hline-1.900 & 5.208 & 4.848 & 4.528 & 4.240 & 3.980 & 3.744 & 3.528 & 3.331 & 3.148 & 2.980 & 2.823 & 2.678 & 2.543 & 2.416 & 2.298 & 2.186 & 2.082 & 1.984 & 1.891 & 1.804 & 1.721 \\
\hline-1.950 & 5.511 & 5.115 & 4.764 & 4.452 & 4.170 & 3.916 & 3.685 & 3.473 & 3.279 & 3.100 & 2.934 & 2.781 & 2.638 & 2.504 & 2.380 & 2.263 & 2.154 & 2.051 & 1.954 & 1.863 & 1.777 \\
\hline-2.000 & 5.845 & 5.407 & 5.022 & 4.681 & 4.376 & 11 & & & 3.41 & & & 2880 & & & 2.466 & 2.344 & 2.229 & 2.121 & 2.020 & 1.924 & 1.835 \\
\hline
\end{tabular}

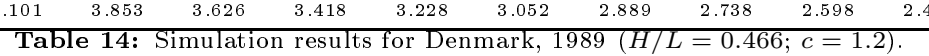




\begin{tabular}{|c|c|c|c|c|c|c|c|c|c|c|c|c|c|c|c|c|c|c|c|c|c|}
\hline & \multicolumn{21}{|c|}{$l=h$} \\
\hline$\phi_{1}=\phi_{2}$ & 1.000 & 1.050 & 1.100 & 1.150 & 1.200 & 1.250 & 1.300 & 1.350 & 1.400 & 1.450 & 1.500 & 1.550 & 1.600 & 1.650 & 1.700 & 1.750 & 1.800 & 1.850 & 1.900 & 1.950 & 2.000 \\
\hline 0.000 & 1.314 & 1.174 & 1.049 & 0.938 & 0.838 & 0.748 & 0.669 & 0.597 & 0.534 & 0.477 & 0.426 & 0.381 & 0.340 & 0.304 & 0.271 & 0.242 & 0.217 & 0.194 & 0.173 & 0.155 & 0.138 \\
\hline-0.050 & 1.397 & 1.248 & 1.114 & 0.995 & 0.889 & 0.794 & 0.709 & 0.633 & 0.565 & 0.505 & 0.451 & 0.403 & 0.360 & 0.321 & 0.287 & 0.256 & 0.229 & 0.204 & 0.183 & 0.163 & 0.146 \\
\hline-0.100 & 1.486 & 1.326 & 1.184 & 1.057 & 0.943 & 0.842 & 0.752 & 0.671 & 0.599 & 0.535 & 0.477 & 0.426 & 0.381 & 0.340 & 0.304 & 0.271 & 0.242 & 0.216 & 0.193 & 0.172 & 0.154 \\
\hline-0.150 & 1.581 & 1.410 & 1.258 & 1.123 & 1.001 & 0.894 & 0.797 & 0.711 & 0.635 & 0.567 & 0.506 & 0.451 & 0.403 & 0.360 & 0.321 & 0.287 & 0.256 & 0.228 & 0.204 & 0.182 & 0.162 \\
\hline-0.200 & 1.683 & 1.501 & 1.338 & 1.193 & 1.064 & 0.949 & 0.846 & 0.755 & 0.673 & 0.601 & 0.536 & 0.478 & 0.427 & 0.381 & 0.340 & 0.303 & 0.271 & 0.241 & 0.215 & 0.192 & 0.172 \\
\hline-0.250 & 1.793 & 1.598 & 1.424 & 1.269 & 1.131 & 1.008 & 0.899 & 0.801 & 0.715 & 0.637 & 0.568 & 0.507 & 0.452 & 0.403 & 0.360 & 0.321 & 0.286 & 0.255 & 0.228 & 0.203 & 0.181 \\
\hline-0.300 & 1.912 & 1.702 & 1.516 & 1.350 & 1.203 & 1.071 & 0.955 & 0.851 & 0.758 & 0.676 & 0.602 & 0.537 & 0.479 & 0.427 & 0.381 & 0.339 & 0.303 & 0.270 & 0.241 & 0.215 & 0.192 \\
\hline-0.350 & 2.039 & 1.814 & 1.615 & 1.437 & 1.279 & 1.139 & 1.015 & 0.904 & 0.805 & 0.717 & 0.639 & 0.569 & 0.508 & 0.452 & 0.403 & 0.359 & 0.320 & 0.286 & 0.255 & 0.227 & 0.203 \\
\hline-0.400 & 2.177 & 1.935 & 1.721 & 1.531 & 1.362 & 1.212 & 1.079 & 0.960 & 0.855 & 0.762 & 0.678 & 0.604 & 0.538 & 0.480 & 0.427 & 0.381 & 0.339 & 0.302 & 0.270 & 0.240 & 0.214 \\
\hline-0.450 & 2.325 & 2.066 & 1.836 & 1.631 & 1.451 & 1.291 & 1.148 & 1.021 & 0.909 & 0.809 & 0.720 & 0.641 & 0.571 & 0.509 & 0.453 & 0.403 & 0.359 & 0.320 & 0.285 & 0.254 & 0.227 \\
\hline-0.500 & 2.487 & 2.207 & 1.960 & 1.741 & 1.547 & 1.375 & 1.222 & 1.087 & 0.967 & 0.860 & 0.765 & 0.681 & 0.606 & 0.539 & 0.480 & 0.428 & 0.381 & 0.339 & 0.302 & 0.269 & 0.240 \\
\hline-0.550 & 2.661 & 2.360 & 2.094 & 1.858 & 1.650 & 1.465 & 1.302 & 1.157 & 1.028 & 0.914 & 0.813 & 0.723 & 0.643 & 0.572 & 0.509 & 0.453 & 0.404 & 0.359 & 0.320 & 0.285 & 0.254 \\
\hline-0.600 & 2.850 & 2.525 & 2.238 & 1.985 & 1.761 & 1.563 & 1.388 & 1.232 & 1.095 & 0.973 & 0.865 & 0.769 & 0.683 & 0.608 & 0.541 & 0.481 & 0.428 & 0.381 & 0.339 & 0.302 & 0.269 \\
\hline-0.650 & 3.054 & 2.704 & 2.395 & 2.122 & 1.881 & 1.668 & 1.480 & 1.313 & 1.166 & 1.036 & 0.920 & 0.817 & 0.726 & 0.646 & 0.574 & 0.510 & 0.454 & 0.404 & 0.359 & 0.320 & 0.285 \\
\hline-0.700 & 3.279 & 2.899 & 2.565 & 2.271 & 2.011 & 1.782 & 1.580 & 1.401 & 1.243 & 1.103 & 0.979 & 0.869 & 0.772 & 0.686 & 0.610 & 0.542 & 0.482 & 0.428 & 0.381 & 0.339 & 0.302 \\
\hline-0.750 & 3.523 & 3.111 & 2.750 & 2.431 & 2.151 & 1.905 & 1.687 & 1.495 & 1.325 & 1.175 & 1.043 & 0.925 & 0.822 & 0.730 & 0.648 & 0.576 & 0.512 & 0.455 & 0.404 & 0.359 & 0.320 \\
\hline-0.800 & 3.789 & 3.342 & 2.950 & 2.606 & 2.304 & 2.038 & 1.804 & 1.597 & 1.415 & 1.254 & 1.111 & 0.986 & 0.874 & 0.776 & 0.689 & 0.612 & 0.543 & 0.483 & 0.429 & 0.381 & 0.339 \\
\hline-0.850 & 4.080 & 3.595 & 3.169 & 2.797 & 2.470 & 2.182 & 1.929 & 1.707 & 1.511 & 1.338 & 1.185 & 1.050 & 0.931 & 0.826 & 0.733 & 0.650 & 0.577 & 0.513 & 0.455 & 0.405 & 0.360 \\
\hline-0.900 & 4.400 & 3.871 & 3.408 & 3.004 & 2.650 & 2.339 & 2.066 & 1.826 & 1.615 & 1.429 & 1.265 & 1.120 & 0.993 & 0.880 & 0.780 & 0.692 & 0.614 & 0.545 & 0.484 & 0.430 & 0.382 \\
\hline-0.950 & 4.752 & 4.174 & 3.670 & 3.230 & 2.846 & 2.509 & 2.214 & 1.955 & 1.727 & 1.527 & 1.351 & 1.195 & 1.058 & 0.938 & 0.831 & 0.736 & 0.653 & 0.579 & 0.514 & 0.456 & 0.405 \\
\hline-1.000 & 5.140 & 4.507 & 3.957 & 3.478 & 3.060 & 2.695 & 2.375 & 2.095 & 1.849 & 1.634 & 1.444 & 1.277 & 1.130 & 1.000 & 0.885 & 0.784 & 0.695 & 0.616 & 0.546 & 0.485 & 0.430 \\
\hline-1.050 & 5.570 & 4.875 & 4.273 & 3.750 & 3.295 & 2.898 & 2.551 & 2.248 & 1.982 & 1.749 & 1.544 & 1.364 & 1.206 & 1.067 & 0.944 & 0.836 & 0.740 & 0.656 & 0.581 & 0.515 & 0.457 \\
\hline-1.100 & 6.046 & 5.281 & 4.621 & 4.048 & 3.552 & 3.119 & 2.743 & 2.414 & 2.126 & 1.874 & 1.653 & 1.459 & 1.289 & 1.139 & 1.007 & 0.891 & 0.789 & 0.698 & 0.619 & 0.548 & 0.486 \\
\hline-1.150 & 6.576 & 5.732 & 5.005 & 4.377 & 3.834 & 3.362 & 2.952 & 2.595 & 2.283 & 2.010 & 1.771 & 1.562 & 1.379 & 1.217 & 1.076 & 0.951 & 0.841 & 0.744 & 0.659 & 0.583 & 0.517 \\
\hline-1.200 & 7.169 & 6.234 & 5.432 & 4.741 & 4.145 & 3.629 & 3.182 & 2.793 & 2.454 & 2.158 & 1.900 & 1.674 & 1.476 & 1.302 & 1.149 & 1.015 & 0.897 & 0.793 & 0.702 & 0.621 & 0.550 \\
\hline-1.250 & 7.834 & 6.794 & 5.906 & 5.144 & 4.489 & 3.923 & 3.434 & 3.010 & 2.641 & 2.320 & 2.040 & 1.795 & 1.581 & 1.393 & 1.229 & 1.085 & 0.958 & 0.846 & 0.748 & 0.662 & 0.586 \\
\hline-1.300 & 8.585 & 7.423 & 6.436 & 5.593 & 4.870 & 4.248 & 3.712 & 3.248 & 2.846 & 2.496 & 2.192 & 1.927 & 1.695 & 1.493 & 1.315 & 1.160 & 1.024 & 0.904 & 0.798 & 0.706 & 0.624 \\
\hline-1.350 & 9.435 & 8.132 & 7.030 & 6.094 & 5.294 & 4.608 & 4.019 & 3.510 & 3.071 & 2.690 & 2.359 & 2.071 & 1.820 & 1.601 & 1.409 & 1.241 & 1.095 & 0.966 & 0.852 & 0.753 & 0.665 \\
\hline-1.400 & 10.405 & 8.936 & 7.700 & 6.655 & 5.767 & 5.008 & 4.358 & 3.800 & 3.318 & 2.902 & 2.541 & 2.228 & 1.956 & 1.718 & 1.511 & 1.330 & 1.171 & 1.032 & 0.911 & 0.804 & 0.710 \\
\hline-1.450 & 11.519 & 9.851 & 8.458 & 7.287 & 6.296 & 5.455 & 4.736 & 4.121 & 3.592 & 3.136 & 2.742 & 2.400 & 2.104 & 1.846 & 1.622 & 1.426 & 1.255 & 1.105 & 0.974 & 0.859 & 0.758 \\
\hline-1.500 & 12.807 & 10.901 & 9.322 & 8.002 & 6.893 & 5.955 & 5.157 & 4.477 & 3.894 & 3.394 & 2.962 & 2.589 & 2.266 & 1.986 & 1.742 & 1.530 & 1.345 & 1.183 & 1.042 & 0.918 & 0.809 \\
\hline-1.550 & 14.310 & 12.115 & 10.312 & 8.817 & 7.568 & 6.517 & 5.629 & 4.874 & 4.230 & 3.679 & 3.205 & 2.797 & 2.444 & 2.139 & 1.874 & 1.644 & 1.443 & 1.268 & 1.116 & 0.982 & 0.865 \\
\hline-1.600 & 16.081 & 13.530 & 11.456 & 9.750 & 8.335 & 7.153 & 6.159 & 5.319 & 4.605 & 3.996 & 3.474 & 3.026 & 2.640 & 2.307 & 2.018 & 1.768 & 1.551 & 1.361 & 1.196 & 1.052 & 0.926 \\
\hline-1.650 & 18.194 & 15.196 & 12.787 & 10.826 & 9.214 & 7.876 & 6.758 & 5.818 & 5.024 & 4.349 & 3.773 & 3.280 & 2.856 & 2.492 & 2.177 & 1.904 & 1.667 & 1.462 & 1.283 & 1.127 & 0.991 \\
\hline-1.700 & 20.750 & 17.181 & 14.354 & 12.079 & 10.227 & 8.703 & 7.439 & 6.383 & 5.494 & 4.743 & 4.105 & 3.561 & 3.095 & 2.695 & 2.350 & 2.053 & 1.795 & 1.572 & 1.378 & 1.209 & 1.062 \\
\hline-1.750 & 23.894 & 19.578 & 16.217 & 13.551 & 11.405 & 9.657 & 8.218 & 7.024 & 6.026 & 5.186 & 4.477 & 3.874 & 3.360 & 2.920 & 2.542 & 2.217 & 1.936 & 1.693 & 1.482 & 1.299 & 1.140 \\
\hline-1.800 & 27.843 & 22.521 & 18.464 & 15.300 & 12.787 & 10.764 & 9.114 & 7.756 & 6.629 & 5.687 & 4.894 & 4.224 & 3.655 & 3.169 & 2.754 & 2.397 & 2.090 & 1.825 & 1.595 & 1.397 & 1.224 \\
\hline-1.850 & 32.935 & 26.209 & 21.218 & 17.405 & 14.428 & 12.062 & 10.154 & 8.599 & 7.318 & 6.254 & 5.364 & 4.616 & 3.984 & 3.447 & 2.988 & 2.596 & 2.260 & 1.970 & 1.720 & 1.503 & 1.316 \\
\hline-1.900 & 39.724 & 30.950 & 24.661 & 19.981 & 16.400 & 13.600 & 11.373 & 9.576 & 8.109 & 6.901 & 5.898 & 5.059 & 4.353 & 3.756 & 3.249 & 2.817 & 2.447 & 2.129 & 1.856 & 1.620 & 1.416 \\
\hline-1.950 & 49.192 & 37.246 & 29.073 & 23.195 & 18.809 & 15.447 & 12.815 & 10.719 & 9.027 & 7.645 & 6.506 & 5.560 & 4.769 & 4.104 & 3.541 & 3.062 & 2.655 & 2.306 & 2.006 & 1.749 & 1.526 \\
\hline-2.000 & 63.256 & 45.979 & 34.911 & 27.301 & 21.807 & 17.699 & 14.544 & 12.070 & 10.099 & 8.506 & 7.205 & 6.132 & 5.240 & 4.495 & 3.867 & 3.336 & 2.886 & 2.501 & 2.172 & 1.890 & 1.647 \\
\hline
\end{tabular}




\begin{tabular}{|c|c|c|c|c|c|c|c|c|c|c|c|c|c|c|c|c|c|c|c|c|c|}
\hline & & & & & & & & & & & $=h$ & & & & & & & & & & \\
\hline$\phi_{1}=\phi_{2}$ & 1.000 & 1.050 & 1.100 & 1.150 & 1.200 & 1.250 & 1.300 & 1.350 & 1.400 & 1.450 & 1.500 & 1.550 & 1.600 & 1.650 & 1.700 & 1.750 & 1.800 & 1.850 & 1.900 & 1.950 & 2.000 \\
\hline 0.000 & 1.314 & 1.182 & 1.063 & 0.955 & 0.859 & 0.772 & 0.694 & 0.624 & 0.561 & 0.505 & 0.453 & 0.408 & 0.367 & 0.330 & 0.296 & 0.266 & 0.239 & 0.215 & 0.194 & 0.174 & 0.156 \\
\hline-0.050 & 1.395 & 1.253 & 1.126 & 1.012 & 0.910 & 0.817 & 0.735 & 0.660 & 0.593 & 0.533 & 0.479 & 0.431 & 0.387 & 0.348 & 0.313 & 0.281 & 0.253 & 0.227 & 0.204 & 0.183 & 0.165 \\
\hline-0.100 & 1.481 & 1.330 & 1.195 & 1.073 & 0.964 & 0.866 & 0.778 & 0.699 & 0.628 & 0.564 & 0.507 & 0.455 & 0.409 & 0.367 & 0.330 & 0.297 & 0.267 & 0.240 & 0.215 & 0.193 & 0.174 \\
\hline-0.150 & 1.573 & 1.412 & 1.267 & 1.138 & 1.022 & 0.917 & 0.824 & 0.740 & 0.664 & 0.597 & 0.536 & 0.481 & 0.432 & 0.388 & 0.349 & 0.313 & 0.281 & 0.253 & 0.227 & 0.204 & 0.183 \\
\hline-0.200 & 1.672 & 1.500 & 1.346 & 1.207 & 1.084 & 0.972 & 0.873 & 0.784 & 0.703 & 0.631 & 0.567 & 0.509 & 0.457 & 0.410 & 0.368 & 0.331 & 0.297 & 0.267 & 0.240 & 0.215 & 0.193 \\
\hline-0.250 & 1.778 & 1.594 & 1.429 & 1.282 & 1.150 & 1.031 & 0.925 & 0.830 & 0.745 & 0.669 & 0.600 & 0.538 & 0.483 & 0.434 & 0.389 & 0.350 & 0.314 & 0.282 & 0.253 & 0.227 & 0.204 \\
\hline-0.300 & 1.892 & 1.695 & 1.519 & 1.362 & 1.221 & 1.095 & 0.981 & 0.880 & 0.789 & 0.708 & 0.635 & 0.570 & 0.511 & 0.459 & 0.412 & 0.369 & 0.332 & 0.298 & 0.267 & 0.240 & 0.215 \\
\hline-0.400 & 2.146 & 1.920 & 1.719 & 1.539 & 1.378 & 1.234 & 1.105 & 0.990 & 0.887 & 0.795 & 0.713 & 0.639 & 0.573 & 0.514 & 0.461 & 0.413 & 0.370 & 0.332 & 0.298 & 0.267 & 0.240 \\
\hline-0.450 & 2.288 & 2.046 & 1.830 & 1.637 & 1.465 & 1.311 & 1.174 & 1.051 & 0.941 & 0.843 & 0.755 & 0.677 & 0.607 & 0.544 & 0.487 & 0.437 & 0.392 & 0.351 & 0.315 & 0.282 & 0.253 \\
\hline-0.500 & 2.443 & 2.181 & 1.950 & 1.743 & 1.559 & 1.394 & 1.248 & 1.117 & 0.999 & 0.895 & 0.801 & 0.718 & 0.643 & 0.576 & 0.516 & 0.462 & 0.414 & 0.371 & 0.333 & 0.299 & 0.268 \\
\hline-0.550 & 2.609 & 2.329 & 2.079 & 1.857 & 1.660 & 1.484 & 1.327 & 1.187 & 1.061 & 0.950 & 0.850 & 0.761 & 0.681 & 0.610 & 0.546 & 0.489 & 0.438 & 0.393 & 0.352 & 0.316 & 0.283 \\
\hline-0.600 & 2.789 & 2.487 & 2.219 & 1.980 & 1.768 & 1.579 & 1.411 & 1.262 & 1.128 & 1.009 & 0.902 & 0.807 & 0.722 & 0.647 & 0.579 & 0.518 & 0.464 & 0.416 & 0.372 & 0.334 & 0.299 \\
\hline-0.650 & 2.984 & 2.658 & 2.369 & 2.113 & 1.885 & 1.683 & 1.503 & 1.342 & 1.199 & 1.072 & 0.958 & 0.857 & 0.766 & 0.686 & 0.614 & 0.549 & 0.492 & 0.440 & 0.394 & 0.353 & 0.316 \\
\hline-0.700 & 3.195 & 2.844 & 2.532 & 2.257 & 2.012 & 1.794 & 1.601 & 1.429 & 1.276 & 1.140 & 1.018 & 0.910 & 0.814 & 0.727 & 0.651 & 0.582 & 0.521 & 0.466 & 0.417 & 0.374 & 0.334 \\
\hline-0.750 & 3.426 & 3.046 & 2.710 & 2.412 & 2.148 & 1.914 & 1.707 & 1.522 & 1.358 & 1.212 & 1.083 & 0.967 & 0.864 & 0.772 & 0.690 & 0.617 & 0.552 & 0.494 & 0.442 & 0.395 & 0.354 \\
\hline-0.850 & 3.951 & 3.504 & 3.110 & 2.763 & 2.456 & 2.185 & 1.944 & 1.731 & 1.543 & 1.375 & 1.226 & 1.094 & 0.976 & 0.871 & 0.778 & 0.695 & 0.621 & 0.555 & 0.496 & 0.444 & 0.397 \\
\hline-0.900 & 4.252 & 3.766 & 3.338 & 2.962 & 2.630 & 2.337 & 2.078 & 1.849 & 1.646 & 1.466 & 1.306 & 1.164 & 1.038 & 0.926 & 0.827 & 0.738 & 0.659 & 0.589 & 0.526 & 0.470 & 0.420 \\
\hline-0.950 & 4.582 & 4.052 & 3.587 & 3.178 & 2.819 & 2.502 & 2.222 & 1.975 & 1.757 & 1.563 & 1.392 & 1.240 & 1.105 & 0.985 & 0.879 & 0.784 & 0.700 & 0.625 & 0.558 & 0.498 & 0.445 \\
\hline-1.000 & 4.944 & 4.365 & 3.859 & 3.415 & 3.025 & 2.681 & 2.379 & 2.113 & 1.877 & 1.669 & 1.485 & 1.322 & 1.177 & 1.049 & 0.935 & 0.833 & 0.743 & 0.663 & 0.592 & 0.529 & 0.472 \\
\hline-1.050 & 5.344 & 4.710 & 4.157 & 3.673 & 3.249 & 2.877 & 2.550 & 2.262 & 2.008 & 1.783 & 1.585 & 1.410 & 1.255 & 1.117 & 0.995 & 0.887 & 0.790 & 0.705 & 0.629 & 0.561 & 0.501 \\
\hline-1.100 & 5.787 & 5.090 & 4.485 & 3.956 & 3.495 & 3.090 & 2.736 & 2.424 & 2.149 & 1.907 & 1.694 & 1.505 & 1.338 & 1.190 & 1.060 & 0.944 & 0.841 & 0.749 & 0.668 & 0.596 & 0.532 \\
\hline-1.150 & 6.278 & 5.511 & 4.846 & 4.268 & 3.764 & 3.324 & 2.938 & 2.600 & 2.303 & 2.041 & 1.811 & 1.608 & 1.428 & 1.270 & 1.129 & 1.005 & 0.895 & 0.797 & 0.710 & 0.633 & 0.564 \\
\hline-1.200 & 6.825 & 5.978 & 5.246 & 4.611 & 4.060 & 3.579 & 3.160 & 2.792 & 2.470 & 2.187 & 1.938 & 1.719 & 1.526 & 1.355 & 1.204 & 1.071 & 0.953 & 0.848 & 0.755 & 0.673 & 0.600 \\
\hline-1.250 & 7.437 & 6.497 & 5.689 & 4.991 & 4.386 & 3.860 & 3.402 & 3.002 & 2.653 & 2.346 & 2.077 & 1.840 & 1.631 & 1.448 & 1.285 & 1.142 & 1.015 & 0.903 & 0.804 & 0.715 & 0.637 \\
\hline-1.300 & 8.125 & 7.079 & 6.182 & 5.412 & 4.746 & 4.169 & 3.669 & 3.233 & 2.852 & 2.519 & 2.227 & 1.971 & 1.746 & 1.548 & 1.373 & 1.219 & 1.083 & 0.962 & 0.856 & 0.761 & 0.678 \\
\hline-1.350 & 8.902 & 7.731 & 6.734 & 5.880 & 5.145 & 4.511 & 3.962 & 3.485 & 3.070 & 2.708 & 2.391 & 2.114 & 1.870 & 1.656 & 1.468 & 1.302 & 1.155 & 1.026 & 0.912 & 0.811 & 0.721 \\
\hline-1.400 & 9.783 & 8.468 & 7.353 & 6.403 & 5.589 & 4.890 & 4.286 & 3.764 & 3.310 & 2.915 & 2.570 & 2.269 & 2.005 & 1.774 & 1.571 & 1.392 & 1.234 & 1.095 & 0.972 & 0.864 & 0.768 \\
\hline-1.450 & 10.791 & 9.304 & 8.051 & 6.990 & 6.085 & 5.311 & 4.645 & 4.071 & 3.574 & 3.142 & 2.767 & 2.439 & 2.153 & 1.902 & 1.682 & 1.489 & 1.319 & 1.169 & 1.037 & 0.921 & 0.818 \\
\hline-1.500 & 11.950 & 10.258 & 8.843 & 7.651 & 6.641 & 5.781 & 5.044 & 4.411 & 3.865 & 3.392 & 2.982 & 2.625 & 2.313 & 2.041 & 1.803 & 1.595 & 1.411 & 1.250 & 1.108 & 0.983 & 0.872 \\
\hline-1.550 & 13.294 & 11.354 & 9.746 & 8.401 & 7.268 & 6.307 & 5.489 & 4.789 & 4.187 & 3.668 & 3.218 & 2.829 & 2.489 & 2.194 & 1.935 & 1.709 & 1.511 & 1.337 & 1.184 & 1.049 & 0.931 \\
\hline-1.600 & 14.869 & 12.626 & 10.783 & 9.255 & 7.977 & 6.900 & 5.988 & 5.210 & 4.545 & 3.973 & 3.479 & 3.053 & 2.682 & 2.360 & 2.080 & 1.834 & 1.620 & 1.432 & 1.267 & 1.121 & 0.994 \\
\hline-1.650 & 16.732 & 14.112 & 11.985 & 10.236 & 8.785 & 7.572 & 6.549 & 5.682 & 4.944 & 4.311 & 3.768 & 3.300 & 2.895 & 2.543 & 2.237 & 1.971 & 1.738 & 1.535 & 1.356 & 1.199 & 1.062 \\
\hline-1.800 & 25.057 & 20.528 & 17.023 & 14.255 & 12.032 & 10.222 & 8.733 & 7.495 & 6.459 & 5.585 & 4.845 & 4.214 & 3.673 & 3.209 & 2.809 & 2.463 & 2.163 & 1.902 & 1.675 & 1.476 & 1.303 \\
\hline-1.850 & 29.335 & 23.689 & 19.424 & 16.117 & 13.502 & 11.399 & 9.686 & 8.276 & 7.103 & 6.121 & 5.293 & 4.591 & 3.992 & 3.480 & 3.040 & 2.661 & 2.333 & 2.048 & 1.801 & 1.585 & 1.397 \\
\hline-1.900 & 34.924 & 27.687 & 22.386 & 18.372 & 15.253 & 12.784 & 10.796 & 9.175 & 7.840 & 6.729 & 5.799 & 5.014 & 4.349 & 3.782 & 3.296 & 2.879 & 2.519 & 2.208 & 1.939 & 1.705 & 1.500 \\
\hline-1.950 & 42.506 & 32.891 & 26.123 & 21.147 & 17.370 & 14.430 & 12.099 & 10.220 & 8.688 & 7.424 & 6.373 & 5.492 & 4.749 & 4.118 & 3.581 & 3.121 & 2.726 & 2.385 & 2.090 & 1.835 & 1.613 \\
\hline-2.000 & 53.343 & 39.915 & 30.967 & 24.639 & 19.970 & 16.416 & 13.646 & 11.446 & 9.672 & 8.223 & 7.028 & 6.033 & 5.199 & 4.496 & 3.899 & 3.390 & 2.954 & 2.580 & 2.257 & 1.978 & 1.736 \\
\hline
\end{tabular}

Table 16: Simulation results for Belgium, $1997(H / L=0.119 ; c=1.2)$ 


\begin{tabular}{|c|c|c|c|c|c|c|c|c|c|c|c|c|c|c|c|c|c|c|c|c|c|}
\hline & \multicolumn{21}{|c|}{$l=h$} \\
\hline$\phi_{1}=\phi_{2}$ & 1.000 & 1.050 & 1.100 & 1.150 & 1.200 & 1.250 & 1.300 & 1.350 & 1.400 & 1.450 & 1.500 & 1.550 & 1.600 & 1.650 & 1.700 & 1.750 & 1.800 & 1.850 & 1.900 & 1.950 & 2.000 \\
\hline 0.000 & 1.314 & 1.159 & 1.022 & 0.902 & 0.795 & 0.701 & 0.618 & 0.545 & 0.481 & 0.424 & 0.374 & 0.330 & 0.291 & 0.257 & 0.226 & 0.200 & 0.176 & 0.155 & 0.137 & 0.121 & 0.106 \\
\hline-0.050 & 1.401 & 1.235 & 1.089 & 0.960 & 0.846 & 0.746 & 0.658 & 0.580 & 0.511 & 0.450 & 0.397 & 0.350 & 0.309 & 0.272 & 0.240 & 0.212 & 0.187 & 0.164 & 0.145 & 0.128 & 0.113 \\
\hline-0.100 & 1.495 & 1.317 & 1.160 & 1.022 & 0.901 & 0.794 & 0.699 & 0.616 & 0.543 & 0.479 & 0.422 & 0.372 & 0.328 & 0.289 & 0.254 & 0.224 & 0.198 & 0.174 & 0.154 & 0.135 & 0.119 \\
\hline-0.150 & 1.596 & 1.405 & 1.237 & 1.089 & 0.959 & 0.845 & 0.744 & 0.655 & 0.577 & 0.509 & 0.448 & 0.395 & 0.348 & 0.306 & 0.270 & 0.238 & 0.210 & 0.185 & 0.163 & 0.143 & 0.126 \\
\hline-0.200 & 1.704 & 1.499 & 1.319 & 1.161 & 1.022 & 0.900 & 0.792 & 0.697 & 0.614 & 0.541 & 0.476 & 0.419 & 0.369 & 0.325 & 0.286 & 0.252 & 0.222 & 0.196 & 0.172 & 0.152 & 0.134 \\
\hline-0.250 & 1.821 & 1.601 & 1.408 & 1.239 & 1.090 & 0.959 & 0.844 & 0.742 & 0.653 & 0.575 & 0.506 & 0.446 & 0.392 & 0.345 & 0.304 & 0.268 & 0.236 & 0.208 & 0.183 & 0.161 & 0.142 \\
\hline-0.300 & 1.948 & 1.711 & 1.504 & 1.322 & 1.162 & 1.022 & 0.899 & 0.791 & 0.695 & 0.612 & 0.538 & 0.474 & 0.417 & 0.367 & 0.323 & 0.284 & 0.250 & 0.220 & 0.194 & 0.171 & 0.150 \\
\hline-0.350 & 2.084 & 1.830 & 1.607 & 1.412 & 1.241 & 1.090 & 0.958 & 0.842 & 0.741 & 0.651 & 0.573 & 0.504 & 0.443 & 0.390 & 0.343 & 0.302 & 0.266 & 0.234 & 0.206 & 0.181 & 0.159 \\
\hline-0.400 & 2.232 & 1.958 & 1.719 & 1.509 & 1.324 & 1.164 & 1.022 & 0.898 & 0.789 & 0.694 & 0.610 & 0.536 & 0.471 & 0.414 & 0.364 & 0.321 & 0.282 & 0.248 & 0.218 & 0.192 & 0.169 \\
\hline-0.450 & 2.393 & 2.097 & 1.839 & 1.613 & 1.415 & 1.243 & 1.091 & 0.958 & 0.841 & 0.739 & 0.649 & 0.570 & 0.501 & 0.441 & 0.387 & 0.341 & 0.300 & 0.263 & 0.232 & 0.204 & 0.179 \\
\hline-0.500 & 2.567 & 2.248 & 1.970 & 1.727 & 1.514 & 1.328 & 1.165 & 1.023 & 0.897 & 0.788 & 0.692 & 0.608 & 0.534 & 0.469 & 0.412 & 0.362 & 0.318 & 0.280 & 0.246 & 0.216 & 0.190 \\
\hline-0.550 & 2.756 & 2.412 & 2.111 & 1.849 & 1.620 & 1.420 & 1.245 & 1.092 & 0.958 & 0.840 & 0.737 & 0.647 & 0.568 & 0.499 & 0.438 & 0.385 & 0.338 & 0.297 & 0.261 & 0.230 & 0.202 \\
\hline-0.600 & 2.962 & 2.589 & 2.265 & 1.982 & 1.734 & 1.519 & 1.331 & 1.167 & 1.023 & 0.897 & 0.787 & 0.690 & 0.606 & 0.532 & 0.467 & 0.410 & 0.360 & 0.316 & 0.278 & 0.244 & 0.214 \\
\hline-0.650 & 3.187 & 2.783 & 2.431 & 2.126 & 1.859 & 1.627 & 1.424 & 1.248 & 1.093 & 0.958 & 0.839 & 0.736 & 0.645 & 0.566 & 0.497 & 0.436 & 0.383 & 0.336 & 0.295 & 0.259 & 0.228 \\
\hline-0.700 & 3.432 & 2.993 & 2.613 & 2.282 & 1.994 & 1.744 & 1.525 & 1.335 & 1.168 & 1.023 & 0.896 & 0.785 & 0.688 & 0.604 & 0.529 & 0.464 & 0.407 & 0.358 & 0.314 & 0.276 & 0.242 \\
\hline-0.750 & 3.701 & 3.224 & 2.811 & 2.453 & 2.141 & 1.870 & 1.635 & 1.429 & 1.250 & 1.094 & 0.958 & 0.839 & 0.735 & 0.644 & 0.564 & 0.495 & 0.434 & 0.381 & 0.334 & 0.293 & 0.257 \\
\hline-0.800 & 3.996 & 3.477 & 3.028 & 2.639 & 2.301 & 2.008 & 1.753 & 1.532 & 1.339 & 1.171 & 1.024 & 0.896 & 0.784 & 0.687 & 0.602 & 0.527 & 0.462 & 0.405 & 0.355 & 0.312 & 0.273 \\
\hline-0.850 & 4.320 & 3.753 & 3.264 & 2.841 & 2.475 & 2.158 & 1.882 & 1.643 & 1.435 & 1.253 & 1.096 & 0.958 & 0.838 & 0.734 & 0.642 & 0.562 & 0.493 & 0.432 & 0.378 & 0.332 & 0.291 \\
\hline-0.900 & 4.677 & 4.058 & 3.524 & 3.063 & 2.665 & 2.321 & 2.022 & 1.763 & 1.539 & 1.343 & 1.173 & 1.025 & 0.896 & 0.784 & 0.686 & 0.600 & 0.525 & 0.460 & 0.403 & 0.353 & 0.310 \\
\hline-0.950 & 5.072 & 4.393 & 3.809 & 3.307 & 2.873 & 2.499 & 2.175 & 1.895 & 1.652 & 1.440 & 1.257 & 1.098 & 0.959 & 0.838 & 0.733 & 0.641 & 0.561 & 0.491 & 0.430 & 0.376 & 0.330 \\
\hline-1.000 & 5.509 & 4.763 & 4.123 & 3.574 & 3.102 & 2.694 & 2.342 & 2.038 & 1.774 & 1.546 & 1.348 & 1.176 & 1.027 & 0.896 & 0.783 & 0.685 & 0.599 & 0.524 & 0.458 & 0.401 & 0.351 \\
\hline-1.050 & 5.995 & 5.173 & 4.471 & 3.869 & 3.352 & 2.908 & 2.525 & 2.194 & 1.908 & 1.661 & 1.447 & 1.261 & 1.100 & 0.960 & 0.838 & 0.732 & 0.640 & 0.559 & 0.489 & 0.428 & 0.374 \\
\hline-1.100 & 6.537 & 5.629 & 4.855 & 4.194 & 3.628 & 3.142 & 2.725 & 2.365 & 2.054 & 1.786 & 1.554 & 1.354 & 1.179 & 1.028 & 0.897 & 0.783 & 0.684 & 0.597 & 0.522 & 0.456 & 0.399 \\
\hline-1.150 & 7.144 & 6.137 & 5.282 & 4.554 & 3.933 & 3.401 & 2.944 & 2.552 & 2.214 & 1.923 & 1.672 & 1.454 & 1.266 & 1.103 & 0.961 & 0.838 & 0.731 & 0.639 & 0.558 & 0.487 & 0.426 \\
\hline-1.200 & 7.826 & 6.706 & 5.758 & 4.954 & 4.270 & 3.686 & 3.186 & 2.758 & 2.389 & 2.073 & 1.799 & 1.564 & 1.360 & 1.183 & 1.031 & 0.898 & 0.783 & 0.683 & 0.596 & 0.521 & 0.455 \\
\hline-1.250 & 8.596 & 7.345 & 6.291 & 5.400 & 4.645 & 4.002 & 3.453 & 2.984 & 2.582 & 2.236 & 1.939 & 1.683 & 1.462 & 1.271 & 1.106 & 0.963 & 0.839 & 0.731 & 0.638 & 0.556 & 0.486 \\
\hline-1.300 & 9.471 & 8.067 & 6.890 & 5.899 & 5.062 & 4.352 & 3.749 & 3.234 & 2.793 & 2.416 & 2.092 & 1.814 & 1.574 & 1.367 & 1.188 & 1.033 & 0.899 & 0.783 & 0.683 & 0.595 & 0.519 \\
\hline-1.350 & 10.470 & 8.886 & 7.565 & 6.459 & 5.529 & 4.743 & 4.076 & 3.510 & 3.027 & 2.614 & 2.260 & 1.957 & 1.696 & 1.471 & 1.277 & 1.110 & 0.965 & 0.840 & 0.731 & 0.637 & 0.555 \\
\hline-1.400 & 11.619 & 9.821 & 8.332 & 7.092 & 6.053 & 5.179 & 4.442 & 3.816 & 3.285 & 2.832 & 2.445 & 2.114 & 1.829 & 1.585 & 1.374 & 1.193 & 1.036 & 0.901 & 0.784 & 0.682 & 0.594 \\
\hline-1.450 & 12.949 & 10.895 & 9.206 & 7.808 & 6.644 & 5.669 & 4.850 & 4.158 & 3.572 & 3.073 & 2.649 & 2.286 & 1.976 & 1.710 & 1.481 & 1.284 & 1.114 & 0.968 & 0.841 & 0.732 & 0.637 \\
\hline-1.500 & 14.503 & 12.138 & 10.210 & 8.626 & 7.314 & 6.222 & 5.308 & 4.539 & 3.891 & 3.341 & 2.874 & 2.477 & 2.137 & 1.846 & 1.597 & 1.383 & 1.199 & 1.040 & 0.903 & 0.785 & 0.683 \\
\hline-1.550 & 16.337 & 13.590 & 11.372 & 9.564 & 8.078 & 6.848 & 5.824 & 4.967 & 4.247 & 3.639 & 3.124 & 2.687 & 2.315 & 1.997 & 1.725 & 1.492 & 1.292 & 1.119 & 0.971 & 0.843 & 0.732 \\
\hline-1.600 & 18.526 & 15.301 & 12.727 & 10.649 & 8.954 & 7.561 & 6.409 & 5.449 & 4.647 & 3.972 & 3.403 & 2.921 & 2.511 & 2.163 & 1.865 & 1.611 & 1.393 & 1.206 & 1.045 & 0.906 & 0.786 \\
\hline-1.650 & 21.176 & 17.342 & 14.323 & 11.913 & 9.967 & 8.379 & 7.075 & 5.995 & 5.097 & 4.345 & 3.713 & 3.180 & 2.729 & 2.346 & 2.020 & 1.742 & 1.504 & 1.300 & 1.125 & 0.975 & 0.845 \\
\hline-1.700 & 24.438 & 19.810 & 16.225 & 13.401 & 11.146 & 9.324 & 7.838 & 6.617 & 5.606 & 4.765 & 4.061 & 3.470 & 2.971 & 2.549 & 2.191 & 1.886 & 1.626 & 1.404 & 1.213 & 1.050 & 0.909 \\
\hline-1.750 & 28.536 & 22.843 & 18.522 & 15.173 & 12.533 & 10.423 & 8.719 & 7.328 & 6.186 & 5.240 & 4.453 & 3.795 & 3.242 & 2.775 & 2.381 & 2.046 & 1.761 & 1.518 & 1.310 & 1.132 & 0.979 \\
\hline-1.800 & 33.820 & 26.647 & 21.341 & 17.310 & 14.182 & 11.715 & 9.743 & 8.149 & 6.849 & 5.780 & 4.896 & 4.160 & 3.544 & 3.027 & 2.591 & 2.222 & 1.910 & 1.643 & 1.416 & 1.222 & 1.056 \\
\hline-1.850 & 40.862 & 31.540 & 24.871 & 19.929 & 16.169 & 13.250 & 10.946 & 9.103 & 7.614 & 6.399 & 5.400 & 4.573 & 3.885 & 3.309 & 2.826 & 2.419 & 2.074 & 1.782 & 1.533 & 1.321 & 1.140 \\
\hline-1.900 & 50.671 & 38.042 & 29.401 & 23.202 & 18.602 & 15.097 & 12.374 & 10.223 & 8.502 & 7.111 & 5.975 & 5.042 & 4.270 & 3.627 & 3.089 & 2.638 & 2.257 & 1.935 & 1.662 & 1.430 & 1.232 \\
\hline-1.950 & 65.209 & 47.061 & 35.401 & 27.394 & 21.636 & 17.355 & 14.090 & 11.551 & 9.544 & 7.938 & 6.639 & 5.578 & 4.707 & 3.985 & 3.385 & 2.883 & 2.461 & 2.106 & 1.805 & 1.550 & 1.333 \\
\hline-2.000 & 88.860 & 60.350 & 43.693 & 32.931 & 25.514 & 20.167 & 16.185 & 13.145 & 10.778 & 8.907 & 7.408 & 6.196 & 5.206 & 4.392 & 3.718 & 3.158 & 2.689 & 2.295 & 1.964 & 1.683 & 1.445 \\
\hline
\end{tabular}




\begin{tabular}{|c|c|c|c|c|c|c|c|c|c|c|c|c|c|c|c|c|c|c|c|c|c|}
\hline & \multicolumn{21}{|c|}{$l=h$} \\
\hline$\phi_{1}=\phi_{2}$ & 1.000 & 1.050 & 1.100 & 1.150 & 1.200 & 1.250 & 1.300 & 1.350 & 1.400 & 1.450 & 1.500 & 1.550 & 1.600 & 1.650 & 1.700 & 1.750 & 1.800 & 1.850 & 1.900 & 1.950 & 2.000 \\
\hline 0.000 & 1.315 & 1.230 & 1.152 & 1.078 & 1.010 & 0.945 & 0.885 & 0.828 & 0.775 & 0.726 & 0.679 & 0.636 & 0.595 & 0.557 & 0.522 & 0.488 & 0.457 & 0.428 & 0.401 & 0.375 & 0.351 \\
\hline-0.050 & 1.373 & 1.285 & 1.202 & 1.125 & 1.054 & 0.985 & 0.922 & 0.863 & 0.808 & 0.756 & 0.708 & 0.662 & 0.620 & 0.580 & 0.543 & 0.508 & 0.475 & 0.445 & 0.416 & 0.390 & 0.365 \\
\hline-0.100 & 1.435 & 1.342 & 1.255 & 1.174 & 1.099 & 1.028 & 0.962 & 0.900 & 0.842 & 0.788 & 0.737 & 0.690 & 0.645 & 0.604 & 0.565 & 0.529 & 0.495 & 0.463 & 0.433 & 0.405 & 0.379 \\
\hline-0.150 & 1.500 & 1.402 & 1.311 & 1.226 & 1.147 & 1.073 & 1.003 & 0.938 & 0.878 & 0.821 & 0.768 & 0.718 & 0.672 & 0.629 & 0.588 & 0.550 & 0.515 & 0.481 & 0.450 & 0.422 & 0.394 \\
\hline-0.200 & 1.569 & 1.466 & 1.370 & 1.281 & 1.197 & 1.120 & 1.047 & 0.979 & 0.915 & 0.856 & 0.800 & 0.749 & 0.700 & 0.655 & 0.612 & 0.573 & 0.536 & 0.501 & 0.469 & 0.438 & 0.410 \\
\hline-0.250 & 1.641 & 1.533 & 1.432 & 1.338 & 1.251 & 1.169 & 1.093 & 1.021 & 0.955 & 0.892 & 0.834 & 0.780 & 0.729 & 0.682 & 0.638 & 0.596 & 0.558 & 0.522 & 0.488 & 0.456 & 0.427 \\
\hline-0.300 & 1.718 & 1.604 & 1.498 & 1.399 & 1.307 & 1.221 & 1.141 & 1.066 & 0.996 & 0.931 & 0.870 & 0.813 & 0.760 & 0.711 & 0.664 & 0.621 & 0.581 & 0.543 & 0.508 & 0.475 & 0.444 \\
\hline-0.400 & 1.884 & 1.757 & 1.640 & 1.531 & 1.429 & 1.333 & 1.244 & 1.163 & 1.086 & 1.014 & 0.947 & 0.884 & 0.826 & 0.772 & 0.721 & 0.674 & 0.630 & 0.589 & 0.550 & 0.514 & 0.481 \\
\hline-0.450 & 1.975 & 1.842 & 1.717 & 1.602 & 1.494 & 1.394 & 1.301 & 1.215 & 1.134 & 1.058 & 0.988 & 0.923 & 0.862 & 0.805 & 0.752 & 0.702 & 0.656 & 0.613 & 0.573 & 0.535 & 0.500 \\
\hline-0.500 & 2.072 & 1.930 & 1.799 & 1.677 & 1.563 & 1.459 & 1.360 & 1.269 & 1.185 & 1.106 & 1.032 & 0.963 & 0.899 & 0.840 & 0.784 & 0.732 & 0.684 & 0.639 & 0.597 & 0.557 & 0.521 \\
\hline-0.550 & 2.174 & 2.025 & 1.886 & 1.757 & 1.637 & 1.526 & 1.423 & 1.327 & 1.238 & 1.155 & 1.078 & 1.006 & 0.939 & 0.876 & 0.818 & 0.763 & 0.713 & 0.666 & 0.622 & 0.581 & 0.542 \\
\hline-0.600 & 2.283 & 2.124 & 1.978 & 1.842 & 1.715 & 1.598 & 1.489 & 1.388 & 1.294 & 1.207 & 1.126 & 1.050 & 0.980 & 0.914 & 0.853 & 0.796 & 0.743 & 0.694 & 0.648 & 0.605 & 0.565 \\
\hline-0.650 & 2.399 & 2.230 & 2.075 & 1.931 & 1.798 & 1.674 & 1.559 & 1.453 & 1.354 & 1.262 & 1.177 & 1.097 & 1.023 & 0.954 & 0.890 & 0.831 & 0.775 & 0.723 & 0.675 & 0.630 & 0.589 \\
\hline-0.700 & 2.522 & 2.344 & 2.179 & 2.027 & 1.885 & 1.755 & 1.633 & 1.521 & 1.417 & 1.321 & 1.230 & 1.147 & 1.069 & 0.997 & 0.929 & 0.867 & 0.809 & 0.755 & 0.704 & 0.657 & 0.613 \\
\hline-0.750 & 2.654 & 2.464 & 2.289 & 2.127 & 1.978 & 1.840 & 1.712 & 1.593 & 1.483 & 1.381 & 1.287 & 1.199 & 1.117 & 1.041 & 0.971 & 0.905 & 0.844 & 0.787 & 0.734 & 0.685 & 0.639 \\
\hline-0.850 & 2.945 & 2.729 & 2.531 & 2.349 & 2.181 & 2.026 & 1.883 & 1.751 & 1.628 & 1.514 & 1.409 & 1.312 & 1.221 & 1.138 & 1.060 & 0.987 & 0.920 & 0.858 & 0.799 & 0.745 & 0.695 \\
\hline-0.900 & 3.106 & 2.876 & 2.665 & 2.471 & 2.292 & 2.128 & 1.977 & 1.836 & 1.707 & 1.587 & 1.476 & 1.373 & 1.278 & 1.190 & 1.108 & 1.032 & 0.961 & 0.895 & 0.834 & 0.778 & 0.725 \\
\hline-0.950 & 3.279 & 3.033 & 2.808 & 2.601 & 2.412 & 2.237 & 2.076 & 1.927 & 1.790 & 1.664 & 1.546 & 1.438 & 1.338 & 1.245 & 1.158 & 1.078 & 1.004 & 0.935 & 0.871 & 0.812 & 0.757 \\
\hline-1.000 & 3.464 & 3.202 & 2.961 & 2.741 & 2.539 & 2.353 & 2.182 & 2.024 & 1.879 & 1.745 & 1.621 & 1.507 & 1.401 & 1.303 & 1.212 & 1.128 & 1.050 & 0.977 & 0.910 & 0.848 & 0.790 \\
\hline-1.050 & 3.664 & 3.382 & 3.125 & 2.890 & 2.674 & 2.476 & 2.294 & 2.127 & 1.973 & 1.831 & 1.700 & 1.579 & 1.467 & 1.364 & 1.268 & 1.180 & 1.098 & 1.022 & 0.951 & 0.885 & 0.825 \\
\hline-1.100 & 3.881 & 3.577 & 3.301 & 3.049 & 2.819 & 2.608 & 2.414 & 2.237 & 2.073 & 1.923 & 1.784 & 1.656 & 1.538 & 1.429 & 1.328 & 1.235 & 1.148 & 1.068 & 0.994 & 0.925 & 0.861 \\
\hline-1.150 & 4.114 & 3.788 & 3.491 & 3.221 & 2.974 & 2.749 & 2.543 & 2.354 & 2.180 & 2.020 & 1.873 & 1.738 & 1.613 & 1.498 & 1.391 & 1.293 & 1.202 & 1.117 & 1.039 & 0.967 & 0.900 \\
\hline-1.200 & 4.367 & 4.015 & 3.695 & 3.405 & 3.141 & 2.900 & 2.680 & 2.478 & 2.294 & 2.124 & 1.968 & 1.825 & 1.692 & 1.570 & 1.458 & 1.354 & 1.258 & 1.169 & 1.087 & 1.011 & 0.940 \\
\hline-1.250 & 4.642 & 4.261 & 3.916 & 3.604 & 3.320 & 3.062 & 2.827 & 2.612 & 2.415 & 2.234 & 2.069 & 1.917 & 1.777 & 1.648 & 1.529 & 1.419 & 1.318 & 1.224 & 1.137 & 1.057 & 0.983 \\
\hline-1.300 & 4.942 & 4.528 & 4.155 & 3.818 & 3.513 & 3.236 & 2.984 & 2.755 & 2.545 & 2.352 & 2.176 & 2.015 & 1.866 & 1.730 & 1.604 & 1.488 & 1.381 & 1.282 & 1.191 & 1.106 & 1.028 \\
\hline-1.350 & 5.270 & 4.819 & 4.415 & 4.051 & 3.722 & 3.424 & 3.154 & 2.908 & 2.683 & 2.478 & 2.291 & 2.119 & 1.961 & 1.817 & 1.683 & 1.561 & 1.448 & 1.343 & 1.247 & 1.158 & 1.076 \\
\hline-1.400 & 5.629 & 5.137 & 4.697 & 4.302 & 3.947 & 3.626 & 3.336 & 3.072 & 2.832 & 2.613 & 2.413 & 2.230 & 2.063 & 1.909 & 1.768 & 1.638 & 1.518 & 1.408 & 1.307 & 1.213 & 1.126 \\
\hline-1.450 & 6.024 & 5.485 & 5.005 & 4.576 & 4.192 & 3.845 & 3.532 & 3.249 & 2.992 & 2.758 & 2.544 & 2.349 & 2.171 & 2.008 & 1.858 & 1.720 & 1.593 & 1.477 & 1.370 & 1.271 & 1.179 \\
\hline-1.500 & 6.460 & 5.867 & 5.342 & 4.875 & 4.457 & 4.082 & 3.745 & 3.440 & 3.164 & 2.913 & 2.684 & 2.476 & 2.286 & 2.113 & 1.953 & 1.807 & 1.673 & 1.550 & 1.436 & 1.332 & 1.235 \\
\hline-1.550 & 6.944 & 6.289 & 5.713 & 5.202 & 4.747 & 4.340 & 3.975 & 3.646 & 3.349 & 3.079 & 2.835 & 2.613 & 2.410 & 2.225 & 2.055 & 1.900 & 1.758 & 1.627 & 1.507 & 1.397 & 1.295 \\
\hline-1.600 & 7.483 & 6.757 & 6.121 & 5.560 & 5.063 & 4.621 & 4.224 & 3.869 & 3.548 & 3.259 & 2.997 & 2.759 & 2.542 & 2.344 & 2.164 & 1.999 & 1.848 & 1.709 & 1.582 & 1.465 & 1.358 \\
\hline-1.650 & 8.086 & 7.277 & 6.573 & 5.955 & 5.410 & 4.927 & 4.496 & 4.111 & 3.764 & 3.453 & 3.171 & 2.915 & 2.683 & 2.473 & 2.280 & 2.105 & 1.944 & 1.797 & 1.662 & 1.538 & 1.424 \\
\hline-1.800 & 10.419 & 9.255 & 8.266 & 7.417 & 6.681 & 6.039 & 5.474 & 4.975 & 4.531 & 4.135 & 3.781 & 3.463 & 3.175 & 2.916 & 2.681 & 2.467 & 2.273 & 2.095 & 1.934 & 1.786 & 1.650 \\
\hline-1.850 & 11.433 & 10.100 & 8.978 & 8.023 & 7.202 & 6.490 & 5.867 & 5.319 & 4.835 & 4.404 & 4.020 & 3.675 & 3.366 & 3.087 & 2.834 & 2.605 & 2.398 & 2.209 & 2.036 & 1.879 & 1.735 \\
\hline-1.900 & 12.614 & 11.071 & 9.789 & 8.708 & 7.786 & 6.992 & 6.302 & 5.699 & 5.167 & 4.697 & 4.279 & 3.906 & 3.572 & 3.271 & 2.999 & 2.754 & 2.532 & 2.330 & 2.146 & 1.979 & 1.825 \\
\hline-1.950 & 14.003 & 12.198 & 10.718 & 9.485 & 8.443 & 7.553 & 6.785 & 6.118 & 5.534 & 5.019 & 4.563 & 4.157 & 3.795 & 3.470 & 3.178 & 2.914 & 2.676 & 2.460 & 2.264 & 2.085 & 1.922 \\
\hline-2.000 & 15.659 & 13.519 & 11.793 & 10.374 & 9.188 & 8.184 & 7.325 & 6.584 & 5.938 & 5.372 & 4.873 & 4.431 & 4.038 & 3.686 & 3.371 & 3.087 & 2.831 & 2.599 & 2.389 & 2.199 & 2.025 \\
\hline
\end{tabular}




\begin{tabular}{|c|c|c|c|c|c|c|c|c|c|c|c|c|c|c|c|c|c|c|c|c|c|}
\hline & \multicolumn{21}{|c|}{$l=h$} \\
\hline$\phi_{1}=\phi_{2}$ & 1.000 & 1.050 & 1.100 & 1.150 & 1.200 & 1.250 & 1.300 & 1.350 & 1.400 & 1.450 & 1.500 & 1.550 & 1.600 & 1.650 & 1.700 & 1.750 & 1.800 & 1.850 & 1.900 & 1.950 & 2.000 \\
\hline 0.000 & 1.314 & 1.163 & 1.030 & 0.912 & 0.807 & 0.714 & 0.632 & 0.559 & 0.495 & 0.438 & 0.388 & 0.343 & 0.304 & 0.269 & 0.238 & 0.211 & 0.186 & 0.165 & 0.146 & 0.129 & 0.114 \\
\hline-0.050 & 1.400 & 1.239 & 1.096 & 0.970 & 0.858 & 0.759 & 0.671 & 0.594 & 0.525 & 0.465 & 0.411 & 0.364 & 0.322 & 0.285 & 0.252 & 0.223 & 0.197 & 0.175 & 0.155 & 0.137 & 0.121 \\
\hline-0.100 & 1.493 & 1.320 & 1.167 & 1.032 & 0.912 & 0.807 & 0.713 & 0.631 & 0.558 & 0.493 & 0.437 & 0.386 & 0.341 & 0.302 & 0.267 & 0.236 & 0.209 & 0.185 & 0.164 & 0.145 & 0.128 \\
\hline-0.150 & 1.592 & 1.406 & 1.243 & 1.099 & 0.971 & 0.858 & 0.759 & 0.671 & 0.593 & 0.524 & 0.463 & 0.410 & 0.362 & 0.320 & 0.283 & 0.250 & 0.221 & 0.196 & 0.173 & 0.153 & 0.135 \\
\hline-0.200 & 1.699 & 1.500 & 1.325 & 1.170 & 1.034 & 0.913 & 0.807 & 0.713 & 0.630 & 0.557 & 0.492 & 0.435 & 0.384 & 0.340 & 0.300 & 0.265 & 0.235 & 0.207 & 0.183 & 0.162 & 0.143 \\
\hline-0.250 & 1.814 & 1.601 & 1.413 & 1.247 & 1.101 & 0.972 & 0.859 & 0.758 & 0.670 & 0.592 & 0.523 & 0.462 & 0.408 & 0.360 & 0.319 & 0.281 & 0.249 & 0.220 & 0.194 & 0.172 & 0.152 \\
\hline-0.300 & 1.938 & 1.709 & 1.508 & 1.330 & 1.174 & 1.036 & 0.914 & 0.807 & 0.712 & 0.629 & 0.556 & 0.490 & 0.433 & 0.383 & 0.338 & 0.299 & 0.264 & 0.233 & 0.206 & 0.182 & 0.161 \\
\hline-0.350 & 2.073 & 1.827 & 1.610 & 1.419 & 1.252 & 1.104 & 0.974 & 0.859 & 0.758 & 0.669 & 0.590 & 0.521 & 0.460 & 0.406 & 0.359 & 0.317 & 0.280 & 0.247 & 0.218 & 0.193 & 0.170 \\
\hline-0.400 & 2.218 & 1.953 & 1.720 & 1.516 & 1.336 & 1.177 & 1.039 & 0.915 & 0.807 & 0.712 & 0.628 & 0.554 & 0.489 & 0.432 & 0.381 & 0.336 & 0.297 & 0.262 & 0.231 & 0.204 & 0.181 \\
\hline-0.450 & 2.375 & 2.090 & 1.840 & 1.619 & 1.425 & 1.257 & 1.107 & 0.976 & 0.860 & 0.758 & 0.668 & 0.589 & 0.520 & 0.459 & 0.405 & 0.357 & 0.315 & 0.278 & 0.245 & 0.217 & 0.191 \\
\hline-0.500 & 2.546 & 2.238 & 1.968 & 1.732 & 1.524 & 1.342 & 1.181 & 1.040 & 0.916 & 0.808 & 0.712 & 0.627 & 0.553 & 0.488 & 0.430 & 0.379 & 0.335 & 0.295 & 0.260 & 0.230 & 0.203 \\
\hline-0.550 & 2.731 & 2.399 & 2.108 & 1.853 & 1.629 & 1.433 & 1.261 & 1.110 & 0.977 & 0.861 & 0.758 & 0.668 & 0.588 & 0.519 & 0.457 & 0.403 & 0.355 & 0.314 & 0.276 & 0.244 & 0.215 \\
\hline-0.600 & 2.933 & 2.573 & 2.259 & 1.984 & 1.743 & 1.532 & 1.348 & 1.185 & 1.043 & 0.918 & 0.808 & 0.711 & 0.626 & 0.552 & 0.486 & 0.428 & 0.378 & 0.333 & 0.294 & 0.259 & 0.228 \\
\hline-0.650 & 3.152 & 2.763 & 2.423 & 2.127 & 1.867 & 1.640 & 1.441 & 1.267 & 1.113 & 0.979 & 0.861 & 0.758 & 0.667 & 0.588 & 0.517 & 0.456 & 0.402 & 0.354 & 0.312 & 0.275 & 0.242 \\
\hline-0.700 & 3.393 & 2.970 & 2.602 & 2.281 & 2.001 & 1.756 & 1.541 & 1.354 & 1.190 & 1.045 & 0.919 & 0.808 & 0.711 & 0.626 & 0.551 & 0.485 & 0.427 & 0.376 & 0.331 & 0.292 & 0.257 \\
\hline-0.750 & 3.655 & 3.196 & 2.797 & 2.449 & 2.146 & 1.882 & 1.651 & 1.448 & 1.272 & 1.117 & 0.981 & 0.863 & 0.758 & 0.667 & 0.587 & 0.516 & 0.454 & 0.400 & 0.352 & 0.310 & 0.273 \\
\hline-0.800 & 3.942 & 3.443 & 3.009 & 2.632 & 2.304 & 2.018 & 1.769 & 1.551 & 1.361 & 1.194 & 1.048 & 0.921 & 0.809 & 0.711 & 0.625 & 0.550 & 0.484 & 0.426 & 0.375 & 0.330 & 0.290 \\
\hline-0.850 & 4.258 & 3.713 & 3.242 & 2.832 & 2.476 & 2.167 & 1.897 & 1.662 & 1.457 & 1.278 & 1.121 & 0.984 & 0.864 & 0.759 & 0.667 & 0.586 & 0.515 & 0.453 & 0.399 & 0.351 & 0.309 \\
\hline-0.900 & 4.605 & 4.010 & 3.496 & 3.051 & 2.664 & 2.329 & 2.037 & 1.783 & 1.561 & 1.368 & 1.199 & 1.052 & 0.923 & 0.810 & 0.711 & 0.625 & 0.549 & 0.483 & 0.424 & 0.373 & 0.328 \\
\hline-0.950 & 4.988 & 4.337 & 3.775 & 3.290 & 2.870 & 2.505 & 2.189 & 1.914 & 1.674 & 1.466 & 1.284 & 1.125 & 0.986 & 0.865 & 0.759 & 0.667 & 0.585 & 0.514 & 0.452 & 0.397 & 0.349 \\
\hline-1.000 & 5.413 & 4.698 & 4.083 & 3.552 & 3.094 & 2.698 & 2.354 & 2.056 & 1.797 & 1.572 & 1.376 & 1.204 & 1.055 & 0.925 & 0.811 & 0.712 & 0.625 & 0.548 & 0.482 & 0.423 & 0.372 \\
\hline-1.050 & 5.884 & 5.097 & 4.422 & 3.841 & 3.341 & 2.909 & 2.535 & 2.212 & 1.931 & 1.687 & 1.475 & 1.291 & 1.130 & 0.989 & 0.867 & 0.760 & 0.667 & 0.585 & 0.513 & 0.451 & 0.396 \\
\hline-1.100 & 6.408 & 5.540 & 4.797 & 4.160 & 3.612 & 3.141 & 2.734 & 2.382 & 2.077 & 1.813 & 1.583 & 1.384 & 1.210 & 1.059 & 0.927 & 0.812 & 0.712 & 0.624 & 0.548 & 0.481 & 0.422 \\
\hline-1.150 & 6.995 & 6.033 & 5.213 & 4.512 & 3.912 & 3.395 & 2.951 & 2.568 & 2.236 & 1.950 & 1.701 & 1.485 & 1.298 & 1.135 & 0.993 & 0.869 & 0.761 & 0.667 & 0.585 & 0.513 & 0.450 \\
\hline-1.200 & 7.653 & 6.584 & 5.676 & 4.903 & 4.242 & 3.676 & 3.190 & 2.772 & 2.411 & 2.099 & 1.829 & 1.596 & 1.393 & 1.217 & 1.064 & 0.930 & 0.814 & 0.713 & 0.624 & 0.547 & 0.480 \\
\hline-1.250 & 8.395 & 7.202 & 6.194 & 5.338 & 4.609 & 3.987 & 3.454 & 2.996 & 2.602 & 2.263 & 1.970 & 1.716 & 1.496 & 1.306 & 1.140 & 0.997 & 0.871 & 0.762 & 0.667 & 0.585 & 0.512 \\
\hline-1.300 & 9.237 & 7.900 & 6.775 & 5.824 & 5.018 & 4.331 & 3.745 & 3.243 & 2.813 & 2.442 & 2.123 & 1.847 & 1.609 & 1.403 & 1.224 & 1.068 & 0.933 & 0.816 & 0.714 & 0.625 & 0.547 \\
\hline-1.350 & 10.196 & 8.690 & 7.429 & 6.369 & 5.474 & 4.714 & 4.068 & 3.517 & 3.044 & 2.639 & 2.291 & 1.991 & 1.732 & 1.508 & 1.314 & 1.147 & 1.001 & 0.874 & 0.764 & 0.668 & 0.585 \\
\hline-1.400 & 11.296 & 9.589 & 8.170 & 6.983 & 5.985 & 5.142 & 4.427 & 3.819 & 3.301 & 2.857 & 2.476 & 2.149 & 1.867 & 1.623 & 1.413 & 1.231 & 1.074 & 0.937 & 0.818 & 0.715 & 0.625 \\
\hline-1.450 & 12.568 & 10.621 & 9.014 & 7.678 & 6.561 & 5.621 & 4.828 & 4.156 & 3.584 & 3.097 & 2.679 & 2.322 & 2.014 & 1.750 & 1.521 & 1.324 & 1.153 & 1.006 & 0.877 & 0.766 & 0.669 \\
\hline-1.500 & 14.049 & 11.813 & 9.981 & 8.469 & 7.212 & 6.161 & 5.277 & 4.532 & 3.900 & 3.363 & 2.904 & 2.512 & 2.176 & 1.888 & 1.639 & 1.425 & 1.240 & 1.080 & 0.941 & 0.821 & 0.717 \\
\hline-1.550 & 15.792 & 13.200 & 11.097 & 9.375 & 7.953 & 6.771 & 5.783 & 4.953 & 4.252 & 3.658 & 3.153 & 2.723 & 2.355 & 2.039 & 1.768 & 1.535 & 1.334 & 1.161 & 1.011 & 0.881 & 0.768 \\
\hline-1.600 & 17.866 & 14.831 & 12.395 & 10.419 & 8.801 & 7.465 & 6.354 & 5.426 & 4.646 & 3.987 & 3.430 & 2.956 & 2.552 & 2.206 & 1.910 & 1.656 & 1.438 & 1.249 & 1.087 & 0.946 & 0.824 \\
\hline-1.650 & 20.366 & 16.769 & 13.920 & 11.634 & 9.778 & 8.258 & 7.004 & 5.960 & 5.089 & 4.356 & 3.738 & 3.215 & 2.770 & 2.391 & 2.067 & 1.789 & 1.551 & 1.346 & 1.169 & 1.017 & 0.885 \\
\hline-1.700 & 23.430 & 19.103 & 15.731 & 13.059 & 10.914 & 9.173 & 7.746 & 6.568 & 5.589 & 4.771 & 4.083 & 3.503 & 3.012 & 2.595 & 2.239 & 1.935 & 1.675 & 1.452 & 1.259 & 1.094 & 0.951 \\
\hline-1.750 & 27.258 & 21.959 & 17.909 & 14.750 & 12.246 & 10.234 & 8.601 & 7.262 & 6.157 & 5.238 & 4.471 & 3.826 & 3.282 & 2.821 & 2.430 & 2.096 & 1.812 & 1.568 & 1.358 & 1.178 & 1.023 \\
\hline-1.800 & 32.158 & 25.520 & 20.570 & 16.781 & 13.824 & 11.478 & 9.592 & 8.061 & 6.806 & 5.770 & 4.908 & 4.188 & 3.583 & 3.073 & 2.642 & 2.275 & 1.962 & 1.695 & 1.467 & 1.271 & 1.102 \\
\hline-1.850 & 38.629 & 30.069 & 23.882 & 19.259 & 15.718 & 12.950 & 10.753 & 8.987 & 7.552 & 6.376 & 5.404 & 4.597 & 3.922 & 3.355 & 2.877 & 2.473 & 2.129 & 1.836 & 1.586 & 1.372 & 1.188 \\
\hline-1.900 & 47.535 & 36.057 & 28.102 & 22.338 & 18.024 & 14.715 & 12.126 & 10.070 & 8.417 & 7.073 & 5.971 & 5.061 & 4.304 & 3.672 & 3.141 & 2.693 & 2.314 & 1.992 & 1.718 & 1.484 & 1.283 \\
\hline-1.950 & 60.508 & 44.265 & 33.643 & 26.253 & 20.886 & 16.861 & 13.770 & 11.350 & 9.427 & 7.879 & 6.621 & 5.589 & 4.737 & 4.029 & 3.436 & 2.939 & 2.520 & 2.165 & 1.863 & 1.606 & 1.387 \\
\hline-2.000 & 81.059 & 56.153 & 41.206 & 31.378 & 24.516 & 19.520 & 15.767 & 12.881 & 10.620 & 8.822 & 7.374 & 6.196 & 5.231 & 4.433 & 3.769 & 3.215 & 2.749 & 2.357 & 2.024 & 1.742 & 1.502 \\
\hline
\end{tabular}




\begin{tabular}{|c|c|c|c|c|c|c|c|c|c|c|c|c|c|c|c|c|c|c|c|c|c|}
\hline & & & & & & & & & & & $l=h$ & & & & & & & & & & \\
\hline$\phi_{1}=\phi_{2}$ & 1.000 & 1.050 & 1.100 & 1.150 & 1.200 & 1.250 & 1.300 & 1.350 & 1.400 & 1.450 & 1.500 & 1.550 & 1.600 & 1.650 & 1.700 & 1.750 & 1.800 & 1.850 & 1.900 & 1.950 & 2.000 \\
\hline 0.000 & 1.315 & 1.245 & 1.179 & 1.117 & 1.058 & 1.002 & 0.949 & 0.898 & 0.851 & 0.806 & 0.763 & 0.723 & 0.684 & 0.648 & 0.614 & 0.582 & 0.551 & 0.522 & 0.494 & 0.468 & 0.443 \\
\hline-0.050 & 1.365 & 1.292 & 1.223 & 1.158 & 1.097 & 1.038 & 0.983 & 0.931 & 0.881 & 0.835 & 0.790 & 0.748 & 0.709 & 0.671 & 0.635 & 0.601 & 0.570 & 0.539 & 0.511 & 0.484 & 0.458 \\
\hline-0.100 & 1.417 & 1.341 & 1.269 & 1.201 & 1.137 & 1.077 & 1.019 & 0.965 & 0.913 & 0.864 & 0.818 & 0.775 & 0.733 & 0.695 & 0.657 & 0.622 & 0.589 & 0.558 & 0.528 & 0.500 & 0.473 \\
\hline-0.150 & 1.472 & 1.393 & 1.318 & 1.247 & 1.180 & 1.117 & 1.057 & 1.000 & 0.946 & 0.896 & 0.848 & 0.802 & 0.759 & 0.719 & 0.680 & 0.644 & 0.610 & 0.577 & 0.546 & 0.517 & 0.490 \\
\hline-0.200 & 1.529 & 1.446 & 1.368 & 1.294 & 1.224 & 1.158 & 1.096 & 1.037 & 0.981 & 0.928 & 0.878 & 0.831 & 0.786 & 0.744 & 0.704 & 0.667 & 0.631 & 0.597 & 0.565 & 0.535 & 0.506 \\
\hline-0.250 & 1.590 & 1.503 & 1.421 & 1.344 & 1.271 & 1.202 & 1.137 & 1.075 & 1.017 & 0.962 & 0.910 & 0.861 & 0.815 & 0.771 & 0.729 & 0.690 & 0.653 & 0.618 & 0.585 & 0.553 & 0.524 \\
\hline-0.300 & 1.653 & 1.562 & 1.477 & 1.396 & 1.320 & 1.248 & 1.180 & 1.116 & 1.055 & 0.998 & 0.943 & 0.892 & 0.844 & 0.799 & 0.755 & 0.715 & 0.676 & 0.639 & 0.605 & 0.572 & 0.542 \\
\hline-0.350 & 1.720 & 1.625 & 1.535 & 1.450 & 1.371 & 1.295 & 1.224 & 1.158 & 1.094 & 1.035 & 0.978 & 0.925 & 0.875 & 0.827 & 0.782 & 0.740 & 0.700 & 0.662 & 0.626 & 0.592 & 0.560 \\
\hline-0.400 & 1.790 & 1.690 & 1.596 & 1.508 & 1.424 & 1.345 & 1.271 & 1.202 & 1.136 & 1.073 & 1.015 & 0.959 & 0.907 & 0.857 & 0.811 & 0.766 & 0.725 & 0.685 & 0.648 & 0.613 & 0.580 \\
\hline-0.450 & 1.864 & 1.759 & 1.660 & 1.568 & 1.480 & 1.398 & 1.320 & 1.247 & 1.179 & 1.114 & 1.053 & 0.995 & 0.940 & 0.888 & 0.840 & 0.794 & 0.751 & 0.710 & 0.671 & 0.635 & 0.600 \\
\hline-0.500 & 1.941 & 1.831 & 1.728 & 1.631 & 1.539 & 1.453 & 1.372 & 1.296 & 1.224 & 1.156 & 1.092 & 1.032 & 0.975 & 0.921 & 0.871 & 0.823 & 0.778 & 0.735 & 0.695 & 0.657 & 0.621 \\
\hline-0.550 & 2.023 & 1.907 & 1.799 & 1.697 & 1.601 & 1.511 & 1.426 & 1.346 & 1.271 & 1.200 & 1.133 & 1.070 & 1.011 & 0.955 & 0.903 & 0.853 & 0.806 & 0.762 & 0.720 & 0.680 & 0.643 \\
\hline-0.600 & 2.110 & 1.988 & 1.874 & 1.767 & 1.666 & 1.571 & 1.483 & 1.399 & 1.320 & 1.247 & 1.177 & 1.111 & 1.049 & 0.991 & 0.936 & 0.884 & 0.835 & 0.789 & 0.746 & 0.705 & 0.666 \\
\hline-0.650 & 2.201 & 2.072 & 1.952 & 1.840 & 1.734 & 1.635 & 1.542 & 1.454 & 1.372 & 1.295 & 1.222 & 1.153 & 1.089 & 1.028 & 0.971 & 0.917 & 0.866 & 0.818 & 0.773 & 0.730 & 0.690 \\
\hline-0.700 & 2.297 & 2.162 & 2.036 & 1.917 & 1.806 & 1.702 & 1.604 & 1.513 & 1.427 & 1.346 & 1.270 & 1.198 & 1.130 & 1.067 & 1.007 & 0.951 & 0.898 & 0.848 & 0.801 & 0.757 & 0.715 \\
\hline-0.750 & 2.400 & 2.257 & 2.123 & 1.999 & 1.881 & 1.773 & 1.670 & 1.574 & 1.484 & 1.399 & 1.319 & 1.244 & 1.174 & 1.108 & 1.045 & 0.987 & 0.931 & 0.879 & 0.830 & 0.784 & 0.741 \\
\hline-0.800 & 2.508 & 2.357 & 2.216 & 2.084 & 1.962 & 1.847 & 1.739 & 1.638 & 1.544 & 1.455 & 1.371 & 1.293 & 1.220 & 1.150 & 1.085 & 1.024 & 0.966 & 0.912 & 0.861 & 0.813 & 0.768 \\
\hline-0.850 & 2.623 & 2.463 & 2.314 & 2.175 & 2.046 & 1.925 & 1.812 & 1.706 & 1.607 & 1.514 & 1.426 & 1.344 & 1.267 & 1.195 & 1.127 & 1.063 & 1.003 & 0.946 & 0.893 & 0.843 & 0.796 \\
\hline-0.900 & 2.745 & 2.576 & 2.418 & 2.272 & 2.135 & 2.008 & 1.889 & 1.777 & 1.673 & 1.575 & 1.484 & 1.398 & 1.317 & 1.242 & 1.171 & 1.104 & 1.041 & 0.982 & 0.926 & 0.874 & 0.825 \\
\hline-0.950 & 2.875 & 2.695 & 2.529 & 2.374 & 2.229 & 2.095 & 1.970 & 1.852 & 1.743 & 1.640 & 1.544 & 1.454 & 1.370 & 1.291 & 1.216 & 1.146 & 1.081 & 1.019 & 0.961 & 0.907 & 0.856 \\
\hline-1.000 & 3.013 & 2.823 & 2.646 & 2.482 & 2.329 & 2.187 & 2.055 & 1.932 & 1.816 & 1.709 & 1.608 & 1.513 & 1.425 & 1.342 & 1.264 & 1.191 & 1.123 & 1.058 & 0.998 & 0.941 & 0.888 \\
\hline-1.050 & 3.161 & 2.958 & 2.771 & 2.596 & 2.435 & 2.285 & 2.145 & 2.015 & 1.894 & 1.780 & 1.675 & 1.575 & 1.483 & 1.396 & 1.314 & 1.238 & 1.166 & 1.099 & 1.036 & 0.977 & 0.921 \\
\hline-1.100 & 3.318 & 3.103 & 2.903 & 2.718 & 2.547 & 2.389 & 2.241 & 2.104 & 1.976 & 1.856 & 1.745 & 1.641 & 1.544 & 1.452 & 1.367 & 1.287 & 1.212 & 1.142 & 1.076 & 1.014 & 0.956 \\
\hline-1.150 & 3.488 & 3.257 & 3.045 & 2.848 & 2.667 & 2.498 & 2.342 & 2.197 & 2.062 & 1.936 & 1.819 & 1.710 & 1.607 & 1.512 & 1.422 & 1.339 & 1.260 & 1.187 & 1.118 & 1.053 & 0.992 \\
\hline-1.200 & 3.670 & 3.423 & 3.196 & 2.987 & 2.794 & 2.615 & 2.450 & 2.296 & 2.154 & 2.021 & 1.897 & 1.782 & 1.675 & 1.574 & 1.481 & 1.393 & 1.311 & 1.234 & 1.162 & 1.094 & 1.031 \\
\hline-1.250 & 3.865 & 3.600 & 3.357 & 3.134 & 2.929 & 2.739 & 2.564 & 2.401 & 2.250 & 2.110 & 1.980 & 1.859 & 1.746 & 1.640 & 1.542 & 1.450 & 1.364 & 1.283 & 1.208 & 1.137 & 1.071 \\
\hline-1.300 & 4.076 & 3.791 & 3.531 & 3.292 & 3.073 & 2.871 & 2.685 & 2.513 & 2.353 & 2.205 & 2.068 & 1.940 & 1.821 & 1.710 & 1.606 & 1.510 & 1.419 & 1.335 & 1.256 & 1.182 & 1.112 \\
\hline-1.350 & 4.303 & 3.996 & 3.717 & 3.461 & 3.227 & 3.012 & 2.814 & 2.631 & 2.462 & 2.305 & 2.160 & 2.025 & 1.900 & 1.783 & 1.674 & 1.573 & 1.478 & 1.389 & 1.306 & 1.229 & 1.156 \\
\hline-1.400 & 4.550 & 4.218 & 3.917 & 3.643 & 3.393 & 3.163 & 2.952 & 2.757 & 2.578 & 2.412 & 2.258 & 2.116 & 1.983 & 1.860 & 1.746 & 1.639 & 1.539 & 1.446 & 1.359 & 1.278 & 1.202 \\
\hline-1.450 & 4.817 & 4.458 & 4.134 & 3.839 & 3.570 & 3.324 & 3.099 & 2.891 & 2.701 & 2.525 & 2.362 & 2.211 & 2.071 & 1.942 & 1.821 & 1.709 & 1.604 & 1.506 & 1.415 & 1.330 & 1.251 \\
\hline-1.500 & 5.109 & 4.719 & 4.367 & 4.049 & 3.760 & 3.497 & 3.256 & 3.035 & 2.832 & 2.645 & 2.472 & 2.313 & 2.165 & 2.028 & 1.901 & 1.782 & 1.672 & 1.570 & 1.474 & 1.385 & 1.301 \\
\hline-1.550 & 5.427 & 5.002 & 4.621 & 4.277 & 3.966 & 3.683 & 3.424 & 3.188 & 2.972 & 2.773 & 2.590 & 2.420 & 2.264 & 2.119 & 1.985 & 1.860 & 1.744 & 1.636 & 1.536 & 1.442 & 1.354 \\
\hline-1.600 & 5.777 & 5.312 & 4.897 & 4.524 & 4.187 & 3.883 & 3.605 & 3.353 & 3.121 & 2.909 & 2.714 & 2.535 & 2.369 & 2.216 & 2.074 & 1.942 & 1.820 & 1.706 & 1.601 & 1.502 & 1.410 \\
\hline-1.650 & 6.162 & 5.651 & 5.197 & 4.792 & 4.427 & 4.098 & 3.800 & 3.529 & 3.282 & 3.055 & 2.847 & 2.657 & 2.481 & 2.318 & 2.168 & 2.029 & 1.900 & 1.780 & 1.669 & 1.566 & 1.469 \\
\hline-1.700 & 6.588 & 6.025 & 5.527 & 5.084 & 4.688 & 4.332 & 4.010 & 3.719 & 3.453 & 3.211 & 2.990 & 2.786 & 2.599 & 2.427 & 2.268 & 2.121 & 1.985 & 1.859 & 1.742 & 1.633 & 1.531 \\
\hline-1.750 & 7.062 & 6.437 & 5.889 & 5.403 & 4.972 & 4.585 & 4.237 & 3.923 & 3.638 & 3.379 & 3.142 & 2.925 & 2.726 & 2.543 & 2.374 & 2.219 & 2.075 & 1.942 & 1.818 & 1.703 & 1.597 \\
\hline-1.800 & 7.592 & 6.895 & 6.288 & 5.754 & 5.282 & 4.861 & 4.483 & 4.144 & 3.837 & 3.558 & 3.305 & 3.073 & 2.861 & 2.666 & 2.487 & 2.322 & 2.170 & 2.029 & 1.899 & 1.778 & 1.665 \\
\hline-1.850 & 8.187 & 7.406 & 6.730 & 6.140 & 5.621 & 5.161 & 4.751 & 4.383 & 4.051 & 3.752 & 3.479 & 3.232 & 3.005 & 2.798 & 2.607 & 2.432 & 2.271 & 2.122 & 1.984 & 1.856 & 1.738 \\
\hline-1.900 & 8.861 & 7.979 & 7.223 & 6.568 & 5.995 & 5.490 & 5.042 & 4.643 & 4.284 & 3.960 & 3.668 & 3.402 & 3.160 & 2.938 & 2.735 & 2.549 & 2.378 & 2.220 & 2.074 & 1.940 & 1.815 \\
\hline-1.950 & 9.631 & 8.627 & 7.775 & 7.043 & 6.408 & 5.852 & 5.361 & 4.925 & 4.536 & 4.186 & 3.870 & 3.585 & 3.325 & 3.088 & 2.872 & 2.674 & 2.492 & 2.325 & 2.170 & 2.028 & 1.896 \\
\hline-2.000 & 10.516 & 9.364 & 8.397 & 7.575 & 6.867 & 6.251 & 5.711 & 5.234 & 4.810 & 4.430 & 4.089 & 3.782 & 3.503 & 3.250 & 3.018 & 2.807 & 2.614 & 2.436 & 2.272 & 2.121 & 1.982 \\
\hline
\end{tabular}

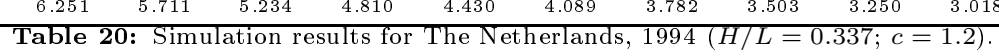




\begin{tabular}{|c|c|c|c|c|c|c|c|c|c|c|c|c|c|c|c|c|c|c|c|c|c|}
\hline & \multicolumn{21}{|c|}{$l=h$} \\
\hline$\phi_{1}=\phi_{2}$ & 1.000 & 1.050 & 1.100 & 1.150 & 1.200 & 1.250 & 1.300 & 1.350 & 1.400 & 1.450 & 1.500 & 1.550 & 1.600 & 1.650 & 1.700 & 1.750 & 1.800 & 1.850 & 1.900 & 1.950 & 2.000 \\
\hline 0.000 & 1.315 & 1.224 & 1.140 & 1.062 & 0.989 & 0.921 & 0.858 & 0.799 & 0.744 & 0.693 & 0.645 & 0.601 & 0.560 & 0.521 & 0.486 & 0.452 & 0.421 & 0.392 & 0.365 & 0.340 & 0.317 \\
\hline-0.050 & 1.376 & 1.281 & 1.193 & 1.111 & 1.034 & 0.963 & 0.896 & 0.835 & 0.777 & 0.724 & 0.674 & 0.627 & 0.584 & 0.544 & 0.506 & 0.471 & 0.439 & 0.409 & 0.381 & 0.354 & 0.330 \\
\hline-0.100 & 1.442 & 1.342 & 1.249 & 1.162 & 1.082 & 1.007 & 0.937 & 0.872 & 0.812 & 0.756 & 0.703 & 0.655 & 0.610 & 0.567 & 0.528 & 0.492 & 0.458 & 0.426 & 0.397 & 0.369 & 0.344 \\
\hline-0.150 & 1.511 & 1.406 & 1.308 & 1.216 & 1.132 & 1.053 & 0.980 & 0.912 & 0.848 & 0.790 & 0.735 & 0.684 & 0.636 & 0.592 & 0.551 & 0.513 & 0.477 & 0.444 & 0.414 & 0.385 & 0.358 \\
\hline-0.200 & 1.584 & 1.473 & 1.370 & 1.274 & 1.184 & 1.102 & 1.025 & 0.953 & 0.887 & 0.825 & 0.768 & 0.714 & 0.664 & 0.618 & 0.575 & 0.535 & 0.498 & 0.463 & 0.431 & 0.401 & 0.373 \\
\hline-0.250 & 1.662 & 1.544 & 1.436 & 1.334 & 1.240 & 1.153 & 1.073 & 0.997 & 0.927 & 0.862 & 0.802 & 0.746 & 0.694 & 0.645 & 0.600 & 0.558 & 0.520 & 0.483 & 0.450 & 0.418 & 0.389 \\
\hline-0.300 & 1.744 & 1.620 & 1.505 & 1.398 & 1.299 & 1.208 & 1.123 & 1.043 & 0.970 & 0.902 & 0.838 & 0.780 & 0.725 & 0.674 & 0.627 & 0.583 & 0.542 & 0.504 & 0.469 & 0.436 & 0.406 \\
\hline-0.400 & 1.924 & 1.785 & 1.657 & 1.538 & 1.428 & 1.325 & 1.231 & 1.144 & 1.062 & 0.987 & 0.917 & 0.852 & 0.792 & 0.736 & 0.684 & 0.636 & 0.591 & 0.549 & 0.511 & 0.475 & 0.442 \\
\hline-0.450 & 2.022 & 1.875 & 1.739 & 1.613 & 1.497 & 1.390 & 1.290 & 1.198 & 1.112 & 1.033 & 0.960 & 0.891 & 0.828 & 0.769 & 0.715 & 0.664 & 0.617 & 0.574 & 0.533 & 0.496 & 0.461 \\
\hline-0.500 & 2.126 & 1.970 & 1.827 & 1.694 & 1.571 & 1.458 & 1.352 & 1.255 & 1.165 & 1.082 & 1.004 & 0.932 & 0.866 & 0.804 & 0.747 & 0.694 & 0.645 & 0.599 & 0.557 & 0.517 & 0.481 \\
\hline-0.550 & 2.237 & 2.072 & 1.920 & 1.779 & 1.649 & 1.529 & 1.418 & 1.316 & 1.221 & 1.133 & 1.051 & 0.976 & 0.906 & 0.841 & 0.781 & 0.725 & 0.674 & 0.626 & 0.581 & 0.540 & 0.502 \\
\hline-0.600 & 2.356 & 2.180 & 2.019 & 1.870 & 1.733 & 1.605 & 1.487 & 1.380 & 1.280 & 1.187 & 1.101 & 1.022 & 0.948 & 0.880 & 0.817 & 0.758 & 0.704 & 0.654 & 0.607 & 0.564 & 0.524 \\
\hline-0.650 & 2.483 & 2.296 & 2.125 & 1.966 & 1.821 & 1.686 & 1.562 & 1.448 & 1.342 & 1.244 & 1.154 & 1.070 & 0.992 & 0.921 & 0.854 & 0.793 & 0.736 & 0.683 & 0.634 & 0.589 & 0.547 \\
\hline-0.700 & 2.618 & 2.420 & 2.237 & 2.069 & 1.914 & 1.772 & 1.641 & 1.520 & 1.408 & 1.305 & 1.209 & 1.121 & 1.039 & 0.964 & 0.894 & 0.830 & 0.770 & 0.714 & 0.663 & 0.616 & 0.572 \\
\hline-0.750 & 2.763 & 2.551 & 2.357 & 2.178 & 2.014 & 1.863 & 1.724 & 1.596 & 1.478 & 1.369 & 1.268 & 1.175 & 1.089 & 1.010 & 0.936 & 0.868 & 0.805 & 0.747 & 0.693 & 0.643 & 0.597 \\
\hline-0.850 & 3.084 & 2.843 & 2.622 & 2.420 & 2.234 & 2.064 & 1.907 & 1.763 & 1.631 & 1.509 & 1.396 & 1.293 & 1.197 & 1.109 & 1.027 & 0.952 & 0.882 & 0.818 & 0.758 & 0.703 & 0.652 \\
\hline-0.900 & 3.264 & 3.005 & 2.768 & 2.553 & 2.355 & 2.174 & 2.007 & 1.855 & 1.714 & 1.585 & 1.466 & 1.357 & 1.256 & 1.162 & 1.077 & 0.997 & 0.924 & 0.856 & 0.794 & 0.736 & 0.682 \\
\hline-0.950 & 3.456 & 3.179 & 2.926 & 2.695 & 2.484 & 2.291 & 2.114 & 1.952 & 1.803 & 1.666 & 1.540 & 1.424 & 1.318 & 1.219 & 1.129 & 1.045 & 0.968 & 0.897 & 0.831 & 0.770 & 0.714 \\
\hline-1.000 & 3.664 & 3.366 & 3.095 & 2.848 & 2.623 & 2.417 & 2.228 & 2.056 & 1.898 & 1.752 & 1.619 & 1.496 & 1.384 & 1.280 & 1.184 & 1.096 & 1.014 & 0.939 & 0.870 & 0.806 & 0.747 \\
\hline-1.050 & 3.889 & 3.568 & 3.277 & 3.012 & 2.771 & 2.551 & 2.350 & 2.167 & 1.999 & 1.844 & 1.703 & 1.573 & 1.453 & 1.344 & 1.242 & 1.149 & 1.063 & 0.984 & 0.911 & 0.844 & 0.782 \\
\hline-1.100 & 4.132 & 3.786 & 3.473 & 3.189 & 2.931 & 2.695 & 2.481 & 2.285 & 2.106 & 1.942 & 1.792 & 1.654 & 1.528 & 1.411 & 1.304 & 1.206 & 1.115 & 1.032 & 0.955 & 0.884 & 0.818 \\
\hline-1.150 & 4.396 & 4.022 & 3.685 & 3.379 & 3.102 & 2.850 & 2.621 & 2.412 & 2.221 & 2.046 & 1.887 & 1.741 & 1.606 & 1.483 & 1.370 & 1.266 & 1.170 & 1.082 & 1.001 & 0.926 & 0.857 \\
\hline-1.200 & 4.684 & 4.279 & 3.914 & 3.585 & 3.287 & 3.016 & 2.771 & 2.547 & 2.344 & 2.158 & 1.988 & 1.833 & 1.690 & 1.560 & 1.440 & 1.330 & 1.229 & 1.135 & 1.050 & 0.971 & 0.898 \\
\hline-1.250 & 4.998 & 4.558 & 4.162 & 3.807 & 3.486 & 3.195 & 2.932 & 2.693 & 2.475 & 2.277 & 2.096 & 1.931 & 1.779 & 1.641 & 1.514 & 1.397 & 1.290 & 1.192 & 1.101 & 1.018 & 0.942 \\
\hline-1.300 & 5.341 & 4.862 & 4.433 & 4.048 & 3.701 & 3.389 & 3.106 & 2.849 & 2.616 & 2.405 & 2.212 & 2.035 & 1.875 & 1.727 & 1.593 & 1.469 & 1.356 & 1.252 & 1.156 & 1.068 & 0.987 \\
\hline-1.350 & 5.719 & 5.194 & 4.727 & 4.310 & 3.935 & 3.597 & 3.293 & 3.017 & 2.768 & 2.541 & 2.335 & 2.147 & 1.976 & 1.820 & 1.676 & 1.545 & 1.425 & 1.315 & 1.214 & 1.121 & 1.036 \\
\hline-1.400 & 6.134 & 5.559 & 5.049 & 4.595 & 4.188 & 3.823 & 3.495 & 3.199 & 2.931 & 2.688 & 2.468 & 2.267 & 2.084 & 1.918 & 1.766 & 1.627 & 1.499 & 1.383 & 1.275 & 1.177 & 1.087 \\
\hline-1.450 & 6.594 & 5.961 & 5.402 & 4.906 & 4.464 & 4.069 & 3.714 & 3.395 & 3.107 & 2.846 & 2.610 & 2.395 & 2.200 & 2.023 & 1.861 & 1.713 & 1.578 & 1.454 & 1.341 & 1.237 & 1.141 \\
\hline-1.500 & 7.104 & 6.405 & 5.791 & 5.248 & 4.766 & 4.336 & 3.952 & 3.607 & 3.296 & 3.016 & 2.763 & 2.533 & 2.325 & 2.135 & 1.963 & 1.805 & 1.662 & 1.530 & 1.410 & 1.300 & 1.199 \\
\hline-1.550 & 7.674 & 6.898 & 6.220 & 5.623 & 5.096 & 4.628 & 4.210 & 3.837 & 3.501 & 3.199 & 2.927 & 2.681 & 2.458 & 2.255 & 2.071 & 1.904 & 1.751 & 1.611 & 1.484 & 1.367 & 1.260 \\
\hline-1.600 & 8.313 & 7.447 & 6.695 & 6.037 & 5.459 & 4.947 & 4.492 & 4.086 & 3.724 & 3.398 & 3.105 & 2.840 & 2.601 & 2.384 & 2.188 & 2.009 & 1.846 & 1.698 & 1.562 & 1.438 & 1.325 \\
\hline-1.650 & 9.034 & 8.063 & 7.225 & 6.496 & 5.858 & 5.297 & 4.800 & 4.359 & 3.965 & 3.613 & 3.297 & 3.012 & 2.755 & 2.523 & 2.313 & 2.122 & 1.948 & 1.790 & 1.646 & 1.514 & 1.394 \\
\hline-1.800 & 11.870 & 10.440 & 9.239 & 8.218 & 7.341 & 6.583 & 5.921 & 5.342 & 4.831 & 4.378 & 3.976 & 3.617 & 3.295 & 3.006 & 2.746 & 2.511 & 2.299 & 2.107 & 1.932 & 1.774 & 1.629 \\
\hline-1.850 & 13.130 & 11.474 & 10.099 & 8.942 & 7.957 & 7.111 & 6.377 & 5.738 & 5.177 & 4.682 & 4.244 & 3.854 & 3.505 & 3.194 & 2.913 & 2.661 & 2.434 & 2.228 & 2.042 & 1.872 & 1.719 \\
\hline-1.900 & 14.613 & 12.676 & 11.088 & 9.767 & 8.652 & 7.702 & 6.885 & 6.177 & 5.559 & 5.016 & 4.537 & 4.112 & 3.734 & 3.397 & 3.095 & 2.823 & 2.579 & 2.358 & 2.159 & 1.978 & 1.814 \\
\hline-1.950 & 16.385 & 14.087 & 12.235 & 10.712 & 9.442 & 8.370 & 7.454 & 6.665 & 5.981 & 5.383 & 4.858 & 4.395 & 3.984 & 3.618 & 3.291 & 2.998 & 2.735 & 2.498 & 2.284 & 2.091 & 1.916 \\
\hline-2.000 & 18.535 & 15.768 & 13.578 & 11.806 & 10.347 & 9.127 & 8.094 & 7.212 & 6.451 & 5.790 & 5.212 & 4.704 & 4.256 & 3.858 & 3.504 & 3.187 & 2.904 & 2.649 & 2.420 & 2.212 & 2.025 \\
\hline
\end{tabular}

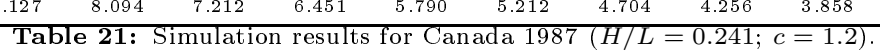




\begin{tabular}{|c|c|c|c|c|c|c|c|c|c|c|c|c|c|c|c|c|c|c|c|c|c|}
\hline & & & & & & & & & & & $l=h$ & & & & & & & & & & \\
\hline$\phi_{1}=\phi_{2}$ & 1.000 & 1.050 & 1.100 & 1.150 & 1.200 & 1.250 & 1.300 & 1.350 & 1.400 & 1.450 & 1.500 & 1.550 & 1.600 & 1.650 & 1.700 & 1.750 & 1.800 & 1.850 & 1.900 & 1.950 & 2.000 \\
\hline 0.000 & 1.315 & 1.228 & 1.147 & 1.072 & 1.001 & 0.935 & 0.874 & 0.816 & 0.762 & 0.712 & 0.665 & 0.621 & 0.580 & 0.542 & 0.506 & 0.473 & 0.442 & 0.413 & 0.386 & 0.360 & 0.337 \\
\hline-0.050 & 1.374 & 1.283 & 1.199 & 1.119 & 1.045 & 0.976 & 0.912 & 0.851 & 0.795 & 0.743 & 0.693 & 0.648 & 0.605 & 0.565 & 0.528 & 0.493 & 0.460 & 0.430 & 0.401 & 0.375 & 0.350 \\
\hline-0.100 & 1.438 & 1.342 & 1.253 & 1.169 & 1.092 & 1.019 & 0.952 & 0.888 & 0.829 & 0.774 & 0.723 & 0.675 & 0.630 & 0.589 & 0.550 & 0.513 & 0.479 & 0.447 & 0.418 & 0.390 & 0.364 \\
\hline-0.150 & 1.504 & 1.404 & 1.310 & 1.222 & 1.141 & 1.065 & 0.994 & 0.927 & 0.866 & 0.808 & 0.754 & 0.704 & 0.657 & 0.613 & 0.573 & 0.535 & 0.499 & 0.466 & 0.435 & 0.406 & 0.379 \\
\hline-0.200 & 1.575 & 1.469 & 1.370 & 1.278 & 1.192 & 1.112 & 1.038 & 0.968 & 0.904 & 0.843 & 0.787 & 0.734 & 0.685 & 0.639 & 0.597 & 0.557 & 0.520 & 0.485 & 0.453 & 0.423 & 0.395 \\
\hline-0.250 & 1.649 & 1.538 & 1.434 & 1.337 & 1.247 & 1.163 & 1.084 & 1.011 & 0.943 & 0.880 & 0.821 & 0.766 & 0.715 & 0.667 & 0.622 & 0.580 & 0.542 & 0.506 & 0.472 & 0.440 & 0.411 \\
\hline-0.300 & 1.729 & 1.611 & 1.501 & 1.399 & 1.304 & 1.216 & 1.133 & 1.057 & 0.985 & 0.919 & 0.857 & 0.799 & 0.746 & 0.695 & 0.649 & 0.605 & 0.565 & 0.527 & 0.491 & 0.459 & 0.428 \\
\hline-0.400 & 1.901 & 1.769 & 1.647 & 1.534 & 1.428 & 1.330 & 1.239 & 1.155 & 1.076 & 1.003 & 0.935 & 0.871 & 0.812 & 0.757 & 0.706 & 0.658 & 0.614 & 0.572 & 0.534 & 0.498 & 0.464 \\
\hline-0.450 & 1.995 & 1.856 & 1.726 & 1.607 & 1.496 & 1.393 & 1.297 & 1.208 & 1.125 & 1.048 & 0.977 & 0.910 & 0.848 & 0.790 & 0.736 & 0.686 & 0.640 & 0.597 & 0.556 & 0.519 & 0.484 \\
\hline-0.500 & 2.094 & 1.947 & 1.811 & 1.684 & 1.567 & 1.458 & 1.357 & 1.264 & 1.177 & 1.096 & 1.021 & 0.950 & 0.885 & 0.825 & 0.769 & 0.716 & 0.668 & 0.622 & 0.580 & 0.541 & 0.504 \\
\hline-0.550 & 2.200 & 2.045 & 1.900 & 1.767 & 1.643 & 1.528 & 1.422 & 1.323 & 1.231 & 1.146 & 1.067 & 0.993 & 0.925 & 0.862 & 0.803 & 0.748 & 0.697 & 0.649 & 0.605 & 0.564 & 0.525 \\
\hline-0.600 & 2.313 & 2.148 & 1.995 & 1.854 & 1.723 & 1.602 & 1.489 & 1.385 & 1.289 & 1.199 & 1.116 & 1.039 & 0.967 & 0.900 & 0.838 & 0.781 & 0.727 & 0.677 & 0.631 & 0.588 & 0.548 \\
\hline-0.650 & 2.433 & 2.258 & 2.096 & 1.946 & 1.808 & 1.680 & 1.561 & 1.451 & 1.349 & 1.255 & 1.167 & 1.086 & 1.011 & 0.941 & 0.876 & 0.815 & 0.759 & 0.707 & 0.658 & 0.613 & 0.571 \\
\hline-0.700 & 2.562 & 2.375 & 2.203 & 2.044 & 1.897 & 1.762 & 1.637 & 1.521 & 1.413 & 1.314 & 1.222 & 1.136 & 1.057 & 0.983 & 0.915 & 0.852 & 0.793 & 0.738 & 0.687 & 0.640 & 0.596 \\
\hline-0.750 & 2.699 & 2.500 & 2.317 & 2.149 & 1.993 & 1.850 & 1.717 & 1.595 & 1.481 & 1.377 & 1.279 & 1.189 & 1.106 & 1.028 & 0.957 & 0.890 & 0.828 & 0.771 & 0.717 & 0.668 & 0.622 \\
\hline-0.850 & 3.002 & 2.776 & 2.568 & 2.379 & 2.203 & 2.042 & 1.893 & 1.756 & 1.630 & 1.513 & 1.404 & 1.304 & 1.212 & 1.126 & 1.047 & 0.973 & 0.905 & 0.841 & 0.783 & 0.728 & 0.677 \\
\hline-0.900 & 3.171 & 2.929 & 2.708 & 2.505 & 2.319 & 2.148 & 1.990 & 1.844 & 1.710 & 1.587 & 1.472 & 1.367 & 1.269 & 1.179 & 1.095 & 1.018 & 0.946 & 0.879 & 0.818 & 0.761 & 0.707 \\
\hline-0.950 & 3.352 & 3.093 & 2.857 & 2.640 & 2.442 & 2.260 & 2.092 & 1.938 & 1.796 & 1.665 & 1.544 & 1.433 & 1.330 & 1.235 & 1.147 & 1.065 & 0.989 & 0.920 & 0.855 & 0.795 & 0.739 \\
\hline-1.000 & 3.546 & 3.269 & 3.016 & 2.785 & 2.574 & 2.380 & 2.202 & 2.038 & 1.887 & 1.749 & 1.621 & 1.503 & 1.394 & 1.294 & 1.201 & 1.115 & 1.035 & 0.962 & 0.894 & 0.831 & 0.772 \\
\hline-1.050 & 3.757 & 3.459 & 3.188 & 2.941 & 2.715 & 2.508 & 2.318 & 2.144 & 1.984 & 1.837 & 1.702 & 1.577 & 1.462 & 1.356 & 1.258 & 1.168 & 1.084 & 1.006 & 0.935 & 0.868 & 0.807 \\
\hline-1.100 & 3.984 & 3.663 & 3.372 & 3.107 & 2.865 & 2.645 & 2.443 & 2.257 & 2.088 & 1.932 & 1.788 & 1.656 & 1.534 & 1.422 & 1.319 & 1.223 & 1.135 & 1.054 & 0.978 & 0.908 & 0.844 \\
\hline-1.150 & 4.230 & 3.884 & 3.571 & 3.286 & 3.027 & 2.791 & 2.576 & 2.378 & 2.198 & 2.032 & 1.880 & 1.740 & 1.611 & 1.492 & 1.383 & 1.282 & 1.189 & 1.103 & 1.024 & 0.950 & 0.882 \\
\hline-1.200 & 4.497 & 4.123 & 3.785 & 3.479 & 3.201 & 2.949 & 2.718 & 2.508 & 2.315 & 2.139 & 1.977 & 1.829 & 1.692 & 1.567 & 1.451 & 1.345 & 1.246 & 1.156 & 1.072 & 0.995 & 0.923 \\
\hline-1.250 & 4.788 & 4.382 & 4.017 & 3.688 & 3.389 & 3.118 & 2.871 & 2.646 & 2.441 & 2.253 & 2.081 & 1.923 & 1.779 & 1.646 & 1.523 & 1.411 & 1.307 & 1.211 & 1.123 & 1.042 & 0.966 \\
\hline-1.300 & 5.105 & 4.665 & 4.269 & 3.913 & 3.591 & 3.300 & 3.035 & 2.794 & 2.575 & 2.375 & 2.192 & 2.024 & 1.870 & 1.729 & 1.600 & 1.481 & 1.371 & 1.270 & 1.177 & 1.091 & 1.012 \\
\hline-1.350 & 5.453 & 4.972 & 4.543 & 4.157 & 3.810 & 3.496 & 3.212 & 2.954 & 2.719 & 2.505 & 2.310 & 2.132 & 1.968 & 1.819 & 1.681 & 1.555 & 1.439 & 1.332 & 1.234 & 1.143 & 1.060 \\
\hline-1.400 & 5.834 & 5.309 & 4.841 & 4.423 & 4.047 & 3.708 & 3.402 & 3.125 & 2.874 & 2.645 & 2.437 & 2.247 & 2.073 & 1.914 & 1.768 & 1.634 & 1.511 & 1.398 & 1.294 & 1.199 & 1.110 \\
\hline-1.450 & 6.255 & 5.679 & 5.168 & 4.712 & 4.304 & 3.938 & 3.608 & 3.310 & 3.040 & 2.795 & 2.572 & 2.369 & 2.184 & 2.015 & 1.860 & 1.718 & 1.588 & 1.468 & 1.358 & 1.257 & 1.164 \\
\hline-1.500 & 6.721 & 6.086 & 5.526 & 5.028 & 4.584 & 4.187 & 3.831 & 3.509 & 3.219 & 2.956 & 2.718 & 2.501 & 2.303 & 2.123 & 1.958 & 1.807 & 1.669 & 1.543 & 1.426 & 1.319 & 1.221 \\
\hline-1.550 & 7.239 & 6.537 & 5.919 & 5.374 & 4.890 & 4.459 & 4.072 & 3.725 & 3.412 & 3.130 & 2.874 & 2.642 & 2.431 & 2.239 & 2.063 & 1.903 & 1.756 & 1.622 & 1.498 & 1.385 & 1.281 \\
\hline-1.600 & 7.818 & 7.037 & 6.355 & 5.755 & 5.225 & 4.755 & 4.335 & 3.959 & 3.621 & 3.317 & 3.042 & 2.793 & 2.568 & 2.362 & 2.175 & 2.004 & 1.848 & 1.706 & 1.575 & 1.455 & 1.345 \\
\hline-1.650 & 8.468 & 7.595 & 6.838 & 6.176 & 5.594 & 5.079 & 4.622 & 4.213 & 3.848 & 3.520 & 3.224 & 2.956 & 2.714 & 2.495 & 2.295 & 2.113 & 1.947 & 1.795 & 1.656 & 1.529 & 1.413 \\
\hline-1.800 & 10.999 & 9.731 & 8.659 & 7.741 & 6.949 & 6.261 & 5.657 & 5.126 & 4.655 & 4.236 & 3.862 & 3.527 & 3.226 & 2.954 & 2.709 & 2.487 & 2.285 & 2.101 & 1.934 & 1.782 & 1.643 \\
\hline-1.850 & 12.110 & 10.650 & 9.429 & 8.394 & 7.508 & 6.743 & 6.076 & 5.491 & 4.976 & 4.519 & 4.113 & 3.750 & 3.425 & 3.132 & 2.868 & 2.630 & 2.414 & 2.218 & 2.040 & 1.877 & 1.729 \\
\hline-1.900 & 13.408 & 11.711 & 10.310 & 9.134 & 8.136 & 7.280 & 6.540 & 5.895 & 5.328 & 4.829 & 4.386 & 3.992 & 3.640 & 3.324 & 3.040 & 2.784 & 2.553 & 2.343 & 2.153 & 1.980 & 1.822 \\
\hline-1.950 & 14.945 & 12.949 & 11.324 & 9.978 & 8.846 & 7.884 & 7.057 & 6.342 & 5.717 & 5.169 & 4.685 & 4.256 & 3.874 & 3.532 & 3.226 & 2.950 & 2.702 & 2.477 & 2.274 & 2.089 & 1.921 \\
\hline-2.000 & 16.790 & 14.409 & 12.504 & 10.947 & 9.654 & 8.565 & 7.637 & 6.840 & 6.148 & 5.544 & 5.013 & 4.545 & 4.129 & 3.758 & 3.427 & 3.130 & 2.863 & 2.621 & 2.403 & 2.206 & 2.026 \\
\hline
\end{tabular}




\section{References}

Acemoglu, D.: 1998, 'Why do New Technologies Complement Skills? Directed Technical Change and Wage Inequality'. Quarterly Journal of Economics 113(4), $1055-1089$.

Acemoglu, D.: 2002, 'Directed Technical Change'. Review of Economic Studies 69(4), 781-810.

Acemoglu, D.: 2003a, 'Cross-Country Inequality Trends'. Economic Journal 113(485), 121-149.

Acemoglu, D.: 2003b, 'Patterns of Skill Premia'. Review of Economic Studies 70(2), 199-230.

Acemoglu, D. and F. Zilibotti: 2001, 'Productivity Differences'. Quarterly Journal of Economics 116(2), 563-606.

Afonso, O.: 2006, 'Skill-Biased Technological Knowledge Without Scale Effects'. Applied Economics 38(1), 13-21.

Afonso, O.: 2007, 'The Impact of Government on Wage Inequality Without Scale Effects'. Economic Modelling. Forthcoming.

Aghion, P. and P. Howitt: 1992, 'A Model of Growth Through Creative Destruction'. Econometrica 60(2), 323-351.

Antràs, P., L. Garicano, and E. Rossi-Hansber: 2005, 'Offshoring in a Knowledge Economy'. NBER Working Paper 11094, National Bureau of Economic Research.

Arbache, J. S., A. Dickerson, and F. Green: 2004, 'Trade Liberalisation and Wages in Developing Countries'. Economic Journal 114(493), F73-F96.

Arrow, K. J.: 1962, 'The Economic Implications of Learning by Doing'. Review of Economic Studies 29(3), 155-173.

Autor, D. H., L. F. Katz, and M. S. Kearny: 2005, 'Trens in U.S. Wage Inequality: Re-assessing the Revisionists'. NBER Working Paper 11627, National Bureau of Economic Research.

Autor, D. H., L. F. Katz, and A. B. Krueger: 1998, 'Computing Inequality: Have Computers Changed the Labour Market?'. Quarterly Journal of Economics 113(4), 1169-1213. 
Autor, D. H., F. Levy, and R. J. Murnane: 2003, 'The Skill Content of Recent Technological Change: An Empirical Exploration'. Quarterly Journal of Economics 118(4), 1279-1333.

Avalos, A. and A. Savvides: 2006, 'The Manufacturing Wage Inequality in Latin America and East Asia: Openness, Technology Transfer, and Labor Supply'. Review of Development Economics 10(4), 553-576.

Baldwin, J. and Z. Lin: 2002, 'Impediments to advanced technology adoption for Canadian manufacturers'. Research Policy 31(1), 1-18.

Barro, R. and X. Sala-i-Martin: 2004, Economic Growth. Cambridge, Massachusetts: The MIT Press, 2nd edition.

Becker, G. S. and K. M. Murphy: 1992, 'The Division of Labor, Coordination Costs, and Knowledge'. Quarterly Journal of Economics 107(4), 1137-1160.

Benhabib, J. and K. Nishimura: 1979, 'The Hopf Bifurcation and Stability of Closed Orbits in Multisector Models of Optimal Economic Growth'. Journal of Economic Theory 21(3), 421-444.

Berman, E., J. Bound, and Z. Griliches: 1994, 'Changes in the Demand for Skilled Labor Within U.S. Manufacturing: Evidence From the Annual Survey of Manufactures'. Quarterly Journal of Economics 109(2), 367-398.

Berman, E., J. Bound, and S. Machin: 1998, 'Implications Of Skill-Biased Technological Change: International Evidence'. Quarterly Journal of Economics 113(4), $1245-1279$.

Bessen, J.: 2002, 'Technology Adoption Costs and Productivity Growth: The Transition to Information Technology'. Review of Economic Dynamics 5(2), 443-469.

Beyer, H., P. Rojas, and R. Vergara: 1999, 'Trade Liberalization and Wage Inequality'. Journal of Development Economics 59(1), 103-123.

Bishop, J. H.: 1979, 'Is the Test Score Decline Responsible for the Productivity Growth Decline?'. American Economic Review 79(1), 178-197.

Black, S. E. and L. M. Lynch: 2001, 'What's Driving the New Economy? The Benefits of Workplace Innovation'. Federal Reserve Bank of New York Staff Report 118, Federal Reserve Bank of New York. 
Blau, F. D. and L. M. Kahn: 1996, 'International Differences in Male Wage Inequality: Institutions versus Market Forces'. Journal of Political Economy 104(4), $791-836$.

Borghans, L. and B. ter Weel: 2007, 'The diffusion of computers and the distribution of wages'. European Economic Review 51(3), 715-748.

Borjas, G. J. and V. Ramey: 1995, 'Foreign Competition, Market Power, and Wage Inequality'. Quarterly Journal of Economics 110(4), 1075-1110.

Bound, J. and G. Johnson: 1992, 'Changes in the Structure of Wages in the 1980s: An Evaluation of Alternative Explanations'. American Economic Review 88(3), 371-392.

Brainerd, E.: 1998, 'Winners and Loosers in Russia's Economic Transition'. American Economic Review 88(5), 1094-1116.

Bresnahan, T., E. Brynjolfsson, and L. Hitt: 1999, 'Information Technology, Workplace Organization, and the Demand for Skilled Labor: Firm-Level Evidence'. NBER Working Paper 7136, National Bureau of Economic Research.

Brynjolfsson, E. and L. M. Hitt: 2000, 'Beyond Computation: Information Technology, Organizational Transformation and Business Performance'. Journal of Economic Perspectives 14(4), 23-48.

Card, D. and J. E. DiNardo: 2002, 'Skill-Biased Technological Change and Rising Wage Inequality: Some Problems and Puzzles'. Journal of Labor Economics 20(4), 733-783.

Card, D., F. Kramarz, and T. Lemieux: 1999, 'Changes in the relative Structure of Wages and Employment: A Comparison of the United States, Canada and France'. Canadian Journal of Economics 32(4), 843-877.

Card, D. and T. Lemieux: 2001, 'Can Falling Supply Explain the Rising Return to College for Younger Men? A Cohort-Based Analysis'. Quarterly Journal of Economics 116(2), 705-746.

Caselli, F.: 1999, 'Technological Revolutions'. American Economic Review 89(1), $78-102$.

Chang, Y., J. F. Gomes, and Schorfheide: 2002, 'Learning-by-Doing as a Propagation Mechanism'. American Economic Review 92(5), 1498-1520. 
Ciffo-Tille, P. and E. Lehmann: 2004, 'Why Will Technical Change not be Permanently Skill-Biased'. Review of Economic Dynamics 7(1), 157-180.

Colgey, T. and J. Nanson: 1995, 'Output Dynamics in Real-Business-Cycle Models'. American Economic Review 85(3), 492-511.

Cooper, R. and A. Johri: 2002, 'Learning-by-Doing and Aggregate Fluctuations'. Journal of Monetary Economics 49(8), 1538-1566.

Crinò, R.: 2005, 'Wages, skills and Integration in Poland, Hungary and Czech Republic: an Industry-level Analysis'. Transition Studies Review 12(3), 432-459.

Davies, S.: 1979, The Diffusion of Process Innovations. Cambridge: Cambridge University Press.

Dejong, D. N. and C. Dave: 2007, Structural Macroeconometrics. Princeton: Princeton University Press.

DiNardo, J., N. Fortin, and T. Lemieux: 1996, 'Labour Market Institutions and the Distribution of Wages'. Econometrica 64(5), 1001-1044.

Dinopoulos, E. and P. Thompson: 1999, 'Scale Effects in Schumpeterian Models of Economic Growth'. Journal of Evolutionary Economics 9(2), 157-185.

Easterly, W., R. King, R. Levine, and S. Rebelo: 1994, 'Policy, Technology Adoption, and Growth'. NBER Working Paper 4681, National Bureau of Economic Research.

Feenstra, R. C. and G. H. Hanson: 1995, 'Foreign Investment, Outsourcing and Relative Wages'. NBER Working Paper 5121, National Bureau of Economic Research.

Feenstra, R. C. and G. H. Hanson: 1997, 'Productivity Measurement and the Impact of Trade and Technology on Wages: Estimates for the US, 1972-1990'. NBER Working Paper 6052, National Bureau of Economic Research.

Freeman, R. B.: 1980, 'Unionism and the Dispersion of Wages'. Industrial and Labor Relations Review 34(1), 3-23.

Freeman, R. B.: 1995, 'Are Your Wages set in Beijing?'. Journal of Economic Perspectives 9(1), 15-32.

Greenwood, J. and M. Yorukoglu: 1996, '1974'. RCER Working Papers 429, University of Rochester - Center for Economic Research (RCER). 
Greiner, A.: 1996, 'Endogenous Growth Cycles - Arrow's Learning by Doing Reconsidered'. Journal of Evolutionary Economics 18(4), 587-604.

Greiner, A. and H. Hanusch: 1994, 'Schumpeter's Circular Flow, Learning by Doing and Cyclical Growth'. Journal of Evolutionary Economics 4(3), 261-271.

Grossman, G. M. and E. Helpman: 1991a, 'Quality Ladders and Product Cycles'. Quarterly Journal of Economics 106(2), 557-586.

Grossman, G. M. and E. Helpman: 1991b, 'Quality Ladders in the Theory of Growth'. Review of Economic Studies 58(1), 43-61.

Haskel, J. and M. J. Slaughter: 2001, 'Trade, Technology, and UK Wage Inequality'. Economic Journal 111(468), 163-187.

Hijzen, A.: 2007, 'International Outsourcing, Technological Change, and Wage Inequality'. Review of International Economics 15(1), 188-205.

Johnson, G.: 1997, 'Changes in Earnings Inequality: The role of demand shifts'. Journal of Economic Perspectives 11(2), 41-54.

Jones, C. I.: 1995a, 'R\&D Based Models of Economic Growth'. Journal of Political Economy 103(4), 759-784.

Jones, C. I.: 1995b, 'Time Series Tests of Endogenous Growth Models'. Quarterly Journal of Economics 110(2), 495-525.

Jorgensen, D. W., F. W. Gollop, and B. M. Fraumeni: 1987, Productivity and U.S. Growth. Amsterdam: North-Holland.

Juhn, C.: 1992, 'Decline of Male Labor Market Participation: The Role of Declining Market Opportunities'. Quarterly Journal of Economics 107(1), 79-121.

Juhn, C., K. M. Murphy, and B. Pierce: 1993, 'Wage Inequality and the Rise in Returns to Skill'. Journal of Political Economy 101(3), 410-442.

Katz, L. F. and K. M. Murphy: 1992, 'Changes in Relative Wages, 1963-1987: Supply and Demand Factors'. Quarterly Journal of Economics 107(1), 35-78.

Kiley, M. T.: 1999, 'The Supply of Skilled Labour and Skill-Biased Technological Progress'. Economic Journal 109(458), 708-724.

Kiley, M. T.: 2001, 'Computers and growth with frictions: aggregate and disaggregate evidence'. Carnegie-Rochester Conference Series on Public Policy 55. 
King, R. G., C. I. Plosser, and S. Rebelo: 1988, 'Production, growth and business cycles: I. The basic neoclassical model'. Journal of Monetary Economics 21(2-3), $195-232$.

Kortum, S.: 1993, 'Equilibrium R\&D and the Patent-R\&D Ratio: U.S. Evidence'. American Economic Review 83(2), 450-457.

Kranz, D. F.: 2006, 'Why has Wage Inequality Increased More in the USA Than in Europe? An Empirical Investigation of the Demand and Supply of Skill'. Applied Economics 38(7), 771-788.

Krueger, A. B.: 1993, 'How Computers Have Changed the Wage Structure: Evidence From Microdata'. Quarterly Journal of Economics 108(1), 33-60.

Kydland, F. E. and E. C. Prescott: 1982, 'Time to Build and Aggregate Fluctuations'. Econometrica 50(6), 1345-1370.

Kydland, F. E. and E. C. Prescott: 1996, 'The Computational Experiment: An Econometric Tool'. Journal of Economic Perspectives 10(1), 69-85.

Lawrence, R. and M. J. Slaughter: 1993, 'International Trade and American Wages in the 1980s: Giant Sucking Sound or Small Hiccup?'. Brookings Papers on Economic Activity. Microeconomics 1993(2), 161-226.

Leamer, E. E.: 1994, 'Trade, Wages and Revolving-Door Ideas'. NBER Working Paper 4716, National Bureau of Economic Research.

Leamer, E. E.: 1996, 'Wage Inequality From International Competition and Technological Change: Theory and Country Experience'. American Economic Review 86(2), 309-314.

Lee, D. S.: 1999, 'Wage Inequality During the 1980s: Rising Dispersion or Falling Minimum Wage?'. Quarterly Journal of Economics 114(3), 977-1023.

Levy, F. and R. J. Murnane: 1992, 'US Earnings and Earnings Inequality: A Review of Recent Trends and Proposed Explanations'. Journal of Economic Literature 30(3), 1333-1381.

Levy, F. and R. J. Murnane: 1996, 'With what skills are computers a complement?'. American Economic Review 86(2), 258-262.

Lloyd-Ellis, H.: 1999, 'Endogenous Technical Change and Wage Inequality'. American Economic Review 89(1), 47-77. 
Lucas, Jr, R. E.: 1988, 'On the Mechanics of Economic Development'. Journal of Monetary Economics 22(1), 3-42.

Lucas, Jr, R. E.: 1993, 'Making a Miracle'. Econometrica 22(2), 251-272.

Machin, S.: 1997, 'The Decline of Labour Market Institutions and the Rise in Wage Inequality in Britain'. European Economic Review 41(3-5), 647-657.

Machin, S. and J. Van Reenen: 1998, 'Technology and Changes in Skill Structure: Evidence From Seven OECD Countries'. Quarterly Journal of Economics 113(4), $1215-1244$.

Mansfield, E.: 1961, 'Technical Change and the Rate of Imitation'. Econometrica 29(4), 741-766.

Mansfield, E.: 1965, 'Rates of Return from Industrial Research and Development'. American Economic Review 55(1-2), 310-322.

Morrison, C. J. and D. Siegel: 1997, 'External Capital Factors and Increasing Returns in U.S. Manufacturing'. Review of Economics and Statistics 79(4), 647-654.

Murphy, K. M. and F. Welch: 1990, 'Empirical Age-Earnings Profiles'. Journal of Labor Economics 8(2), 202-229.

Murphy, K. M. and F. Welch: 1992, 'The Structure of Wages'. Quarterly Journal of Economics 107(1), 285-326.

Nahuis, R. and S. Smulders: 2002, 'The Skill Premium, Technological Change and Appropriability'. Journal of Economic Growth 7(2), 137-156.

Nickell, S. and B. Bell: 1996, 'Changes in the Distribution of Wages and Unemployment in OECD Countries'. American Economic Review 86(2), 302-08.

Parente, S. L.: 1995, 'A Model of Technology Adoption and Growth'. Economic Theory 6(3), 405-420.

Parente, S. L. and E. C. Prescott: 1994, 'Barriers to Technology Adoption and Development'. Journal of Political Economy 102(2), 298-321.

Rivera-Batiz, L. A. and P. M. Romer: 1991, 'Economic Integration and Endogenous Growth'. Quarterly Journal of Economics 106(2), 531-555.

Robertson, R.: 2004, 'Relative Prices and Wage Inequality: Evidence From Mexico'. Journal of International Economics 64(2), 387-409. 
Romer, P. M.: 1986, 'Increasing Returns and Long-Run Growth'. Journal of Political Economy 94(5), 1002-1037.

Romer, P. M.: 1993, 'Ideas Gaps and Object Gaps in Economic Development'. Journal of Monetary Economics 32(3), 543-573.

Sachs, J. D. and H. J. Shatz: 1994, 'Trade and Jobs in U.S. Manufacturing'. Brookings Papers on Economic Activity 1994(1), 1-84.

Schumpeter, J.: 1942, Capitalism, Socialism and Democracy. New York: Harper.

Segerstrom, P. S., T. C. A. Anant, and E. Dinopoulos: 1990, 'A Schumpeterian Model of Product Life Cycle'. American Economic Review 80(5), 1077-1092.

Solow, R. M.: 1956, 'A Contribution to the Theory of Economic Growth'. Quarterly Journal of Economics 74(1), 65-94.

Stokey, N. L.: 1988, 'Learning by Doing and the Introduction of New Goods'. Journal of Political Economy 96(4), 701-717.

Thompson, P.: 1996, 'Technological Opportunity and the Growth of Knowledge: A Schumpeterian Approach to Measurement'. Journal of Evolutionary Economics 6(1), $77-97$.

Welch, F.: 1979, 'Effects of Cohort Size on Earnings'. Journal of Political Economy $87(5), 65-97$.

Wood, A.: 1995, 'How Trade Hurt Unskilled Workers'. Journal of Economic Perspectives $\mathbf{9}(3), 57-80$.

Wood, A.: 1997, 'Openness and Wage Inequality in Developing Countries: The Latin American Challenge to East Asian Conventional Wisdom'. The World Bank Economic Review 11(1), 33-57.

Yabuuchi, S. and S. Chaudhuri: 2007, 'International migration of labour and skilledunskilled wage inequality'. Economic Modelling 24(1), 128-137.

Young, A.: 1991, 'Learning by Doing and the Dynamic Effects of International Trade'. Journal of Political Economy 106(2), 369-405.

Young, A.: 1993, 'Invention and Bounded Learning by Doing'. Journal of Political Economy 101(3), 443-472.

Zhu, S. C. and D. Trefler: 2005, 'Trade and Inequality in Developing Countries: A General Equilibrium Analysis'. Journal of International Economics 65(1), 21-48. 